\title{
Analyzing the Performance of a Heat Pump Water Heater when Coupled with a Heat Recovery Ventilator for Heating Applications in Canada
}

\author{
by \\ Patrick J. A. Smith, \\ B.Eng., Carleton University, 2015
}

A thesis submitted to the Faculty of Graduate and Postdoctoral Affairs in partial fulfillment of the requirements for the degree of

Master of Applied Science

in

Mechanical Engineering

Carleton University

Ottawa, Ontario

(C) 2018, Patrick J. A. Smith 


\section{Abstract}

The objective of this thesis is to determine the suitability of an air source heat pump water heater (HPWH) for Canadian climates. The performance of a commercially available HPWH was evaluated at a series of air temperature and humidity set-points representing outdoor conditions in Canadian climates. The resulting cost of energy in each climate was compared to the cost when using the unit with basement air and when using an electric water heater. A computer model was developed to simulate the annual performance of the unit when installed in a house and coupled with a heat recovery ventilator (HRV). The effects of the HRV on the performance of the HPWH were found to be negligible when the heating and cooling loads were taken into consideration. It was found that HPWHs have a lower cost of energy than electric water heaters in regions with time-of-use utility rates. 


\section{Acknowledgements}

I would like to thank my supervisor, Dr. Cynthia Cruickshank, for her guidance, support, and patience over the course of this project.

I would like to thank my colleagues at Carleton University, including Chris Baldwin, Dylan Bardy, Daniel Bowie, Sebastien Brideau, Jayson Bursill, Chris Comtois, Brock Conley, Nina Dmytrenko, Alex Hayes, Kevin Khalaf, Curtis Meister, David Ouellette, Tyler Ulmer, Sarah Wert, and Adam Wills, for their friendship, mentorship, and assistance throughout my research.

I would like to thank my friends, including David Coffin, Samantha Dupuis, Simon Dow, Colt Frid, Alex Harmsen, and Charlotte White, for their friendship and support.

Finally, I would like to thank my parents, Garry and Christine, for their endless love, support, and understanding. 


\section{Table of Contents}

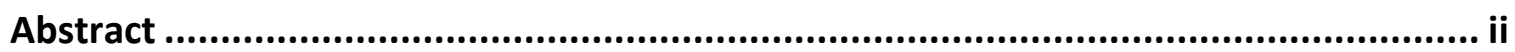

Acknowledgements ............................................................................... ii

Table of Contents ...................................................................................... iv

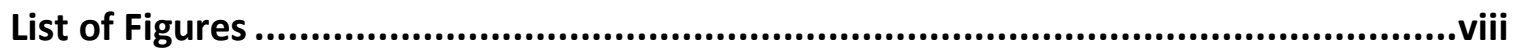

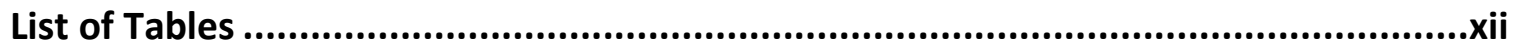

List of Abbreviations..................................................................................

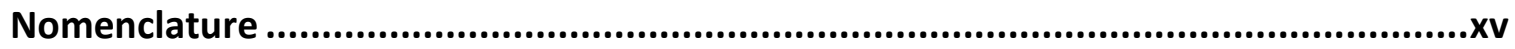

1 Chapter: Introduction .......................................................................... 1

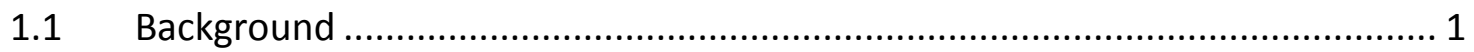

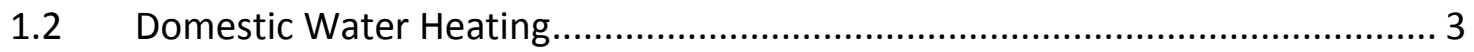

1.2.1 Natural Gas Water Heaters ............................................................. 5

1.2.2 Electric Water Heaters .................................................................................. 5

1.2.3 Heat Pump Water Heaters ....................................................................... 7

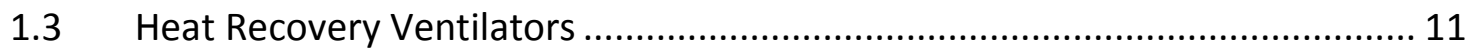

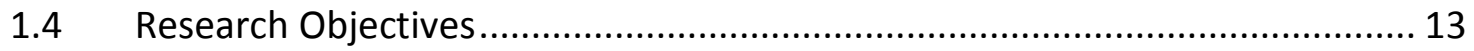

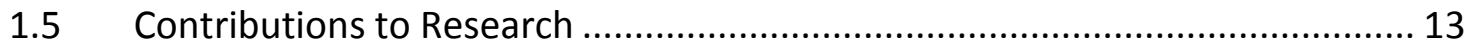

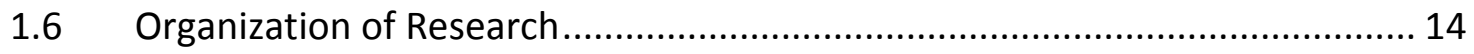

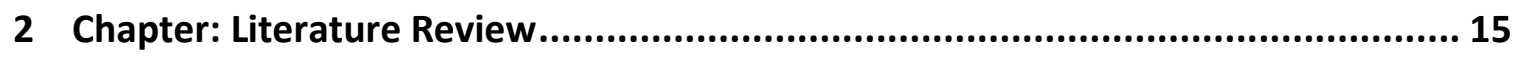

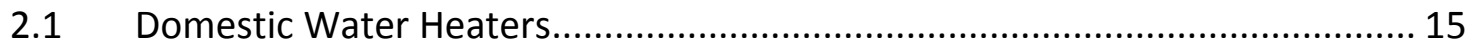

2.2 Previous Research in Heat Pump Water Heaters ....................................... 18

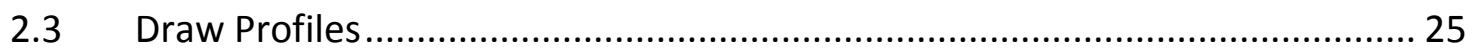




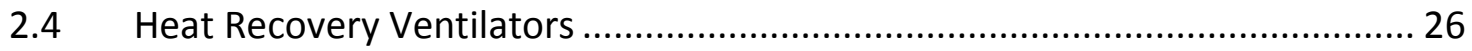

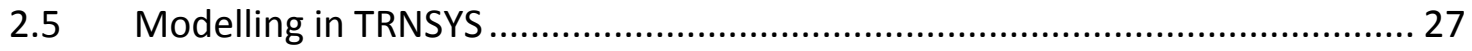

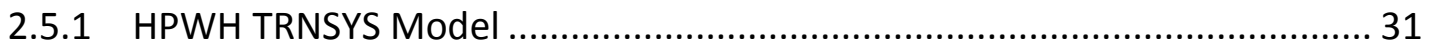

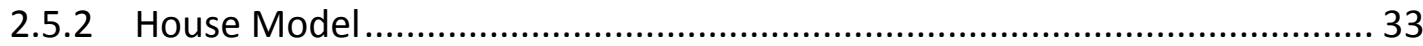

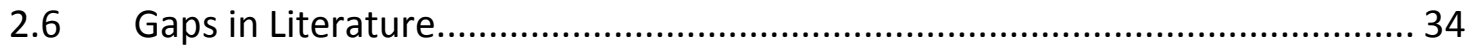

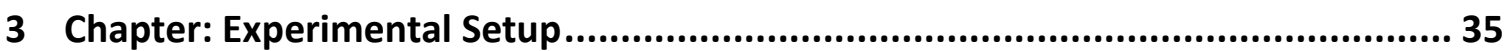

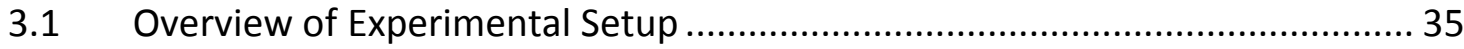

Air Handling Unit................................................................................ 41

3.2.1 Limitations of the Air Handling Unit .................................................... 44

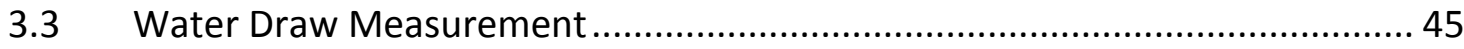

3.4 Heat Pump Water Heater .............................................................. 46

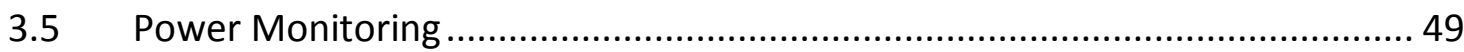

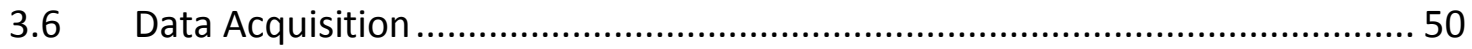

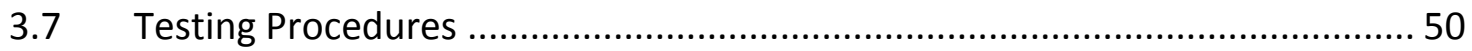

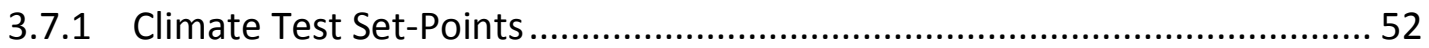

3.8 Calculating the Coefficient of Performance.................................................. 56

Calibration and Uncertainty Analysis .................................................. 58

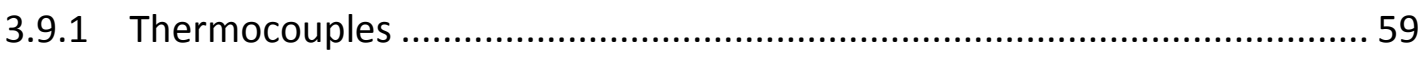

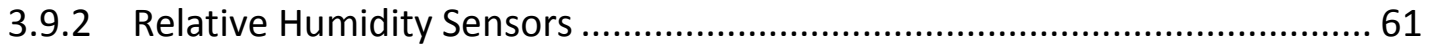

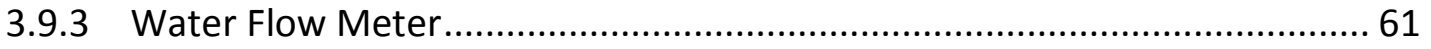

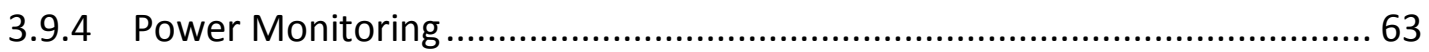

3.9.5 Total Uncertainty of Heat Delivery and Coefficient of Performance ........... 64 


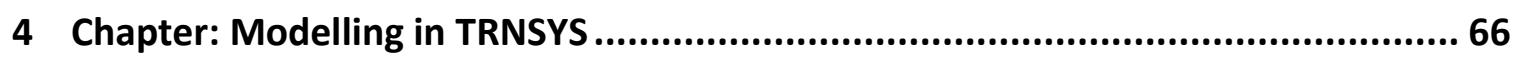

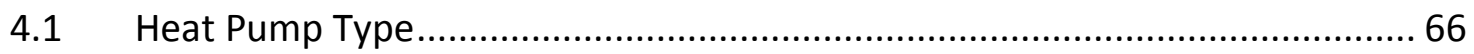

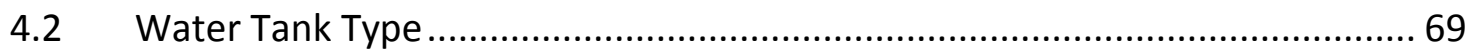

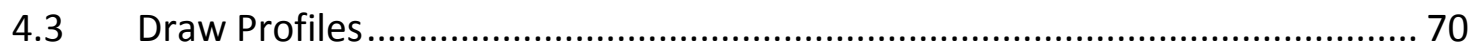

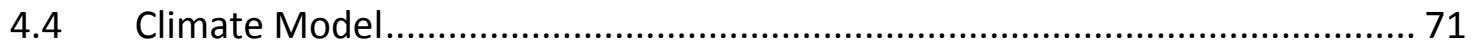

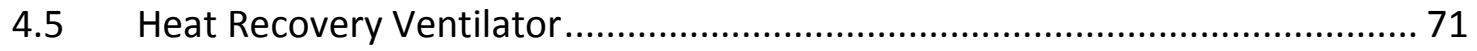

4.6 House Model ..................................................................................... 72

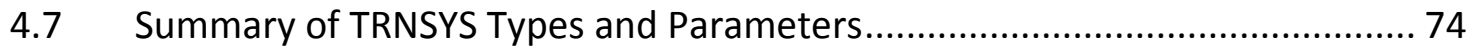

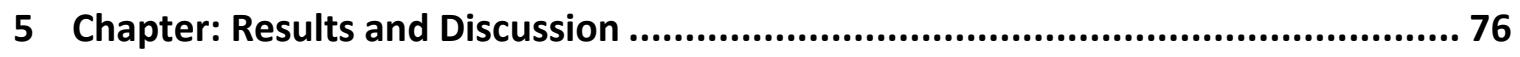

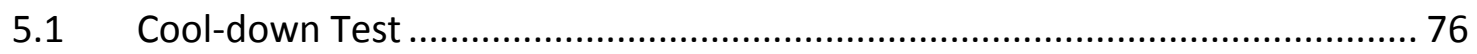

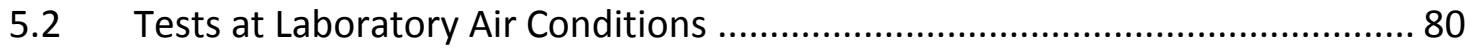

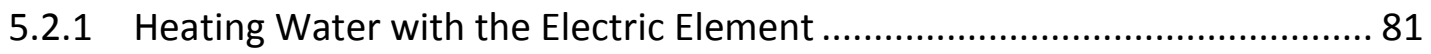

5.2.2 Heating Water with the Heat Pump .................................................... 83

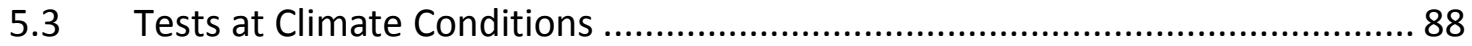

5.3.1 Economic Benefits of a HPWH Compared to Electric Water Heaters .......... 94

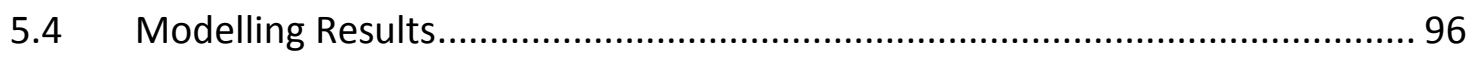

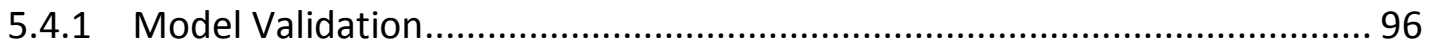

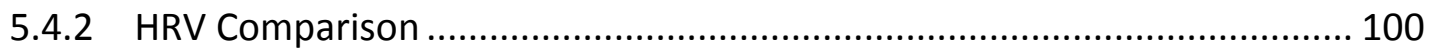

5.4.2.1 Preliminary Results for Coupling HRV with HPWH in Canadian Cities 100

5.4.2.2 Benefits of an HRV in an Annual Simulation in Canadian Cities ......... 103

6 Chapter: Conclusions and Future Work ................................................. 112 


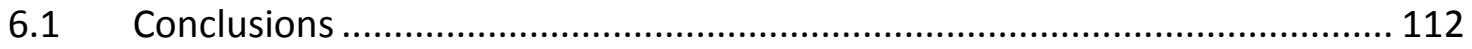

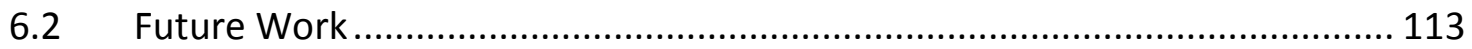

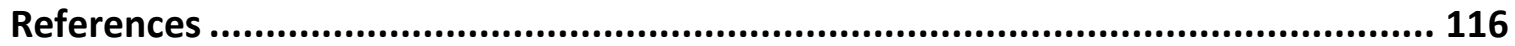

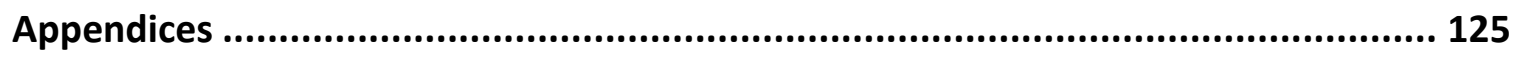

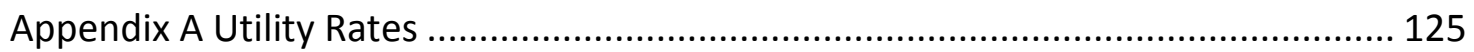

Appendix B Calculating the Dew Point Temperature ......................................... 127

Appendix C Performance Map Data ........................................................... 128

Appendix D Climate Test and Modelling Data ................................................. 131

D.1 Additional Climate Test Data ............................................................. 131

D.2 Additional Model Validation Data ..................................................... 153

Appendix E Cost of Energy of a Water Heater ................................................... 159 


\section{List of Figures}

Figure 1-1: Canada's secondary energy use by sector $[1]$......................................... 2

Figure 1-2: Energy use by end-use in Canada [1] .................................................... 2

Figure 1-3: Operation of a heat pump cycle coupled with a domestic hot water tank ..... 8

Figure 1-4: Illustration of a HPWH coupled with outdoor air in the cooling season........ 10

Figure 1-5: Illustration of a HPWH coupled with basement air in the heating season .... 10

Figure 1-6: Illustration of an HRV coupled with a HPWH in the heating season.............. 12

Figure 2-1: Effect of air temperature on heat delivery at a constant $20 \%$ relative

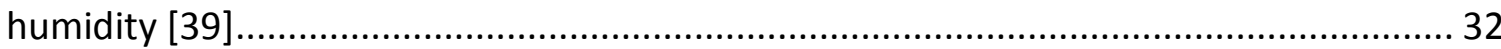

Figure 2-2: Effect of air temperature on compressor power at a constant $20 \%$ relative

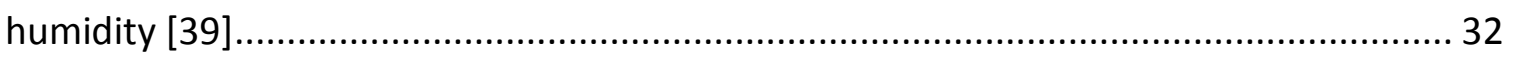

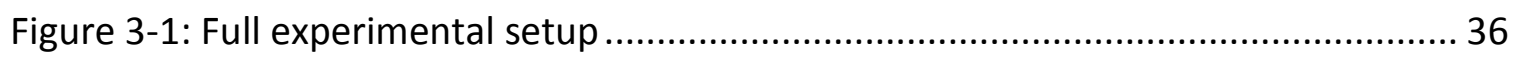

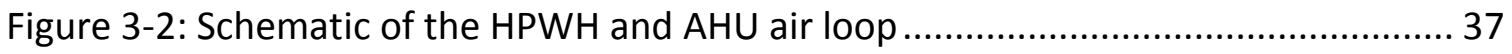

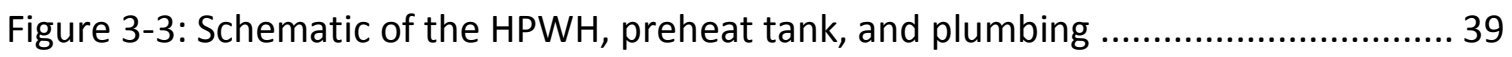

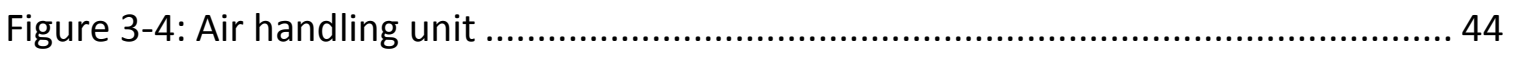

Figure 3-5: Water draw system, with the solenoid on the left and the water flow meter

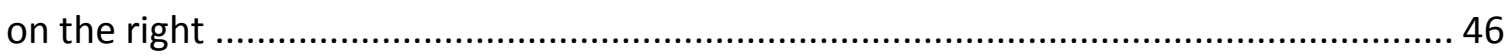

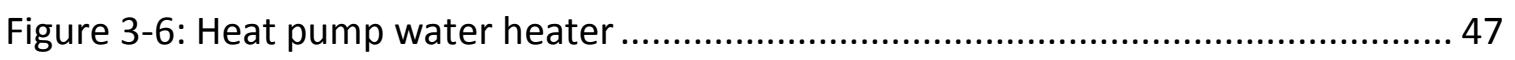

Figure 4-1: Annual house simulation flow chart..................................................... 74

Figure 5-1: Energy balance on a tank node (adopted from [39]) ................................. 78

Figure 5-2: Temperature of the tank nodes after a 48-hour cooldown test .................. 79

Figure 5-3: Water temperature and power consumption using the electric element..... 82 
Figure 5-4: Energy consumption and COP of the HPWH using the electric element 83

Figure 5-5: Water temperature profile and power consumption of the HPWH at laboratory air conditions. 85

Figure 5-6: Cumulative energy and COP of the HPWH at laboratory air conditions 86

Figure 5-7: Temperature at each node during charging and discharging, laboratory conditions. 87

Figure 5-8: Water temperature and power consumption for a Montreal summer day .. 89 Figure 5-9: Cumulative energy, COP, and cost of energy for a Montreal summer day ... 90 Figure 5-10: Comparison of energy consumption and CCOP for all climate tests 91

Figure 5-11: Comparing HPWH operating cost with outdoor air, basement air and resistance heaters 95

Figure 5-12: Comparison of water temperature and power consumption between the experiment and model for a Montreal summer day...... 98

Figure 5-13: Comparison of cumulative energy, coefficient of performance, and cost of energy between the experiment and model for a Montreal summer day ..... 99

Figure 5-14: Comparing model results of the energy consumption of a HPWH with outdoor air and an HRV for different cities in the summer. 101 Figure 5-15: Comparing model results of the cost of a HPWH with outdoor air and an HRV for different cities in the summer 102

Figure 5-16: Annual energy consumption results for each Canadian city..................... 108

Figure 5-17: Annual energy cost results for each Canadian city ................................ 109

Figure D-1: Temperature and power consumption at $10^{\circ} \mathrm{C}$ without humidification ..... 131 
Figure D-2: Cumulative energy and $\mathrm{COP}$ at $10^{\circ} \mathrm{C}$ without humidification

Figure D-3: Temperature and power consumption at $10^{\circ} \mathrm{C}$ with humidification..... 133

Figure D-4: Cumulative energy and $\mathrm{COP}$ at $10^{\circ} \mathrm{C}$ with humidification 134

Figure D-5: Temperature and power consumption for a Calgary summer day 135

Figure D-6: Cumulative energy, COP, and cost of energy for a Calgary summer day .... 136

Figure D-7: Water temperature and power consumption for a Calgary fall day 137

Figure D-8: Cumulative energy, COP, and cost of energy for a Calgary fall day..... 138

Figure D-9: Water temperature and power consumption for an Edmonton spring day 139

Figure D-10: Cumulative energy, COP, and cost of energy for an Edmonton spring day 140

Figure D-11: Temperature and power consumption for an Edmonton summer day .... 141 Figure D-12: Cumulative energy, COP, and cost of energy for an Edmonton summer day 142

Figure D-13: Temperature and power consumption for a Halifax summer day 143

Figure D-14: Energy consumption, CCOP, and cost of energy for a Halifax summer day 144

Figure D-15: Temperature and power consumption for a St. John's summer day 145

Figure D-16: Energy consumption, CCOP, and cost of energy for a St. John's summer day 146

Figure D-17: Temperature and power consumption for a Toronto fall day...... 147

Figure D-18: Energy consumption, CCOP, and cost of energy for a Toronto fall day .... 148

Figure D-19: Temperature and power consumption for a Toronto summer day 149 
Figure D-20: Energy consumption, CCOP, and cost of energy for a Toronto summer day

Figure D-21: Temperature and power consumption for a Yellowknife summer day..... 151

Figure D-22: Energy consumption, CCOP, and cost of energy for a Yellowknife summer

day

Figure D-23: Experimental and model results for temperature and power consumption

for an Ottawa summer day. 153

Figure D-24: Experimental and model results for energy consumption, CCOP, and cost of energy for an Ottawa summer day 154

Figure D-25: Experimental and model results for temperature and power consumption for a Regina summer day 155 Figure D-26: Experimental and model results for energy consumption, CCOP, and cost of energy for a Regina summer day 156

Figure D-27: Experimental and model results for temperature and power consumption for a Vancouver summer day 157

Figure D-28: Experimental and model results for energy consumption, CCOP, and cost of energy for a Vancouver summer day. 158

Figure E-1: Cost of energy for various Canadian cities using an electric water heater .. 159 Figure E-2: Cost of energy for various Canadian cities using basement air 160 


\section{List of Tables}

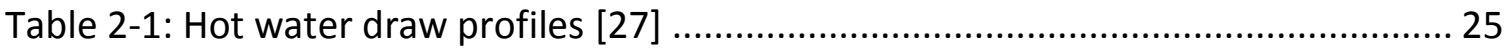

Table 2-2: Description of TRNSYS types from literature review [38] [37] ...................... 28

Table 2-3: Review of TRNSYS components used in literature ...................................... 30

Table 3-1: List of equipment and sensors used in the HPWH apparatus ........................ 40

Table 3-2: List of air handling unit and data acquisition equipment ............................ 41

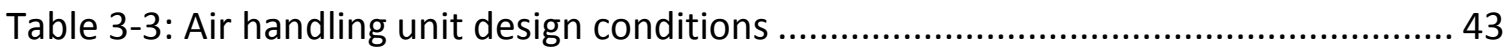

Table 3-4: Testing conditions for various Canadian cities and seasons (Part 1 of 2) ....... 54

Table 3-5: Testing conditions for various Canadian cities and seasons (Part 2 of 2) ....... 55

Table 3-6: Total measurement uncertainty for the thermocouples [45] ....................... 61

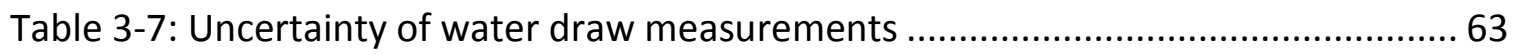

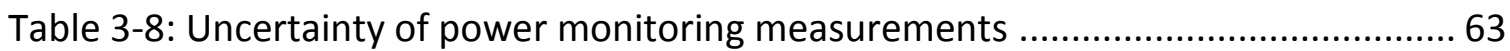

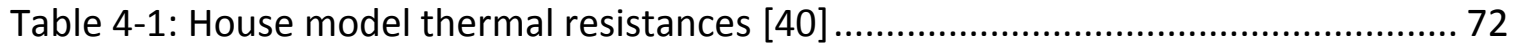

Table 4-2: Summary of TRNSYS types used for each component ............................... 74

Table 4-3: Summary of TRNSYS model parameters................................................. 75

Table 5-1: Universal heat transfer coefficient and heat loss at each node.................... 80

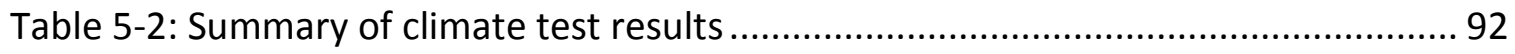

Table 5-3: Summary of results for tests conducted at $10^{\circ} \mathrm{C}$ with and without the

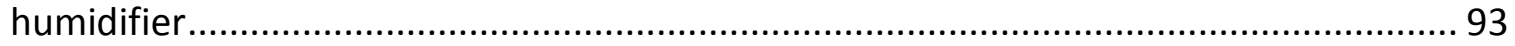

Table 5-4: Description of the annual simulation scenarios ...................................... 103

Table 5-5: Annual results comparing the energy consumption and cost of the Ottawa

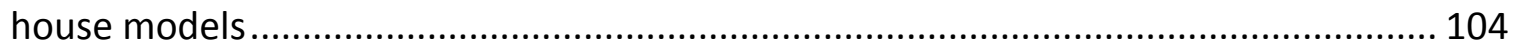


Table 5-6: Annual house model results for each Canadian city 107

Table A-1: Time-of-use electricity rates for Ontario [55] 125

Table A-2: Time-of-use electricity rates for Halifax [56]. 126

Table A-3: Flat rate electricity costs for other Canadian cities. 126

Table A-4: Costs of electricity and primary heating sources of various Canadian cities 126 Table C-1: Total cooling capacity (W) as a function of air temperature, air humidity, and water temperature [39]

Table C-2: Sensible cooling capacity (W) as a function of air temperature, air humidity, and water temperature [39]

Table C-3: Compressor power (W) as a function of air temperature, air humidity, and water temperature [39]

Table C-4: Heat delivery (W) as a function of air temperature, air humidity, and water temperature [39] 130 


\section{List of Abbreviations}

$\begin{array}{ll}\text { AHU } & \text { Air Handling Unit } \\ \text { CDAQ } & \text { Compact Data Acquisition System } \\ \text { CJC } & \text { Cold Junction Compensation (Temperature) } \\ \text { CSA } & \text { Canadian Standards Association } \\ \text { CCOP } & \text { Cumulative Coefficient of Performance } \\ \text { COP } & \text { Coefficient of Performance } \\ \text { DAQ } & \text { Data Acquisition System } \\ \text { DHW } & \text { Domestic Hot Water } \\ \text { EF } & \text { Energy Factor } \\ \text { HPWH } & \text { Heat Pump Water Heater } \\ \text { HRV } & \text { Heat Recovery Ventilator } \\ \text { PID } & \text { Proportional-Integral-Derivative } \\ \text { R22 } & \text { Refrigerant 22 } \\ \text { RH } & \text { Relative Humidity } \\ \text { RTD } & \text { Resistance Temperature Detector } \\ \text { TC } & \text { Thermocouple } \\ \text { TESS } & \text { Thermal Energy Systems Specialists } \\ \text { TMY } & \text { Typical Meteorological Year } \\ \text { TRNSYS } & \text { Transient System Simulations Tool } \\ \text { VI } & \text { Visual Interface }\end{array}$




\section{Nomenclature}

Symbol Description

$A_{\mathrm{c}, \mathrm{i}} \quad$ Cross-sectional area of node

Units

$A_{\mathrm{s}, \mathrm{i}} \quad$ Surface area of node

$\mathrm{m}^{2}$

$A_{\mathrm{s}, \mathrm{tank}}$

Surface area of the tank

$\mathrm{m}^{2}$

$C_{\text {energy }}$

Cost of energy

$\mathrm{m}^{2}$

$C_{\mathrm{p}, \mathrm{air}}$

$C_{\mathrm{p}, \mathrm{w}}$

Specific heat of air

$\$$

$C_{\text {util }}$

Specific heat of water

$\mathrm{kJ} / \mathrm{kgK}$

CJC

Utility rate

$\mathrm{kJ} / \mathrm{kgK}$

$E_{\text {deliv }}$

Cold junction compensation temperature

$\$ / k W h$

${ }^{\circ} \mathrm{C}$

$E_{\text {in }}$

Heat delivery energy

$\mathrm{kJ}, \mathrm{kWh}$

Energy used to power HPWH

$\mathrm{kJ}, \mathrm{kWh}$

$h \quad$ Height of the tank

$\mathrm{m}$

$\mathrm{h}_{\text {in }} \quad$ Inlet air enthalpy

$\mathrm{kJ} / \mathrm{kg}$

$h_{\text {out }}$

Exhaust air enthalpy

$\mathrm{kJ} / \mathrm{kg}$

$k \quad$ Thermal conductivity of water

$\mathrm{W} / \mathrm{mK}$

$\Delta k \quad$ Destratification conductivity

$\mathrm{W} / \mathrm{mK}$

$\dot{m} \quad$ Mass flow rate of air

$\mathrm{kg} / \mathrm{s}$

$\dot{m}_{\text {down }}$

Mass flow rate of water circulating down in tank

$\mathrm{kg} / \mathrm{h}$

$\dot{m}_{\text {inlet }}$

$\dot{m}_{\text {outlet }}$

Mass flow rate of water entering tank

$\mathrm{kg} / \mathrm{h}$

$\mathrm{kg} / \mathrm{h}$

$\dot{m}_{\text {up }} \quad$ Mass flow rate of water circulating up in tank

$\mathrm{kg} / \mathrm{h}$

$M_{\mathrm{i}} \quad$ Mass of node

$N \quad$ Number of samples

$P \quad$ Probability, confidence interval

$\mathrm{kg}$

$P_{\text {tot }}$

$P_{\mathrm{w}}$

Atmospheric pressure

Partial pressure of water

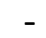

$\%$

$P_{\mathrm{ws}}$

$\dot{Q}_{\text {aux,i }}$

Partial pressure of water at the dew point

$\mathrm{kPa}$

$\mathrm{kPa}$

$\mathrm{kPa}$

$Q_{\text {loss,i }}$

Auxiliary heat input to node

$\mathrm{kJ} / \mathrm{h}$

$Q_{\text {loss,tank }}$

$Q_{\text {sens }}$

Heat lost from node to the environment

$\mathrm{kJ}$

Heat lost from the tank to the environment $\mathrm{kJ}$

$Q_{\text {total }}$

Sensible cooling capacity

W

Measured property $i$

$r \quad$ Radius of the tank

RH Relative humidity

$\%$

$S_{\mathrm{X}} \quad$ Sample standard deviation

$S_{\overline{\mathrm{X}}} \quad$ Standard deviation of the means

$s_{\mathrm{X}}^{2} \quad$ Sample variance

$t \quad$ Time

$T_{\mathrm{d}}$

Time

${ }^{\circ} \mathrm{C}$

$T_{\text {design }}$

Dew point temperature

${ }^{\circ} \mathrm{C}$ 


\begin{tabular}{|c|c|c|}
\hline Symbol & Description & Units \\
\hline$T_{\text {env }}$ & Air temperature of surrounding space & ${ }^{\circ} \mathrm{C}$ \\
\hline$T_{\mathrm{i}}$ & Water temperature of node & ${ }^{\circ} \mathrm{C}$ \\
\hline$T_{\text {in }}$ & Inlet air temperature & ${ }^{\circ} \mathrm{C}$ \\
\hline$T_{\text {inlet }}$ & Inlet water temperature & ${ }^{\circ} \mathrm{C}$ \\
\hline$T_{\text {lab }}$ & Air temperature at laboratory conditions & ${ }^{\circ} \mathrm{C}$ \\
\hline$T_{\text {mean,tank }}$ & Mean water temperature of the tank & ${ }^{\circ} \mathrm{C}$ \\
\hline$T_{\mathrm{n}}$ & Temperature constant & ${ }^{\circ} \mathrm{C}$ \\
\hline$T_{\text {out }}$ & Exhaust air temperature & ${ }^{\circ} \mathrm{C}$ \\
\hline$T_{\text {outlet }}$ & Outlet water temperature & ${ }^{\circ} \mathrm{C}$ \\
\hline$T_{\text {ref }}$ & Reference water temperature & ${ }^{\circ} \mathrm{C}$ \\
\hline$t_{\mathrm{v}, \mathrm{P}}$ & Coverage factor based on confidence interval & - \\
\hline$u_{\mathrm{b}}$ & Bias uncertainty & - \\
\hline$u_{\mathrm{b}, \mathrm{i}}$ & Bias uncertainty of measured property $i$ & - \\
\hline$u_{\mathrm{b}, \mathrm{y}}$ & Bias uncertainty of derived property $y$ & - \\
\hline$u_{\mathrm{p}}$ & Precision uncertainty & - \\
\hline$u_{\mathrm{p}, \mathrm{i}}$ & Precision uncertainty of measured property $i$ & - \\
\hline$u_{\mathrm{p}, \mathrm{y}}$ & Precision uncertainty of derived property $y$ & - \\
\hline$u_{\mathrm{T}}$ & Total uncertainty & - \\
\hline$U_{\mathrm{i}}$ & Universal heat loss coefficient of node & $\mathrm{kJ} / \mathrm{m}^{2} \mathrm{~K}$ \\
\hline $\bar{U}_{\text {tank }}$ & Mean universal heat loss coefficient of tank & $\mathrm{kJ} / \mathrm{m}^{2} \mathrm{~K}$ \\
\hline$v$ & Degrees of freedom & - \\
\hline$V$ & Voltage & V \\
\hline$V_{\text {tank }}$ & Volume of the tank & $\mathrm{m}^{3}, \mathrm{~L}$ \\
\hline$\Delta x$ & Distance between nodes & $\mathrm{m}$ \\
\hline $\bar{x}$ & Sample mean value & - \\
\hline$x_{\mathrm{i}}$ & Measurement $i$ & - \\
\hline$X$ & Moisture content & $\mathrm{kg}_{\text {water }} / \mathrm{kg}_{\text {air }}$ \\
\hline$y$ & Derived property $y$ & - \\
\hline$\rho_{\mathrm{w}}$ & Density of water & $\mathrm{kg} / \mathrm{m}^{3}$ \\
\hline
\end{tabular}




\section{Chapter: Introduction}

\subsection{Background}

Natural Resources Canada's Office of Energy Efficiency states that the industrial, transportation, and residential sectors are the three largest contributors to energy use in Canada, with a total of $87 \%$ of the total energy use in 2013 [1]. The residential sector uses $17 \%$ of the total, of which $63 \%$ of the energy is used for space heating, while $19 \%$ is used for heating water, as seen in Figure 1-1 and Figure 1-2. Thus, reducing the energy required to heat water will contribute to the on-going efforts to reduce energy use in Canada and the associated greenhouse gas emissions. This reduction can be accomplished by installing a high efficiency water heater or improving the performance of the existing water heater.

There is further incentive to reduce greenhouse gas emissions due to a carbon tax, which affects $97 \%$ of Canadians. The Canadian government has outlined a federal carbon tax that will affect provinces that do not have their own tax in 2018 [2]. These taxes and energy acts help to deter greenhouse gas emissions and promote the use of clean energy. For example, by the year 2020, through the Clean Energy Act, the province of British Columbia is aiming to reduce the demand for electricity by $66 \%$ and generate at least $93 \%$ of the electricity in the province from renewable sources [3]. This includes reducing the greenhouse gas emissions in the province by $33 \%$ compared to those in 2007, and keeping utility rates among the most competitive in North America. 


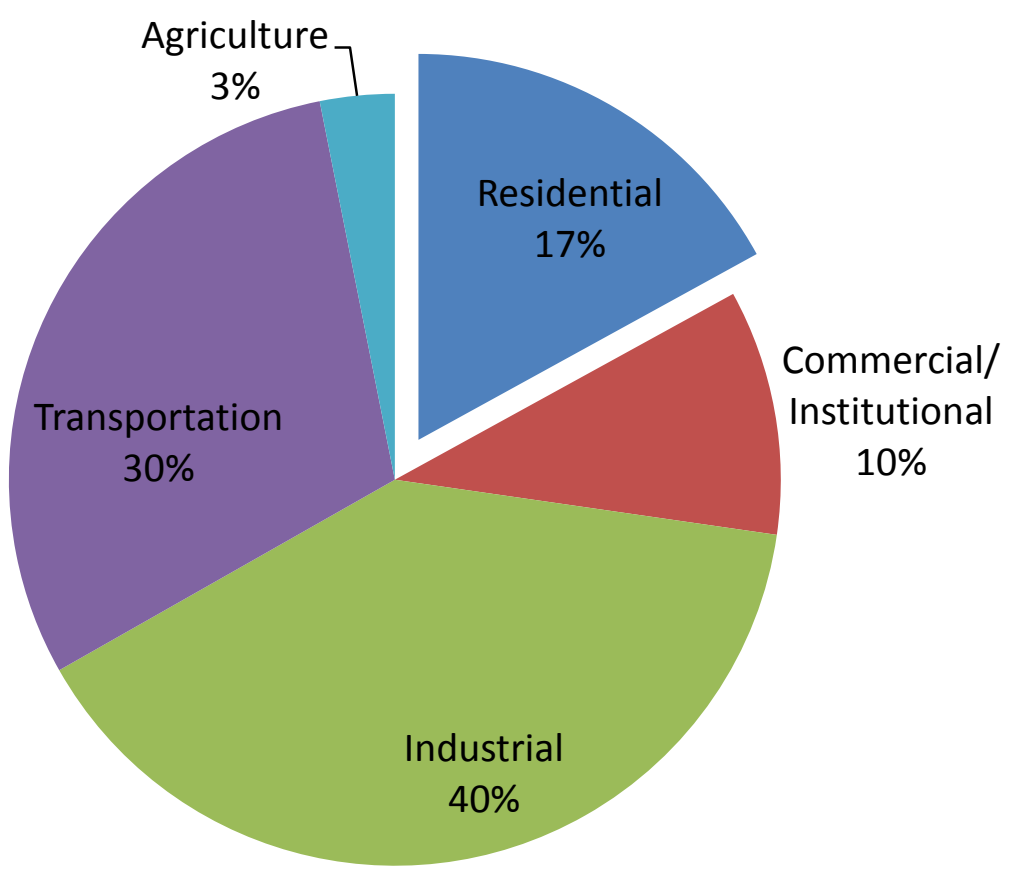

Figure 1-1: Canada's secondary energy use by sector [1]

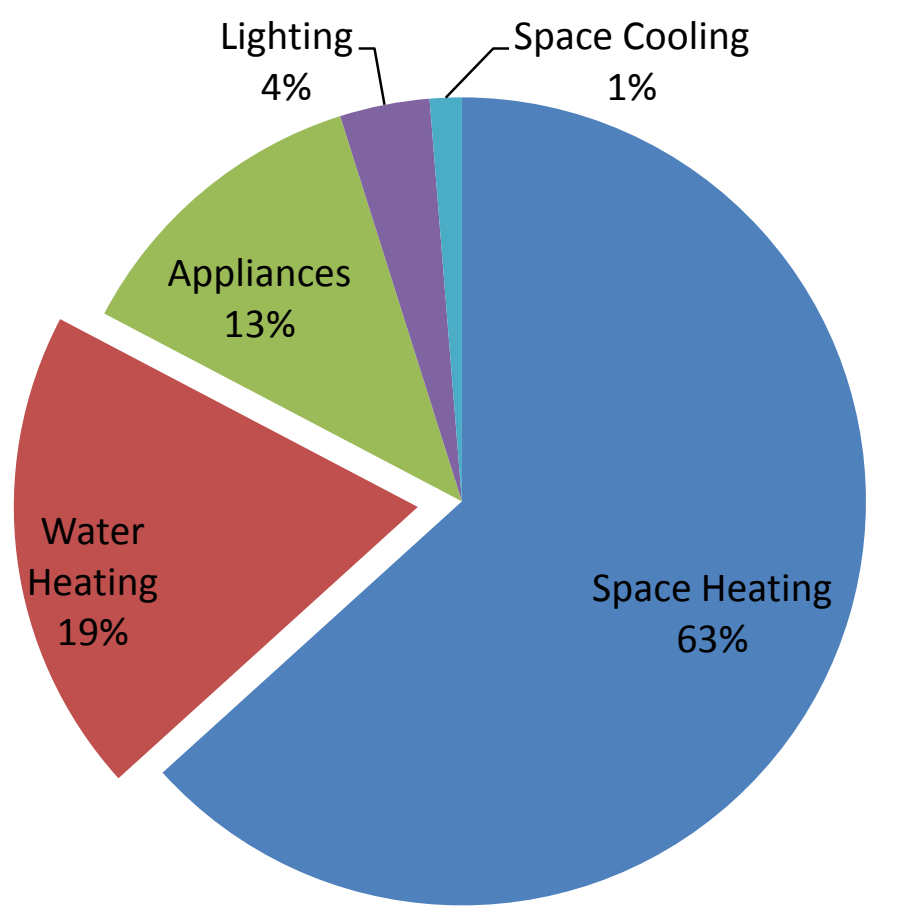

Figure 1-2: Energy use by end-use in Canada [1] 
The purpose of this thesis was to analyze the performance of heat pump water heaters (HPWHs) in a Canadian climate with the aim to reduce the cost of residential water heating. The analysis involved comparing energy consumption and utility cost of HPWHs to electric water heaters in basement installations, ducting outdoor air to the intake of the HPWH, and coupling the HPWH with a heat recovery ventilator (HRV). This study involved both experimental and simulation work.

\subsection{Domestic Water Heating}

In 2013, 294.6 PJ was used to heat water in the Canadian residential sector [1]; of this, $68 \%$ was used by natural gas boilers, and $25 \%$ was used by electric water heaters, which includes HPWHs. In Canada, natural gas boilers make up 51\% of water heaters, whereas electricity makes up 44\%, heating oil accounts for $4 \%$, and wood accounts for $1 \%$. In Ontario, natural gas, electricity, heating oil, and wood account for $73 \%, 23 \%, 3 \%$, and $1 \%$ of water heaters, respectively [1]. Natural gas is significantly cheaper than electricity in most of Canada, and has a shorter hot water recovery time, which has resulted in it being the dominant energy source for water heating [4]. In addition to this, natural gas has a flat utility rate, while the cost of electricity can increase at peak times in many regions of Canada. Thus, many consumers continue to use natural gas for water heating as they can save a significant amount of money compared to electric water heaters. However, natural gas is a non-renewable source of energy, and contributes more to greenhouse gas emissions than electric water heaters. 
Using heat pump water heaters, which are relatively unknown to Canadians, can reduce both emissions and the cost of energy if used in the appropriate environment.

Both the initial cost and the operation cost must be considered when purchasing a water heater. While some water heaters may have a lower initial cost, they may also consume more energy, and thus result in a higher energy bill [5]. The estimated life cycle of the water heater (which is typically 10 years) should also be considered. The three water heaters that were studied for this thesis were the natural gas, electric, and heat pump water heaters. Tankless water heaters were not covered.

The energy factor (EF) is a metric used to rate the efficiency of natural gas and electric water heaters. It is defined as the total amount of energy in the form of heat delivered to the user divided by the total amount of energy used to operate the water heater [5]. The energy factor is determined based on a series of tests, using a standard air temperature, air humidity, and water draw patterns [6]. For electric and heat pump water heaters, the coefficient of performance (COP) is also used. The COP, rather than being determined by a number of standardized tests, is based on the amount of heat delivered to the water in the tank divided by the amount of energy used to operate the unit during an arbitrary time period. In this research, the COP is calculated based on the experimental results. The heating seasonal performance factor (HSPF) of a heat pump is calculated by dividing the total heat output of a heat pump (in BTU) by the total energy use (in Wh) over the heating season. Similarly, the seasonal energy efficiency ratio (SEER) is calculated by dividing the total cooling (in BTU) by the total energy use (in Wh) over the course of the cooling season [7]. 


\subsubsection{Natural Gas Water Heaters}

Natural gas water heaters use combustion to heat domestic hot water. These water heaters require an air intake, exhaust, and a natural gas line to operate. The exhausted gases are diluted by being mixed with conditioned house air. The gas burner is located at the bottom of the tank, and when activated, the combustion gases transfer heat to the water in the tank as they are exhausted out of the top of the unit. An advantage of a natural gas water heater is that the unit can continue to operate during a power outage [5].

The energy factor for a natural gas water heater with a storage tank is around 0.67, whereas a natural gas water heater that heats the water instantaneously without a storage tank has an energy factor around 0.82 . Heat is lost through the chimney and the pilot light is continuous, resulting in these inefficiencies [5]. The cost of a 189 L (50 US gallon) natural gas storage tank water heater typically ranges between $\$ 700$ and $\$ 1000[8]$.

\subsubsection{Electric Water Heaters}

Electric water heaters use electric heating elements immersed in the water tank. An advantage of an electric water heater is that no air supply is needed, unlike natural gas and heat pump water heaters, making them easier and cheaper to install in a new home. Typical electric water heaters have an upper and lower element. The upper element is used to heat the upper portion of water to meet high hot water demands. When the upper portion is at the temperature set-point, the lower element is engaged 
to heat the lower portion of water [5]. Since the elements are in the water tank itself, the electricity is converted to heat with minimal loss in heat transfer. Some of the heat is lost through the tank walls to the surroundings, resulting in an energy factor below 1. This heat loss is given as the standby loss of the electric water heater [5].

A 189 L (50 US Gallon) electric water heater typically costs between \$450 and $\$ 650$ [9]. While this is initially cheaper than a natural gas unit (which sells for $\$ 700$ to $\$ 1100[8])$, the cost of electricity is higher than that of natural gas.

The cost of electricity in Canada varies by province. Some provinces use a flat electricity rate, whereas other provinces, such as Ontario and Nova Scotia, are regulated with time-of-use electricity rates, such that the price is increased during peak periods. In a recent study, Hydro-Quebec compared monthly electricity bills of $1000 \mathrm{kWh}$ of 21 North American cities [10]. According to this study, Quebec, followed by Manitoba and British Columbia, had the lowest residential electricity rates per $1000 \mathrm{kWh}$ in Canada in 2015. The highest residential energy bills in Canada were in Nova Scotia, Prince Edward Island, and Saskatchewan, with Ontario being close behind.

Time-of-use rates result in electricity costs being higher than natural gas during peak and mid-peak hours, when most people are typically using hot water. Time-of-use electricity rates can be beneficial for both electric and heat pump water heaters in certain cases, such as when the tank is charged during off-peak hours overnight, resulting in a potentially lower energy bill than if natural gas was used. For the Canadian locations researched in the current work, the utility costs of electricity and the primary heating sources are shown in Appendix A. 


\subsubsection{Heat Pump Water Heaters}

While both electric water heaters and HPWHs run on electricity, they use different technologies to transfer heat to the water. Typical electric water heaters convert electricity directly into heat, while a HPWH uses electricity to operate a fan and compressor which extracts heat from the surrounding air using a heat exchanger and a heat transfer fluid. The extracted heat is then transferred to the hot water tank through the condenser [5].

A heat pump can be represented by a thermodynamic cycle that transfers energy from a source to a sink, using an evaporator, a compressor, a condenser, and an expansion valve. The refrigerant present in the heat transfer loop evaporates at a low pressure by extracting heat from the source at the evaporator. The compressor increases the pressure of the refrigerant, which then condenses in the condenser, releasing heat to the load. The expansion valve then lowers the pressure of the refrigerant and the cycle starts over [7]. A number of source-sink configurations exist, e.g., air-to-water heat pumps (such as the one studied in this work) and air-to-air heat pumps. The latter are typically used for refrigerators, space heating, and air conditioning in Canada [7]. In the case of air-to-air heat pumps for residential space heating, the evaporator is located outside of the house and the condenser is located inside of the house. In the cooling season, the process is reversed (the condenser is located outside and evaporator inside), and the indoor air in the house is rejected outside, cooling and dehumidifying the house [7]. 
In the case of a HPWH, energy in the form of heat is extracted from the surrounding air space (lowering the incoming air temperature) and is absorbed by the refrigerant; the refrigerant then undergoes the thermodynamic cycle and rejects the energy at the condenser which in turns heats the water in the storage tank. The process is non-reversible, that is, the HPWH cannot be used to heat the incoming air by cooling down the water. This process is illustrated in Figure 1-3.

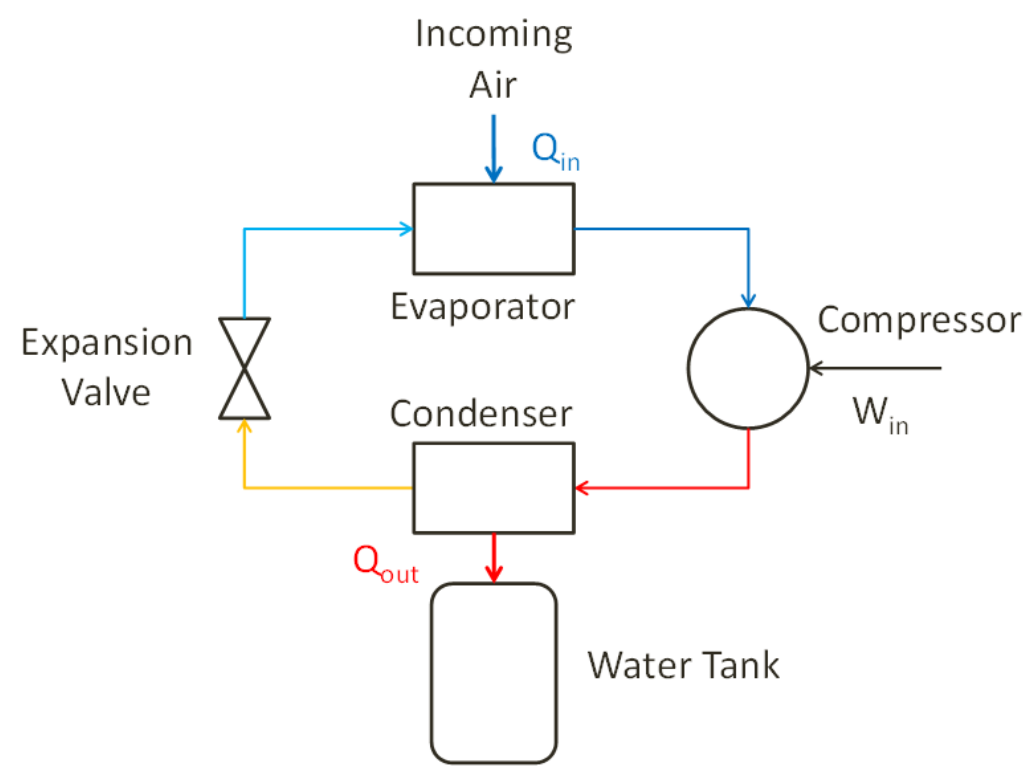

Figure 1-3: Operation of a heat pump cycle coupled with a domestic hot water tank

The cooled air leaving the HPWH cools the surrounding space which can be advantageous in the cooling season, as it decreases the cooling load. While space cooling represents only $1 \%$ of residential energy usage, and increases every year [1], the use of air conditioning causes peak electricity loads on the grid and can cause brownouts. Therefore reducing the peak cooling load is beneficial. Similarly, in the winter, the surrounding space will continue to be cooled, which will then increase the 
heating load. The building's space heating will have to reheat the area, potentially consuming more energy than is saved by the HPWH.

One possible way to reduce the effect of the increased heating load is to direct the exhaust air outdoors (using ducts) during the heating season. In the cooling season, the exhausted air could be directed to the surrounding space to reduce the cooling load, as shown in Figure 1-4.

HPWHs have a COP typically between 2 to 3 [11], i.e., for every unit of electrical energy used to power the HPWH, 2 to 3 units of energy heat the water, respectively. This means that even though electricity may be more expensive than natural gas, significantly more heat would be obtained per unit of electrical energy used. The COP of a HPWH is not constant, as it depends on the incoming air temperature and humidity. Higher air temperature and humidity both increase the COP [11]. Thus, if the outdoor air is ducted to the air intake of the HPWH, greater performance would be achieved by the unit in the cooling seasons. A control strategy could be used so that the outside air is ducted to the HPWH intake during the cooling season, as seen in Figure 1-4, resulting in higher HPWH performance. Similarly, if the outdoor air is at a lower temperature than the surrounding space (e.g. during the heating season), then the surrounding air can be used. This configuration is illustrated in Figure 1-5. R134a is the heating fluid used in the heat exchanger of the experimental HPWH. 


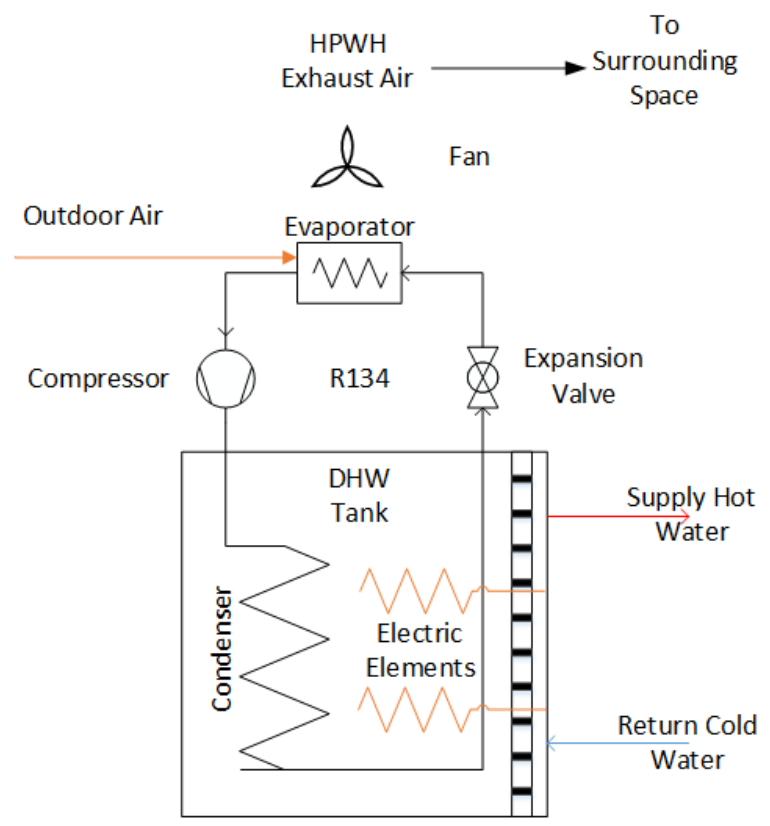

Figure 1-4: Illustration of a HPWH coupled with outdoor air in the cooling season

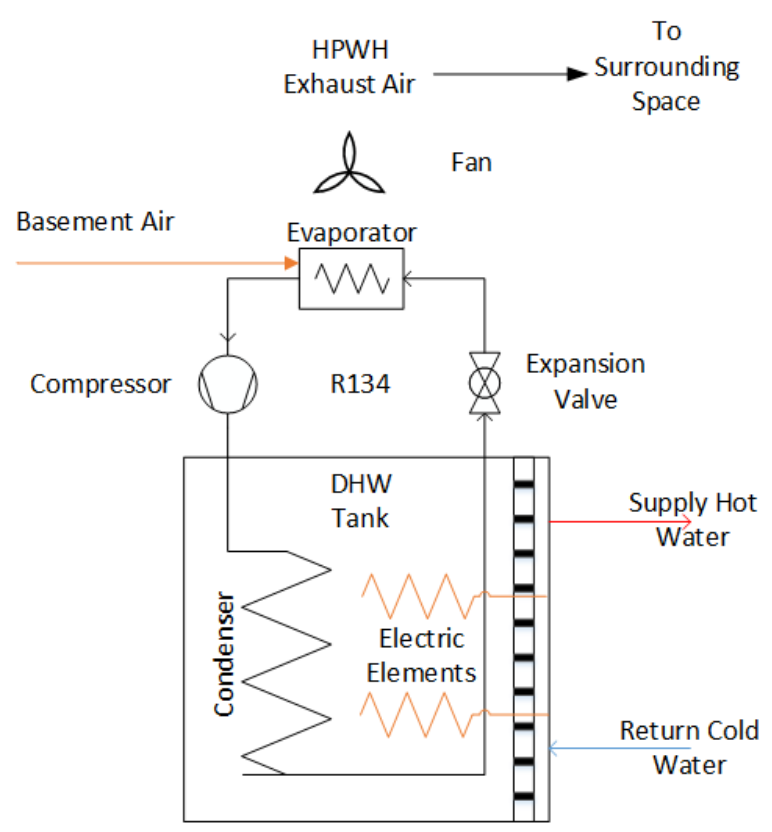

Figure 1-5: Illustration of a HPWH coupled with basement air in the heating season 
One disadvantage of HPWHs is a lower hot water recovery rate when compared to conventional natural gas or electric water heaters, as it does not directly heat the water. Thus, for high hot water demands, a larger capacity water tank is required to compensate [5]. Many commercial HPWH models also include an electric element in the tank to provide faster hot water recovery at the expense of increased energy use.

The 189 L HPWH used for this thesis work costs $\$ 1800$. This is roughly twice the cost of a natural gas water heater, and three times the cost of an electric water heater.

\subsection{Heat Recovery Ventilators}

A heat recovery ventilator is a ventilation device that exchanges heat between the incoming fresh air and the exhaust air of the building. This allows for the incoming air to be preheated in the heating season or precooled in the cooling season, resulting in reduced heating and cooling costs of a home. HRVs are becoming more common in modern households due to the increased airtightness of the homes. Installing an HRV allows for increased fresh air flow and reduced pollutants indoors [12]. By combining an HRV with a HPWH, as seen in Figure 1-6, it is believed that increased performance would be observed in the heating season, but decreased performance would occur in the cooling season, when compared to a HPWH using outdoor air. 


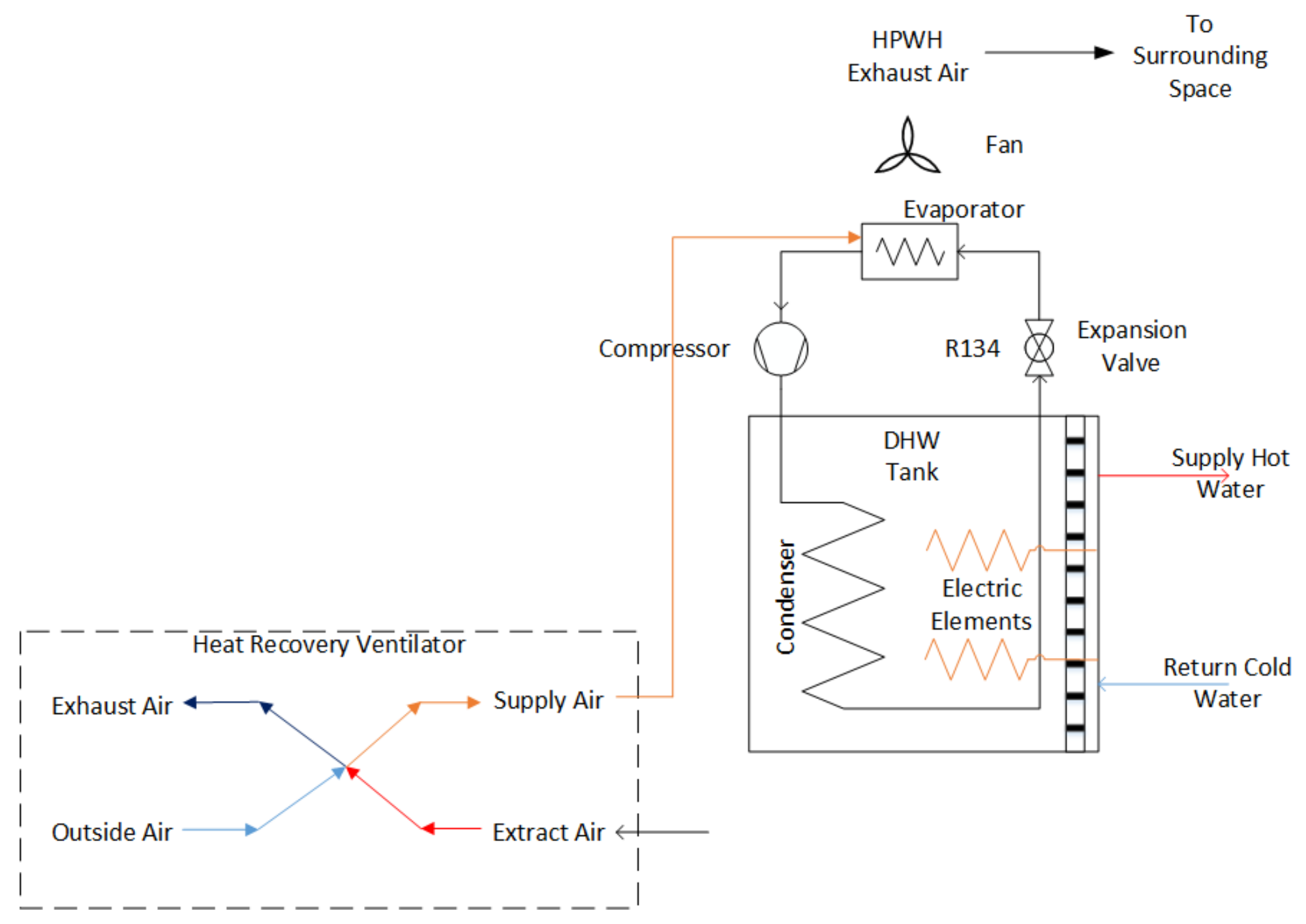

Figure 1-6: Illustration of an HRV coupled with a HPWH in the heating season 


\subsection{Research Objectives}

The objectives of the research are as follows:

- Establish a method of testing air temperature and air humidity conditions for multiple Canadian cities in each Canadian climate zone, including hot, cold, humid, and dry climates;

- Evaluate the performance and energy cost of a HPWH in Canadian climates at outdoor air conditions experimentally;

- Evaluate the annual performance and cost of the HPWH with an HRV through modelling under the same outdoor air conditions using numerical modelling;

- Evaluate the contribution of HPWHs on the heating and cooling loads using numerical modelling; and

- Compare the cost of energy of a HPWH to electric water heaters experimentally.

\subsection{Contributions to Research}

The contributions to the research include:

- Design of an experimental procedure to determine the performance of the HPWH in various Canadian cities and climates;

- Cost analysis and comparison of a HPWH and an electric water heater for each city and climate based on experimental data;

- Further validation of a previously developed HPWH computer model using the Transient System Simulation Tool (TRNSYS) software; 
- Cost and energy comparison using the HPWH with and without the HRV using the TRNSYS model;

- Modification of an existing TRNSYS house model with space heating and space cooling to compare the HPWH with basement conditions, outdoor conditions, and coupled with an HRV; and

- Annual performance simulations of the TRNSYS house model to compare the cost and energy use for various conditions.

\subsection{Organization of Research}

The thesis is divided into the following chapters:

- Chapter 1 - Introduction: Provides background information, motivation, and definitions for the topics discussed in the research;

- Chapter 2 - Literature Review: Provides an analysis of previous studies done, their contributions to the research, and work that can be further developed;

- Chapter 3 - Experimental Setup: Provides a description of the equipment and instrumentation used in the research;

- Chapter 4 - Modelling: Provides a description of TRNSYS, the modelling components used, and the simulation scenarios used in the research;

- Chapter 5 - Results and Discussion: Provides the experimental results, modelling validation and results, and compares HPWHs in various configurations;

- Chapter 6-Conclusions and Future Work: Summarizes the research findings and discusses future work for the research topics. 


\section{Chapter: Literature Review}

\subsection{Domestic Water Heaters}

In 2009, the residential sector accounted for $24 \%$ of the total energy consumption in Canada, compared to $25 \%$ in the United States, and the global average of $31 \%$ [13]. In 2013, the total energy consumption in the residential sector decreased to $17 \%$ [1]. In the commercial sector of the United States, water heating was the fourth largest energy use, behind space heating, air conditioning, and lighting, while in the residential sector, water heating contributed to $17 \%$ of residential energy use [14]. In Europe, $68 \%$ of building energy consumption was used for space heating, while $12 \%$ was used for domestic hot water heating [15]. Thus, there was a significant amount of energy that was used specifically for residential water heating. Based on the European Commission Statistical Pocketbook 2015 [16], it can be seen that in 2013, 295.9 million tons of oil equivalent (represented by the unit Mtoe) or $26.8 \%$ of final energy consumption in Europe was in the household sector, second only to $31.6 \%$ of final energy consumption by transport. It can be seen that reducing the household energy usage can provide significant energy savings overall. The energy consumption in the household sector reached a peak in Europe in 2010 of 307.3 Mtoe [15] and has decreased slightly since, however the percentage of energy consumption has increased from $26 \%$ in 2010 [15] to $26.8 \%$ in 2013 [16].

In Canada and the US, $25 \%$ and $40 \%$ of residences, respectively, heat water using electricity, while this percentage can vary greatly among each province and state. Another common way to heat water is by using fossil fuels [14]. These electric and fossil 
fuel-based water heaters are not very efficient, and thus a more efficient, sustainable energy source should be used. Heat pumps are an alternative that have the potential to reduce energy consumption and energy cost, and can be used for both water heating and space heating. Heat pump water heaters have been available for residential use since the mid-1980's. Heat pumps, and thus HPWHs, are initially more expensive [14] when compared to electrical or gas heaters, so their efficiency and coefficient of performance must be large enough to achieve energy savings to compensate.

In the United States, it has been mandated that for all electric water heaters, as of April 16, 2015, the energy factor, which is defined as the ratio of useful output energy to the total energy input [17], will not be lower than the following for a tank with a rated storage volume at or below 55 US gallons (208 L) [18].

$$
\mathrm{EF} \geq 0.960-(0.0003 * \text { Rated Storage Volume in US gallons })
$$

In the case of HPWHs, the energy factor is similar to the COP. For a water heater with a storage capacity over 55 US gallons, the energy factor will not be lower than the following [18].

$$
\mathrm{EF} \geq 2.057-(0.00113 * \text { Rated Storage Volume in US gallons })
$$

For the $189 \mathrm{~L}$ (50 US gallon) HPWH used in the research presented in this thesis, the energy factor cannot be below 0.945 based on these standards. Typically, electric water heaters have an energy factor of 0.9 or higher, whereas most HPWHs have an energy factor between 2 and 3 [14]. Thus, it can be seen that for the 50 US gallon HPWH, its lowest energy factor is higher than that of an electric water heater, and typical HPWHs have twice to three times the energy factor of an electric water heater. 
The performance of HPWHs can be affected by many variables, but the incoming air temperature is a large factor in colder climates like those found in Canada [5]. This is due to the lower sensible heat that can be extracted from cold air. Depending on the compressor and refrigerant used, the HPWH will have a range of temperatures at which it operates optimally. This means that when the incoming air temperature is too low, the heat pump will operate with a low COP, and a backup electrical resistance element will be used to heat the water at a faster rate. Due to the slower heating rates of heat pumps, a HPWH will generally have a higher capacity tank than a comparable electric water heater [14]. Due to the larger capacity, and the addition of a heat pump, a HPWH will take up more space than an electric water heater, which can cause issues if retrofitting an older residence with a HPWH. In addition, since heat pumps extract energy (heat) out of the ambient air and exhaust cooler air, this can lead to an increased heating load in the winter if the HPWH is exhausting the air into the building. This could even prove to be more costly than an electric water heater in some scenarios. However, in the summer, or in hotter climates, the HPWH will still cool the space, reducing the cooling load, and thus providing more energy savings. One possible alternative in colder climates is to duct the incoming air of the HPWH to some waste heat from other residential systems that are normally exhausted outside. This could effectively provide additional heating and prove to be viable in the winter. However, this scenario needs further testing to determine its viability.

While a lower hot water storage tank temperature set-point will result in less energy required by the HPWH, and thus a high COP, there is a lower limit to the 
temperature that can be set. Domestic hot water tanks are at risk to the bacteria known as legionella, which cause Legionnaire's disease [19]. While some may prefer to set their hot water temperature set-point to $49^{\circ} \mathrm{C}$ to reduce scalding, it has been shown that legionella can still grow at this temperature. There is typically no bacterial growth at a set-point of $55^{\circ} \mathrm{C}$, while a set-point at or above $60^{\circ} \mathrm{C}$ has shown to kill the bacteria [19]. It is also important to consider the thermal stratification of the water within the tank. Thermal stratification is a natural effect where the hottest water is at the top of the tank (as it is less dense), and the coldest water is at the bottom (as it is more dense). When the water at the top of the tank reaches the desired set-point, the water below that point in the tank is at a lower temperature, and thus bacteria may grow near the bottom of the tank. Due to this, it is important to have the hot water temperature setpoint at or above $55^{\circ} \mathrm{C}[19]$.

\subsection{Previous Research in Heat Pump Water Heaters}

Vieira et al. [20] tested the use of heat pump water heaters in various Australian climates. It should be noted that the refrigerant used in these tests was refrigerant 417, which has a lower freezing point and thus higher performance at lower temperatures than that of refrigerant 134a (R134a), which is used in the unit tested in this thesis. These tests analyzed the energy performance and level of service of the HPWHs in question by varying the coefficient of performance, water heating capacity, tank insulation thickness, tank size, and hot water set-point temperature. The HPWHs were installed outdoors in order to use the exact air conditions in each climate. In this study, 
tropical, semi-arid, sub-tropical, temperate, and cool temperate climates were examined, representing different Australian cities. It was found that, in terms of technical specifications of the HPWHs, the COP had the largest effect on the energy consumption of the HPWH, followed by, in descending order, the hot water tank storage capacity, the hot water temperature set-point, and the water heating capacity. It should be noted that the COP of the unit is dependent on the conditions of the air and water entering the unit, and cannot be directly controlled. Thus, having favourable conditions have the largest effect on the energy consumption of the HPWH. An important observation from this study is that the insulation material did not have a significant effect on the energy performance in the tested weather conditions. The study concluded that both the technical specifications and the on-site conditions had a larger effect on the energy consumption in colder climates. Likewise, in terms of on-site conditions, the hot water consumption pattern and temperature set-point had the largest effect on the energy consumption of the HPWHs. The effects of the COP and the hot water temperature set-point on the energy consumption are not surprising, as a high COP itself is determined by lower energy consumption, and decreasing the temperature set-point results in the HPWH shutting off sooner, saving energy. This study shows that the selection of HPWHs in these climates is more restricted, and the parameters should be more closely considered when purchasing a residential HPWH.

Willem, Lin, and Lekov [6] reviewed the efficiency and performance of HPWHs in residential applications. They found that while HPWHs typically have COPs ranging between 1.8 and 2.5 , it could potentially be increased to range from 2.8 to 5.5 . They 
also observed different schedule optimizations for HPWHs. By optimizing the schedule of the HPWH, the compressor would turn on at the most efficient time of the day.

Guo et al. [21] optimized the schedule of a HPWH in Shanghai, China. The simulation showed that the COP could be between 2.8 and 5.5 with an ambient air temperature of $35^{\circ} \mathrm{C}$ when optimized based on the schedule. A higher ambient temperature improves the performance of the HPWH, so optimizing the schedule of the unit based on energy usage would involve turning the unit on later in the day. It was concluded that the optimal start-up time would be between 12:00 and 14:00. In areas with time-of-use utility rates, this would coincide with peak hours, thus increasing the energy cost, and offsetting the benefits. In these areas, it would be more beneficial to engage the unit during off-peak hours, which would result in a lower COP, but significantly lower energy costs. They noted that, based on peak rates in Shanghai, the optimal start-up time in these cases would be at $22: 00$. In the winter, the heat pump would be shut off overnight at 2:00; otherwise, the optimal shut-off time is 4:00.

Heschong Mahone Group [22] investigated the energy savings of HPWHs in single family homes in various US regions through simulations. The study also observed the effects of HPWHs on heating and cooling loads. The energy savings were compared to vintage and newer residences with both electric and gas water heaters. During the study, it was found that while the HPWH increases the heating load on the HVAC system, it is still more efficient to set the unit to heat pump only mode rather than electric resistance mode throughout the entire winter. It was noted that the HPWH has 
the potential to save more energy when replacing electric water heaters than when replacing gas water heaters.

One interesting conclusion is that during the cooling season, the reduced HVAC energy consumption also reduced the HPWH energy input, thus improving the unit's efficiency. The opposite was true during the heating season. The study showed that HPWHs save the most energy in hot inland climate zones, and save the least energy in cold coastal areas [22]. This is due to the higher heating load penalty experienced in coastal climates. It is worth assessing the effects of the HPWH on the heating and cooling loads in Canadian regions, since there is a larger range of climates.

HPWHs have been sold for decades but, due to high initial costs and equipment failures, had low sales. The technology has improved greatly, and many of the issues were addressed in newer generations. In addition to this, and with regulatory changes in the US, HPWHs are becoming more favourable [6].

Baxter and Linkous [23] tested 10 newer generation residential HPWHs by simulating 10 years of compressor cycling in an environmentally controlled laboratory. Over the course of the tests, the thermal expansion valve of one unit needed to be replaced, however no major failures occurred in the heat pumps. These units were tested for 10 years as that is the typical lifetime of electric and gas water heaters.

Shapiro and Puttagunta [24] tested 14 HPWHs in-situ in cold climates in the US for over 1 year. These units, ranging in capacity from $190 \mathrm{~L}$ to $300 \mathrm{~L}$, were installed in Massachusetts and Rhode Island. One unit experienced temperatures below $10^{\circ} \mathrm{C}$ for a large part of the year, thus the electric element was used for heating as a backup. The 
other 13 units had COPs ranging from 1.5 to 2.6. The larger capacity units tended to have a higher COP, as they used the electric elements to heat the water less frequently.

It was noted that the heat lost to the environment is larger for HPWHs rather than electric water heaters. This could be due to the condenser and extra piping. The efficiency of HPWHs installed in confined spaces was typically $16 \%$ lower than units in open spaces [24].

Bursill [25] evaluated the performance of a commercially available HPWH in cold climates. The tank contained a single $1500 \mathrm{~W}$ electrical element located near the top of the tank and a wrap-around heating coil, using refrigerant 134a. The tests were performed using Canadian Standards Association (CSA) draw profiles, discussed later in this chapter. The experimental data was used to calibrate a model within TRNSYS and to devise an optimized control strategy for use in cold climates. An optimized control strategy is necessary since the use of an air source heat pump cools down the surrounding space, which is beneficial in warmer climates, but in colder climates, leads to an increased heating load in the winter. Previously, control strategies for HPWHs were only concerned with the hot water temperature set-point, without considering this additional heating load. The control strategy involved using various set-points for both the heat pump and the electrical resistance heater. The heat pump and electrical resistance heater each affected certain nodes, or sections of water, within the tank, and those nodes were heated to the set-point temperatures.

Bursill pre-heated the incoming mains water to $26^{\circ} \mathrm{C}$ before entering the $300 \mathrm{~L}$ (80 US gallon) HPWH. It should be noted that this mains water temperature is 
high, and may have affected the results, as a typical temperature for mains water is $10^{\circ} \mathrm{C}[26]$. The water would have a smaller temperature increase to reach the desired set-point, thus resulting in less energy being used. The water draw temperature was also kept consistent at $55^{\circ} \mathrm{C}$. One of the conclusions reached in Bursill's research was that having a higher temperature set-point for the water would decrease the COP of the HPWH; however, this decrease in performance can be offset by shifting electrical demand to off-peak hours, reducing the cost of energy. This higher water temperature would also have the benefit of restricting the growth of bacteria, as discussed earlier.

Bursill's experiments used a HPWH with one electrical resistance heater, with ambient conditions being approximately $20^{\circ} \mathrm{C}, 50 \%$ relative humidity. Bursill's research showed that, as expected, the highest COP occurred when only the heat pump was used, with a COP ranging from 1.7 to 2 , and the lowest COP (below 1 ) occurred when the electrical resistance heater was used without the heat pump. The experimental COP for the electrical heater is as expected, with the theoretical COP being approximately 0.9 [14]. The COP approached approximately 1.3 when both the heat pump and electrical resistance heater were used simultaneously. This drop in COP was caused by the higher power draw of the electric heater than the heat pump cycle. Using both of these heating methods provides a compromise between efficiency and hot water demand.

Bursill recommended implementing an air handling unit (AHU) with a new HPWH unit in future experiments [27]. This AHU would allow for a large range of desired temperatures and humidity levels to be tested, as opposed to being limited to the 
laboratory air conditions. This means that a more accurate performance map could be developed with a wider range of data points. Different climates and scenarios can also be tested experimentally with the use of the AHU. An air handling unit has been installed in the experimental setup of this research in order to meet these suggestions.

Johnson [28] noted that while the European Union defines heat pumps as renewable, as their carbon footprint due to power generation is under the allowed threshold, these footprint measurements do not account for the manufacturing of the heat pump or the emissions of the fluorocarbon refrigerant. It was found that the fluorocarbon refrigerant adds $20 \%$ to the carbon footprint in addition to the power generation, and the heat pump manufacture and disposal accounts for $3 \%$ of the carbon footprint. It was also noted that the carbon footprint per kWh of a heat pump is higher than a gas water heater.

R134a has been most commonly used in HPWHs, replacing refrigerant 22 (R22) in the 2000s due to its negative impact on the ozone layer [6]. R134a has a $25 \%$ higher COP than R22, however it has high global warming potential, thus it is still dangerous to the environment. Alternative refrigerants could be used to both improve the performance and reduce the environmental impact. $\mathrm{CO}_{2}$ has a much higher efficiency than R134a, capable of achieving a COP above 4.0, however it is not a solution due to it being a greenhouse gas. 


\subsection{Draw Profiles}

The CSA-F379.1-88 standard for Solar Domestic Hot Water Systems provides hot water draw profiles for various occupancies [29]. These draw profiles are used in the experiments that follow in this thesis, as shown in Table 2-1 [27].

Table 2-1: Hot water draw profiles [27]

\begin{tabular}{c|ccc}
\hline \multirow{2}{*}{ Hour } & \multicolumn{3}{|c}{ Draw Volume (L) } \\
\cline { 2 - 4 } & Schedule A & Schedule B & Schedule C \\
\hline 7 & 5 & 10 & 10 \\
8 & 25 & 25 & 25 \\
9 & 0 & 5 & 25 \\
10 & 45 & 45 & 45 \\
11 & 0 & 5 & 25 \\
12 & 5 & 10 & 10 \\
13 & 0 & 5 & 5 \\
14 & 0 & 0 & 0 \\
15 & 0 & 0 & 0 \\
16 & 0 & 10 & 15 \\
17 & 5 & 25 & 25 \\
18 & 10 & 45 & 45 \\
19 & 30 & 25 & 25 \\
20 & 20 & 10 & 30 \\
21 & 0 & 5 & 10 \\
22 & 0 & 0 & 5 \\
\hline \hline Total & 150 & 225 & 300 \\
\hline
\end{tabular}

The three schedules in Table 2-1 are used for different occupancies in a household. Schedule A represents the water draw of a household with an occupancy of 1-2 persons (150 L/day), Schedule B represents an occupancy of 3-4 persons ( $225 \mathrm{~L} /$ day), and Schedule C represents an occupancy of 5 persons (300 L/day) [30]. These draw profiles assume that there is negligible draw overnight between the hours of 11 PM and 7 AM. Thus, a full day of draw testing can be completed in 13 hours. However, the water 
in the tank must reach a certain temperature set-point before testing can begin. The CSA-F379.1 standard is based on a water flow rate of $11.5 \mathrm{~L} / \mathrm{min}$ from the outlet of the water tank [27]. The CSA-F379.1 draw profiles have been used in past research, including Bursill's [27], Dickinson's [30], Cruickshank's [31], as well as the research by Banister, Wagar, and Collins [32]. These draw profiles are used in both the experiments and modelling in the research presented in this thesis. Given that the HPWH used in this research has a capacity of 189 L, and a first-hour rating of 246 L (65 US gallons), Schedule A was tested rather than Schedules B and C. The first-hour rating of a water heater represents the amount of hot water that can be delivered in an hour, if the full tank of water is heated.

\subsection{Heat Recovery Ventilators}

Zhang, Fung, and Jhingan [33] simulated the feasibility of both HRVs and energy recovery ventilators (ERVs) in residential applications. It was found that in cold climates, an HRV is more effective than an ERV. On the other hand, an ERV is more effective in humid climates. This is due to the sensible and latent heat recovery provided by ERVs. In cold climates, ERVs would not be as cost-effective due to the lack of moisture in the ambient air to provide latent heat recovery. Thus, HRVs would provide more energy savings in cold climates. The simulations also showed that the free cooling provided by HRVs and ERVs is beneficial to both warm and cold climates.

Yaïchi, Ghorab, and Entchev [34] used computational fluid dynamics (CFD) for the detailed design of ERVs and HRVs in Calgary, Halifax, Ottawa, and Vancouver in the 
summer and winter. The independent variables that were observed were air velocity, outdoor air temperature, outdoor air humidity, and whether the unit used counter flow or co-current flow. The performance of the HRVs and ERVs were determined based on the effectiveness and fan power consumption of the units. The HRVs had higher performance when configured in counter flow. Increasing the air velocity from $0.5 \mathrm{~m} / \mathrm{s}$ to $2.5 \mathrm{~m} / \mathrm{s}$ decreased the performance by $20 \%$ for an HRV in counter flow. This makes sense, as the study by Bao, Wang, and Yang [35] showed that decreased air flow correlated with increased efficiency. It is important to note that the airflow of the HRV used in the work of this thesis is low when compared to other HRVs, thus will result in increased performance.

Outdoor temperature and humidity had minor effects on the performance of the unit within a given season [34]. As expected, the humidity had negligible effect on the sensible effectiveness. The effectiveness was $7.5 \%$ higher in the summer than in the winter for a counter flow HRV. At high flow velocities, the summer season resulted in $18.6 \%$ higher power consumption. At low flow velocities, the season had a negligible impact on the effectiveness.

\subsection{Modelling in TRNSYS}

TRNSYS is a modelling program developed by Thermal Energy System Specialists (TESS) in Madison, Wisconsin [36]. The components in the modelled systems are represented with "Types," and can simulate a wide range of components such as water tanks, heat pumps, heat exchangers, and turbomachinery by performing a series of 
calculations on the input variables to determine the output variables. A TRNSYS model is created to simulate the experimental setup of the HPWH used in this research. This model is calibrated using a performance map of the HPWH that was obtained experimentally. A performance map is a table of values that lists the dependant variables (such as heat extracted to the water and power consumption) given a set of independent variables (such as the inlet air temperature, inlet air humidity, and water temperature), so that the performance of the HPWH can be estimated based on the input conditions. The TRNSYS model was used to extend the testing conditions and results, as well as test different modifications. Table 2-2 describes the TRNSYS Types that were encountered in the literature review.

Table 2-2: Description of TRNSYS types from literature review [37] [38]

\begin{tabular}{|c|c|c|}
\hline Type & Component & Description \\
\hline $4 b$ & DHW Tank & $\begin{array}{l}\text { Storage tank with thermal stratification, } \mathrm{N}<100 \text { nodes, fixed hot } \\
\text { and cold fluid inlet positions }\end{array}$ \\
\hline 60 & DHW Tank & $\begin{array}{l}\text { Storage tank with thermal stratification, like Type } 4 \text {. Allows for } \\
\text { multiple heat exchangers, inlet flows, and outlet flows }\end{array}$ \\
\hline $1237-1$ & DHW Tank & $\begin{array}{c}\text { Vertical cylindrical storage tank with a wrap-around heat } \\
\text { exchanger }\end{array}$ \\
\hline $5 b$ & $\begin{array}{l}\text { Heat } \\
\text { Exchanger }\end{array}$ & $\begin{array}{l}\text { Counter flow heat exchanger, with variable hot and cold side } \\
\text { inlet temperatures and flow rates }\end{array}$ \\
\hline 938 & Heat Pump & $\begin{array}{l}\text { Using an air source, heats a liquid. Coupled with a DHW tank to } \\
\text { simulate a HPWH }\end{array}$ \\
\hline $9 a$ & Water Draw & Reads data from an input file at constant time intervals \\
\hline $14 b$ & Water Draw & $\begin{array}{l}\text { Time dependent forcing function. Allows for the water flow rate } \\
\text { to be changed at various timesteps }\end{array}$ \\
\hline $15-6$ & Weather & $\begin{array}{l}\text { Reads data from an external weather data file at constant time } \\
\text { intervals }\end{array}$ \\
\hline 109 & Weather & $\begin{array}{l}\text { Reads data from an external weather data file at constant time } \\
\text { intervals }\end{array}$ \\
\hline
\end{tabular}


Banister, Wagar, and Collins [32] experimented with a solar-assisted heat pump connected to a domestic hot water (DHW) tank in Ottawa, Canada, and modelled the system in TRNSYS. This TRNSYS model was validated with the experimental setup to ensure accuracy [32]. Type $4 b$ was used for the DHW tank, Type 110 for the heat pump, Type $5 b$ for the heat exchanger, Type 109 for the weather data, and Type $14 b$ for the water draw [32]. Using the typical meteorological year (TMY) data for Ottawa, August 14 and October 29 were used to represent typical summer and fall weather, respectively. August 14 has clear skies and large amounts of solar irradiation, whereas October 29 has cloud coverage and less solar irradiation. The selected days represented extreme conditions; however, this research was concerned with a broader scope of testing conditions, as using a single day of weather data can highlight effects of the best and worst weather scenarios, but does not represent the typical results that would be observed over a month, season, or year.

Dickinson [30] modelled the stratified DHW tank using Type 60, which was developed to replace Type 4, as it can more accurately represent thermal stratification within the tank. Dickinson also mentions Type 534, which is a component provided in the optional TESS library add-on to TRNSYS also capable of modelling a stratified DHW tank. A variant of Type 534 is capable of modelling a wrap-around heat exchanger, which is included in the HPWH in the research presented in this thesis.

Bursill [27] modelled a HPWH with a stratified tank in TRNSYS. The model used a TMY2 weather file, which simulates weather data in the selected city using data from 1961 to 1990. Type 938, from the TESS library in TRNSYS, was used to model the air-to- 
water heat pump. Type 938 represents an air source HPWH, which extracts heat from the incoming air to the entering water [38]. This heated water is then compressed and would be output to the heat exchanger of the DHW tank. The hot water tank was modelled with Type 1237-1, which is based off of the TESS library Type 534. Type 534 is typically used to model cylindrical hot water tanks with an immersed heat exchanger [25], whereas Type 1237-1 adds the capability of modelling a wrap-around coil condenser in the tank [38]. The HPWH used in Bursill's research used a wrap-around heat exchanger, so Type 1237-1 was an appropriate model. The experimental setup shown in this thesis builds upon and modifies the experimental setup that was used by Bursill. Thus, the TRNSYS types that Bursill used may also be viable for use in the modelling in this thesis, however, a new HPWH type was created to overcome the limitations of Type 1237-1, as discussed later. Table 2-3 below shows a comparison of the TRNSYS types used for each component in the literature studied.

Table 2-3: Review of TRNSYS components used in literature

\begin{tabular}{c|ccc}
\hline \multirow{2}{*}{ Component } & \multicolumn{3}{|c}{ TRNSYS Type } \\
\cline { 2 - 4 } & Banister [32] & Dickinson [30] & Bursill [25] [27] \\
\hline Heat Pump & - & - & 938 \\
DHW Tank & $4 b$ & 60 & $1237-1$ \\
Heat Exchanger & $5 b$ & - & - \\
Weather & 109 & - & $15-6$ \\
Water Draw & $14 b$ & $14 b$ & $9 a$ \\
\hline
\end{tabular}

Bursill [25] developed a model in TRNSYS based on an experimental $300 \mathrm{~L} \mathrm{HPWH}$ setup in order to extend the testing results. The model was calibrated with the energy consumption from the experimental results, using the CSA-F379.1-88 
standard water draw profiles. This same approach is used in developing the TRNSYS model discussed in this thesis.

\subsubsection{HPWH TRNSYS Model}

Khalaf [39] developed a new TRNSYS type, Type 240, to represent a HPWH with a wrap-around condenser coil. This was developed due to limitations in the HPWH TRNSYS types that are included in the TRNSYS and TESS libraries. A performance map was developed by Khalaf to observe the effects of the independent variables on the performance of the HPWH. The HPWH used in Khalaf's research was also used for all of the research presented in this thesis. The independent variables of the performance map include the air temperature, the air humidity, and the water temperature in the tank. The air temperature was adjusted in $10^{\circ} \mathrm{C}$ intervals, the relative humidity in $10 \%$ intervals, and the water temperature in $10^{\circ} \mathrm{C}$ intervals. The performance map was used as an input file in Type 240.

Figure 2-1 illustrates the heat delivery as a function of water and air temperature, while Figure 2-2 shows the effect on the compressor power [39]. These tests were performed with a constant air relative humidity of $20 \%$. Results from Khalaf's work indicated that as the water temperature increased, the heat delivery decreased, and the compressor power consumption increased slightly to account for this. Similarly, higher air temperature resulted in a significantly higher heat delivery and higher power consumption. It was concluded that increasing the water temperature in the tank resulted in a lower COP, and increasing the air temperature increased the COP. 


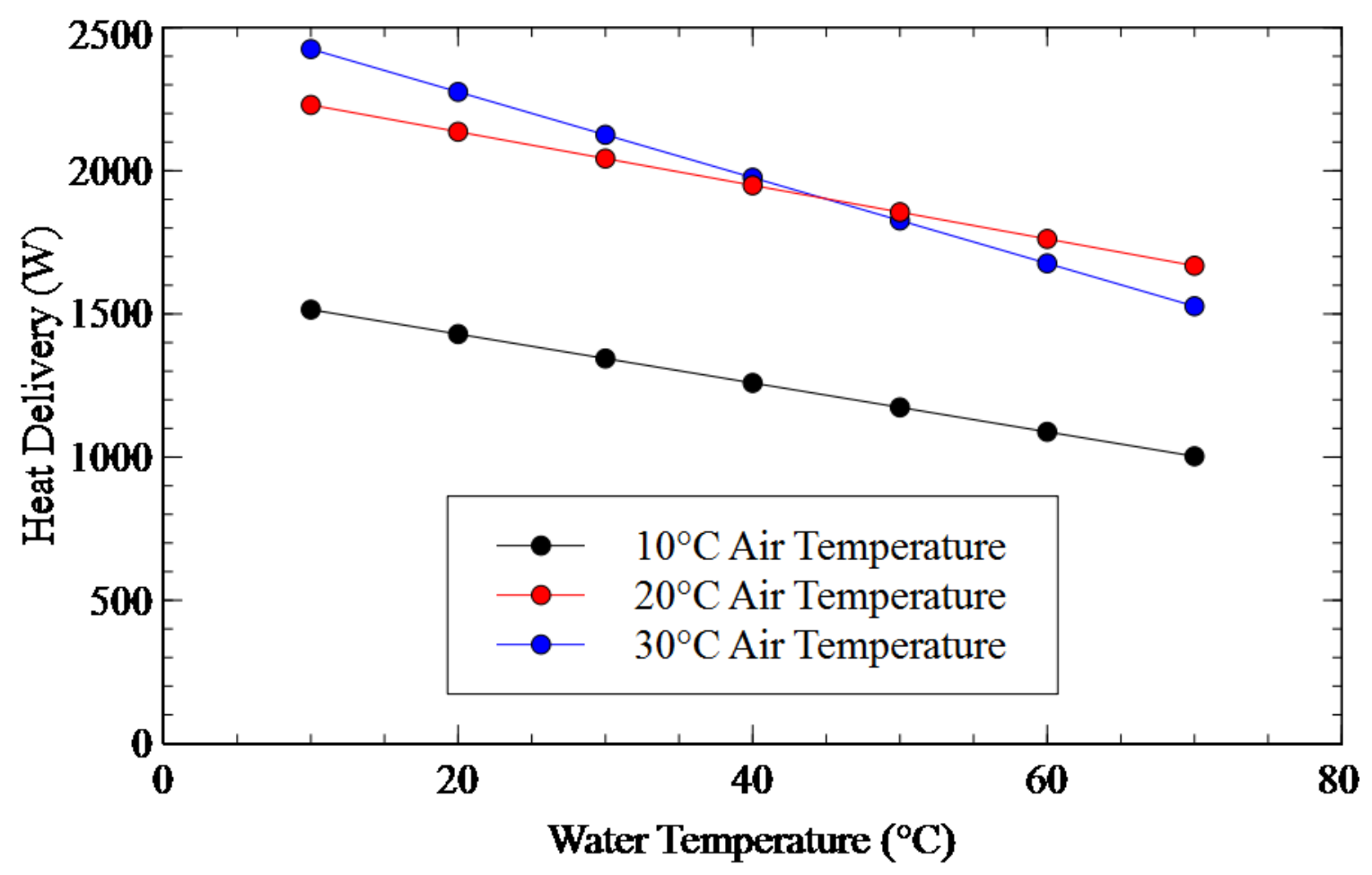

Figure 2-1: Effect of air temperature on heat delivery at a constant $20 \%$ relative humidity [39]

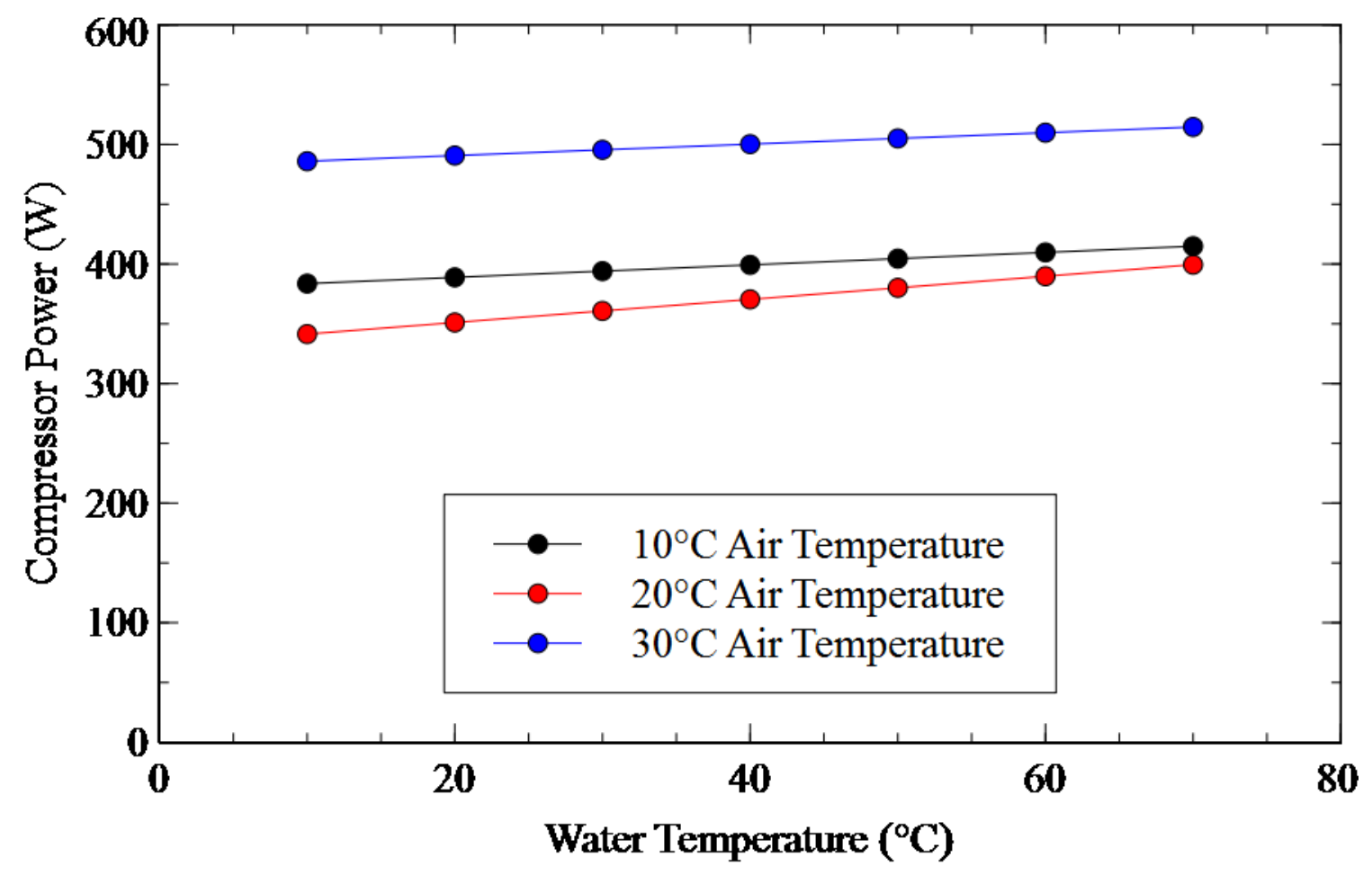

Figure 2-2: Effect of air temperature on compressor power at a constant $20 \%$ relative humidity [39] 
In Khalaf's testing [39], it was noted that increasing the relative humidity from $20 \%$ to $70 \%$ at an air temperature of $20^{\circ} \mathrm{C}$ led to a negligible increase in heat delivery and compressor energy consumption, thus had little effect on the unit's performance. In the present research, however, it was found that the relative humidity did have a larger effect at higher air temperatures.

\subsubsection{House Model}

A house model, using Type 56 in TRNSYS, was developed by Baldwin and Cruickshank [40] and modified by Khalaf [39]. Khalaf had run annual simulations to compare the cost of energy and greenhouse gas emissions of a HPWH to those of a natural gas and an electric water heater. Khalaf's research concluded that the natural gas water heater had the lowest annual cost of energy, followed by the HPWH and the electric water heater. The HPWH was found to have the lowest level of greenhouse gas emissions, while the natural gas water heater had the highest, as expected.

Khalaf's research also determined that a replacement HPWH installation would have a payback period of 3 years in Ottawa if a heat pump was used as the space heating method and a payback period of 4 years if an electric baseboard heater was used. In Toronto, the respective payback periods are 3 and 5 years, in Montreal they are 4 and 12 years, and in Vancouver they are 5 and 13 years. Water heaters have a typical life cycle of 10 years. Khalaf concluded that a replacement HPWH installation had a greater effect on the cost of energy in areas with time-of-use energy billing, as the HPWH took advantage of the off-peak periods. The replacement unit was economically 
viable in each scenario except in Montreal or Vancouver when electric baseboard heating was installed [39].

\subsection{Gaps in Literature}

The literature that was reviewed for the current work has not considered the effects of HPWHs in many Canadian cities. While Khalaf had researched HPWHs in Ottawa, Montreal, and Vancouver, more climates will be investigated in the current work. In addition to this, many Canadian regions have different electricity rates, whether flat or time-of-use, and some use alternative sources for heating water. As such, the cities for the current work will be chosen so that similar climates with different utility rates and different heating sources can be compared to each other. There is also a lack of research on coupling HPWHs with outdoor air or HRVs in Canadian climates. The current work will investigate these effects on the performance of the HPWH through both experimental and simulation-based testing. 


\section{Chapter: Experimental Setup}

This chapter provides an overview of the experimental setup used to test the performance of a heat pump water heater under varying operating conditions. Following the general overview, the components used in the experimental setup will be described in further detail. The experiments described in this thesis were performed in the Solar Energy Systems Laboratory in the Canal Building at Carleton University.

\subsection{Overview of Experimental Setup}

The experimental apparatus was designed and built to evaluate the power consumption and performance of a HPWH in Canadian cities with a range of air temperatures and humidities. The apparatus consisted of a heat pump water heater, an air handling unit for temperature and humidity control, a pre-heat tank, a power monitoring system, thermocouples for air and water temperature measurements, relative humidity sensors, proportional control valves, an air velocity sensor, a water flow meter, solenoids, recirculation pumps, and a data acquisition system. The heat pump water heater and pre-heat tank were already present in the laboratory when the research began. A photograph of the overall setup is shown in Figure 3-1. 


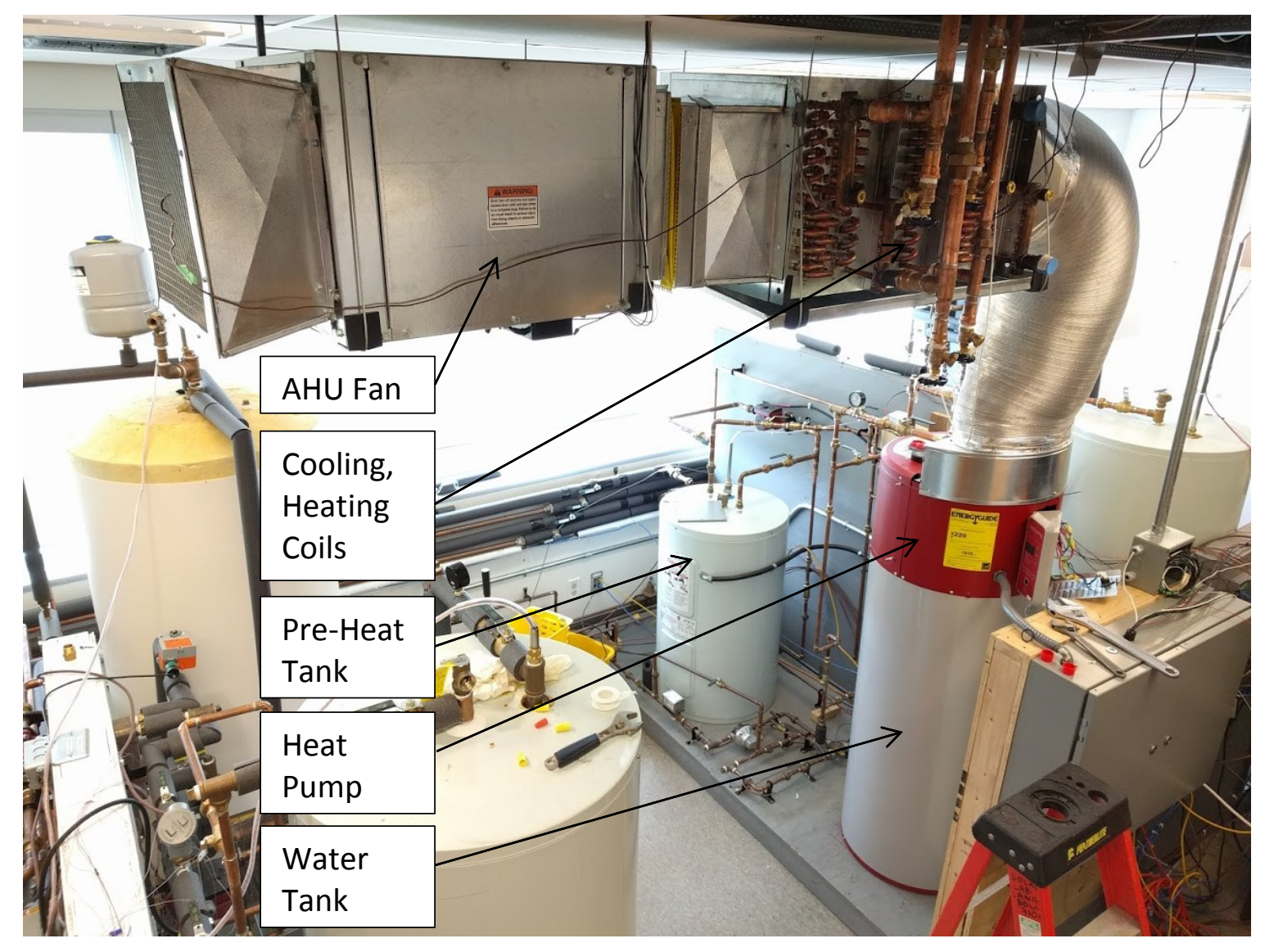

Figure 3-1: Full experimental setup

A schematic showing the path of the air entering the air handling unit and being supplied to the HPWH is shown in Figure 3-2. For each test, air was drawn from the laboratory into the air handling unit by a fan, was humidified by the spray humidifier, and cooled or heated by the cooling coil and heating coil, respectively, depending on the air temperature and humidity set-points. An air velocity sensor was used in a proportional-integral-derivative (PID) loop in LabVIEW to adjust the speed of the fan so that the air flow rate matched that of the HPWH exhaust fan. The conditioned air was then directed to the evaporator of the HPWH, which exchanged heat with the 
refrigerant in the heat pump cycle. Colder air was then exhausted from the back of the HPWH unit into the laboratory.

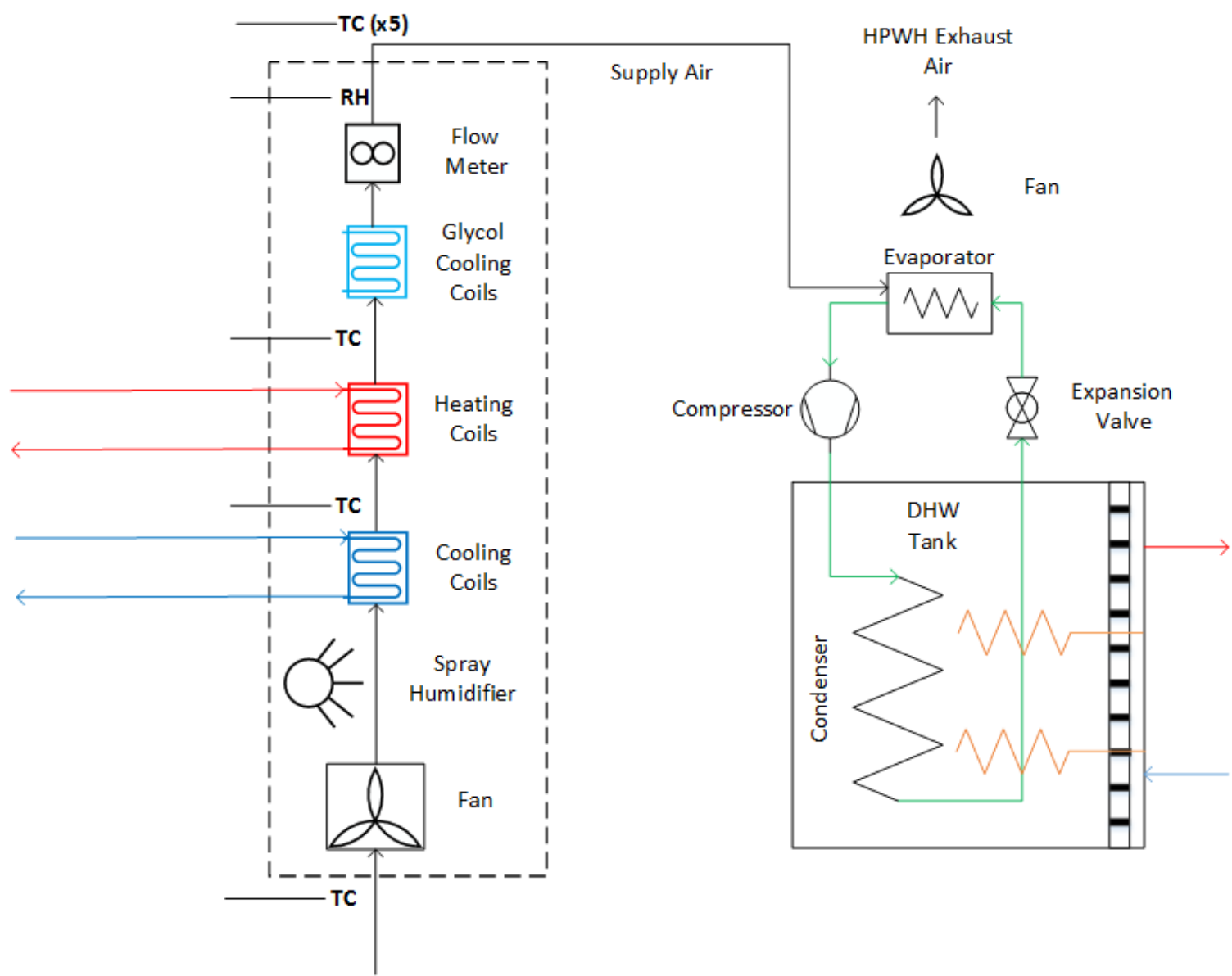

Lab Air

\section{Legend}

TC - Thermocouple

$\longrightarrow$ Hot Water
$\longrightarrow$ Cold Water

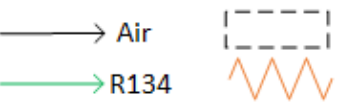

Air Handing Unit

RH - Relative Hum id ity Sensor

R134

Electric Element

Figure 3-2: Schematic of the HPWH and AHU air loop

A schematic showing the path of the water through the experimental setup is shown in Figure 3-3. For each test, the mains water entered the pre-heat tank, which recirculated the water back into the tank to remove any stratification and ensure that the water was at a uniform temperature. A thermocouple probe was installed in the 
pre-heat tank to ensure that there was no stratification. Once a uniform mains water temperature was reached, the water entered at the bottom of the HPWH storage tank. The tank in the HPWH was $1 \mathrm{~m}$ tall. A probe consisting of 10 thermocouples was installed in the HPWH tank, spaced equally $10 \mathrm{~cm}$ apart. Each of these thermocouples measures the temperature of a $10 \mathrm{~cm}$ high, cylindrical element of water. This measured temperature corresponds to the uniform temperature of the respective node. The top of the tank was referred to as Node 1 (TC-1 in Figure 3-3), and the bottom of the tank was referred to as Node 10 (TC-10 in Figure 3-3). Once the water in the HPWH tank was heated, it was drawn from the top of the tank, mixed with mains water to reach a delivery temperature of $55^{\circ} \mathrm{C}$, and drawn into a drain using a solenoid. A water flow meter was used to measure the water draw volume. The HPWH also had a recirculation pump, which was used in performance map and cool-down testing to bring the water in the HPWH tank to a uniform temperature. Thermowells were used to measure the temperature of the water entering the HPWH tank, leaving the HPWH tank, and being delivered to the draw system. 


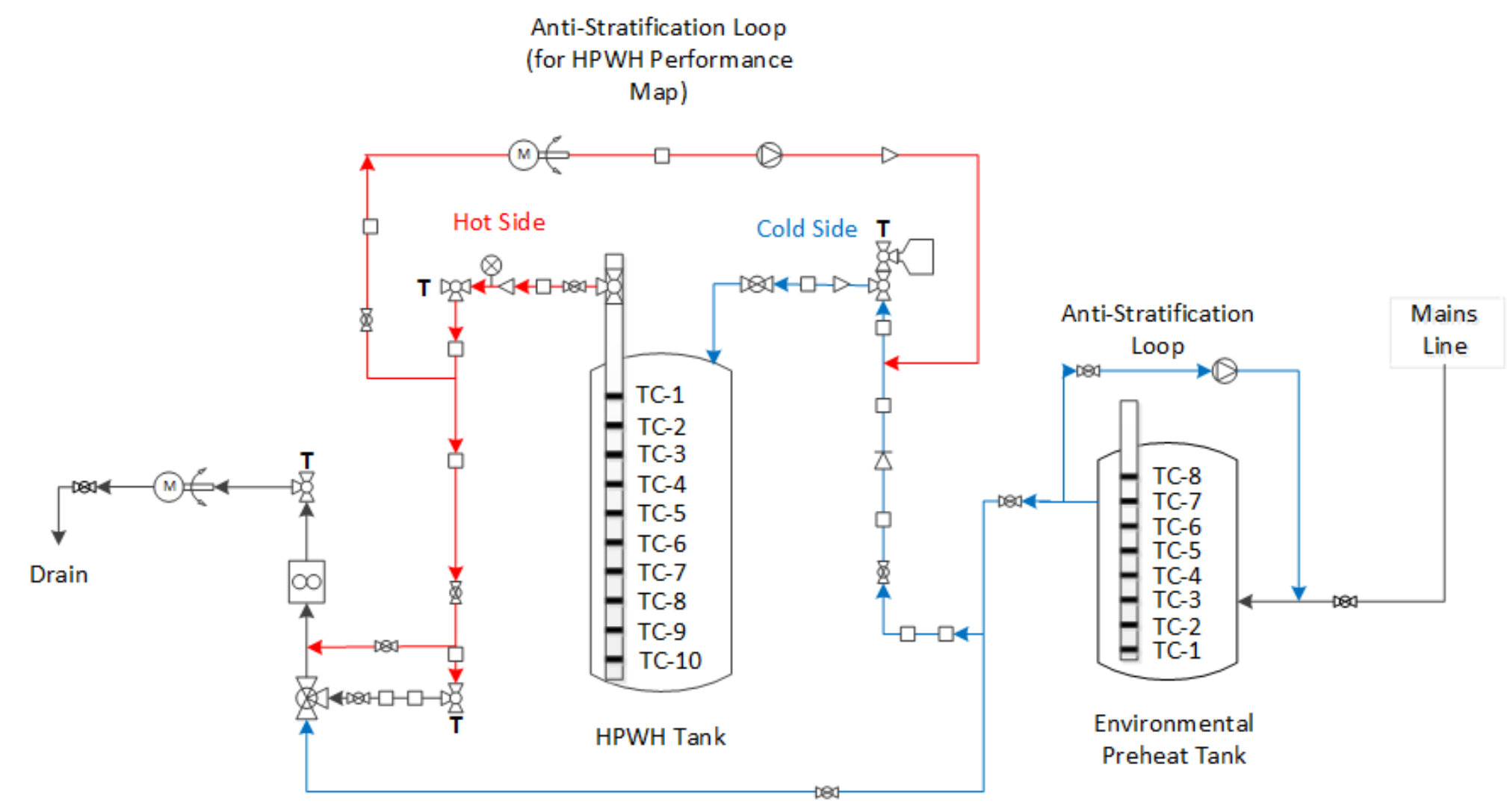

\begin{tabular}{|c|c|c|c|c|c|c|c|}
\hline \multicolumn{8}{|l|}{ Legend } \\
\hline$\infty$ Flow Meter & $\$$ Tempering Valve & Dos & $\begin{array}{l}\text { Threaded Tee (for } \\
\text { Instrumentation) }\end{array}$ & $\triangle$ Check Valve & $D$ & $\begin{array}{l}3 / 4^{\prime \prime}-1 / 2 " \\
\text { Ad aptor }\end{array}$ & Thermowell \\
\hline$\otimes$ Pump & $\infty$ Valve & (i)f & Solenoid Valve & $\otimes$ Pressure Gauge & $\square$ & Union & $\begin{array}{l}\text { Expansion } \\
\text { Tank }\end{array}$ \\
\hline
\end{tabular}

Figure 3-3: Schematic of the HPWH, preheat tank, and plumbing 
A list of equipment and sensors in the HPWH experimental setup is provided in

Table 3-1.

Table 3-1: List of equipment and sensors used in the HPWH apparatus

\begin{tabular}{|c|c|c|c|}
\hline Component & Manufacturer & Model & Description \\
\hline $\begin{array}{c}\text { Heat Pump Water } \\
\text { Heater }\end{array}$ & General Electric & GEH50DEEDSRB & $\begin{array}{c}189 \text { L tank, } \\
\text { refrigerant } 134 a, \\
600 \text { W compressor, } \\
\text { two } 3380 \text { W electric } \\
\text { heating elements } \\
{[41]}\end{array}$ \\
\hline Pre-Heat Tank & Giant & 142ETE-3F7M & $\begin{array}{c}\text { Recirculates mains } \\
\text { water for consistent } \\
\text { temperature }\end{array}$ \\
\hline Pumps & Grundfos & UPS15-58FC & $\begin{array}{l}\text { Pre-heat tank and } \\
\text { HPWH recirculation } \\
\text { pumps }\end{array}$ \\
\hline Solenoids & Schneider Electric & AG13Q020 & $\begin{array}{c}\text { Draws water and } \\
\text { activates } \\
\text { recirculation pumps }\end{array}$ \\
\hline Relays & $\begin{array}{c}\text { Finder, Phoenix } \\
\text { Contact, ABB }\end{array}$ & $6 \mathrm{~A}, 10 \mathrm{~A}, 30 \mathrm{~A}$ & $\begin{array}{c}\text { Control solenoids, } \\
\text { pumps, main } \\
\text { power, and HPWH } \\
\text { components }\end{array}$ \\
\hline Thermocouples & Omega & $\begin{array}{l}\text { Type T (30 gauge } \\
\text { and } 24 \text { gauge) }\end{array}$ & $\begin{array}{c}\text { Measure water and } \\
\text { air temperature }\end{array}$ \\
\hline $\begin{array}{l}\text { Relative Humidity } \\
\text { Sensors }\end{array}$ & Omega & HX94AC & $\begin{array}{c}\text { Measure relative } \\
\text { humidity of air at } \\
\text { HPWH inlet and } \\
\text { exhaust }\end{array}$ \\
\hline Air Velocity Sensor & Omega & FMA-904-A-V1 & $\begin{array}{l}\text { Measures fan } \\
\text { output speed }\end{array}$ \\
\hline Water Flow Meter & Blancett & 1100 & $\begin{array}{c}\text { Measures water } \\
\text { draw volume }\end{array}$ \\
\hline $\begin{array}{c}\text { Current } \\
\text { Transformers }\end{array}$ & $\begin{array}{l}\text { Dent, Continental } \\
\text { Control Systems }\end{array}$ & $\begin{array}{c}\text { CTHSC-020-U/B, } \\
\text { CTHSC-050-U/B, } \\
\text { ACT-0750-030 }\end{array}$ & $\begin{array}{c}\text { Measure current for } \\
\text { use in power } \\
\text { monitoring system }\end{array}$ \\
\hline
\end{tabular}


A list of equipment used in the air handling unit and data acquisition (DAQ) system is shown in Table 3-2.

Table 3-2: List of air handling unit and data acquisition equipment

\begin{tabular}{|c|c|c|c|}
\hline Component & Manufacturer & Model & Description \\
\hline Fan & Greenheck & SQ-98-V6-7-X & Variable speed fan \\
\hline Humidifier & Skuttle & Model 592 & Spray humidifier \\
\hline $\begin{array}{l}\text { Proportional } \\
\text { Control Valves }\end{array}$ & Belimo & LF24-SR, TFB24-SR & $\begin{array}{l}\text { Control the flow } \\
\text { through the heating } \\
\text { and cooling coils }\end{array}$ \\
\hline DAQ Unit & National Instruments & cDAQ-9188 & Compact DAQ \\
\hline \multirow{5}{*}{ DAQ Cards } & \multirow{5}{*}{ National Instruments } & 9214 & Thermocouple cards \\
\hline & & 9264 & Analog output card \\
\hline & & 9207 & Analog input card \\
\hline & & 9476 & Digital output card \\
\hline & & 9422 & Digital input card \\
\hline Power Monitoring & $\begin{array}{l}\text { Dent, Continental } \\
\text { Control Systems }\end{array}$ & $\begin{array}{l}\text { Powerscout 24, } \\
\text { Wattnode Pulse }\end{array}$ & $\begin{array}{l}\text { Measures power } \\
\text { consumption, } \\
\text { transmits to DAQ }\end{array}$ \\
\hline $\begin{array}{l}\text { Data Acquisition } \\
\text { Software }\end{array}$ & National Instruments & & $\begin{array}{l}\text { Processes, records, } \\
\text { and displays data }\end{array}$ \\
\hline Power Supplies & Weidmüller, Rhino & $\begin{array}{l}24 \text { VDC Class } 2 \\
\text { Power Supply }\end{array}$ & Powers equipment \\
\hline
\end{tabular}

\subsection{Air Handling Unit}

An air handling unit was designed and constructed to adjust the air temperature and humidity entering the heat pump water heater. The air handling unit was built such that air would be drawn from the laboratory, and ducted directly to the air inlet of the HPWH, such that all of the conditioned air flowed directly across the evaporator of the HPWH. The AHU had a fan, humidifier, cooling coil, heating coil, and a glycol cooling coil.

When the fan from the HPWH was operating without assistance from the air handling unit, the air flow rate was measured to be $260 \mathrm{~m}^{3} / \mathrm{h}$. Thus, the fan in the air 
handling unit was set to operate at the same flow rate. This was achieved using an air velocity sensor in a PID loop to adjust the fan speed until $260 \mathrm{~m}^{3} / \mathrm{h}$ was achieved. In order to avoid overworking the compressor of the HPWH and causing wear, it was designed to shut off when the incoming air temperature was below $7^{\circ} \mathrm{C}$ or above $49^{\circ} \mathrm{C}$ [42]. These temperatures were used as design constraints for the cooling and heating coils. The temperature in the laboratory, $T_{\text {lab }}$, fluctuates throughout the year, reaching temperatures as low as $16^{\circ} \mathrm{C}$ or as high as $25^{\circ} \mathrm{C}$. As such, the heating and cooling coils were selected to reach their design temperature set-point, $T_{\text {design }}$, regardless of the laboratory conditions. The heating coil used hot water as a working fluid, with a maximum delivery temperature of $50^{\circ} \mathrm{C}$. The cooling coil used cold water as a working fluid, with the minimum delivery temperature being $10^{\circ} \mathrm{C}$. As such, if temperatures below $10^{\circ} \mathrm{C}$ are to be achieved, a second cooling coil using glycol as its working fluid would need to be installed in the air handling unit. This glycol cooling coil would operate simultaneously with the cold water cooling coil to reach a minimum delivery temperature of $0^{\circ} \mathrm{C}$. For the experiments conducted as a part of this research, only the heating and cold water cooling coils were operational. The glycol cooling coil was designed for future tests on the HPWH apparatus. The design conditions for the coils are presented in Table 3-3. 
Table 3-3: Air handling unit design conditions

\begin{tabular}{c|cccc}
\hline Coil & $T_{\text {lab }}\left({ }^{\circ} \mathrm{C}\right)$ & $T_{\text {design }}\left({ }^{\circ} \mathrm{C}\right)$ & $\begin{array}{c}\text { Design Fluid Flow } \\
\text { Rate }(L / m i n)\end{array}$ & Heat Transfer (kW) \\
\hline Heating Coil & 16 & 50 & 5 & 8.38 \\
Cooling Coil & 25 & 10 & 10 & 3.70 \\
$\begin{array}{c}\text { Glycol Cooling } \\
\text { Coil }\end{array}$ & 10 & 0 & 5 & 2.45 \\
\hline
\end{tabular}

A spray humidifier was used to increase the moisture content in the air and evaluate the effect of humidity on the performance of the HPWH. The relative humidity sensor at the outlet of the air handling unit was used to control the humidifier and measure the humidity entering the evaporator of the HPWH. The cold water cooling coils were located before the heating coils so that the air could be dehumidified to a dew point of $10^{\circ} \mathrm{C}$ before being heated to a higher temperature. Thermocouples were used to measure the ambient temperature of the laboratory and the temperature after each coil. These temperatures were then used with PID loops in LabVIEW and proportional control valves to adjust the flow rate of the fluid in the coils so that the temperature set-point could be reached. Five thermocouples were located by the exit of the air handling unit to obtain an accurate measurement of the temperature entering the evaporator of the HPWH. A photograph of the air handling unit as it is set up in the laboratory can be viewed in Figure 3-4. 


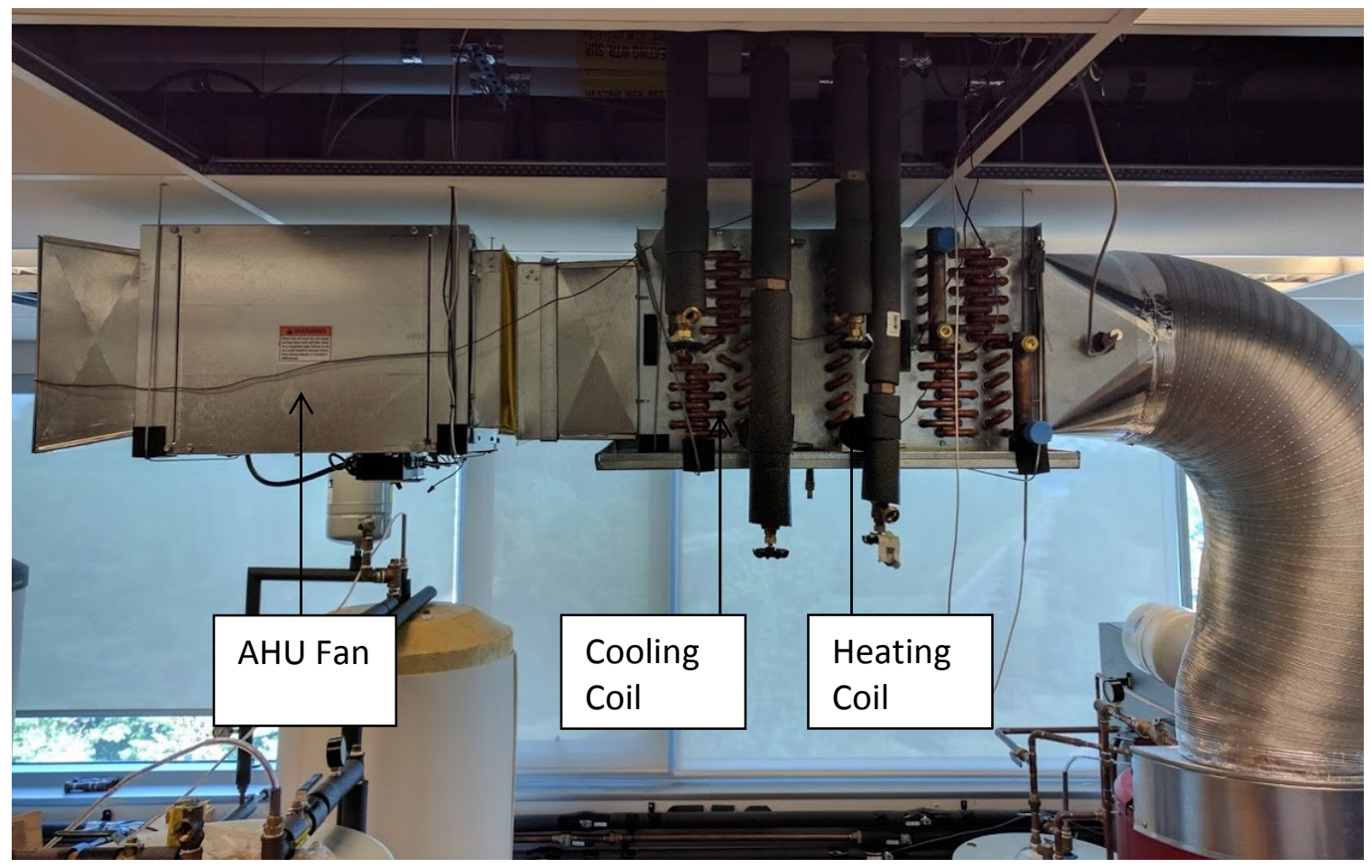

Figure 3-4: Air handling unit

\subsubsection{Limitations of the Air Handling Unit}

The humidity of the laboratory air varied throughout the year due to both fluctuations in the outdoor air humidity and the building's ventilation system. The air was considerably drier in the colder months of the year, when some of the experiments that were conducted required more humid air. In order to keep a consistent humidity level for performance map testing and to test an increased range of humidity set-points, a humidifier was installed in the experimental setup. This was done to allow the laboratory air to meet the set-points needed to test 'outdoor' air conditions. A limitation of the humidifier was that it did not have a high enough flow rate to introduce sufficient moisture in the air to reach the desired humidity set-points for tests in some of the extremely humid climates. Thus, the heat pump would have higher performance 
in reality than said climate tests would indicate, due to additional latent heat transfer from the air.

Similarly, there were some limitations with the dehumidification method used in the air handling unit. The cooling coil would cool the air down to a minimum of $10^{\circ} \mathrm{C}$, and the heating coil would heat the air back up to the set-point. This would allow the air to be dehumidified to a minimum dew point of $10^{\circ} \mathrm{C}$. However, some of the tests that correspond to dry climates had dew points below $10^{\circ} \mathrm{C}$. Thus, those respective tests resulted in higher performance than would actually be observed in said climate. On some days, the laboratory would have a dew point below $10^{\circ} \mathrm{C}$, so said tests were reattempted to achieve lower humidity.

\subsection{Water Draw Measurement}

A solenoid was used to control the water draw of the system. When the solenoid was activated in LabVIEW by a relay, it enabled $55^{\circ} \mathrm{C}$ water to be drawn into a drain. $\mathrm{A}$ flow meter was installed to measure the flow rate and volume being drawn. The tests were set up in LabVIEW such that at every hour, water would be drawn until a set volume, measured by the flow meter and established in the CSA draw profiles, was met. The solenoid and flow meter can be seen in Figure 3-5. 


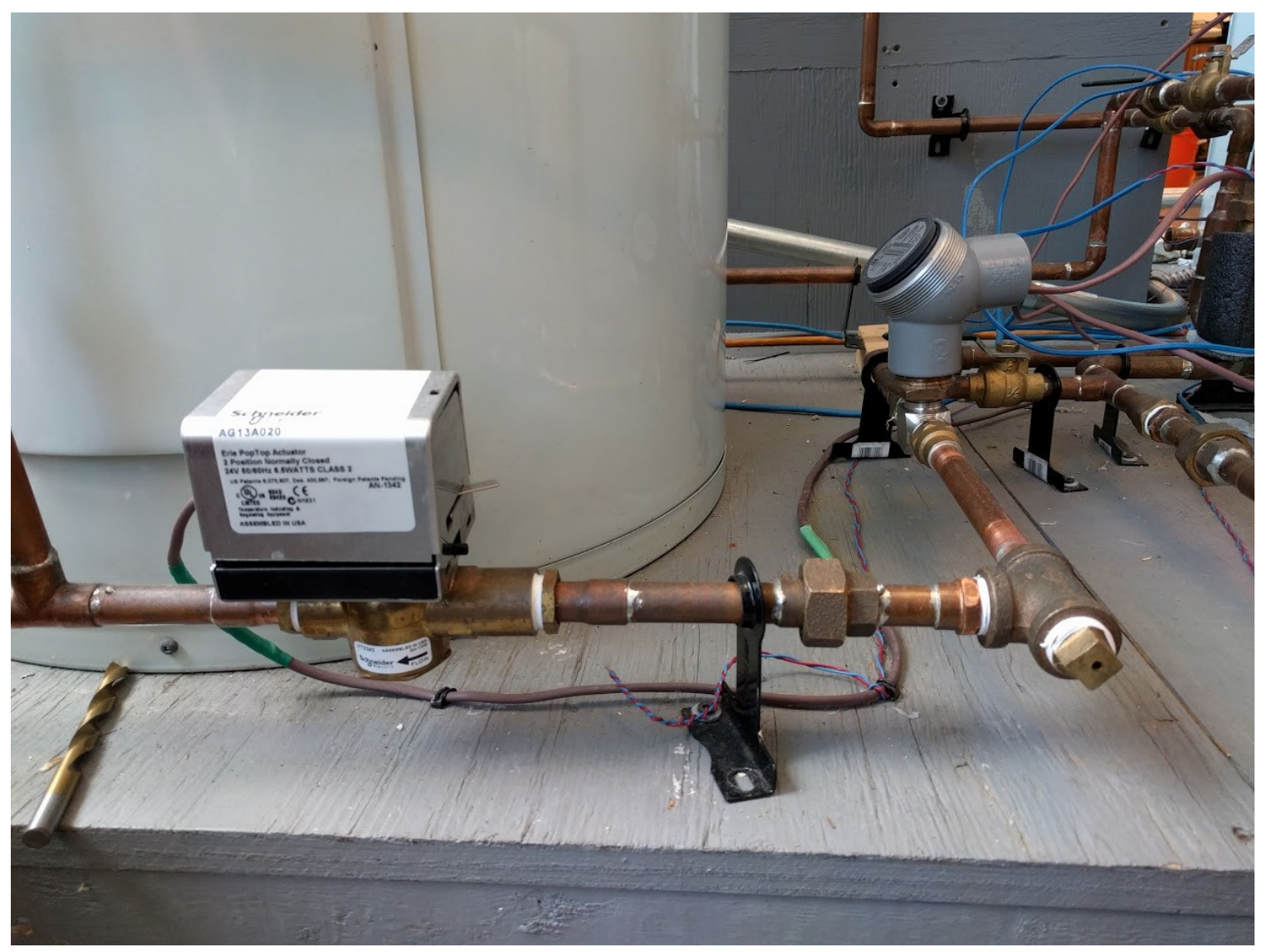

Figure 3-5: Water draw system, with the solenoid on the left and the water flow meter on the right

\subsection{Heat Pump Water Heater}

The commercially available, pre-packaged heat pump water heater used in this research was composed of an air source heat pump, a domestic hot water tank, and two electrical resistance heaters. The air source heat pump cycle consisted of an evaporator, a $600 \mathrm{~W}$ compressor, a condenser that wrapped around the hot water tank, a fan, and an expansion valve. Refrigerant $134 a$ was used as its working fluid. The wrap-around condenser coil delivered heat to the upper half of the water tank, as determined experimentally by Khalaf [39]. The top of the HPWH had an air intake, which was modified to directly connect to the air handling unit. The fan exhausted air out the back 
of the heat pump unit. The domestic hot water tank had a capacity of 189 L (50 US gal), which is suitable for a 2 to 3 occupant household with high demand or a 3 to 4 occupant household with average or low demand [42]. One of the resistance elements was positioned within the lower half of the tank, and the other was positioned within the upper half of the tank. These resistance elements were each rated at $3380 \mathrm{~W}$, and can be used instead of the heat pump cycle when the hot water demand is too high. The energy factor of the HPWH unit was stated to be 2.4 by the manufacturer. A photograph of the HPWH can be seen in Figure 3-6.

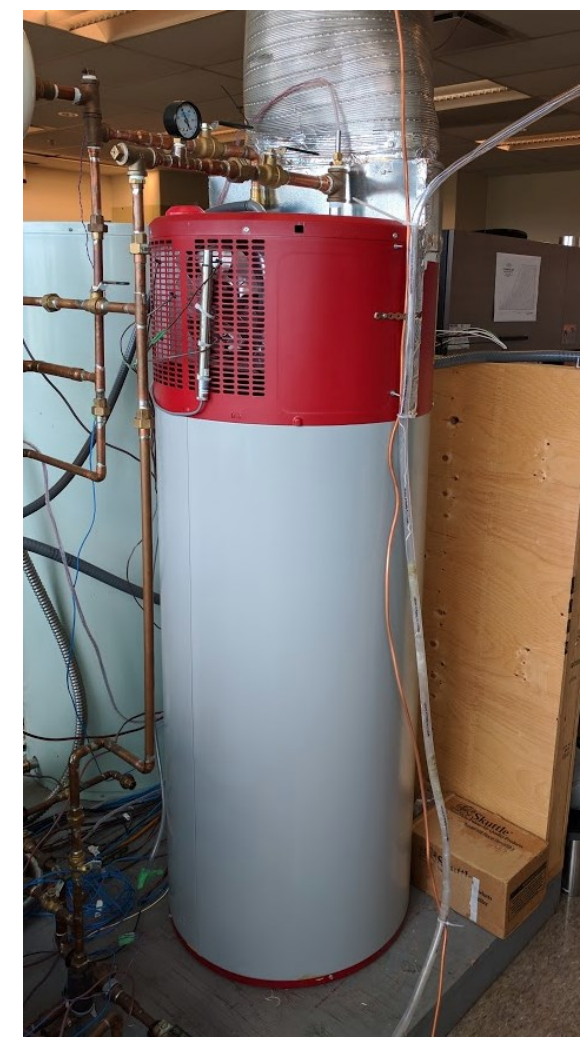

Figure 3-6: Heat pump water heater

The HPWH had a front control panel, which allowed the user to adjust the operational mode. The HPWH could be set to exclusively use the heat pump to heat the water, exclusively use the resistance elements, use a hybrid of the two options, or to 
use a low-energy use vacation mode, where the water is held at a lower temperature for extended periods of time to reduce the amount of electricity used. The hot water temperature set-point could also be adjusted using the control panel. While using the heat pump exclusively with a low hot water set-point would result in the largest savings, it was not always the best option. The electrical element was able to heat up the water much faster, while using more energy. Keeping a lower hot water set-point puts the user at risk of legionella being present in the water, while increasing the set-point can stop the growth of the bacteria, or eliminate it. It is recommended to keep the water temperature set-point above $55^{\circ} \mathrm{C}$ to stop the growth of bacteria [19]. A set-point of $60^{\circ} \mathrm{C}$ was used in this research to eliminate any bacteria and account for the lower water temperature at the bottom of the tank due to stratification.

For research purposes, the HPWH was modified so that the settings could be adjusted through LabVIEW. This was done by disconnecting the front panel, and extending the wires to relays in an electrical box, which were then controlled through the DAQ and LabVIEW. These modifications allowed greater control of the unit, such that the control strategy could be modified if necessary. It also allowed for the controls of the unit to be automated through LabVIEW.

A thermocouple probe was installed in the HPWH to record the temperature at 10 different points and to observe the effects of stratification. These 10 thermocouples measure the temperatures that correspond to the 10 nodes that are referred to in this research. Thermocouples were also installed at the air inlet and exhaust of the HPWH, in groups of 5 , to accurately measure the air entering and leaving the heat pump. Relative 
humidity sensors were placed at the end of the air handling unit and at the heat pump exhaust to measure the humidity and to observe the effects of latent heat transfer across the heat pump cycle.

\subsection{Power Monitoring}

A power monitoring system was used to measure the energy being used by the HPWH and its components. These energy consumption measurements were then used to calculate the COP of the unit. The HPWH components that were measured include the fan, compressor, upper and lower elements, and the total power being drawn by the unit. Current transformers were installed on the wires of the measured components, and the current was sent to the power monitoring system, which then converted the current into a power reading, and output the values as pulses to the DAQ and LabVIEW.

Two different power monitoring systems were used in the research presented in this thesis. The first was the Dent Powerscout 24, which allowed for each component of the HPWH to be monitored separately. This allowed for the power consumption of the fan and control panel of the HPWH to be accounted for when developing the TRNSYS model. This power monitoring system was used in 8 of the 15 tests that were performed. After these 8 tests, the unit had malfunctioned and needed to be replaced. Thus, the second power monitoring system, the Continental Control Systems Wattnode Pulse, was installed, which was capable of measuring only the total power being consumed by the HPWH. This was sufficient for the remaining tests, as the idle power consumption of the different components had already been established previously. 


\subsection{Data Acquisition}

A data acquisition system was used to display and record the measured variables during the experiments. The data acquisition system was a National Instruments cDAQ 9188, which had thermocouple cards, analog input and output cards, and digital input and output cards. The thermocouple cards received air and water temperature readings from the thermocouples installed in the $A H U$, the $\mathrm{HPWH}$, and the plumbing components. The analog input cards received signals for the cooling coil and heating coil proportional control valves, air velocity sensor, and relative humidity sensors. The analog output cards sent out voltage signals to the AHU fan and the proportional control valves based on PID loops using the data from the analog input values. The digital input card received the power consumption of the HPWH components from the power monitoring system. The digital output card controlled the relays to control the HPWH fan, compressor, elements, solenoids, recirculation pumps, and main power for the HPWH system. All of the data from the DAQ was sent to the LabVIEW software for graphical programming and displaying and recording data.

\subsection{Testing Procedures}

There were multiple test procedures that were completed, including tests at laboratory air conditions, tests at climate conditions, a cool-down test, charging tests with either the electric element or the heat pump, and discharging tests. If a test is said to be performed at laboratory air conditions, this means that the incoming air from the laboratory was not heated, cooled, humidified, or dehumidified within the AHU. Climate 
tests, however, were performed by using the AHU to reach the given outdoor air temperature and air humidity set-points.

The hot water temperature set-point was $60^{\circ} \mathrm{C}$ for all tests conducted on the HPWH. The charging and discharging tests involved filling the tank with unheated mains water until the water was at a uniform temperature. Then, data was recorded using LabVIEW, and the heat pump was in operation until the water was heated to the setpoint of $60^{\circ} \mathrm{C}$. After this, the water was drawn at $3.8 \mathrm{~L} / \mathrm{min}$ until it reached mains water temperature. This flow rate was used because the flow rate of $11.5 \mathrm{~L} / \mathrm{min}$ specified by CSA-F379.1-88 [29] caused additional mixing of the mains water and hot water in the tank which could not be replicated in the model. This test was performed to illustrate the charging and discharging time of the HPWH.

The tests performed at both laboratory and outdoor air conditions began with the water at a uniform temperature of $60^{\circ} \mathrm{C}$. These tests used CSA draw Schedule A [29] (as previously described in Table 2-1), with the beginning of the test representing 6:00 A.M. When CSA Schedule A indicated that a draw should occur, the water was drawn until the required volume was reached. When the unit's internal sensors detected that the water temperature was below $60^{\circ} \mathrm{C}$, then the heat pump activated until the water once again reached the set-point. The power consumption of the HPWH and the water temperature at each node were then used to calculate the heat delivery and the COP of the unit. These test results were then used to assess the performance of the HPWH for various scenarios, including basement installations and various outdoor air conditions. The test results were also used to validate the TRNSYS model. 


\subsubsection{Climate Test Set-Points}

A set of climate conditions that are representative of ten Canadian cities were tested using the HPWH and air handling unit. The represented cities were Ottawa, Toronto, Halifax, Vancouver, St John's, Regina, Yellowknife, Montreal, Calgary, and Edmonton. These cities were chosen as they represent all of the Canadian climate zones as defined by the American Society of Heating, Refrigerating and Air-Conditioning Engineers Standard 90.1 [43]. Some provinces use flat utility rates, while others use time-of-use utility rates. Each climate was tested in the summer season. The climate conditions representing Toronto and Calgary were also tested for the fall, whereas Edmonton was tested in the spring. Any seasons that were not tested were due to frequent temperatures below $10^{\circ} \mathrm{C}$, as these temperatures were below the cooling capabilities of the AHU. Each test was performed for 15 hours, using CSA draw Schedule A [29]. In addition, two tests were performed with the air temperature at the lower limit of $10^{\circ} \mathrm{C}$; one of these tests had no additional humidification provided by the humidifier, and the other had the humidifier engaged for the entire test. In each climate test, the air temperature, air humidity, air flow rate, water temperature at each node, water volume draw, and power draw were measured at one-minute intervals. This interval was more than sufficient to obtain accurate data.

To determine the outdoor air temperature and humidity set-points for the climate tests, annual weather files, specifically the Canadian Weather Year for Energy Calculation files, were used for each of the cities [44]. The representative days were chosen to be January 20-22 for the winter, April 20-22 for the spring, July 20-22 for the 
summer, and October 20-22 for the fall. These dates were chosen as they are in the middle of the respective seasons. The testing conditions for each city and season can be seen in Table 3-4 and Table 3-5. The hourly data was observed at these peak periods of the year, and the set-points were chosen so that they would change every 2 to 3 hours, so that the heating and cooling coils would have a stable flow rate. The dew points for each set-point were determined, as shown in Appendix B, and those below $10^{\circ} \mathrm{C}$ are shaded in the tables below. These humidity set-points, as well as any dry bulb temperature set-points below $10^{\circ} \mathrm{C}$, could not be reached due to the limitations of the cooling coil, as it was unable to cool the air below $10^{\circ} \mathrm{C}$. In these cases, the tests were still performed.

Any seasonal temperatures that were consistently below $10^{\circ} \mathrm{C}$ were not included in the testing conditions. As a result, there are no winter climates that were tested. However, since the HPWH used refrigerant 134a, it would shut off when the air temperature was below $7^{\circ} \mathrm{C}$. Thus, the electric resistance heaters would be used in these cases, and no benefit of using a HPWH would be observed. 
Table 3-4: Testing conditions for various Canadian cities and seasons (Part 1 of 2)

\begin{tabular}{|c|c|c|c|c|c|c|c|c|c|c|c|c|c|c|c|}
\hline \multirow[b]{3}{*}{ Hour } & \multirow{3}{*}{$\begin{array}{c}\text { Draw Volume (L) } \\
\text { Schedule A }\end{array}$} & \multirow{2}{*}{\multicolumn{2}{|c|}{$\begin{array}{c}\text { Ottawa } \\
\text { Summer }\end{array}$}} & \multirow{2}{*}{\multicolumn{2}{|c|}{$\begin{array}{c}\text { Vancouver } \\
\text { Summer }\end{array}$}} & \multirow{2}{*}{\multicolumn{2}{|c|}{$\begin{array}{l}\text { St John's } \\
\text { Summer }\end{array}$}} & \multirow{2}{*}{\multicolumn{2}{|c|}{$\begin{array}{c}\text { Regina } \\
\text { Summer }\end{array}$}} & \multirow{2}{*}{\multicolumn{2}{|c|}{$\begin{array}{c}\text { Yellowknife } \\
\text { Summer }\end{array}$}} & \multicolumn{4}{|c|}{ Toronto } \\
\hline & & & & & & & & & & & & \multicolumn{2}{|c|}{ Summer } & \multicolumn{2}{|c|}{ Fall } \\
\hline & & $\begin{array}{c}\text { Temp } \\
\left({ }^{\circ} \mathrm{C}\right)\end{array}$ & $\begin{array}{l}\text { RH } \\
\text { (\%) }\end{array}$ & $\begin{array}{c}\text { Temp } \\
\left({ }^{\circ} \mathrm{C}\right)\end{array}$ & $\begin{array}{l}\text { RH } \\
\text { (\%) }\end{array}$ & $\begin{array}{c}\text { Temp } \\
\left({ }^{\circ} \mathrm{C}\right)\end{array}$ & $\begin{array}{l}\text { RH } \\
\text { (\%) }\end{array}$ & $\begin{array}{c}\text { Temp } \\
\left({ }^{\circ} \mathrm{C}\right)\end{array}$ & $\begin{array}{l}\text { RH } \\
\text { (\%) }\end{array}$ & $\begin{array}{c}\text { Temp } \\
\left({ }^{\circ} \mathrm{C}\right)\end{array}$ & $\begin{array}{l}\text { RH } \\
\text { (\%) }\end{array}$ & $\begin{array}{c}\text { Temp } \\
\left({ }^{\circ} \mathrm{C}\right)\end{array}$ & $\begin{array}{l}\text { RH } \\
\text { (\%) }\end{array}$ & $\begin{array}{c}\text { Temp } \\
\left({ }^{\circ} \mathrm{C}\right)\end{array}$ & $\begin{array}{l}\text { RH } \\
\text { (\%) }\end{array}$ \\
\hline 7 & 5 & \multirow{3}{*}{24.9} & \multirow{3}{*}{69} & \multirow{4}{*}{17.2} & \multirow{4}{*}{78} & \multirow{2}{*}{11.1} & \multirow{2}{*}{77} & \multirow{2}{*}{11} & \multirow{2}{*}{82} & \multirow{3}{*}{12.8} & \multirow{3}{*}{72} & \multirow{4}{*}{20.8} & \multirow{4}{*}{96} & \multirow{4}{*}{11.7} & \multirow{4}{*}{89} \\
\hline 8 & 25 & & & & & & & & & & & & & & \\
\hline 9 & 0 & & & & & \multirow{3}{*}{14.4} & \multirow{3}{*}{62} & \multirow{2}{*}{15.7} & \multirow{2}{*}{67} & & & & & & \\
\hline 10 & 45 & \multirow{3}{*}{25.8} & \multirow{3}{*}{67} & & & & & & & & & & & & \\
\hline 11 & 0 & & & \multirow{3}{*}{19.4} & \multirow{3}{*}{73} & & & 195 & 57 & 15.6 & 49 & & & & \\
\hline 12 & 5 & & & & & & & J. & ונד & & & 22 & 88 & & \\
\hline 13 & 0 & & & & & 17.2 & 54 & 216 & 54 & 167 & 42 & & & & \\
\hline 14 & 0 & & & & & & & $2+.0$ & 34 & 10.1 & 42 & & & 15 & 90 \\
\hline 15 & 0 & 27.3 & 47 & 217 & 66 & 183 & 38 & 23 & 51 & & & & & & \\
\hline 16 & 0 & & & $2+.1$ & & 10.5 & 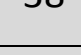 & 20 & ג & 17.8 & 38 & 21.5 & 93 & & \\
\hline 17 & 5 & & & & & 15 & 53 & & & & & & & & \\
\hline 18 & 10 & & & & & J & בנ & 253 & 44 & & & & & & \\
\hline 19 & 30 & 26.6 & 37 & & & & & 20.5 & 44 & 16.7 & 38 & 22.5 & 88 & 11.7 & 83 \\
\hline 20 & 20 & & & 20 & 76 & 128 & 62 & & & & & & & & \\
\hline 21 & 0 & 211 & 19 & & & 12.0 & 02 & 210 & 58 & 156 & 12 & 205 & 93 & 89 & 89 \\
\hline 22 & 0 & 21.1 & 4 & & & & & $2+$. & 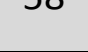 & 10.0 & 42 & 20.5 & כנה & 0.3 & J \\
\hline
\end{tabular}


Table 3-5: Testing conditions for various Canadian cities and seasons (Part 2 of 2)

\begin{tabular}{|c|c|c|c|c|c|c|c|c|c|c|c|c|c|}
\hline \multirow[b]{3}{*}{ Hour } & \multirow{3}{*}{$\begin{array}{c}\text { Draw Volume (L) } \\
\text { Schedule A }\end{array}$} & \multirow{2}{*}{\multicolumn{2}{|c|}{$\begin{array}{c}\text { Montreal } \\
\text { Summer }\end{array}$}} & \multicolumn{4}{|c|}{ Calgary } & \multicolumn{4}{|c|}{ Edmonton } & \multirow{2}{*}{\multicolumn{2}{|c|}{$\begin{array}{c}\text { Halifax } \\
\text { Summer }\end{array}$}} \\
\hline & & & & \multicolumn{2}{|c|}{ Summer } & \multicolumn{2}{|c|}{ Fall } & \multicolumn{2}{|c|}{ Spring } & \multicolumn{2}{|c|}{ Summer } & & \\
\hline & & $\begin{array}{c}\text { Temp } \\
\left({ }^{\circ} \mathrm{C}\right)\end{array}$ & $\begin{array}{l}\text { RH } \\
\text { (\%) }\end{array}$ & $\begin{array}{c}\text { Temp } \\
\left({ }^{\circ} \mathrm{C}\right)\end{array}$ & $\begin{array}{l}\text { RH } \\
\text { (\%) }\end{array}$ & $\begin{array}{c}\text { Temp } \\
\left({ }^{\circ} \mathrm{C}\right)\end{array}$ & $\begin{array}{l}\text { RH } \\
\text { (\%) }\end{array}$ & $\begin{array}{c}\text { Temp } \\
\left({ }^{\circ} \mathrm{C}\right)\end{array}$ & $\begin{array}{l}\text { RH } \\
\text { (\%) }\end{array}$ & $\begin{array}{c}\text { Temp } \\
\left({ }^{\circ} \mathrm{C}\right)\end{array}$ & $\begin{array}{l}\text { RH } \\
\text { (\%) }\end{array}$ & $\begin{array}{c}\text { Temp } \\
\left({ }^{\circ} \mathrm{C}\right)\end{array}$ & $\begin{array}{l}\text { RH } \\
\text { (\%) }\end{array}$ \\
\hline 7 & 5 & \multirow{5}{*}{25.6} & \multirow{5}{*}{73} & 186 & 47 & \multirow{4}{*}{8.4} & \multirow{4}{*}{34} & \multirow{3}{*}{11.6} & \multirow{3}{*}{60} & \multirow{3}{*}{15.1} & \multirow{3}{*}{91} & \multirow{3}{*}{15} & \multirow{3}{*}{15} \\
\hline 8 & 25 & & & 10.0 & 41 & & & & & & & & \\
\hline 9 & 0 & & & \multirow{2}{*}{24.9} & \multirow{2}{*}{36} & & & & & & & & \\
\hline 10 & 45 & & & & & & & \multirow{2}{*}{16.1} & \multirow{2}{*}{45} & \multirow{3}{*}{17.6} & \multirow{3}{*}{78} & \multirow{3}{*}{18.8} & \multirow{3}{*}{18} \\
\hline 11 & 0 & & & \multirow{4}{*}{30.6} & \multirow{4}{*}{23} & 11.9 & 30 & & & & & & \\
\hline 12 & 5 & \multirow{5}{*}{27.8} & \multirow{5}{*}{55} & & & 132 & 27 & \multirow{5}{*}{18.2} & & & & & \\
\hline 13 & 0 & & & & & & & & & & & & \\
\hline 14 & 0 & & & & & & & & 37 & & & 22.6 & 20 \\
\hline 15 & 0 & & & & & 15 & 21 & & & 189 & 78 & & \\
\hline 16 & 0 & & & 327 & 17 & & & & & 18.9 & 10 & & \\
\hline 17 & 5 & & & $3<.1$ & 17 & 12.6 & 26 & 151 & 58 & & & 24.5 & 20 \\
\hline 18 & 10 & 26.9 & 41 & & & & & & & & & & \\
\hline 19 & 30 & & & 290 & 16 & 10.5 & 29 & & & & & 213 & 18 \\
\hline 20 & 20 & & & 29.9 & 10 & & & 111 & 74 & 16 & 03 & 21.3 & 10 \\
\hline 21 & 0 & 22.6 & 50 & 254 & 21 & 76 & 41 & 11.1 & 14 & 10 & בנד & 199 & 17 \\
\hline 22 & 0 & & & 20.4 & $2+$ & 1.0 & 41 & & & & & J & 17 \\
\hline
\end{tabular}




\subsection{Calculating the Coefficient of Performance}

The instantaneous coefficient of performance of a heat pump was calculated using Equation 3.1,

$$
\text { COP }=\frac{E_{\text {deliv }}}{E_{\text {in }}}
$$

where $C O P$ is the coefficient of performance, $E_{\text {deliv }}$ is the heat that is delivered directly to the water from the heat pump, and $E_{\text {in }}$ is the energy that is used to power the unit. The average energy over 30 seconds entering the unit was recorded, which was then integrated over the time period to obtain the energy consumption reading. The heat delivery could not be directly measured on the apparatus, so the change in water temperature at each thermocouple (which corresponds to the change in temperature of the respective node) was used to approximate the value. The heat delivery was calculated using Equation 3.2,

$$
\Delta E_{\text {deliv }}=\frac{\left(V_{\mathrm{i}} \rho_{\mathrm{w}} C_{\mathrm{p}, \mathrm{w}}\left(T_{\mathrm{t}, \mathrm{i}}-T_{\mathrm{ref}}\right)\right)-\left(V_{\mathrm{i}} \rho_{\mathrm{w}} C_{\mathrm{p}, \mathrm{w}}\left(T_{\mathrm{t}-1, \mathrm{i}}-T_{\mathrm{ref}}\right)\right)}{t} \quad[\mathrm{~W}]
$$

where $V_{\mathrm{i}}$ is the volume of the node, $\rho_{\mathrm{w}}$ is the density of water for the node, $C_{\mathrm{p}, \mathrm{w}}$ is the specific heat capacity of water, $T_{t, i}$ is the water temperature of the node measured at the time increment $t, T_{\text {ref }}$ is the reference mains water temperature of $20^{\circ} \mathrm{C}$, and $t$ is the time increment. This equation was used to calculate the heat delivery at each node for every time step, and can be simplified to Equation 3.3.

$$
\Delta E_{\text {deliv }}=\frac{V_{\mathrm{i}} \rho_{\mathrm{w}} C_{\mathrm{p}, \mathrm{w}}\left(T_{\mathrm{t}, \mathrm{i}}-T_{\mathrm{t}-1, \mathrm{i}}\right)}{t} \quad[\mathrm{~W}]
$$


Equation 3.4 and Equation 3.5 show the calculations for $\rho_{\mathrm{w}}$ and $C_{\mathrm{p}, \mathrm{w}}$ over the range of $0^{\circ} \mathrm{C}$ to $100^{\circ} \mathrm{C}[45]$.

$$
\begin{gathered}
\rho_{\mathrm{w}}(T)=1.68 \cdot 10^{-5} T^{3}-0.0061 T^{2}+0.022 T+1000 \pm 0.25 \quad\left[\frac{\mathrm{kg}}{\mathrm{m}^{3}}\right] \\
C_{\mathrm{p}, \mathrm{w}}(T)=4.2 \pm 0.02 \quad\left[\frac{\mathrm{kJ}}{\mathrm{kg} \mathrm{K}}\right]
\end{gathered}
$$

Based on these equations, a typical water density of $1000 \mathrm{~kg} / \mathrm{m}^{3}$ has an uncertainty of $0.025 \%$. The uncertainty of the specific heat capacity of water is $0.48 \%[45]$.

The instantaneous COP (from Equation 3.1) varied over short periods of time due to small fluctuations in temperature and over long periods of time due to the changing set-points. Due to this variation, a cumulative coefficient of performance (CCOP) was used to quantify the relative performance over the operation period. The CCOP is calculated with experimental data by dividing the sum of the heat delivery through the entire test by the sum of the energy used to power the unit, as shown in Equation 3.6,

$$
\text { CСOP }=\frac{\sum E_{\mathrm{deliv}}}{\sum E_{\mathrm{in}}}
$$

To calculate the cost of energy for each test, the energy consumption was multiplied by the utility cost for the respective region, as seen in Equation 3.7,

$$
C_{\text {energy }}=E_{\text {in }} C_{\text {util }}
$$

where $C_{\text {energy }}$ is the cost of energy for the timestep, $E_{\text {in }}$ is the energy input to the HPWH for the timestep in $\mathrm{kWh}$, and $C_{\mathrm{util}}$ is the utility rate of the region for the timestep in $\$ / \mathrm{kWh}$. For regions with time-of-use utility rates, the value of $C_{\mathrm{util}}$ varies throughout the day. The utility rates for each region are shown in Appendix A. 


\subsection{Calibration and Uncertainty Analysis}

An uncertainty analysis was performed to quantify the error of the measured variables. Precision uncertainty occurs due to fluctuations within a large number of measurements. Bias uncertainty is an offset resulting from the measurement equipment itself, and can either be provided by the manufacturer or found through calibration methods.

To begin to estimate the precision uncertainty, Equation 3.8 shows the sample mean value for finite-sized data [46],

$$
\bar{x}=\frac{1}{N} \sum_{i=1}^{N} x_{\mathrm{i}}
$$

where $\bar{x}$ is the sample mean value, $x_{\mathrm{i}}$ is the measurement, $N$ is the number of measurements, and $i$ is the measurement number between 1 and $N$. Equation 3.9 shows the calculation for the sample variance [46],

$$
s_{\mathrm{X}}^{2}=\frac{1}{N-1} \sum_{i=1}^{N}\left(x_{\mathrm{i}}-\bar{x}\right)^{2}
$$

where $s_{\mathrm{X}}^{2}$ is the sample variance. Equation 3.10 shows the calculation for the sample standard deviation [46],

$$
s_{\mathrm{X}}=\sqrt{s_{\mathrm{X}}^{2}}=\left(\frac{1}{N-1} \sum_{i=1}^{N}\left(x_{\mathrm{i}}-\bar{x}\right)^{2}\right)^{\frac{1}{2}}
$$

where $s_{\mathrm{x}}$ is the standard deviation. Equation 3.11 is used to calculate the standard deviation of the means, 


$$
s_{\overline{\mathrm{x}}}=\frac{s_{\mathrm{X}}}{\sqrt{N}}
$$

where $s_{\overline{\mathrm{x}}}$ is the standard deviation of the means. The degrees of freedom are calculated with Equation 3.12,

$$
v=N-1
$$

where $v$ is the number of degrees of freedom. Equation 3.13 is used to find the precision uncertainty,

$$
u_{\mathrm{p}}=t_{\mathrm{v}, \mathrm{P}} S_{\overline{\mathrm{x}}}
$$

where $u_{\mathrm{p}}$ is the precision uncertainty and $t_{\mathrm{v}, \mathrm{P}}$ is the coverage factor, which is found in a $t$ distribution table [46] based on the number of degrees of freedom and the confidence interval. A confidence interval of $95 \%$ was used in this research.

Once the precision uncertainty is determined, the bias uncertainty must be calculated so that the total uncertainty can be estimated. Once the precision and bias uncertainties are found, the sum of squares can be taken, as seen in Equation 3.14,

$$
u_{\mathrm{T}}=\sqrt{u_{\mathrm{b}}^{2}+u_{\mathrm{p}}^{2}}
$$

where $u_{\mathrm{T}}$ is the total uncertainty and $u_{\mathrm{b}}$ is the bias uncertainty.

\subsubsection{Thermocouples}

The National Institute of Standards and Technology provides a reference table for Type T thermocouple wire, converting from the measured voltage to temperature. For special limits of error wire thermocouples, such as those used in the research of this thesis, the bias uncertainty is $0.5^{\circ} \mathrm{C}$ [47]. In addition, there is a bias uncertainty caused 
by measurement and by the cold junction compensation (CJC) temperature. The thermocouple card used with the DAQ (NI 9214) has a bias uncertainty of $0.25^{\circ} \mathrm{C}$ for the CJC temperature [48].

The wire calibration and measurement error method by Baldwin [45] was used, as the thermocouples used in this research were fabricated from the same wire rolls. Baldwin used a Fluke 7102 temperature bath that had a uniform temperature that was measured by a resistant temperature detector (RTD) with $0.02^{\circ} \mathrm{C}$ bias uncertainty. The 30 gauge and 24 gauge thermocouples that were used in this work were placed in the temperature bath. The temperature from the RTD, the CJC temperature, and the voltage of the thermocouples were measured as the temperature of the bath was varied from $5^{\circ} \mathrm{C}$ to $95^{\circ} \mathrm{C}$ in $2^{\circ} \mathrm{C}$ intervals.

From these data, a sixth order polynomial calibration equation was found for each gauge of thermocouple. Equation 3.15 and Equation 3.16 were developed by Baldwin to determine the temperature reading of the 30 gauge and 24 gauge thermocouple wires, respectively,

$$
\begin{gathered}
T=0.00109 V^{6}+0.00615 V^{5}-0.0799 V^{4}+0.212 V^{3}-0.708 V^{2} \\
+24.65 V-0.186+C J C \\
T=0.00258 V^{6}-0.00374 V^{5}-0.0633 V^{4}+0.227 V^{3}-0.741 V^{2} \\
+24.68 V+0.091+C J C
\end{gathered}
$$

where $T$ is the temperature in ${ }^{\circ} \mathrm{C}, V$ is the voltage of the thermocouple in $\mathrm{mV}$, and $C J C$ is the cold junction compensation temperature in ${ }^{\circ} \mathrm{C}[45]$. 
The uncertainty determined by Baldwin was found using the error from the calibrated readings and the error provided by the manufacturer. The summary of the uncertainties for the 24 gauge and 30 gauge thermocouples are shown in Table 3-6 [45]. It can be seen that the 24 gauge thermocouple wire had an uncertainty of $0.46^{\circ} \mathrm{C}$ and the 30 gauge thermocouple wire had an uncertainty of $0.49^{\circ} \mathrm{C}$. At a measured temperature of $60^{\circ} \mathrm{C}$, the highest uncertainty was $0.82 \%$.

Table 3-6: Total measurement uncertainty for the thermocouples [45]

\begin{tabular}{c|cc}
\hline Source of error & 24 gauge $\left({ }^{\circ} \mathrm{C}\right)$ & 30 gauge $\left({ }^{\circ} \mathrm{C}\right)$ \\
\hline Cold junction temperature - calibration & 0.25 & 0.25 \\
Cold junction temperature - experimental & 0.25 & 0.25 \\
Regression prediction error & 0.16 & 0.24 \\
RTD & 0.02 & 0.02 \\
Resistance error & 0.04 & 0.04 \\
Bath uniformity & 0.02 & 0.02 \\
Voltage error - calibration & 0.18 & 0.18 \\
Voltage error - experimental & 0.18 & 0.18 \\
\hline Total Uncertainty & 0.46 & 0.49 \\
\hline
\end{tabular}

\subsubsection{Relative Humidity Sensors}

The manufacturer bias uncertainty for the relative humidity sensors was $2.5 \%$ within the humidity range of $20 \%$ to $80 \%$ at $22^{\circ} \mathrm{C}$ [49]. This corresponds to a moisture content range of $0.0033 \mathrm{~kg}$ of water to $0.0133 \mathrm{~kg}$ of water per $\mathrm{kg}$ of dry air. All of the tests performed were within this range.

\subsubsection{Water Flow Meter}

The water flow meter used in the experiments would send a pulse to the DAQ when a certain amount of water had passed through. Specifically, the flow meter sent 
282.8 pulses to the DAQ for every liter of water during a certain time period. If a given pulse started at the end of one time period and ended after the next period starts, the pulse was not counted towards the first period, but was counted as a full pulse for the second time period. This resulted in the occasional time period reading a higher flow rate than the other time periods. For longer water draws, this pulse error was less obvious, but for shorter water draws, the flow rate can seem inconsistent, which contributed to the bias uncertainty of the water flow meter. A pulse from the flow meter is equal to $0.0035 \mathrm{~L}$ of water, and each reading has $1 \%$ bias uncertainty according to manufacturer data [50]. This bias uncertainty was found to be insignificant.

There was also uncertainty caused by the time delay in the water draw solenoid. Each water draw commenced at a given hour in the test by a solenoid opening to allow the fluid to pass through to the drain. There was a delay between the LabVIEW VI reaching the required time (as stated in CSA Schedule A) and the solenoid fully opening. Likewise, there was a delay between the draw volume set-point being reached and the solenoid completely closing to prevent any further water being drawn. As a result, there was always more water drawn than the draw profile set-point for a given time period. Thus, the smallest water draw of $5 \mathrm{~L}$ had the largest uncertainty percentage. This precision uncertainty was calculated by comparing the measured volume draw to the ideal volume draw using Equation 3.10.

Table 3-7 lists the total uncertainty of the water draw measurements and the total uncertainty compared to the CSA draw volume set-points due to the time delay. 
Table 3-7: Uncertainty of water draw measurements

\begin{tabular}{c|cc}
\hline Source of Error & Uncertainty - Measurement $(\mathrm{L})$ & Uncertainty - Set-Point $(\mathrm{L})$ \\
\hline 5 L Draw & 0.02 & 0.07 \\
10 L Draw & 0.03 & 0.11 \\
20 L Draw & 0.03 & 0.13 \\
25 L Draw & 0.02 & 0.14 \\
30 L Draw & 0.03 & 0.12 \\
45 L Draw & 0.03 & 0.12 \\
\hline
\end{tabular}

It can be seen that each measurement had an uncertainty of up to $0.03 \mathrm{~L}$, whereas the uncertainty compared to the CSA draw volume set-point can be up to $0.14 \mathrm{~L}$. These uncertainties were considered negligible.

\subsubsection{Power Monitoring}

The uncertainties for the Powerscout 24 system and the Wattnode system were found separately, as they each had different resolutions; the Powerscout had a resolution of $0.12 \mathrm{~W}$ per pulse over 30 seconds, while the Wattnode had a much larger resolution of $90 \mathrm{~W}$ per pulse over 30 seconds. The uncertainty for the test using the HPWH element, which used the Wattnode system, was also determined separately, as it consumes up to $3380 \mathrm{~W}$ of electricity, whereas the compressor typically consumes $400 \mathrm{~W}$ to $600 \mathrm{~W}$. The uncertainties, shown in Table 3-8, were $1 \mathrm{~W}$ for the Powerscout, 2.6 $\mathrm{W}$ for the Wattnode, and $28.2 \mathrm{~W}$ for the element test with the Wattnode.

Table 3-8: Uncertainty of power monitoring measurements

\begin{tabular}{c|c}
\hline Source of Error & Uncertainty - Measurement (W) \\
\hline Powerscout & 1 \\
Wattnode & 2.6 \\
Element Test & 28.2 \\
\hline
\end{tabular}




\subsubsection{Total Uncertainty of Heat Delivery and Coefficient of Performance}

If a property is derived from multiple measured properties, the bias and precision uncertainties are calculated using Equation 3.17 and Equation 3.18 [51],

$$
\begin{aligned}
& u_{\mathrm{b}, y}=\sqrt{\sum_{i=1}^{N}\left(\frac{\partial y}{\partial i} u_{\mathrm{b}, \mathrm{i}}\right)^{2}} \\
& u_{\mathrm{p}, y}=\sqrt{\sum_{i=1}^{N}\left(\frac{\partial y}{\partial i} u_{\mathrm{p}, \mathrm{i}}\right)^{2}}
\end{aligned}
$$

where $u_{\mathrm{b}, \mathrm{y}}$ is the bias uncertainty of the derived property $y, \frac{\partial y}{\partial i}$ is the partial derivate of property $y$ with respect to measured property $i, u_{\mathrm{b}, \mathrm{i}}$ is the bias uncertainty of measured property $i, u_{\mathrm{p}, y}$ is the precision uncertainty of derived property $y$, and $u_{\mathrm{p}, \mathrm{i}}$ is the precision uncertainty of measured property $i$. To determine the uncertainty of $\Delta E_{\text {deliv }}$, the partial derivatives are represented in Equation 3.19,

$$
\begin{gathered}
\frac{\partial E_{\text {deliv }}}{\partial V_{\mathrm{i}}}=\frac{\rho_{\mathrm{w}} C_{\mathrm{p}, \mathrm{w}} \delta T}{t} \\
\frac{\partial E_{\mathrm{deliv}}}{\partial \rho_{\mathrm{w}}}=\frac{V_{\mathrm{i}} C_{\mathrm{p}, \mathrm{w}} \delta T}{t} \\
\frac{\partial E_{\text {deliv }}}{\partial C_{\mathrm{p}, \mathrm{w}}}=\frac{V_{\mathrm{i}} \rho_{\mathrm{w}} \delta T}{t} \\
\frac{\partial E_{\text {deliv }}}{\partial \delta T}=\frac{V_{\mathrm{i}} \rho_{\mathrm{w}} C_{\mathrm{p}, \mathrm{w}}}{t}
\end{gathered}
$$

where $\delta T$ represents the temperature difference between two timesteps, and it is assumed that the timestep $t$ is constant. The partial derivatives for the COP are found in Equation 3.20, 


$$
\begin{gathered}
\frac{\partial C O P}{\partial E_{\text {deliv }}}=\frac{1}{E_{\text {in }}} \\
\frac{\partial C O P}{\partial E_{\mathrm{in}}}=\left(\frac{E_{\text {in }}}{E_{\text {deliv }}}\right)^{2}
\end{gathered}
$$

and using the bias and precision uncertainties of the measured properties, it is found that the total uncertainty for the heat delivery is $0.1 \mathrm{~kW}$, or $6 \%$, and the total uncertainty of the COP is 0.2 , or $10 \%$.

\subsection{Summary}

Using the uncertainties presented in this chapter, along with Equation 3.6 and Equation 3.17 and Equation 3.18, the total uncertainties on the heat delivery and COP were calculated to be $6 \%$ and $10 \%$, respectively. Upon completion of the experimental setup and its instrumentation, a series of tests were performed. The initial tests were used to determine the charging and discharging times of the HPWH compressor and to analyze the daily performance and energy consumption of the unit when using either the compressor or the electrical resistance element to heat the water. Following this, the daily climate tests outlined in Section 3.7.1 were performed. These daily climate tests were then used to validate the TRNSYS model and simulate the benefits of coupling the HPWH with an HRV. 


\section{Chapter: Modelling in TRNSYS}

A computer model was developed in TRNSYS to simulate the Geospring HPWH with a wrap-around condenser coil. In TRNSYS, "Types" are predefined subroutines that are used to represent physical components to model transient energy systems. These Types are found in either the standard or TESS libraries. Each type uses a series of equations to solve for the outputs based on the inputs. Types can be linked together so that the output of one type is the input of another. With this TRNSYS model, parameters could be added or adjusted to the HPWH in order to observe the effect on the COP of the unit.

This chapter describes the TRNSYS model and the components that were used. The HPWH was represented by a heat pump type connected to a water storage tank type. Air temperature and air humidity values were inputted as TMY2 weather files or text files. CSA water draw profiles were inputted using a forcing function. The performance and energy consumption were calculated within the model and outputted as plots and text files. A heat recovery ventilator type was coupled with the heat pump type to evaluate the benefits on the performance of the system. A house type was also used to perform an annual simulation with heating and cooling loads integrated into the model.

\subsection{Heat Pump Type}

Existing components in both the TESS and standard TRNSYS libraries were insufficient for modelling the air source heat pump contained in the experimental 
apparatus. This is due to the fact that the experimental HPWH contains a wrap-around condenser coil around the water tank, and other heat pump components were not fully capable of representing this geometry. Type 1237, which is a DHW storage tank with a wrap-around heat exchanger, was not used due to its limitation with the working fluid. That is, it does not allow for refrigerant 134a to be used properly, as it changes phase throughout the heat transfer process, which Type 1237 does not account for.

In order to model the heat pump water heater, a new heat pump type developed by Khalaf [39] was used (Type 240). This type includes a domestic hot water tank (Type 534) and a wrap-around condenser coil. A performance map for the HPWH used for this thesis was also included in Type 240, as well as most of the tank properties. Type 240 allowed for the heat from the wrap-around coil to be delivered to the nodes of the water tank. Since the exact geometry of the wrap-around coil of the HPWH could not be determined without destructive damage to the apparatus, it was approximated based on experimental data by Khalaf [39]. It was also observed that the heat from the wrap-around coil was not delivered uniformly to the tank nodes. As a result, the distribution of the heat along the condenser coil was determined experimentally. A feature of Type 240 allowed for miscellaneous heat gains at different tank nodes. This allowed the upper and lower elements of the experimental HPWH to be modelled.

The independent variables that were used in the performance map were the air temperature, the air humidity, and the water temperature. The dependent variables were the total cooling capacity, the sensible cooling capacity, the compressor power, and the heat rejection. Appendix $\mathrm{C}$ contains the tabulated performance map data found 
by Khalaf. Type 240 interpolates the performance map data to calculate the energy values that are needed. If one of the independent variables exceeds the limits of the performance map, the model does not extrapolate, but rather uses the limit of the respective variable.

Equation 4.1 shows the formula for the sensible cooling capacity [52],

$$
Q_{\text {sens }}=\dot{m} C_{\text {p,air }}\left(T_{\text {in }}-T_{\text {out }}\right) \quad[\mathrm{W}]
$$

where $Q_{\text {sens }}$ is the sensible cooling capacity, $\dot{m}$ is the mass flow rate of air in $\mathrm{kg} / \mathrm{s}, C_{\mathrm{p} \text {,air }}$ is the specific heat of air in $\mathrm{kJ} / \mathrm{kgK}, T_{\text {in }}$ is the inlet air temperature in ${ }^{\circ} \mathrm{C}$, and $T_{\text {out }}$ is the exhaust temperature in ${ }^{\circ} \mathrm{C}$. Using experimental data, the sensible cooling capacity was determined for the performance map. Equation 4.2 shows the equation for the total cooling capacity,

$$
Q_{\text {total }}=\dot{m}\left(h_{\text {in }}-h_{\text {out }}\right)
$$

where $Q_{\text {total }}$ is the total cooling capacity, $h_{\text {in }}$ is the enthalpy of the inlet air, and $h_{\text {out }}$ is the enthalpy of the exhaust air. The enthalpy at the inlet and exhaust conditions were determined with Equation 4.3,

$$
h=1.006 T+X(2501+1.805 T)
$$

where $X$ is the moisture content of the air. Equation 4.4 was used to find the moisture content [53],

$$
X=\frac{0.62199 P_{\mathrm{w}}}{P_{\text {tot }}-P_{\mathrm{w}}} \quad\left[\frac{\mathrm{kg} \text { water }}{\mathrm{kg} \text { air }}\right]
$$

where $P_{\mathrm{w}}$ is the partial pressure of water vapour in $\mathrm{kPa}$, and $P_{\text {tot }}$ is the atmospheric pressure in kPa. Equation 4.5 was used to find $P_{\mathrm{w}}$, 


$$
P_{\mathrm{w}}=P_{\mathrm{ws}}\left(T_{\mathrm{d}}\right)=\frac{1000 X}{0.62199+1000 X} \quad[\mathrm{hPa}]
$$

where $P_{\mathrm{ws}}\left(T_{\mathrm{d}}\right)$ is the partial pressure at the dew point temperature. The dew point temperature, $T_{\mathrm{d}}$, was found experimentally, as shown in Appendix B, and $P_{\mathrm{ws}}$ was determined using Equation 4.6,

$$
P_{\mathrm{ws}}=A \cdot 10^{\frac{m T_{\mathrm{d}}}{T_{\mathrm{d}}+T_{\mathrm{n}}}} \quad[\mathrm{hPa}]
$$

where $A, m$, and $T_{\mathrm{n}}$ are constants defined in Equation 4.7 [53],

$$
\begin{gathered}
A=6.116441, \\
m=7.591386, \\
T_{\mathrm{n}}=240.7263 \quad\left[{ }^{\circ} \mathrm{C}\right]
\end{gathered}
$$

Once the enthalpy is known, the total cooling capacity can be calculated. The compressor power was measured using the power monitoring system, and the heat delivery energy calculation was determined using the method shown in Section 3.8. For more detailed information on the performance map and Type 240, refer to Khalaf [39].

\subsection{Water Tank Type}

Type 534 was used to simulate the domestic hot water storage tank in the TRNSYS model. Type 534 is a vertical, cylindrical storage tank, with the option of including immersed heat exchangers, located in the TESS library [38]. The geometry of the tank can be defined, as well as the heat loss coefficient of the outer walls. The experimental unit has a storage tank height of $1.015 \mathrm{~m}$ and a capacity of $189.3 \mathrm{~L}$. The heat loss coefficients of the tank were determined experimentally with a cool-down 
test. The water in the tank was heated up to a uniform set-point, and the temperature of the nodes was monitored for 48 hours. This allowed for the heat loss at each node to be analyzed. The experimental cool-down test is discussed in more detail later in the thesis, in Section 5.1.

Type 534 divides its tank into nodes, where the nodal temperatures are uniform and correspond to the thermocouples in the experimental setup. As such, each node can have its own individual heat input. The number of nodes in the tank was set to be equal to the number of nodes in the condenser coil of Type 240 . This way, the calculated heat delivery to each node from the condenser of Type 240 was used as an input to the respective node in Type 534. Each node also allows for a miscellaneous heat input. The electric elements in the experimental HPWH unit were modelled in this way.

\subsection{Draw Profiles}

CSA water draw profiles were used in the experimental climate tests, as discussed earlier. In order to validate the model, the experimental water draws were used as an input, rather than the ideal CSA draw profiles. This is due to a slight discrepancy between the water draw stated in the CSA draw profile and the water draw in the experimental tests. This discrepancy was caused by a delay in the relay response and the time that the solenoid took to completely stop any water from being drawn. These experimental draws were used as inputs to the TRNSYS simulation using Type 14.

Each climate test had its own experimental water draw data. Based on the water flow rate of $3.8 \mathrm{~L} / \mathrm{min}$ in the experimental setup and the time step in the TRNSYS model, 
the hourly water draws were programmed into TRNSYS using the forcing function Type 14. Every hour, a control signal in the model was sent to draw water for a set amount of time until the experimental water draw was achieved.

\subsection{Climate Model}

The TRNSYS climate model was created so that each climate test could be evaluated and validated. This was done by altering the input conditions and creating a separate model for each climate. Different cities and climates were simulated in this model by altering the incoming air conditions, the utility rates, and the water draw schedule. The incoming air conditions were changed by using a different input file based on the experimental data. The utility rates were changed by either adjusting the flat utility rate parameter, or by altering the forcing function to account for the season and time-of-use rates. The water draw schedule used the experimental volume draws for each respective climate test.

\subsection{Heat Recovery Ventilator}

Type 667 is an air-to-air heat recovery ventilator subroutine in the TESS library. It uses a constant effectiveness approach to model a fresh air and an exhaust air stream passing through an HRV [38]. To model the parameters, a commercial HRV was chosen that closely resembled the air flow rate of the HPWH. A sensible effectiveness of 0.60 was used, based on an HRV model that operated at the same flow rate as the HPWH [54]. A house model, located in Ottawa, developed by Baldwin and 
Cruickshank [40] and modified by Khalaf [39], was used to obtain typical exhaust air conditions entering the HRV.

Two models were created that incorporated the HRV. The initial model introduced an HRV into the validated daily climate tests, as a way to compare any potential energy savings, given a certain city and day of the year. A second model was based on the house model developed by Baldwin [40] and Khalaf [39] in order to obtain annual data with an HRV and HPWH.

\subsection{House Model}

Type 56 is used to model the thermal behavior of a multi-zone building. Baldwin and Cruickshank modeled a two-story, single detached house, located in Ottawa, Canada, which was used to determine the annual energy consumption and cost of energy [40]. The house consisted of a main floor, a second floor, a basement, and an attic, all of which had $110 \mathrm{~m}^{2}$ of floor space and are each their own zones. The house had windows covering one third of the above ground total wall area. The heater in the house had a COP of 1 , representing baseboard heating, while the air conditioner had a COP value of 3. The thermal resistances of the house model are shown in Table 4-1.

Table 4-1: House model thermal resistances [40]

\begin{tabular}{c|c}
\hline Parameter & Thermal Resistance $\left(\mathrm{m}^{2} \mathrm{~K} / \mathrm{W}\right)$ \\
\hline Above Grade Walls & 4.5 \\
Attic & 11.5 \\
Below Grade Walls & 2.7 \\
Under Slab & 1.9 \\
\hline
\end{tabular}


Khalaf modified the house model to include the HPWH, using basement air as its air source [39]. Energy consumption and the associated costs were determined for off-peak, mid-peak, and on-peak times in the heating and cooling seasons. Using this model, a base case was established to determine the annual cost of energy.

For the purposes of this thesis, the model was then modified to represent different scenarios that would then be compared to the base case. For the base case, the HPWH was installed in the basement of the house, using the surrounding basement air as the intake. For the second case, the HPWH was reconfigured so that it would use outdoor Ottawa air as its air source using Type 15. Type 15 allowed for an Ottawa weather file to be inputted to the model. This replicated the climate tests that were performed as part of the experimental research, only on an annual, rather than daily, scale. For the third case, the HRV was introduced into the model with outdoor air, along with the exhaust air from the house, entering the HRV. The heated fresh air leaving the HRV was then used as the air intake for the HPWH, and an annual simulation was run. For the fourth case, a control was introduced, so that when the air entering the HPWH was below $7^{\circ} \mathrm{C}$, the heat pump would turn off, and the electric resistance elements would be used to heat the water instead. This was done to replicate the manufacturer's intended behavior of the HPWH. For the final case, the HPWH would use the HRV air unless the basement air was warmer, in which case the basement air would be used as the source instead. These five scenarios are shown in a flow chart in Figure 4-1. 


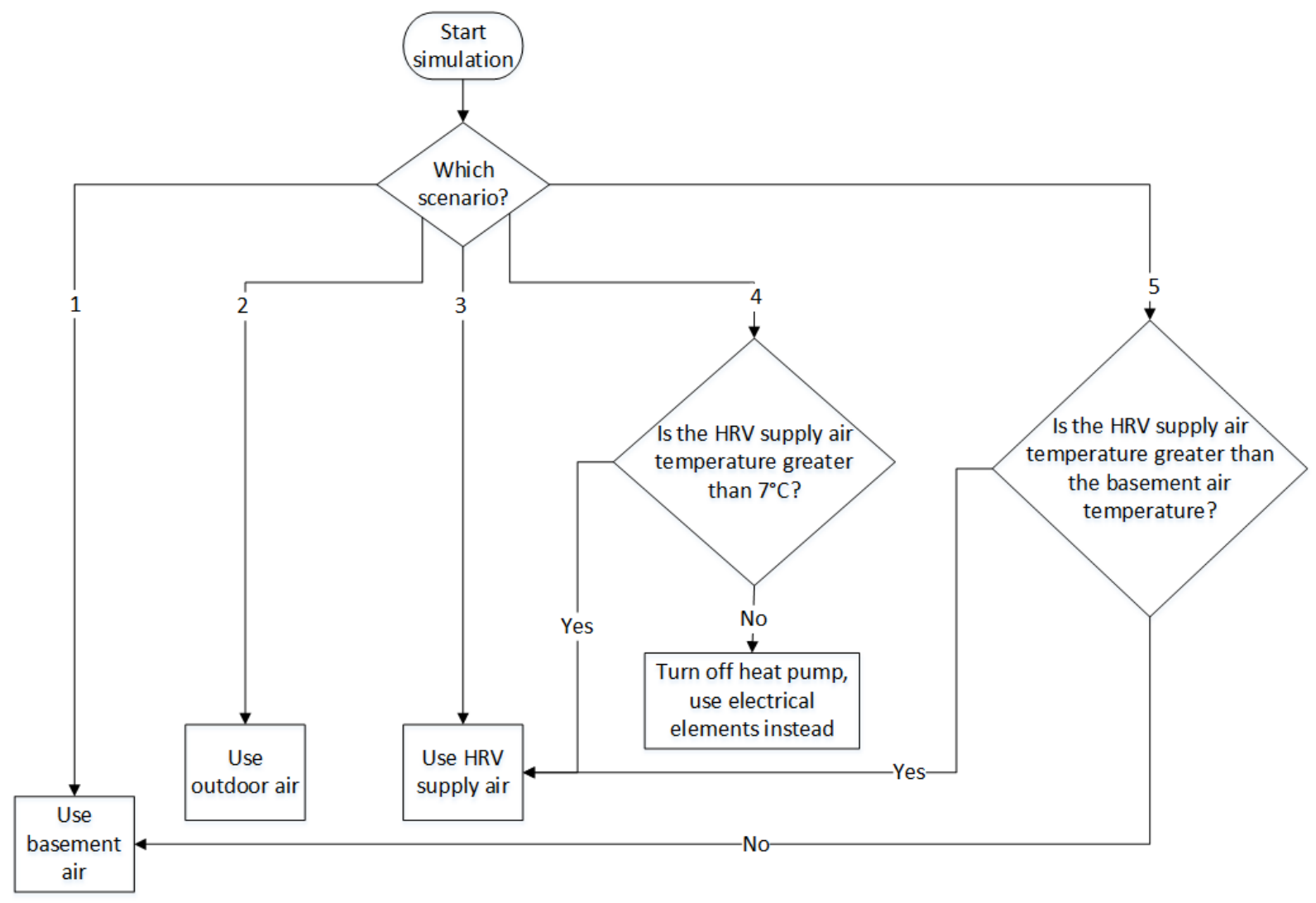

Figure 4-1: Annual house simulation flow chart

\subsection{Summary of TRNSYS Types and Parameters}

Table 4-2 summarizes the TRNSYS types used in the TRNSYS models.

Table 4-2: Summary of TRNSYS types used for each component

\begin{tabular}{c|c}
\hline Component & TRNSYS Type \\
\hline Heat Pump & Type 240 \\
DHW Storage Tank & Type 534 \\
HRV & Type 667 \\
House & Type 56 \\
CSA Draw Profile & Type 14 \\
Experimental Air Temperatures & Type 9a \\
TMY Weather Data & Type 15 \\
\hline
\end{tabular}


Table 4-3 summarizes the TRNSYS parameters used in the daily, seasonal, and annual climate simulations.

Table 4-3: Summary of TRNSYS model parameters

\begin{tabular}{c|c|c|c}
\hline Model & Time period (h) & Time step & Output variables \\
\hline $\begin{array}{c}\text { Daily, } \\
\text { Outdoor Air }\end{array}$ & $6-24$ & $0.0039 \mathrm{~h}$ & $\begin{array}{c}\text { HPWH Energy, Heat Rejection, COP, } \\
\text { Cost of Energy, Node Temperature }\end{array}$ \\
\hline $\begin{array}{c}\text { Seasonal, } \\
\text { Outdoor Air }\end{array}$ & $\begin{array}{c}1872-4103 \text { (Spring), } \\
6104-6359 \text { (Summer), } \\
6360-8496 \text { (Fall) }\end{array}$ & $0.2 \mathrm{~min}$ & $\begin{array}{c}\text { HPWH Energy, Heat Rejection, COP, } \\
\text { Cost of Energy, Node Temperature }\end{array}$ \\
\hline $\begin{array}{c}\text { Annual, } \\
\text { House }\end{array}$ & $0-8760$ & $1 \mathrm{~min}$ & $\begin{array}{c}\text { Air and Node Temperature, COP, } \\
\text { HPWH Energy (On, Off, Mid-Peak), } \\
\text { Heating Energy (On, Off, Mid-Peak), } \\
\text { Cooling Energy (On, Off, Mid-Peak) }\end{array}$ \\
\hline
\end{tabular}




\section{Chapter: Results and Discussion}

A number of experiments and simulations were conducted for this thesis. The results and discussion of this work are presented in this chapter. Experimental tests were conducted on the HPWH; these include a cool-down test, baseline tests using unaltered laboratory air, and daily climate tests. Simulations of the HPWH were also conducted; these include daily climate simulations, seasonal simulations, and annual simulations with the HPWH coupled with an HRV in a modelled house.

\subsection{Cool-down Test}

A cool-down test was performed on the HPWH tank in order to quantify the heat loss to the environment. The testing method was based on a procedure previously used by Cruickshank [31]. Before this test was performed, the water in the tank was heated to a uniform temperature of $60^{\circ} \mathrm{C}$. Following this, the HPWH was turned off for 48 hours, while the ambient air temperature and the water temperature at the 10 thermocouple locations were recorded every 3 minutes. For this test, the geometry of the tank was assumed to be cylindrical with a flat bottom and top, as the exact curvature could not be determined without damaging the equipment. Using the temperature data and geometry of the tank, the heat loss rate and heat loss coefficient could be determined. Equation 5.1 is the first principle heat balance of a node [31] [39], 


$$
\begin{aligned}
M_{\mathrm{i}} C_{\mathrm{p}, \mathrm{w}} \frac{d T_{\mathrm{i}}}{d t}= & \frac{(k+\Delta k) A_{\mathrm{c}, \mathrm{i}}}{\Delta x_{\mathrm{i}+1 \rightarrow \mathrm{i}}}\left(T_{\mathrm{i}+1}-T_{\mathrm{i}}\right)+\frac{(k+\Delta k) A_{\mathrm{c}, \mathrm{i}}}{\Delta x_{\mathrm{i}-1 \rightarrow \mathrm{i}}}\left(T_{\mathrm{i}-1}-T_{\mathrm{i}}\right) \\
& +\left(U_{\mathrm{i}}\right) A_{\mathrm{s}, \mathrm{i}}\left(T_{\mathrm{env}}-T_{\mathrm{i}}\right)+\dot{m}_{\mathrm{down}} C_{\mathrm{p}, \mathrm{w}} T_{\mathrm{i}-1}-\dot{m}_{\mathrm{up}} C_{\mathrm{p}, \mathrm{w}} T_{\mathrm{i}+1} \\
& +\dot{m}_{\text {inlet }} C_{\mathrm{p}, \mathrm{w}} T_{\text {inlet }}-\dot{m}_{\text {outlet }} C_{\mathrm{p}, \mathrm{w}} T_{\text {outlet }}+\dot{Q}_{\text {aux }, \mathrm{i}}
\end{aligned}
$$

where $M_{\mathrm{i}}$ is the mass of the water node, $C_{\mathrm{p}}$ is the specific heat capacity of water, $\frac{d T_{\mathrm{i}}}{d t}$ is the change in node temperature over time, $k$ is the thermal conductivity of the water in the tank, $\Delta k$ is the destratification conductivity [39], $A_{c, i}$ is the cross-sectional area of the tank node, $\Delta x_{\mathrm{i}+1 \rightarrow \mathrm{i}}$ is the center-to-center distance between nodes, $T_{\mathrm{i}}$ is the temperature of the water at the respective node, $T_{\mathrm{i}+1}$ and $T_{\mathrm{i}-1}$ are the temperatures of the node above and below the current node, respectively, $U_{\mathrm{i}}$ is the universal heat loss coefficient of the water tank node, $A_{\mathrm{s}, \mathrm{i}}$ is the surface area of the node, $T_{\mathrm{env}}$ is the ambient air temperature, $\dot{m}_{\text {down }}$ and $\dot{m}_{\text {up }}$ are the mass flow rates of the water circulating in the tank, $\dot{m}_{\text {inlet }}$ and $\dot{m}_{\text {outlet }}$ are the mass flow rates of the water entering and exiting the HPWH tank, $T_{\text {inlet }}$ and $T_{\text {outlet }}$ are the temperatures of the water entering and exiting the tank, and $\dot{Q}_{\text {aux,i }}$ is the auxiliary heat being applied to the node [39]. The energy balance of the node is illustrated in Figure 5-1. For the cool-down test, there is no water entering or exiting the tank, and there is no auxiliary heat applied to any of the nodes, so $\dot{m}_{\text {inlet, }} \dot{m}_{\text {outlet, }}$ and $\dot{Q}_{\text {aux,i }}$ are zero. Similarly, the mass of the node, the specific heat capacity of water, the thermal conductivity terms, the surface area and cross-sectional area terms, distances between the nodes, and ambient air temperature are assumed to be constant. Thus, the $U_{\mathrm{i}}$ may be different for each node due to the mass flow rates of the water circulating in the tank caused by thermal stratification. 


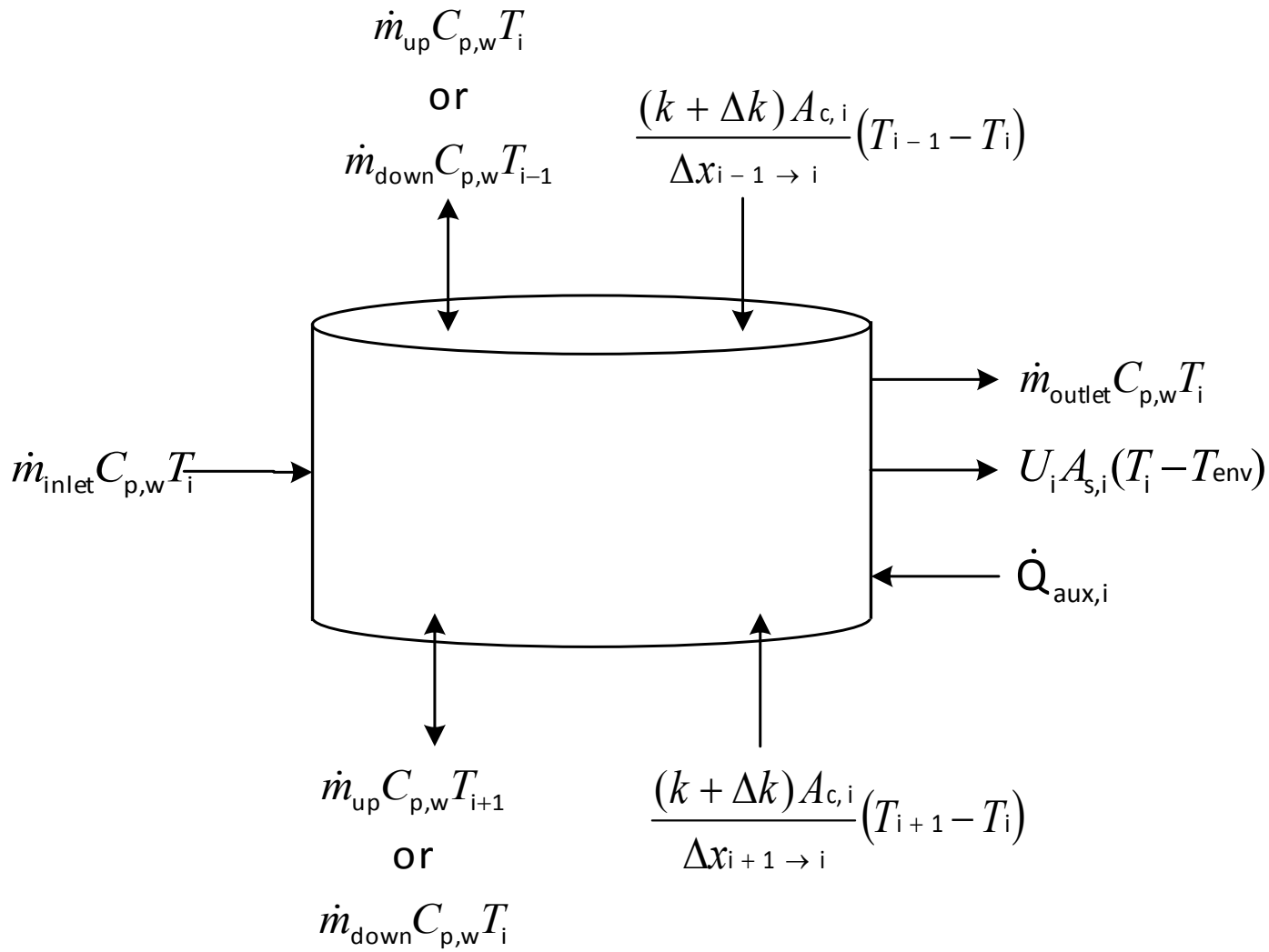

Figure 5-1: Energy balance on a tank node (adopted from [39])

$U_{\mathrm{i}}$ is obtained using Equation 5.2,

$$
U_{\mathrm{i}}=\frac{Q_{\text {loss }, \mathrm{i}}}{A_{\mathrm{s}, \mathrm{i}}\left(T_{\mathrm{i}}-T_{\mathrm{env}}\right)} \quad\left[\frac{\mathrm{W}}{\mathrm{m}^{2} \mathrm{~K}}\right]
$$

where $Q_{\text {loss,i }}$ is the heat loss of the node. Equation 5.3 is used to calculate the mean universal heat loss coefficient,

$$
\bar{U}_{\text {tank }}=\frac{Q_{\text {loss,tank }}}{A_{\mathrm{s}, \text { tank }}\left(T_{\text {mean,tank }}-T_{\text {env }}\right)} \quad\left[\frac{\mathrm{W}}{\mathrm{m}^{2} \mathrm{~K}}\right]
$$

where $\bar{U}_{\text {tank }}$ is the mean universal heat loss coefficient, $Q_{\text {loss,tank }}$ is the heat loss of the tank, $A_{\mathrm{s}, \operatorname{tank}}$ is the surface area of the tank, and $T_{\text {mean,tank }}$ is the mean temperature of the water in the tank. The surface area of the tank is calculated using Equation 5.4,

$$
A_{\mathrm{s}, \mathrm{tank}}=2 \pi r h+2 \pi r^{2} \quad\left[\mathrm{~m}^{2}\right]
$$


where $r$ is the radius of the tank and $h$ is the height of the tank. The height of the tank is $1 \mathrm{~m}$, and the radius must be determined using Equation 5.5,

$$
V_{\text {tank }}=\pi r^{2} h \quad\left[\mathrm{~m}^{3}\right]
$$

where $V_{\operatorname{tank}}$ is the volume of the tank, $0.18927 \mathrm{~m}^{3}$. Once the surface area of the tank is determined, the surface area of each node is determined, since the volume of each node is constant. This is due to the assumed cylindrical geometry across all 10 nodes, since the exact curvature of the top and bottom of the storage tank could not be determined. In reality, the top and bottom nodes would have larger volumes. The recorded water temperature over time is shown in Figure 5-2. Node 1 represents the top node of the tank, and Node 10 represents the bottom node.

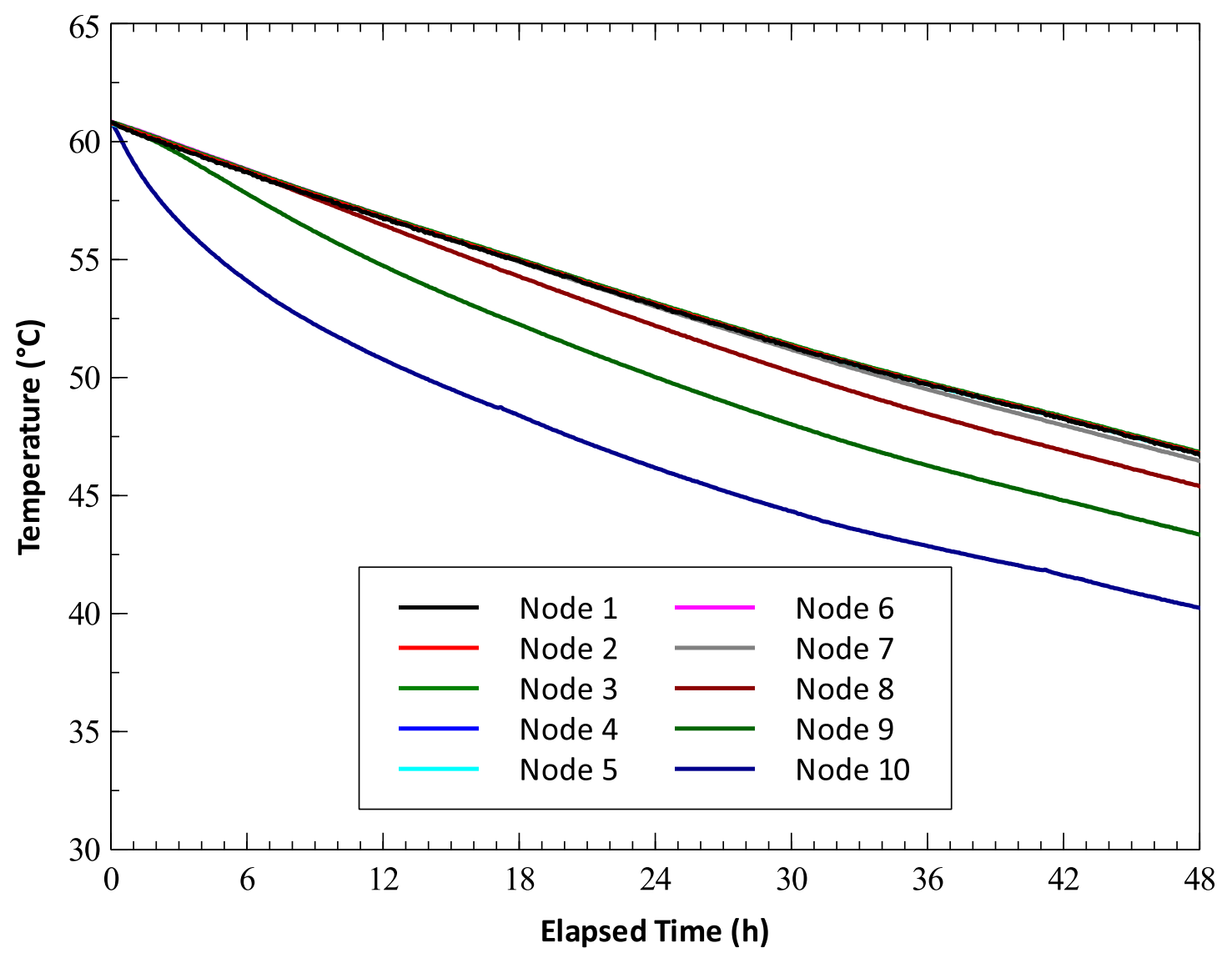

Figure 5-2: Temperature of the tank nodes after a 48-hour cooldown test 
It can be seen that the temperature decrease of Nodes 1 through 7 are linear for the 48 hours. As Nodes 1 and 10 have the highest surface area, it is expected that they would cool down the fastest. However, due to thermal stratification, the heat is displaced towards the upper part of the tank, thus Nodes 8 through 10 cool down at higher rates. The values for $U_{\mathrm{i}}, \bar{U}_{\text {tank }}, Q_{\text {loss,i }}$, and $Q_{\text {loss,tank }}$ are summarized in Table 5-1.

Table 5-1: Universal heat transfer coefficient and heat loss at each node

\begin{tabular}{c|cc}
\hline & $\begin{array}{c}\boldsymbol{U}_{\mathrm{i}} \\
\left(\mathbf{W} / \mathrm{m}^{2} \mathrm{~K}\right)\end{array}$ & $\begin{array}{c}\boldsymbol{Q}_{\text {loss }} \\
(\mathbf{W})\end{array}$ \\
\hline Node 1 & 0.96 & 7.22 \\
Node 2 & 0.96 & 7.51 \\
Node 3 & 0.96 & 7.52 \\
Node 4 & 0.96 & 7.47 \\
Node 5 & 0.96 & 7.47 \\
Node 6 & 0.96 & 7.53 \\
Node 7 & 0.99 & 7.58 \\
Node 8 & 1.09 & 8.17 \\
Node 9 & 1.28 & 12.09 \\
Node 10 & 2.43 & 18.97 \\
\hline Total & 1.15 & 9.15 \\
\hline \multicolumn{2}{|c}{}
\end{tabular}

\subsection{Tests at Laboratory Air Conditions}

Three HPWH tests were performed with unaltered laboratory air (i.e., without heating or cooling the air within the laboratory). The first two tests began with the water in the storage tank at a uniform $60^{\circ} \mathrm{C}$, and had water drawn hourly according to CSA Schedule A [29]. The first test used the electric element to heat the water as necessary to the set-point temperature of $60^{\circ} \mathrm{C}$. The second test used the HPWH to heat the water as necessary to the set-point temperature of $60^{\circ} \mathrm{C}$. These first two tests represented baselines for the energy consumption of a typical electric water heater and HPWH, respectively, in a lower occupancy household, using the surrounding basement 
air as an air source (rather than using outdoor air or an HRV, as discussed later). Later in the thesis, in Section 5.3.1, the results of the climate tests will be compared to these baselines to determine whether there will be any energy or cost savings.

The third test started with the water in the tank at a uniform mains water temperature. The HPWH was used to heat the water to the set-point temperature of $60^{\circ} \mathrm{C}$. Then, the water in the tank was discharged, by leaving the water draw solenoid fully open, until it was once again at a uniform mains water temperature. This test was used to determine the time it took to fully charge and fully discharge the storage tank.

\subsubsection{Heating Water with the Electric Element}

The water temperature profile and power consumption of an electric water heater are shown in Figure 5-3. These were used to calculate the energy consumption, heat delivery, coefficient of performance, and cost of energy for an electric water heater on a typical day. It can be seen that the electric element heated the water at a high rate (when compared to the HPWH later), and that the water was typically heated above its set-point temperature of $60^{\circ} \mathrm{C}$. 


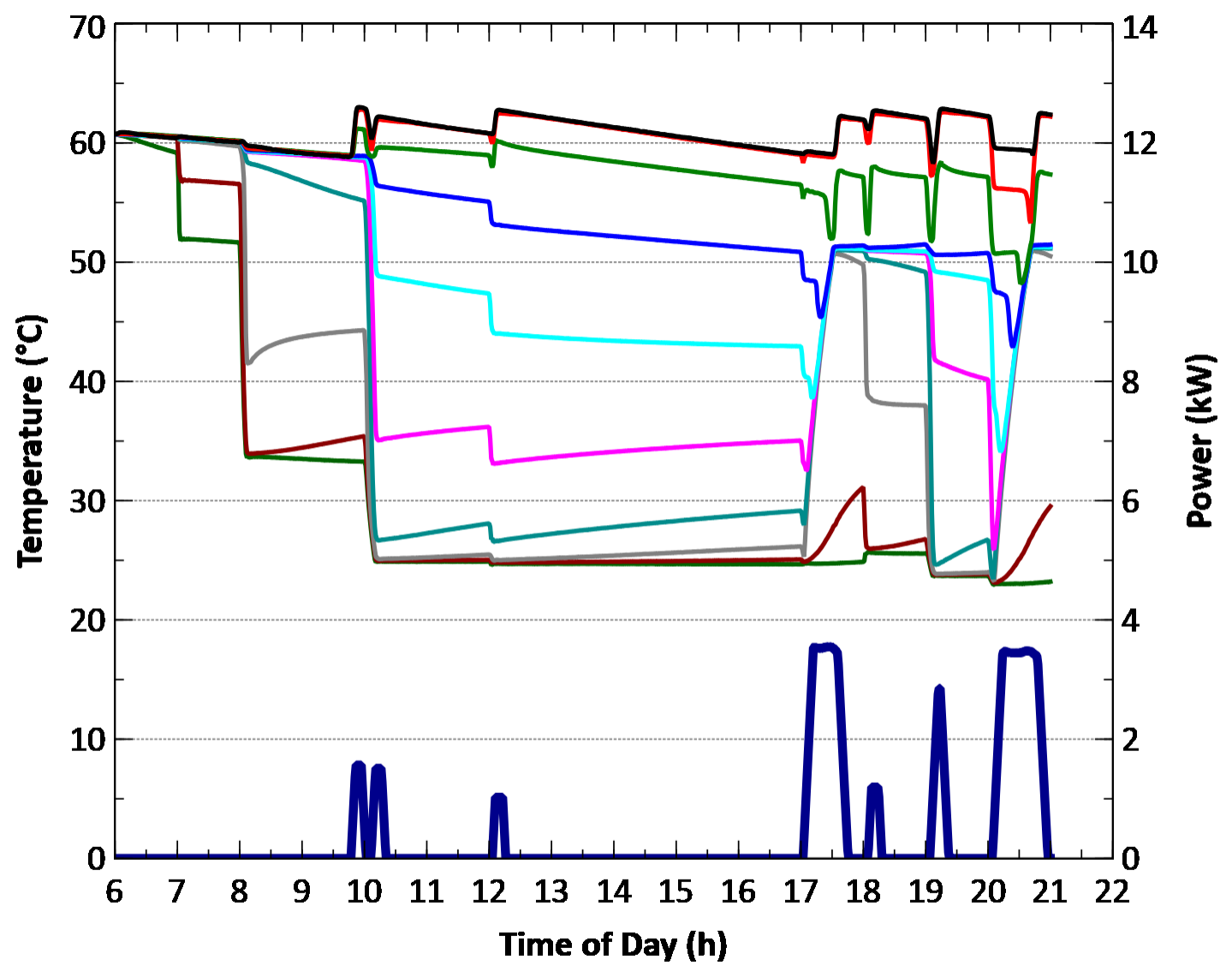

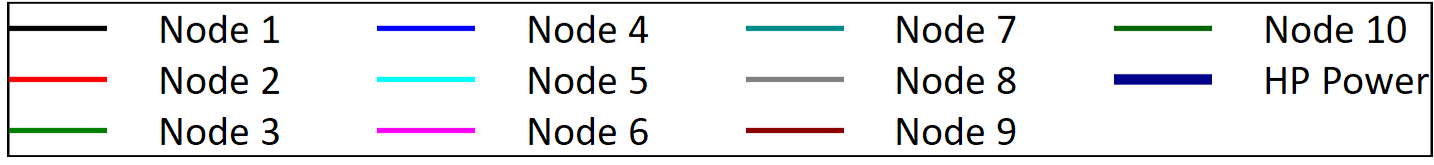

Figure 5-3: Water temperature and power consumption using the electric element

The cumulative energy consumption, heat delivery, and coefficient of performance of the electric water heater are shown in Figure 5-4. It can be seen that the CCOP was approximately 1 , as expected for an electric water heater. Note that while it is typical to use the energy factor to rate the performance of an electric water heater, the CCOP was used for comparison with the HPWH. 


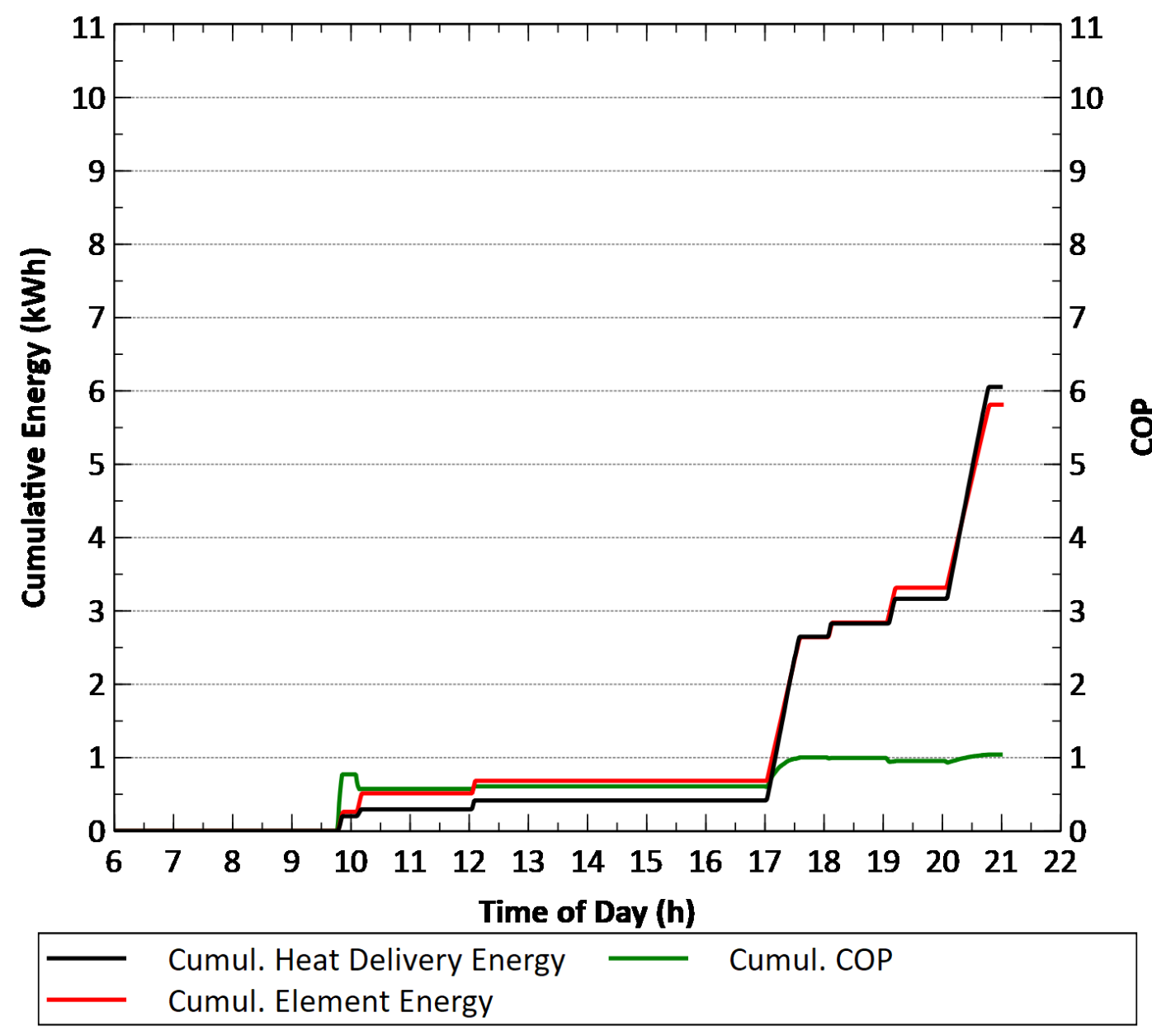

Figure 5-4: Energy consumption and COP of the HPWH using the electric element

\subsubsection{Heating Water with the Heat Pump}

Two tests were performed with the HPWH using the laboratory air conditions.

The first test at laboratory conditions involved charging the tank to a uniform $60^{\circ} \mathrm{C}$, followed by hourly water draws determined by CSA draw Schedule A [29]. The test began at the set-point in order to illustrate that the HPWH had heated the water overnight. This test represented a HPWH installed using the surrounding air, unheated and uncooled, as its air source. The test results can be seen in Figure 5-5. When compared to the electric water heater results in Figure 5-3, it can be seen that the 
HPWH heated the water at a much lower rate, but it also used significantly lower electricity, since the compressor used up to $600 \mathrm{~W}$, while the electric element used up to $3.5 \mathrm{~kW}$. It was observed that Nodes 7 through 10 were at a much lower temperature than the upper nodes, and that Nodes 1 through 4 were approximately the same temperature throughout the test. This was partly due to thermal stratification, and partly due to the location of the condenser coil of the HPWH; the coil ended between Nodes 4 and 5, thus the heat was delivered to these upper nodes. At hour 7, a $5 \mathrm{~L}$ water draw was made, as illustrated by the drop in water temperature for the lower nodes. At hour $8,25 \mathrm{~L}$ of water was drawn, which caused a larger drop in water temperature, and caused the HPWH to heat the water back to its set-point. At the end of the test, the HPWH finished charging the water back to its set-point. 


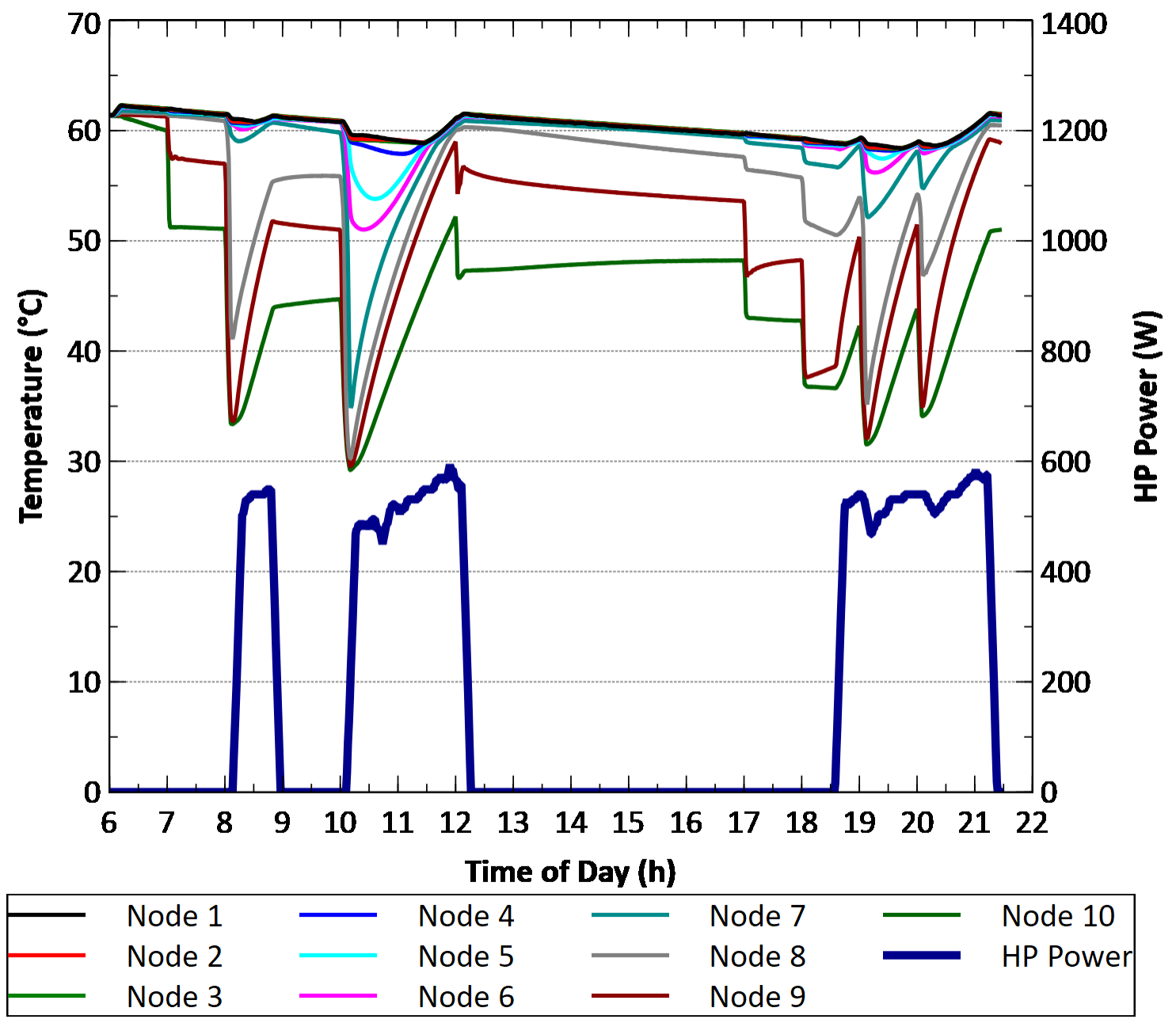

Figure 5-5: Water temperature profile and power consumption of the HPWH at laboratory air conditions

The cumulative energy input, heat delivery, and coefficient of performance for the electric water heater are shown in Figure 5-6. There was a significant increase in the CCOP as the HPWH first turned on at hour 8 . This was due to the measurement for the consumed electricity lagging behind the calculated heat delivery energy by a time step; the CCOP can be seen to stabilize as the experiment continued. In addition, according to the performance map established by Khalaf [39], as the water temperature increases, both the heat delivery decreases, and the compressor power increases, causing a slight 
decrease in CCOP. It can be seen that at the end of the test, the CCOP was approximately 2.6. The energy factor of the unit is reported as 2.4 by the US Department of Energy [41], which shows that this value is a reasonable result for a daily test.

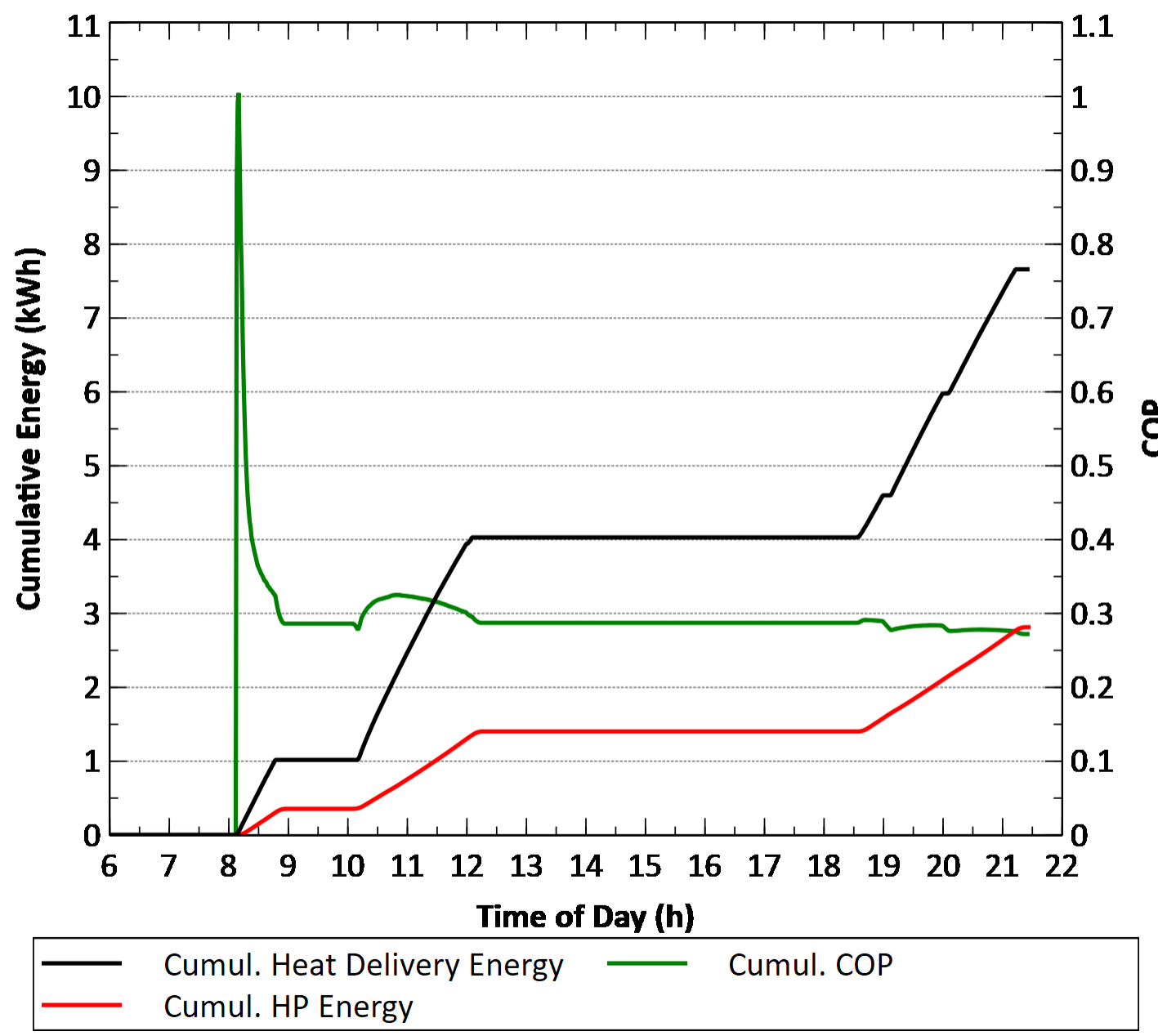

Figure 5-6: Cumulative energy and COP of the HPWH at laboratory air conditions

The second test involved charging the water in the tank using the HPWH from uniform mains water temperature to a hot water temperature set-point of $60^{\circ} \mathrm{C}$, followed by completely filling the tank with mains water so that there was no hot water remaining. This highlighted the time needed to fully charge and fully discharge the tank. The results of this test can be seen in Figure 5-7. The tank took approximately 6 hours to 
fully charge, and 2 hours to fully discharge. After less than 1 hour of discharging, the water temperature at the top of the tank dropped below $55^{\circ} \mathrm{C}$, thus it no longer met the hot water demand. It can also be seen that as the tank discharged, the upper nodes decreased in temperature at a lower rate. This was because mains water was being directly introduced to the bottom of the tank, causing the lower nodes to cool down faster.

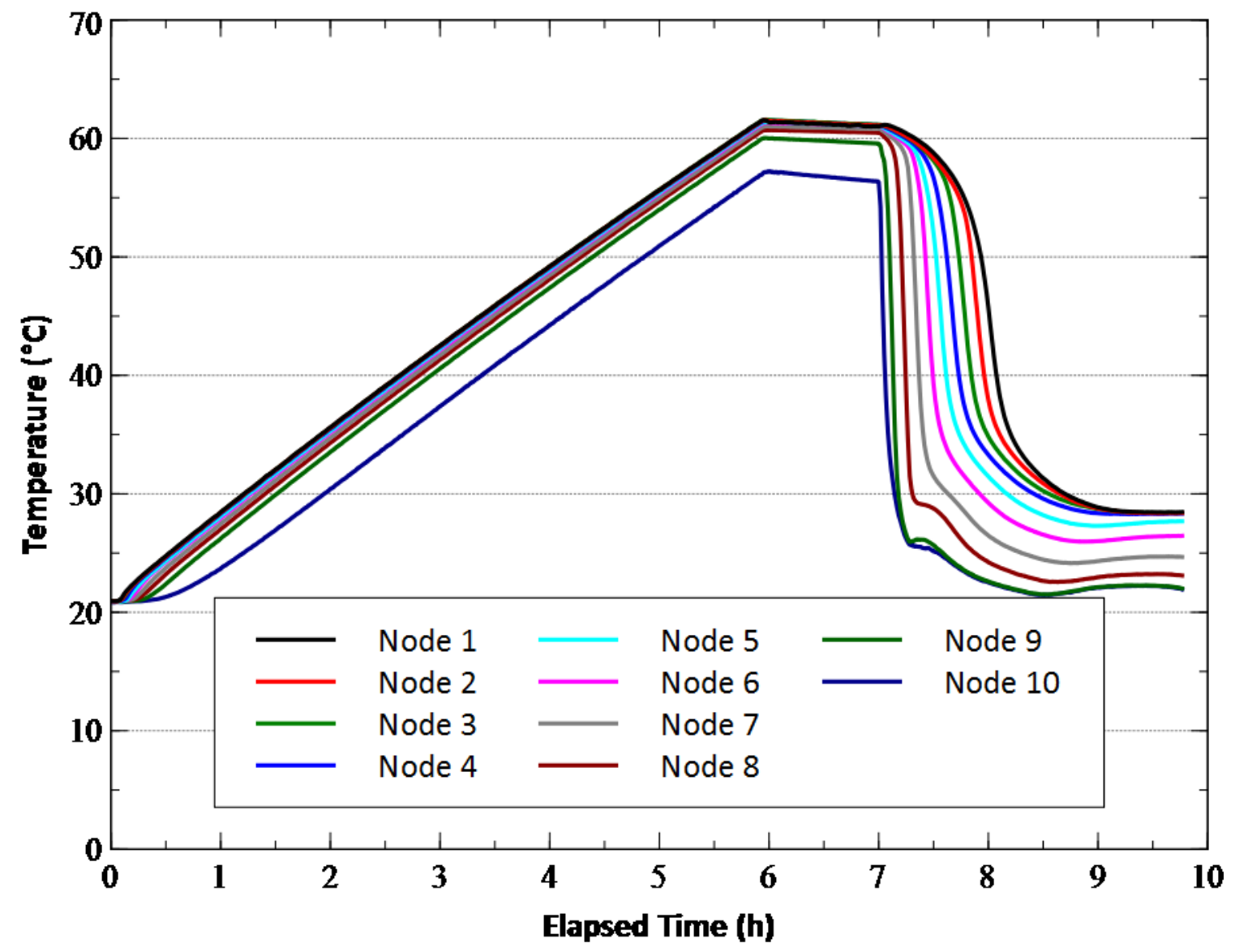

Figure 5-7: Temperature at each node during charging and discharging, laboratory conditions 


\subsection{Tests at Climate Conditions}

The HPWH was tested at various climate conditions for 10 cities. These tests used the outdoor air temperature and humidity set-points established in Table 3-4 and Table 3-5, and did not account for any heating or cooling input from buildings. These set-points were based on a single representative day in the middle of the respective season, allowing for an accurate representation of the seasons in each climate. These results were later used to validate the TRNSYS model for a more comprehensive analysis. The water temperature profile and power consumption for the Montreal summer data can be seen in Figure 5-8. The temperatures of Nodes 2 through 5 were removed for clarity, as they were very close to the temperature of Node 1 . The HPWH can be seen to behave similarly to the laboratory air results in Figure 5-3, noting that the HPWH operated for less time in the Montreal case due to the higher air temperature. 


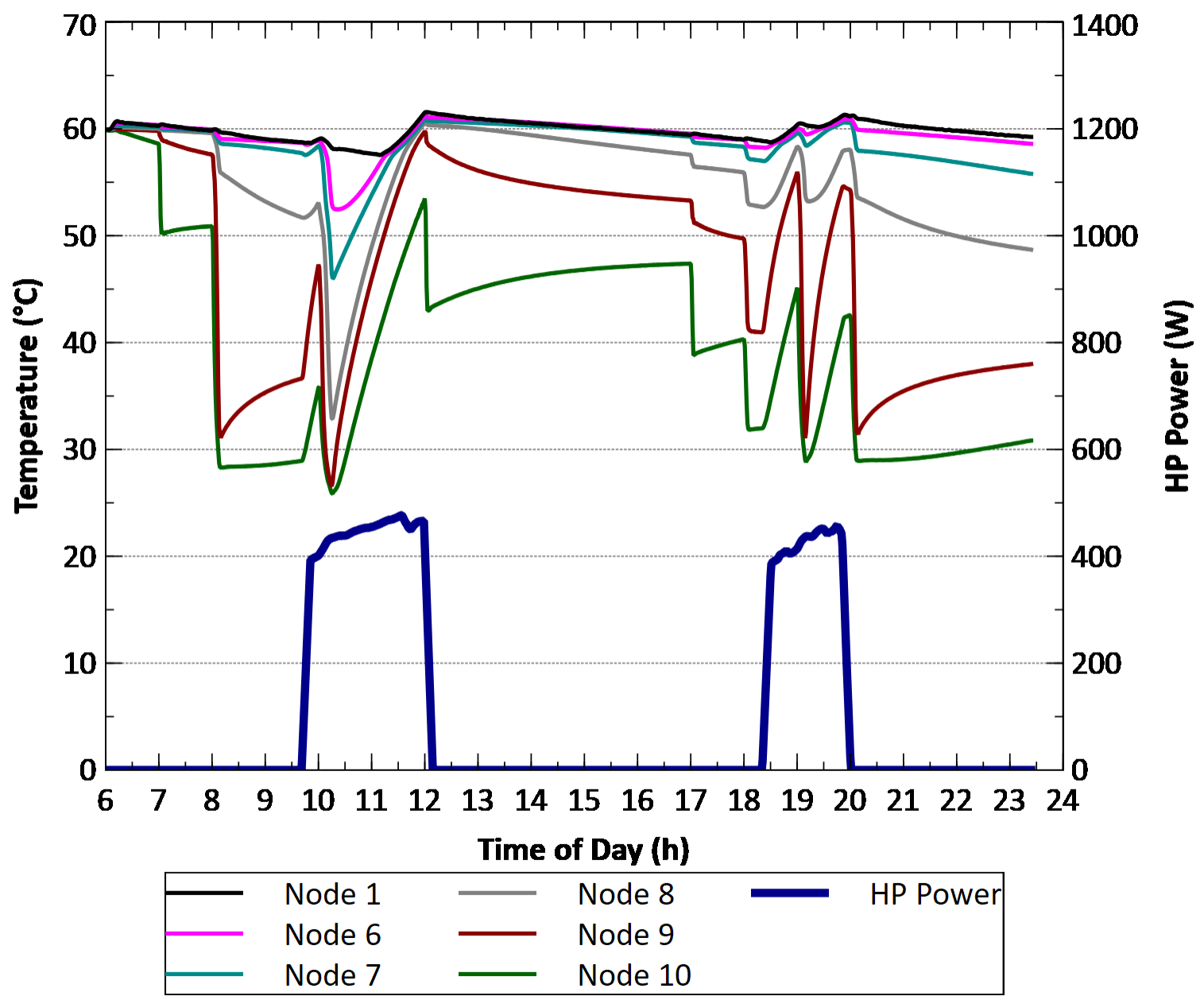

Figure 5-8: Water temperature and power consumption for a Montreal summer day

The cumulative energy, CCOP, and cost of energy are shown in Figure 5-9. It can be seen that the CCOP was above 3 , due to the higher temperature and humidity in the summer. 
Table 5-2 contains the summary of the results for all of the climate tests. It is important to note that the cost of energy was calculated based solely on the energy drawn by the HPWH. Another limitation of these climate results is that they do not include the effect of the HPWH on the heating and cooling loads of the building. The Montreal and Ottawa summer tests were the only climates that resulted in a CCOP above 3. Other summer tests resulted in a CCOP between 2.4 and 3 , except for the Edmonton summer test, which had a CCOP of 2.19.

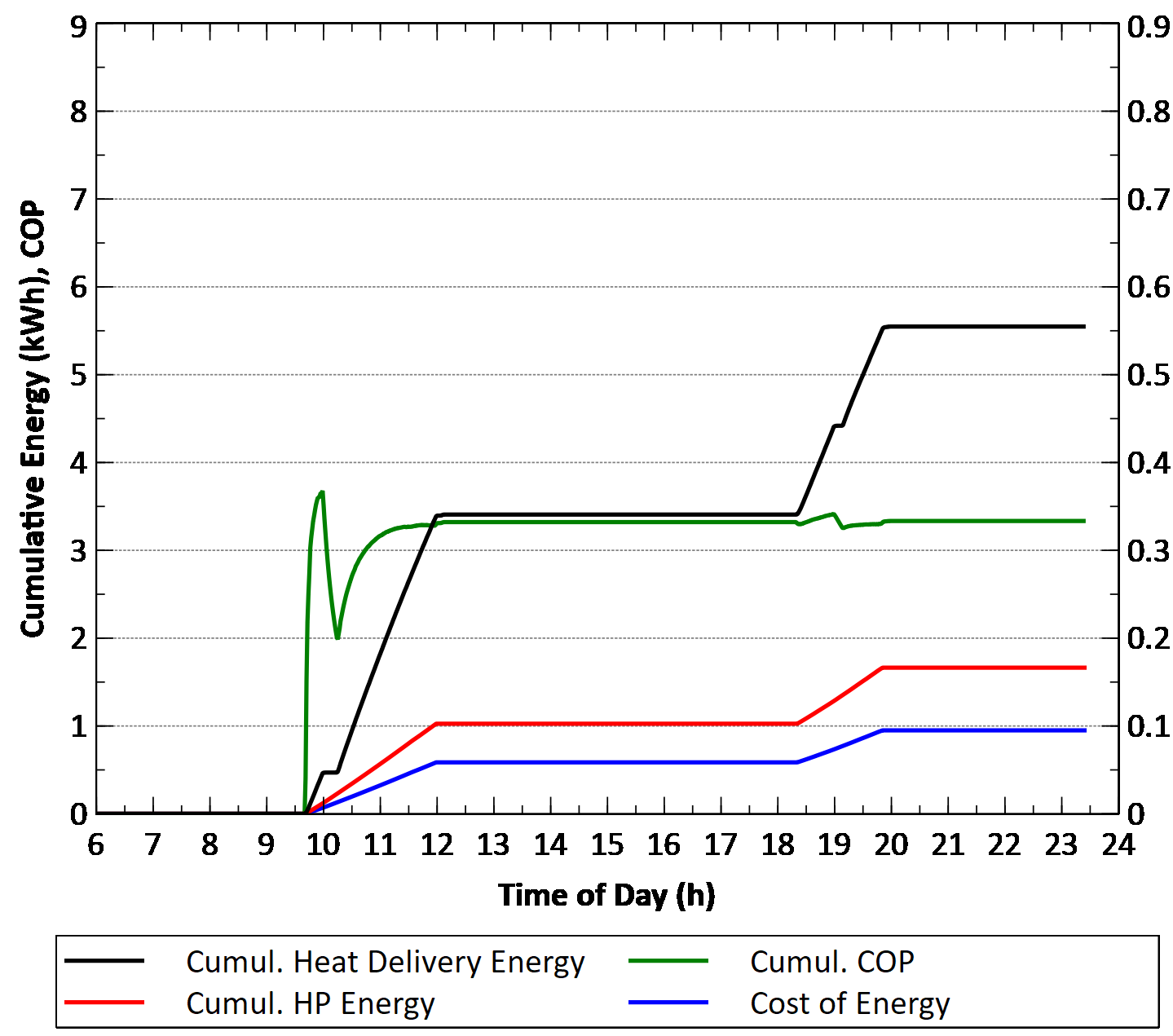

Figure 5-9: Cumulative energy, COP, and cost of energy for a Montreal summer day 


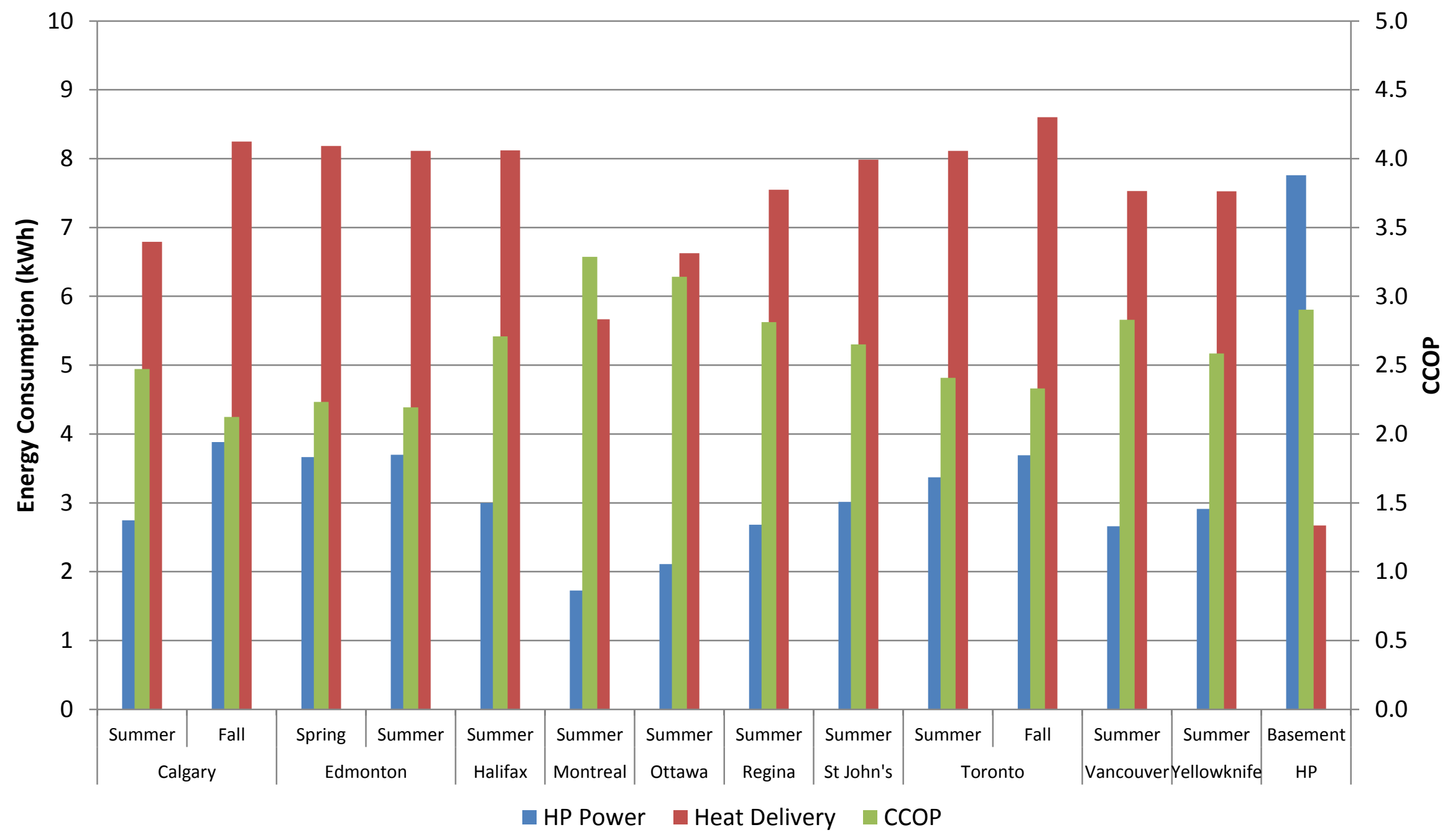

Figure 5-10: Comparison of energy consumption and CCOP for all climate tests 
Table 5-2: Summary of climate test results

\begin{tabular}{cc|cccc}
\hline City & Season & $\begin{array}{c}\text { HP Energy } \\
\text { (kWh) }\end{array}$ & $\begin{array}{c}\text { Heat Delivery } \\
\text { (kWh) }\end{array}$ & CCOP & $\begin{array}{c}\text { Daily Cost } \\
\text { of Energy } \\
\text { (\$) }\end{array}$ \\
\hline Montreal & Summer & 1.72 & 5.67 & 3.29 & 0.10 \\
Edmonton & Spring & 3.67 & 8.19 & 2.23 & 0.15 \\
Edmonton & Summer & 3.70 & 8.11 & 2.19 & 0.16 \\
Calgary & Summer & 2.75 & 6.79 & 2.47 & 0.12 \\
Calgary & Fall & 3.88 & 8.25 & 2.12 & 0.17 \\
Vancouver & Summer & 2.66 & 7.53 & 2.83 & 0.22 \\
Ottawa & Summer & 2.11 & 6.63 & 3.14 & 0.27 \\
St John's & Summer & 3.01 & 7.99 & 2.65 & 0.29 \\
Regina & Summer & 2.68 & 7.55 & 2.81 & 0.41 \\
Halifax & Summer & 3.00 & 8.12 & 2.71 & 0.45 \\
Toronto & Summer & 3.37 & 8.11 & 2.41 & 0.43 \\
Toronto & Fall & 3.69 & 8.60 & 2.33 & 0.48 \\
Yellowknife & Summer & 2.91 & 7.53 & 2.58 & 0.69 \\
\hline
\end{tabular}

For the Calgary fall climate test, the CCOP dropped down to 2.12, since the air temperature was close to the lower limit of $10^{\circ} \mathrm{C}$ for the majority of the test. This lower limit exists since the cooling coil is incapable of cooling the air below $10^{\circ} \mathrm{C}$. This shows that, as expected, warmer and more humid climates result in increased performance of the HPWH, as the increased air temperature results in higher heat delivery and a higher COP. For the Edmonton spring test, the resulting CCOP was 2.23. The HPWH performed better in this test than in the Calgary fall test, again due to the higher temperature and humidity. It is of interest to note that Ottawa has a significantly lower cost of energy in the summer than Toronto, despite both cities having the same time-of-use rates and draw profile. This is due to the fact that the representative day for Ottawa results in a higher air temperature than that of Toronto. However, the Toronto set-points have a significantly higher relative humidity than those of Ottawa. Thus, it is observed that the 
air dry bulb temperature has a significantly higher effect on the performance of the HPWH than the air humidity.

Due to the limitation that the air cannot be cooled below $10^{\circ} \mathrm{C}$, the winter season could not be tested for any of the climates, and the fall season could only be tested for Toronto and Calgary. Because of this, it is important to note that the climate tests represent the performance of the HPWH at conditions in relatively warm seasons. As a result, it was determined to perform two additional tests. Both of these tests were run at an air temperature set-point of $10^{\circ} \mathrm{C}$. One of these tests was performed without any humidification, and the other was performed with the humidifier operating for the entire test. These tests represented the performance of the HPWH at the lowest air temperature that could be tested. Table 5-3 summarizes the results of the tests conducted at $10^{\circ} \mathrm{C}$.

Table 5-3: Summary of results for tests conducted at $10^{\circ} \mathrm{C}$ with and without the humidifier

\begin{tabular}{c|c|cc}
\hline \multicolumn{1}{c}{} & & $\begin{array}{c}10^{\circ} \mathrm{C}, \\
\text { Without } \\
\text { Humidifier }\end{array}$ & $\begin{array}{c}10^{\circ} \mathrm{C}, \text { With } \\
\text { Humidifier }\end{array}$ \\
\hline \multirow{4}{*}{} & HP Energy (kWh) & 3.79 & 3.58 \\
& Heat Delivery (kWh) & 8.48 & 8.31 \\
& CCOP & 2.24 & 2.32 \\
\hline \multirow{4}{*}{ Daily } & Ontario, Jan - Apr & 0.44 & 0.42 \\
Energy & Ontario, May - Dec & 0.49 & 0.47 \\
(\$) & Halifax, Mar - Nov & 0.47 & 0.46 \\
& Halifax, Dec - Feb & 0.56 & 0.55 \\
& Vancouver & 0.31 & 0.30 \\
& St John's & 0.37 & 0.35 \\
& Regina & 0.57 & 0.54 \\
& Yellowknife & 0.90 & 0.85 \\
& Montreal & 0.22 & 0.21 \\
& Calgary & 0.17 & 0.16 \\
& Edmonton & 0.16 & 0.15 \\
\hline
\end{tabular}


It can be seen that Montreal and Vancouver had a daily cost of energy twice that of their summer conditions, while Toronto, Calgary, and Edmonton had a negligible cost difference compared to the climate tests. Other climates experienced a significant increase in cost under these lower temperature conditions. These results make sense, as the lower incoming air temperature resulted in lower HPWH performance. When using the humidifier, the HPWH energy consumption decreased more than the heat delivery, resulting in an overall increase in CCOP and decrease in daily cost of energy. Appendix D contains the remaining climate test data plots.

\subsubsection{Economic Benefits of a HPWH Compared to Electric Water Heaters}

For each climate test that was performed, the cost of energy was compared to the cost of using basement air conditions at the intake of the HPWH and the cost of using an electric water heater, based on the results obtained in Section 5.2.1 and Section 5.2.2. Figure 5-11 shows the cost of energy comparisons for all 10 Canadian cities. Appendix E contains the utility rate data for each city. These results are representative of the energy consumption of HPWH water heater itself, and do not include heating or cooling loads of the building. 


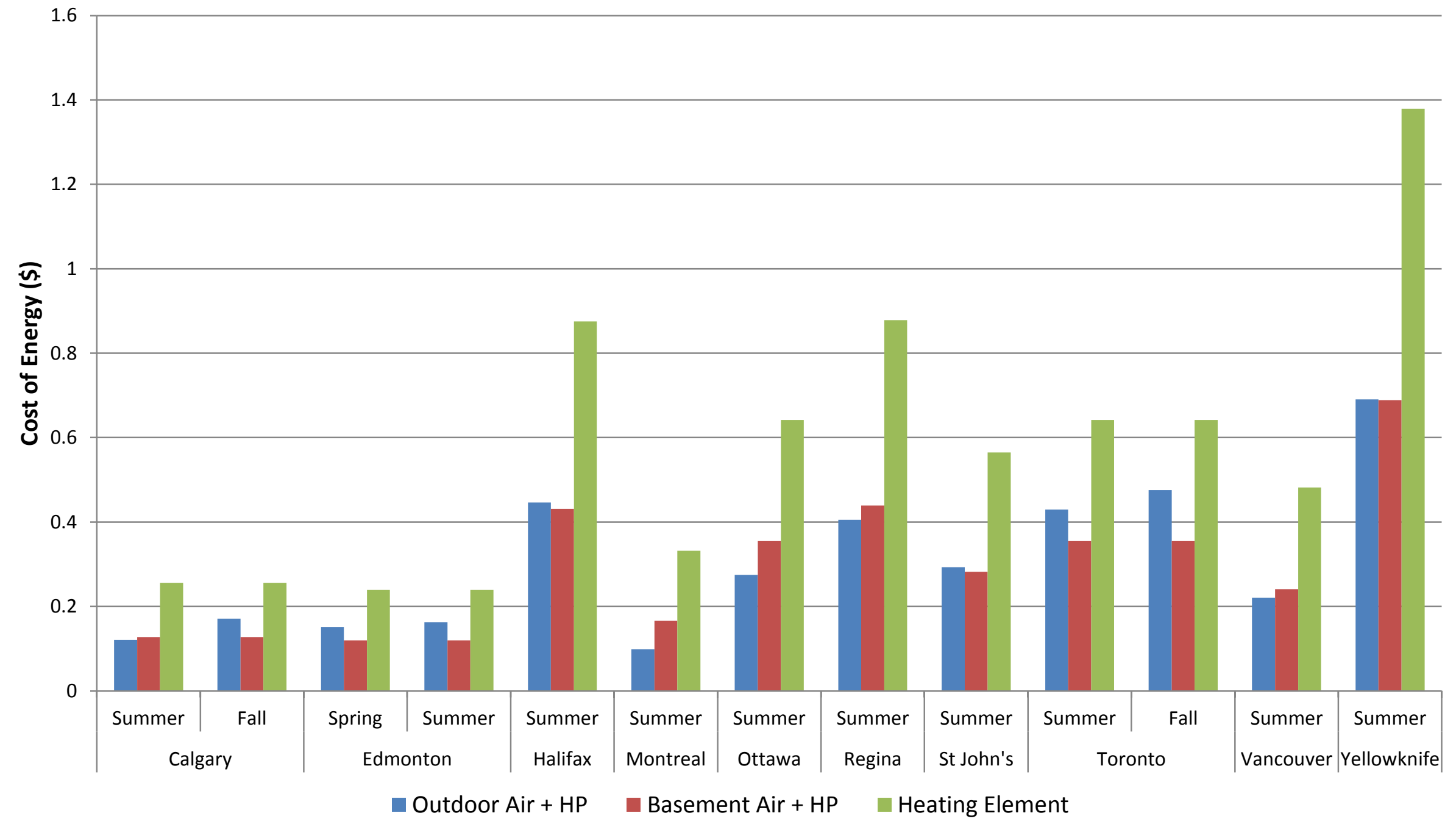

Figure 5-11: Comparing HPWH operating cost with outdoor air, basement air and resistance heaters 
Reduced energy costs were observed for Calgary, Montreal, Ottawa, Regina, and Vancouver in the summer when using outdoor air directed into the HPWH air intake. It can be seen from these results that the air temperature had a much larger effect on the performance of the HPWH than the air humidity. The results show that the HPWH benefitted from being ducted directly to the outdoor air when the outdoor air temperature was greater than the basement air temperature, thus out of the 10 cities analyzed, only the summer months of warmer climates had a lower daily cost of energy than the basement installation. It should be noted that the heating load of the building would increase with a HPWH installation. This increased heating load would result in a higher energy bill for the consumer. There were two other approaches to improving the COP of the HPWH that were further investigated. The first solution was to simply use the basement air as an intake if the basement is warmer than the outdoor air. The second solution was to install an HRV in the system, such that the heated fresh air exiting the HRV would be ducted to the intake of the HPWH. These approaches were modelled in TRNSYS.

\subsection{Modelling Results}

\subsubsection{Model Validation}

Two model validations were performed. The first model validation was performed by Khalaf [39], comparing the experimental and simulation results for charging and discharging of the water tank at laboratory air conditions. For the purposes of the research presented in this thesis, further validation of the heat pump model was 
performed. Khalaf's validation tests were performed at laboratory air conditions, which were relatively stable. Unlike Khalaf's work, the tests presented in this thesis varied the air temperature and humidity. Therefore the TRNSYS model was modified significantly, and the climate tests were used as a second validation.

Figure 5-12 shows the comparison between the water temperatures of the nodes in the tank and the power consumption of the heat pump for the Montreal summer test. It can be seen that the behavior of the water temperature profile of the tank generally agrees between the results, with the largest discrepancy occurring after the water draws. This is due to the fact that the water was drawn from Node 1 in the model. While this is also how the experimental setup functions, a jetting effect occurred during draws due to the high volume flow rate, which mixed the water, resulting in the top nodes having a lower temperature, and the bottom nodes having a higher temperature. This mixing rate was not quantified, thus was not accounted for in the model, but was minimized by reducing the water draw flow rate from $11.5 \mathrm{~L} / \mathrm{min}$ (as described in CSA-F379.1-88) to $3.8 \mathrm{~L} / \mathrm{min}$. 


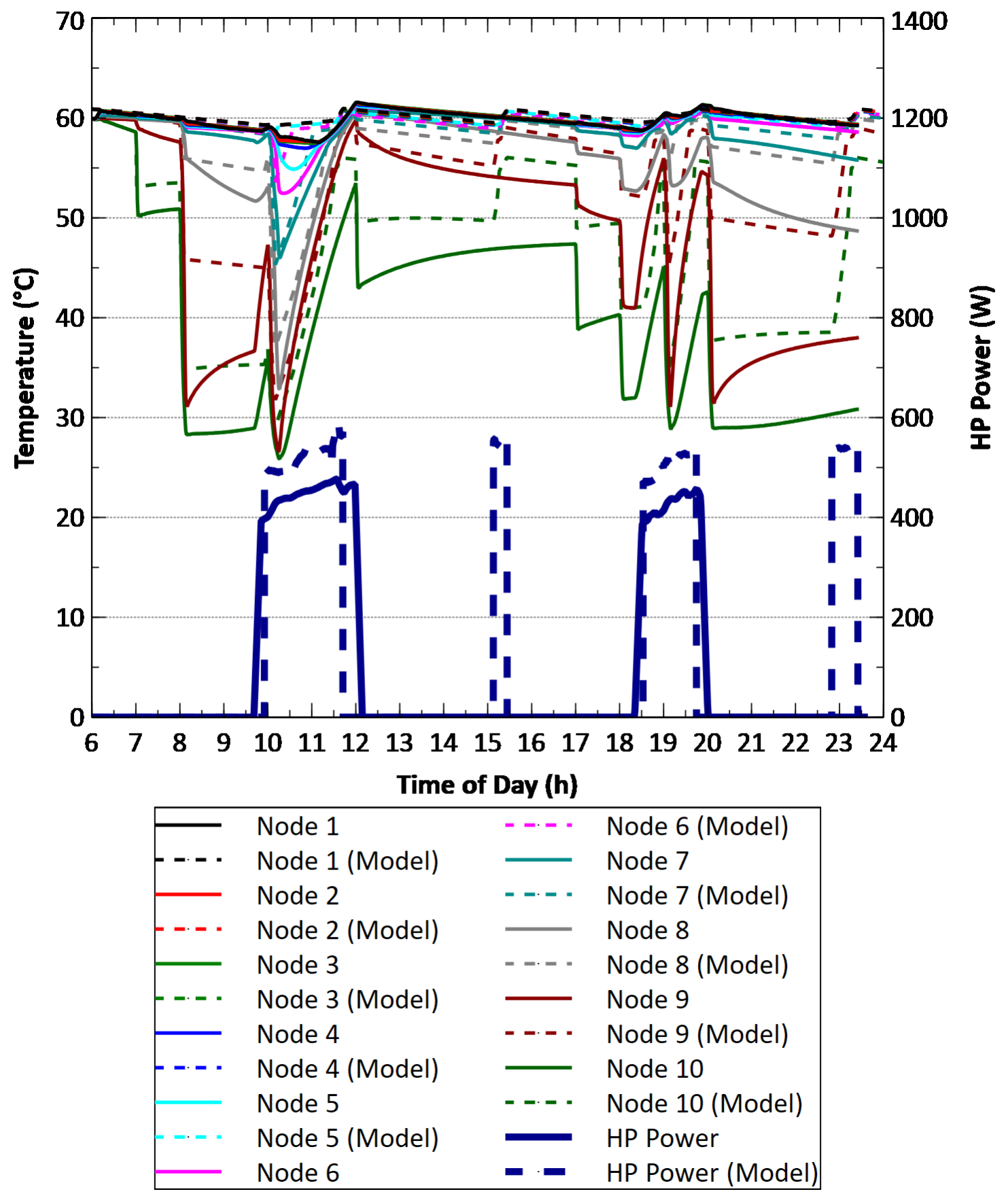

Figure 5-12: Comparison of water temperature and power consumption between the experiment and model for a Montreal summer day

Figure 5-13 shows the comparison between the model and the experiment for the cumulative heat delivery, energy consumed by the unit, CCOP, and cost of energy. At hour 10, it can be seen that there is a large decrease in the CCOP of the experimental 
results. This is caused by the fact that there is a water draw of $45 \mathrm{~L}$ while the heat pump is operating, and as a result, the water temperature is decreasing faster than it is increasing. The heat delivery is essentially 0 , while the HPWH energy consumption is non-zero, resulting in a large decrease of CCOP. Apart from this discrepancy, it can be seen that the results agree fairly well. Appendix D contains the additional validation plots for Ottawa, Regina, and Vancouver.

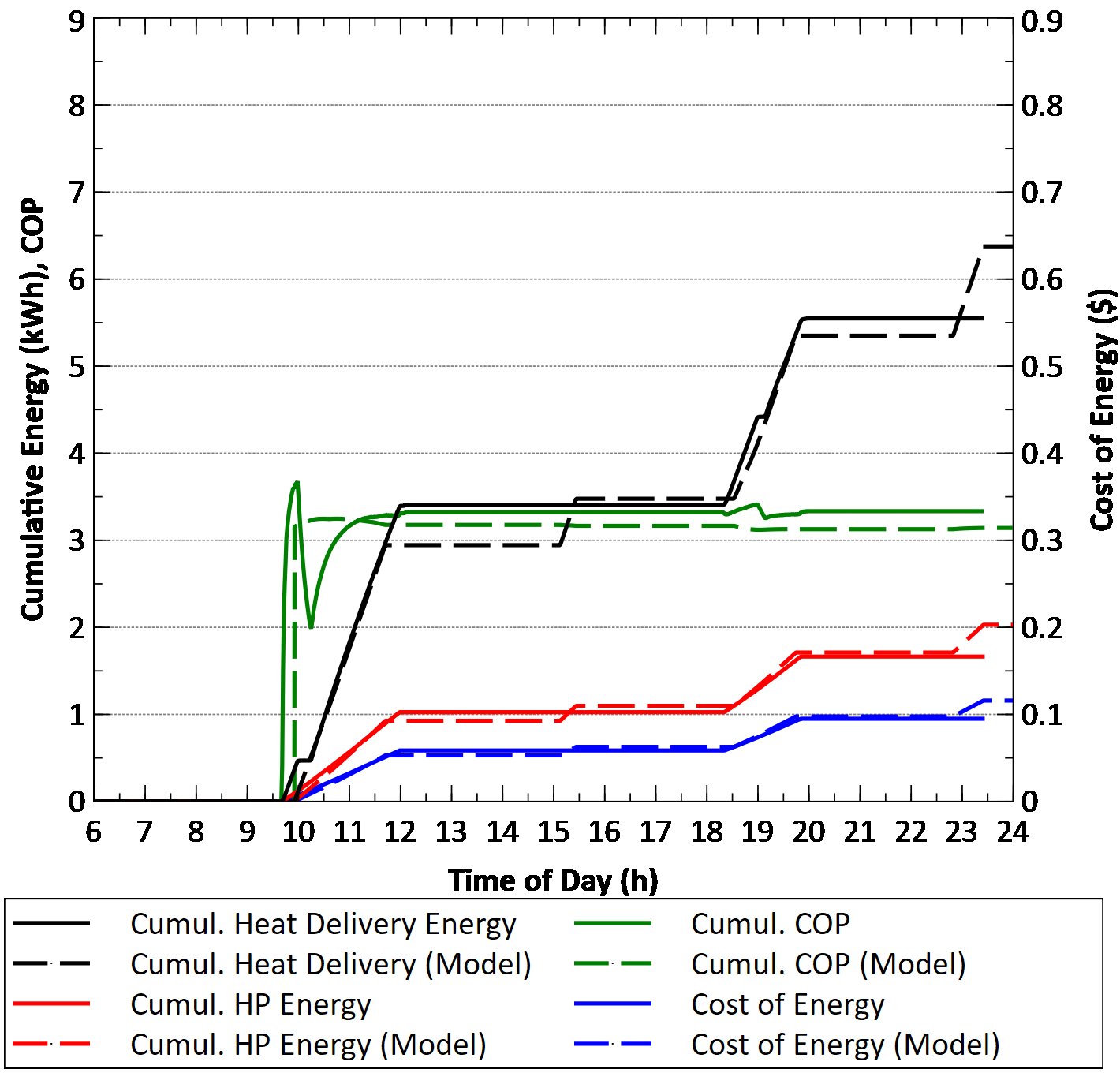

Figure 5-13: Comparison of cumulative energy, coefficient of performance, and cost of energy between the experiment and model for a Montreal summer day 


\subsubsection{HRV Comparison}

An HRV was included in the TRNSYS models to observe the benefits on the energy performance of the HPWH. Two different simulations were performed. The first simulation involved coupling a HRV with a HPWH for a representative day in Ottawa, Vancouver, Regina, and Montreal. The second involved an annual simulation of a home in each of these 4 cities, with a HPWH and HRV in various configurations.

\subsubsection{Preliminary Results for Coupling HRV with HPWH in Canadian Cities}

The Ottawa, Vancouver, Regina, and Montreal TRNSYS models were modified to include a HRV before the intake of the HPWH. The conditions of the house's exhaust air entering the HRV were extracted from a house model developed by Baldwin and Cruickshank [40] and Khalaf [39], discussed earlier in Section 4.6. The heat pump energy consumed, heat delivery, CCOP, and daily cost of energy were compared for a HPWH with and without an HRV, without including the heating or cooling loads. The results can be seen in Figure 5-14 and Figure 5-15. The Vancouver summer simulation was the only scenario that would benefit from the HRV, while the other scenarios observe a higher daily cost of energy. This was due to the fact that the simulations represented a summer day, so the HRV would pre-cool the air before it entered the HPWH, which decreased the COP of the HPWH system. Based on these results and observations, it was determined that another simulation should be conducted to compare the cost of energy, as well as the heating load, cooling load, and HPWH energy used over an entire year. 


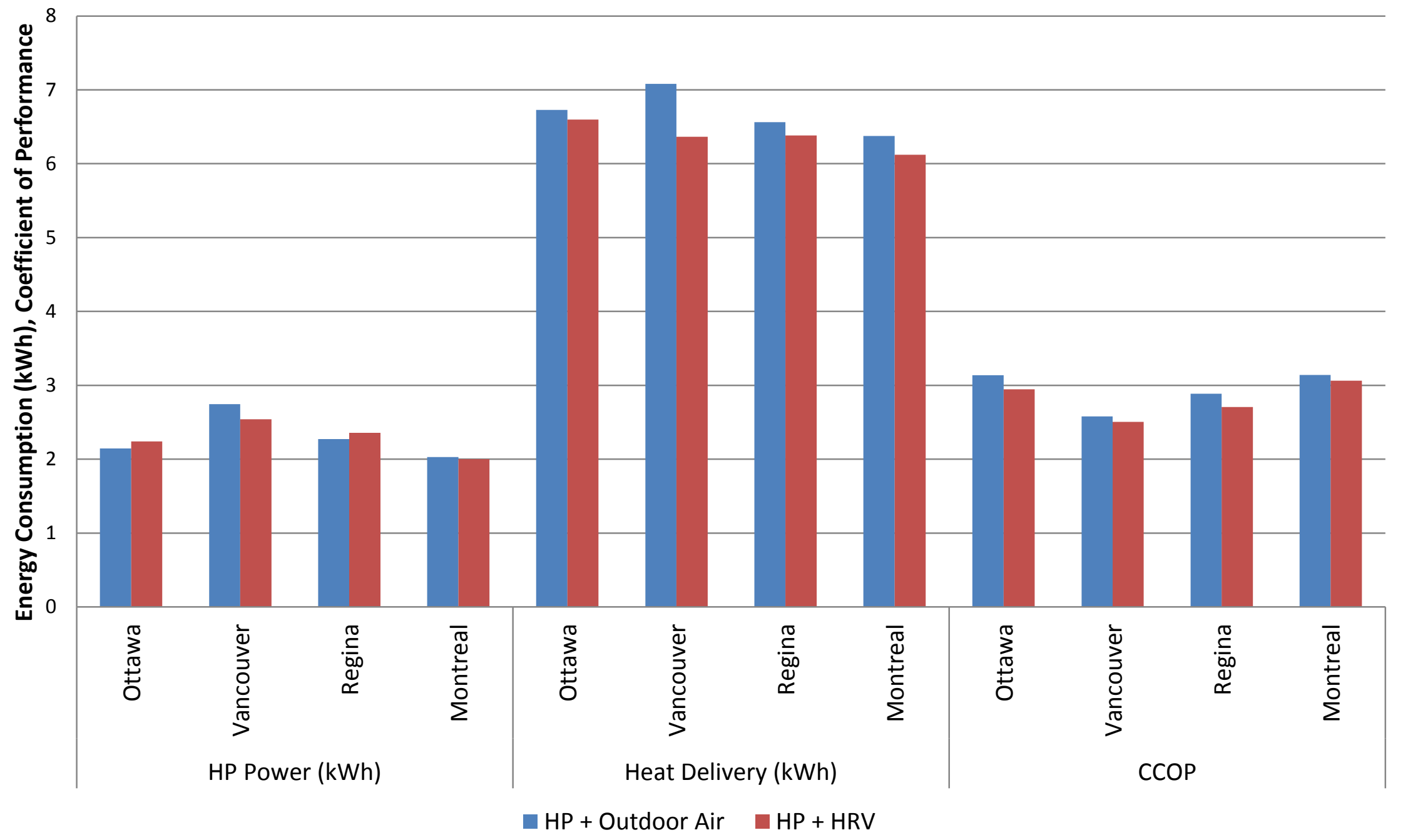

Figure 5-14: Comparing model results of the energy consumption of a HPWH with outdoor air and an HRV for different cities in the summer 


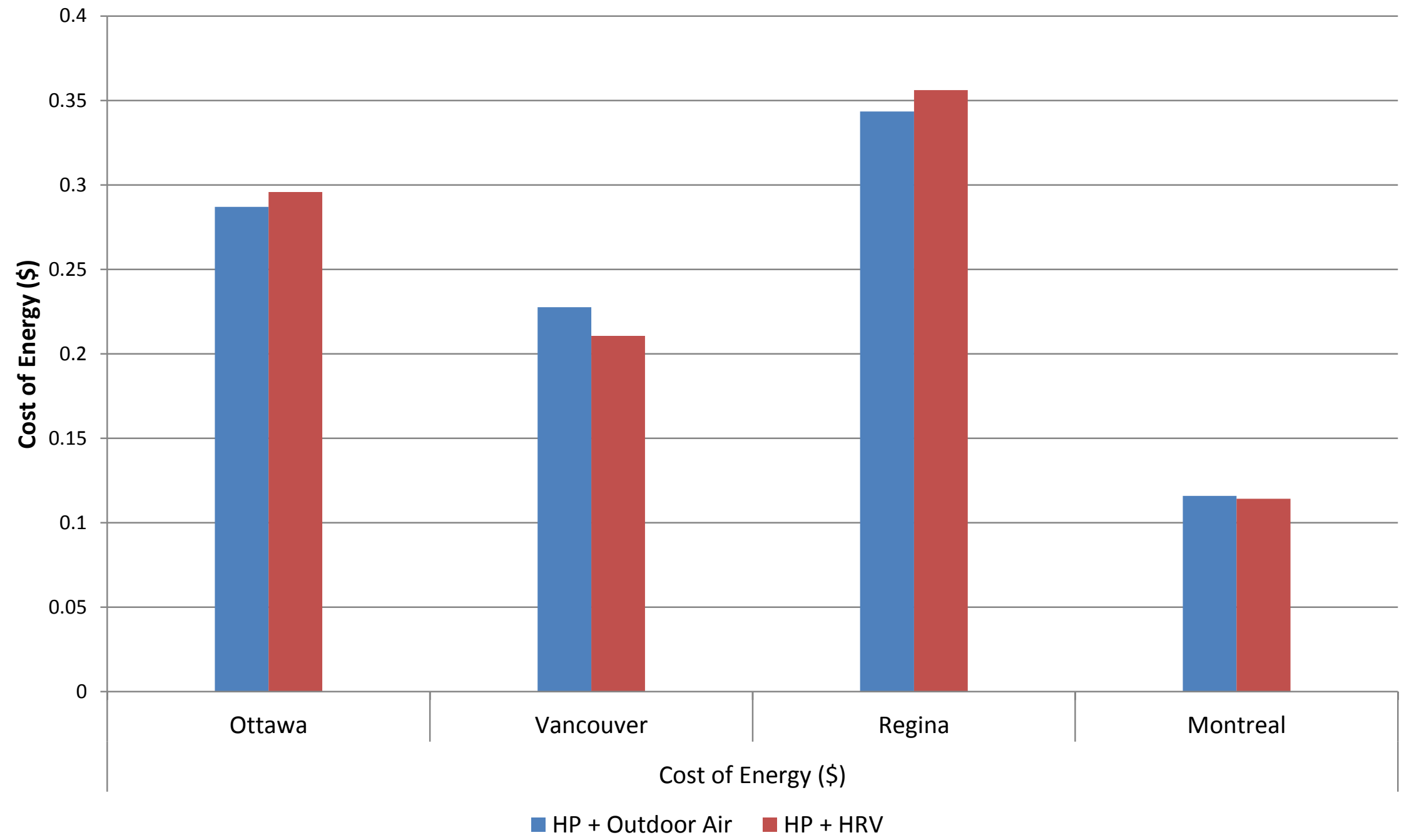

Figure 5-15: Comparing model results of the cost of a HPWH with outdoor air and an HRV for different cities in the summer 


\subsubsection{Benefits of an HRV in an Annual Simulation in Canadian Cities}

The house model developed by Khalaf [39] was further modified in the research presented in this thesis to include a HRV coupled to the HPWH. The revised model simulated five different scenarios for a home with a HPWH installed, summarized in Table 5-4. The first scenario had the HPWH installed with the intake and exhaust open to the basement air. The second scenario had the HPWH ducted to the outdoor air without an HRV. The third scenario had the HPWH ducted to an HRV, which was ducted to the outdoor air. The fourth scenario was the same as the third, except with a control implemented so that the HPWH compressor turned off when the intake air was below $7^{\circ} \mathrm{C}$, and the heating element was used instead. The fifth scenario used the higher temperature air between the basement air and the HRV air. The results of the simulations for Ottawa are shown in Table 5-5. The energy consumption of each component and the cost of energy are divided into the peak, mid-peak, and off-peak results for both the heating and cooling seasons. The cost of energy calculations were determined based on the heating, cooling, and HPWH loads, and do not include the plug loads, lighting loads, etc. of the building.

Table 5-4: Description of the annual simulation scenarios

\begin{tabular}{c|ccc}
\hline Scenario & Air Source for HPWH & $\begin{array}{c}\text { Temperature } \\
\text { Cutoff for HPWH }\end{array}$ & Notes \\
\hline $\mathbf{1}$ & Basement & N/A & - \\
$\mathbf{2}$ & Outdoor & N/A & - \\
$\mathbf{3}$ & HRV & N/A & - \\
$\mathbf{4}$ & HRV & $7^{\circ} \mathrm{C}$ & Used resistance element below \\
& HRV / Basement & N/A & Used the higher air temperature \\
$\mathbf{5}$ & between the HRV and basement \\
\hline
\end{tabular}


Table 5-5: Annual results comparing the energy consumption and cost of the Ottawa house models

\begin{tabular}{|c|c|c|c|c|c|c|c|c|}
\hline Scenario & Energy / Cost & $\begin{array}{c}\text { Cooling } \\
\text { Peak }\end{array}$ & $\begin{array}{c}\text { Heating } \\
\text { Peak }\end{array}$ & $\begin{array}{c}\text { Cooling } \\
\text { Mid }\end{array}$ & $\begin{array}{c}\text { Heating } \\
\text { Mid }\end{array}$ & $\begin{array}{c}\text { Cooling } \\
\text { Off }\end{array}$ & $\begin{array}{c}\text { Heating } \\
\text { Off }\end{array}$ & Total \\
\hline \multirow{5}{*}{1} & HPWH Energy (kWh) & 99 & 51 & 50 & 92 & 264 & 256 & 811 \\
\hline & Heating Load (kWh) & 26 & 2131 & 107 & 719 & 2670 & 13495 & 19148 \\
\hline & Cooling Load (kWh) & 912 & 0 & 299 & 0 & 418 & 0 & 1629 \\
\hline & Total Energy (kWh) & 1037 & 2182 & 455 & 811 & 3353 & 13751 & 21588 \\
\hline & $\begin{array}{l}\text { Total Cost of Energy } \\
\text { (\$) }\end{array}$ & 186.65 & 392.81 & 60.02 & 107.00 & 291.69 & 1196.31 & 2234.48 \\
\hline \multirow{5}{*}{2} & HPWH Energy (kWh) & 103 & 29 & 57 & 146 & 291 & 348 & 985 \\
\hline & Heating Load (kWh) & 33 & 2393 & 116 & 973 & 2796 & 14993 & 21305 \\
\hline & Cooling Load (kWh) & 935 & 0 & 309 & 0 & 439 & 0 & 1683 \\
\hline & Total Energy (kWh) & 1071 & 2422 & 483 & 1120 & 3526 & 15352 & 22974 \\
\hline & $\begin{array}{c}\text { Total Cost of Energy } \\
\text { (\$) }\end{array}$ & 192.85 & 435.96 & 63.75 & 147.81 & 306.75 & 1335.59 & 2482.71 \\
\hline \multirow{5}{*}{3} & HPWH Energy (kWh) & 90 & 41 & 66 & 113 & 258 & 321 & 889 \\
\hline & Heating Load (kWh) & 26 & 2182 & 108 & 776 & 2635 & 13829 & 19557 \\
\hline & Cooling Load (kWh) & 955 & 0 & 315 & 0 & 444 & 0 & 1714 \\
\hline & Total Energy (kWh) & 1071 & 2223 & 488 & 889 & 3337 & 14150 & 22159 \\
\hline & $\begin{array}{l}\text { Total Cost of Energy } \\
\text { (\$) }\end{array}$ & 192.79 & 400.17 & 64.45 & 117.39 & 290.33 & 1231.09 & 2296.21 \\
\hline \multirow{5}{*}{4} & HPWH Energy (kWh) & 88 & 147 & 69 & 165 & 259 & 581 & 1308 \\
\hline & Heating Load (kWh) & 26 & 2180 & 108 & 750 & 2643 & 13712 & 19418 \\
\hline & Cooling Load (kWh) & 954 & 0 & 314 & 0 & 444 & 0 & 1712 \\
\hline & Total Energy (kWh) & 1067 & 2327 & 491 & 915 & 3345 & 14293 & 22437 \\
\hline & $\begin{array}{l}\text { Total Cost of Energy } \\
\text { (\$) }\end{array}$ & 192.14 & 418.86 & 64.76 & 120.76 & 291.01 & 1243.46 & 2330.99 \\
\hline
\end{tabular}




\begin{tabular}{|c|c|c|c|c|c|c|c|c|}
\hline Scenario & Energy / Cost & $\begin{array}{c}\text { Cooling } \\
\text { Peak }\end{array}$ & $\begin{array}{l}\text { Heating } \\
\text { Peak }\end{array}$ & $\begin{array}{l}\text { Cooling } \\
\text { Mid }\end{array}$ & $\begin{array}{l}\text { Heating } \\
\text { Mid }\end{array}$ & $\begin{array}{c}\text { Cooling } \\
\text { Off }\end{array}$ & $\begin{array}{l}\text { Heating } \\
\text { Off }\end{array}$ & Total \\
\hline \multirow{5}{*}{5} & HPWH Energy (kWh) & 91 & 51 & 65 & 92 & 256 & 255 & 810 \\
\hline & Heating Load (kWh) & 26 & 2129 & 104 & 720 & 2624 & 13482 & 19086 \\
\hline & Cooling Load (kWh) & 955 & 0 & 315 & 0 & 445 & 0 & 1714 \\
\hline & Total Energy (kWh) & 1072 & 2180 & 485 & 812 & 3324 & 13737 & 21610 \\
\hline & $\begin{array}{l}\text { Total Cost of Energy } \\
\text { (\$) }\end{array}$ & 192.93 & 392.41 & 64.00 & 107.12 & 289.22 & 1195.16 & 2240.84 \\
\hline
\end{tabular}


Introducing an HRV in the Ottawa house slightly decreased the peak energy consumption of the HPWH, and increased its mid-peak consumption. The off-peak energy consumption of the HPWH decreased in the summer and increased in the winter, as the higher temperature in the summer increased the performance of the HPWH, consuming less energy, and vice-versa in the winter. This shift towards mid-peak usage insignificantly affected the annual cost of energy. Coupling the HPWH with a HRV increased the heating load in the winter, decreased the heating load in the summer, and increased the cooling load annually. As the summer season had an insignificant heating load, this lead to an overall increase in heating and cooling loads. This was possibly due to the HRV pre-cooling the incoming air in the summer, leading to the decreased performance of the HPWH, and colder exhaust air leaving the HPWH. The HRV also preheated the incoming air in the winter, increasing the performance of the HPWH, but the effect of the HPWH on the cooling load was not completely negated.

Scenarios 1 and 5 provide the lowest costs of energy, with Scenario 5 costing $\$ 6.40$ more annually. Scenario 5 had the highest installation cost, due to the addition of the HRV and controls. The cooling load was lowest in Scenario 1, and the heating load was the lowest in Scenarios 1 and 5. It was determined that the best case for minimizing cost, cooling and heating loads, and HPWH consumption was simply installing the HPWH in the basement without any ducting or HRV, as in Scenario 1. The annual house simulation was repeated for the remaining Canadian cities. The simulation results for all 10 cities are tabulated in Table 5-6. The annual energy consumption results are shown in Figure 5-16, while the annual cost of energy results are shown in Figure 5-17. 
Table 5-6: Annual house model results for each Canadian city

\begin{tabular}{|c|c|c|c|c|c|c|c|c|c|c|c|}
\hline Scenario & Energy / Cost & Ottawa & Toronto & Halifax & Vancouver & St. John's & Regina & Yellowknife & Montreal & Calgary & Edmonton \\
\hline \multirow{5}{*}{1} & HPWH (kWh) & 811 & 814 & 817 & 815 & 830 & 799 & 805 & 811 & 806 & 806 \\
\hline & Heating (kWh) & 19148 & 18025 & 17290 & 14077 & 20246 & 20151 & 32221 & 19027 & 19432 & 21789 \\
\hline & Cooling (kWh) & 1629 & 1575 & 1144 & 1511 & 784 & 2192 & 1478 & 1644 & 1865 & 1645 \\
\hline & Total (kWh) & 21588 & 20413 & 19251 & 16403 & 21860 & 23141 & 34504 & 21482 & 22103 & 24240 \\
\hline & Cost (\$) & 2234.48 & 2126.37 & 2109.97 & 1359.83 & 2124.59 & 3496.59 & 8184.29 & 1226.64 & 971.27 & 996.49 \\
\hline \multirow{5}{*}{2} & HPWH (kWh) & 985 & 981 & 933 & 982 & 1019 & 1003 & 1027 & 985 & 1002 & 1001 \\
\hline & Heating (kWh) & 21305 & 19930 & 19105 & 15197 & 22358 & 22801 & 35792 & 21147 & 21838 & 24368 \\
\hline & Cooling (kWh) & 1683 & 1626 & 1175 & 1539 & 790 & 2217 & 1453 & 1701 & 1866 & 1655 \\
\hline & Total (kWh) & 23974 & 22537 & 21213 & 17717 & 24167 & 26021 & 38272 & 23834 & 24705 & 27025 \\
\hline & Cost (\$) & 2482.71 & 2345.97 & 2371.78 & 1468.78 & 2348.75 & 3931.80 & 9078.19 & 1360.90 & 1085.61 & 1110.99 \\
\hline \multirow{5}{*}{3} & HPWH (kWh) & 889 & 882 & 878 & 835 & 897 & 895 & 935 & 886 & 877 & 911 \\
\hline & Heating (kWh) & 19557 & 18347 & 19249 & 14152 & 20633 & 20736 & 33261 & 19414 & 19928 & 22377 \\
\hline & Cooling (kWh) & 1714 & 1659 & 1211 & 1579 & 833 & 2267 & 1521 & 1733 & 1925 & 1711 \\
\hline & Total (kWh) & 22159 & 20888 & 21338 & 16565 & 22363 & 23897 & 35716 & 22033 & 22729 & 24999 \\
\hline & Cost (\$) & 2296.21 & 2178.57 & 2298.61 & 1373.28 & 2173.49 & 3610.87 & 8471.92 & 1258.08 & 998.79 & 1027.69 \\
\hline \multirow{5}{*}{4} & HPWH (kWh) & 1308 & 1018 & 941 & 835 & 946 & 1724 & 3135 & 1329 & 1445 & 1694 \\
\hline & Heating (kWh) & 19418 & 18310 & 17561 & 14152 & 20613 & 20388 & 32231 & 19237 & 18819 & 22032 \\
\hline & Cooling (kWh) & 1712 & 1659 & 1212 & 1579 & 833 & 2266 & 1521 & 1733 & 1931 & 1712 \\
\hline & Total (kWh) & 22437 & 20988 & 19714 & 16565 & 22392 & 24378 & 36887 & 22299 & 22195 & 25438 \\
\hline & Cost (\$) & 2330.99 & 2191.21 & 2229.42 & 1373.28 & 2176.26 & 3683.49 & 8749.61 & 1273.27 & 975.30 & 1045.74 \\
\hline \multirow{5}{*}{5} & HPWH (kWh) & 810 & 806 & 805 & 835 & 813 & 800 & 798 & 810 & 795 & 803 \\
\hline & Heating (kWh) & 19086 & 17955 & 17228 & 14152 & 20205 & 23139 & 35705 & 18958 & 23434 & 21746 \\
\hline & Cooling (kWh) & 1714 & 1660 & 1212 & 1579 & 834 & 1086 & 719 & 1734 & 738 & 1714 \\
\hline & Total (kWh) & 21610 & 20422 & 19244 & 16565 & 21851 & 25025 & 37222 & 21501 & 24968 & 24263 \\
\hline & Total Cost (\$) & 2240.84 & 2131.73 & 2169.67 & 1373.28 & 2123.75 & 3781.23 & 8829.04 & 1227.70 & 1097.15 & 997.45 \\
\hline
\end{tabular}




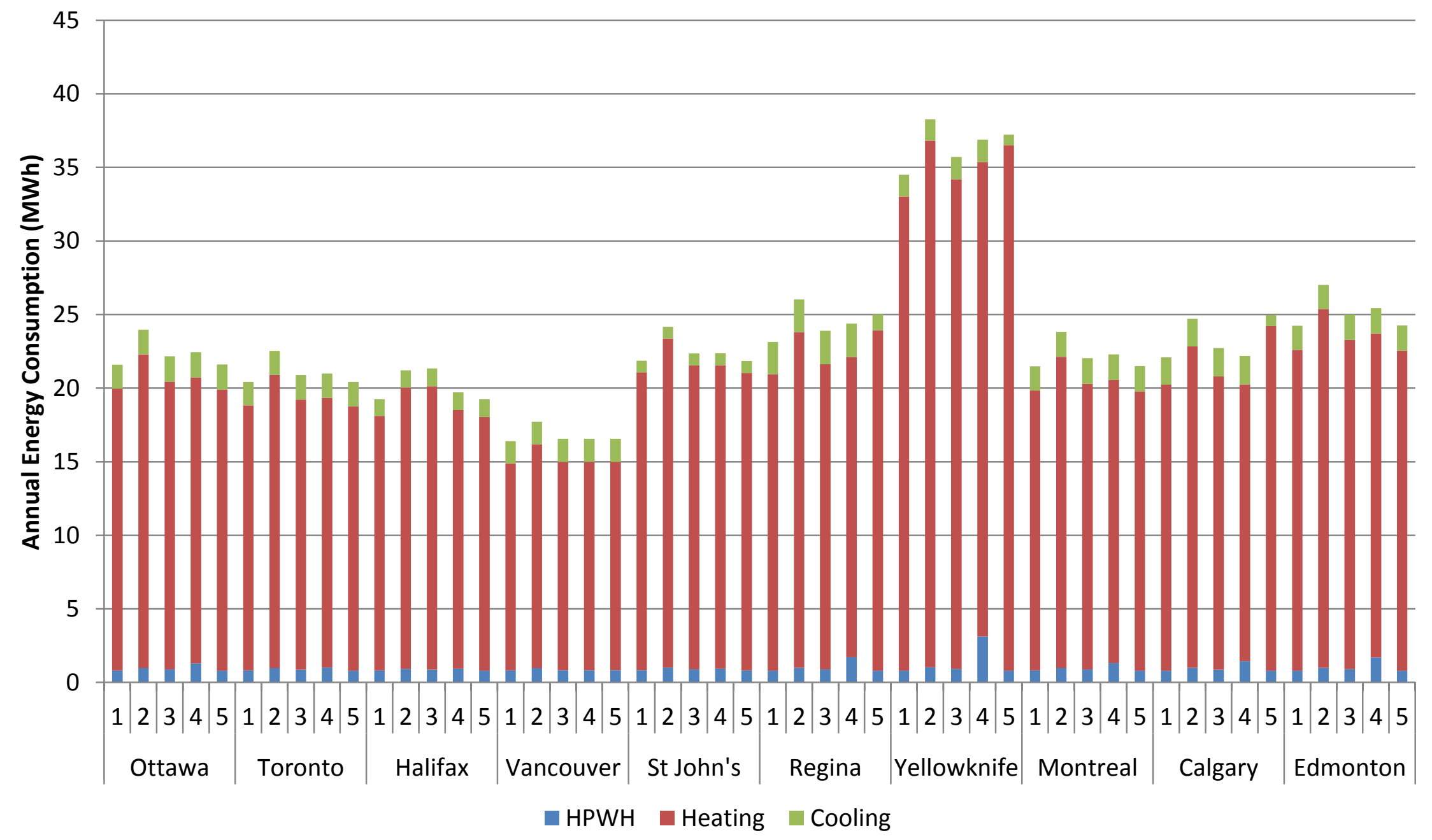

Figure 5-16: Annual energy consumption results for each Canadian city 


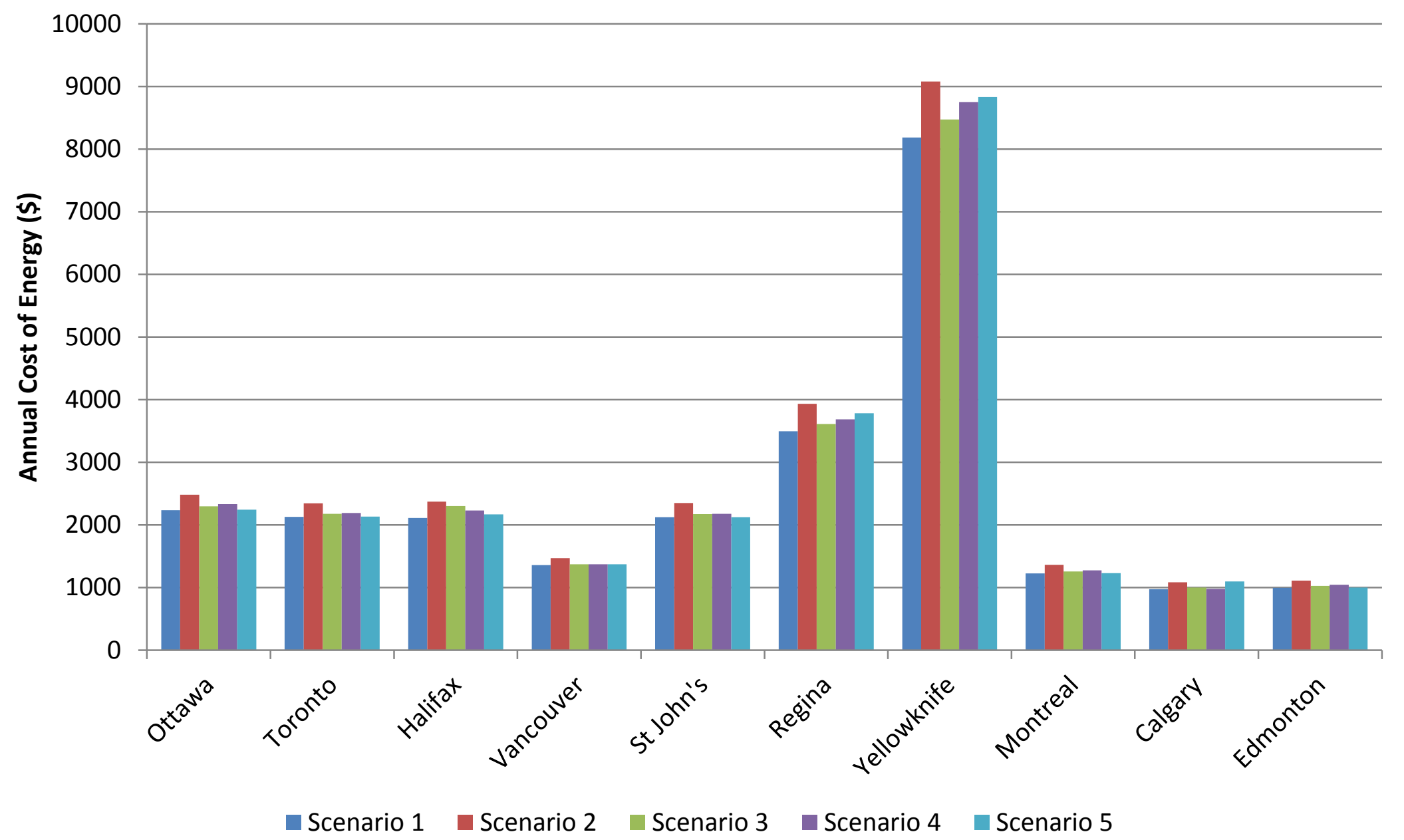

Figure 5-17: Annual energy cost results for each Canadian city 
It was observed in Table 5-6 that the energy consumption results for Montreal were quite similar to those of Ottawa for all five scenarios. This was expected, as these two cities are in the same climate. The annual costs of the two cities, however, were vastly different. This is due to the lower, flat utility rates in Montreal, and the higher, time-of-use rates implemented in Ottawa. For this reason, electricity is the dominant energy source in Quebec, while natural gas is the dominant energy source in Ontario.

The heating load clearly has the largest contribution to the annual electricity consumption. Generally, the scenario with the lowest heating load also has the lowest annual energy consumption in each city. The heating load increases between Scenarios 1 and 2 in all of the cities. This is because the outdoor air is colder than the basement or HRV air for the majority of the year, resulting in lower performance of the HPWH, and colder air being exhausted, ultimately raising the heating load to the house.

In Vancouver, it can be seen that the third, fourth, and fifth scenarios resulted in the exact same energy loads and costs. This was due to the fact that the air leaving the HRV was above the basement temperature throughout the whole year.

It can be seen that in Scenario 2, the HPWH energy and the annual heating load increased significantly in all 10 cities, while the annual cooling load typically increased marginally, when compared to the basement installation. As a result, Scenario 2 was the least efficient and most expensive option for all three energy loads.

For the third scenario, with an HRV without the $7^{\circ} \mathrm{C}$ HPWH cutoff, the HPWH energy, heating load, and cooling load all increased slightly from the basement installation results. As such, the annual cost of energy increased with the HRV. When 
the temperature cutoff was integrated into the controls of the HPWH and HRV in Scenario 4, similar results occur. The annual cost of energy was similar in Scenario 4 . In Halifax and Calgary, the heating load decreased from Scenario 3 to 4 . In every city except for Vancouver and St. John's, the HPWH energy increased significantly. This was due to the resistance heater activating when the air temperature leaving the HRV was too low. In Yellowknife, the HPWH energy consumption increase was significant, and resulted in a $\$ 300$ increase in the annual cost of energy.

For Scenario 5, the HPWH was coupled with the HRV, and the basement air was used to heat the water if it was warmer than the air leaving the HRV. The HPWH energy, heating load, cooling load, and cost of energy all remained similar to the first scenario. The exceptions to this were Regina, Yellowknife and Calgary. In Regina, the heating load was $3000 \mathrm{kWh}$ higher than Scenario 1, and the cooling load was $1100 \mathrm{kWh}$ lower. In Calgary, the heating load was $4000 \mathrm{kWh}$ higher than Scenario 1, and the cooling load was $1100 \mathrm{kWh}$ lower. In Yellowknife, the heating load was $3500 \mathrm{kWh}$ higher, and the cooling load was $700 \mathrm{kWh}$ lower than Scenario 1. The increased total annual energy leads to a significantly higher annual cost of energy in each of these cities.

In all of the cities except for St. John's, the basement installation of the HPWH had the lowest annual cost of energy. The fifth scenario had the second lowest cost of energy in most of these cities as well. In St. John's, the annual energy cost of Scenario 1 was only \$1 more than Scenario 5, which is insignificant. When considering the additional cost of the HRV and the control system, then the basement installation had the overall lowest annual cost of energy for all 10 cities based on these simulations. 


\section{Chapter: Conclusions and Future Work}

\subsection{Conclusions}

Heat pump water heaters are not recommended for use in all Canadian climates, due to the large variations in outdoor air temperature in many regions. It is important to note that due to the limitations of the experimental apparatus, the air conditions in the colder seasons could not be tested, thus the performance of the unit, which was determined experimentally, may be higher than in reality for the climates tested. It is also important to note that the utility rates of the tested regions will change over time, which would affect the total cost of energy. When HPWHs are compared to electric water heaters, the savings in energy cost can be significant, either when using outdoor air or basement air, based on the experimental results. It was found that ducting the outdoor air to the intake of the HPWH resulted in negligible or non-existent utility cost savings. Therefore, it is not worth the extra installation cost of the ducting when compared to installing the HPWH unit in the basement as-is. While a HPWH itself costs more than an electric water heater, the payback period will be within the life cycle of the unit in areas that have time-of-use energy billing. In regions such as Quebec, where the electricity rates are significantly lower, installing an electric water heater is more economically viable than a HPWH. A basement installation of the HPWH has a negligible effect on the annual cooling load compared to ducting the exhaust air outside.

The modelling results compared different installation scenarios of a HPWH in Canadian homes over the course of a year, including ducting the outdoor air to the intake of the unit, installing an $\mathrm{HRV}$, and controlling the unit to activate the electric 
elements in suboptimal conditions. Each of these modifications was shown to either increase or have an insignificant effect on the energy consumed by the HPWH, the heating load, the cooling load, and the annual cost of energy in most cities. In some climates, controlling the HPWH such that either the HRV air or basement air was used resulted in a slight decrease in utility costs. However, when considering the cost of the HRV installation and controls, the slightly lower utility costs were not sufficient to recommend the installation of the additional equipment. Therefore, it was concluded from these simulations that when purchasing a HPWH, installing the HPWH in the basement is the most economically viable option in most Canadian climates.

\subsection{Future Work}

The research in this thesis contributes to the knowledge of HPWHs in Canadian climates. As many regions have cold climates that are well outside of the testing range of the experiments, it is recommended that research is conducted on using a different refrigerant in the heat pump that is capable of operating under a lower temperature range. It is also recommended to install a heat rejection line filled with glycol in the AHU of the laboratory to achieve air temperatures below $10^{\circ} \mathrm{C}$ in the test setup. A HPWH using a different refrigerant coupled with outdoor air and an HRV may result in greater performance than a typical HPWH basement installation and is worth investigating. Given the TRNSYS model used in the research, which was based off of a performance map using data obtained experimentally, this refrigerant could not be simulated. It is 
recommended that a new model for a HPWH be developed from first principles and validated with multiple commercial units.

The performance of the HPWH may be increased by lowering the hot water setpoint. While this would lead to increased bacteria growth in the water tank, it is recommended to periodically increase the hot water set-point to $60^{\circ} \mathrm{C}$ to counteract the growth. This cycle could be performed overnight during off-peak times in regions with time-of-use utility rates to minimize the increased cost of energy to the user. This could result in an increased COP for the majority of the year, with occasional decreases in COP during the periods with increased water temperature. If this proves to be beneficial, it could be integrated in the controls of commercial HPWH units. Other methods that may lead to an increase in COP would be to duct waste heat from the building to the inlet of the HPWH or to prioritize heating the water during off-peak times in preparation for peak hot water draws. With these increases in performance and decreases in total cost of energy, the payback period of the HPWH would be lower and more appealing to consumers. In future work, it would be interesting to see an emphasis on the performance of the HPWH, rather than the total cost of energy. This is due to the fact that the utility rates presented in this research will change over time, and the performance of the unit relative to other climates would be more beneficial.

The experiments performed in this research used a humidifier that was incapable of reaching the high humidity set-points of summer climates. The effect of humidity on the HPWH performance was observed, however, the range of set-points was quite narrow compared to that of outdoor air, especially for a region with dry 
winters and humid summers such as Ottawa. This affected the model, as the performance map did not include these unattainable humidity levels. It is recommended that a humidifier with a greater water flow rate is installed to achieve these set-points. In addition, the performance map can be revised to include the moisture content of the air rather than the relative humidity. This would allow for the performance map to include data with higher humidity set-points at high temperatures. When implemented in the HPWH model, this would more accurately represent the performance of the unit at these high humidity levels, and the COP would be expected to increase.

A more detailed economic analysis should be performed, using the initial cost and salvage cost of HPWHs, electric water heaters, and natural gas boilers to determine the present value and payback period of each unit.

It is recommended to modify the house model to account for different building archetypes. Certain buildings may lead to a reduction in performance and increased heating loads, while others may see benefits when a HPWH is installed.

If research into coupling HPWHs with outdoor air and HRVs is continued, it is recommended to develop a control strategy to determine when to draw air from the HRV or the basement to optimize the performance of the unit and the cost of energy. 


\section{References}

[1] Natural Resources Canada, Energy Use Data Handbook - 1990 to 2013, Ottawa: Office of Energy Efficiency, 2013.

[2] Government of Canada, "The Government of Canada releases technical paper on pricing carbon pollution," 18 May 2017. [Online]. Available: https://www.canada.ca/en/environment-climatechange/news/2017/05/the_government_ofcanadareleasestechnicalpaperonpricin gcarbonpoll.html. [Accessed 5 June 2017].

[3] British Columbia, "Clean Energy Act," 31 May 2013. [Online]. Available: http://www.bclaws.ca/civix/document/id/consol24/consol24/00_10022_01.

[4] Manitoba Hydro, "Home Water Heating Costs," 2017.

[5] Natural Resources Canada, "Water Heater Guide," Office of Energy Efficiency, Ottawa, 2012.

[6] H. Willem, Y. Lin and A. Lekov, "Review of energy efficiency and system performance of residential heat pump water heaters," Energy and Buildings, vol. 143, pp. 191-201, 2017.

[7] Natural Resources Canada, "Heating and Cooling With a Heat Pump," Office of Energy Efficiency, Gatineau, 2004.

[8] Lowe's Canada, "Gas Water Heaters," [Online]. Available: https://www.lowes.ca/building-supplies/heating-cooling-ventilation/waterheaters/type/gas/. [Accessed 13 January 2017]. 
[9] Lowe's Canada, "Electric Water Heaters," [Online]. Available:

https://www.lowes.ca/building-supplies/heating-cooling-ventilation/waterheaters/type/electric/. [Accessed 13 January 2017].

[10] Hydro Québec, "Comparison of Electricity Prices in Major North American Cities," 2015.

[11] U.S. Department of Energy, "Heat Pump Water Heaters," [Online]. Available: https://energy.gov/energysaver/heat-pump-water-heaters. [Accessed 12 February 2016].

[12] Natural Resources Canada, "Heat Recovery Ventilators," Office of Energy Efficiency, Ottawa, 2012.

[13] L. G. Swan and V. I. Ugursal, "Modeling of end-use energy consumption in the residential sector: A review of modeling techniques," Renewable and Sustainable Energy Reviews, vol. 13, no. 8, pp. 1819-1835, 2009.

[14] A. Hepbasli and Y. Kalinci, "A review of heat pump water heating systems," Renewable and Sustainable Energy Reviews, vol. 13, no. 6-7, pp. 1211-1229, 2009.

[15] K. Belz, K. F. Werner, T. Schmidt, W. K. L. Ruck, F. Kuznik and L. F. Cabeza, "Chapter 17 - Thermal Energy Storage Systems for Heating and Hot Water in Residential Buildings," Woodhead Publishing, 2015.

[16] European Commission, "EU Energy in Figures - Statistical Pocketbook 2015," European Union, Belgium, 2015.

[17] U.S. Department of Energy, "Energy Conservation: Improving Energy Efficiency: 
Definition," in U.S.C. Title 42 - The Public Health and Welfare, U.S. Government Printing Office, 2010.

[18] U.S. Department of Energy, "Energy and Water Conservation Standards," in Code of Federal Regulations, U.S. Government Printing Office, 2015.

[19] B. Lévesque, M. Lavoie and J. Joly, "Residential water heater temperature: 49 or 60 degrees Celsius?," The Canadian Journal of Infectious Diseases, vol. 15, no. 1, pp. 11-12, 2004.

[20] A. S. Vieira, R. A. Stewart and C. D. Beal, "Air source heat pump water heaters in residential buildings in Australia: Identification of key performance parameters," Energy and Buildings, vol. 91, pp. 148-162, 2015.

[21] J. J. Guo, J. Y. Wu, R. Z. Wang and S. Li, "Experimental research and operation optimization of an air-source heat pump water heater," Applied Energy, vol. 88, no. 11, pp. 4128-4138, 2011.

[22] H. M. Group, "Energy Performance Analysis for Heat Pump Water," Pacific Gas and Electric Company, Gold River, CA, 2009.

[23] V. D. Baxter and R. L. Linkous, "Durability Testing Results: Oak Ridge National Laboratory Report - "Durability Testing of a Drop-In Heat Pump Water"," Oak Ridge National Laboratory, Oak Ridge, TN, 2002.

[24] C. Shapiro and S. Puttagunta, "Field Performance of Heat Pump Water Heaters in the Northeast," NREL, Golden, CO, 2016.

[25] J. Bursill and C. A. Cruickshank, "Heat Pump Water Heater Control Strategy 
Optimization for Cold Climates," Journal of Solar Energy Engineering, 2015.

[26] Health Canada, "Guidelines for Canadian Drinking Water Quality: Guideline Technical Document - Temperature," 1995. [Online]. Available:

https://www.canada.ca/en/health-canada/services/publications/healthyliving/guidelines-canadian-drinking-water-quality-guideline-technical-documenttemperature.html.

[27] J. Bursill, "Evaluation of Heat Pump Water Heater Performance and Optimization Strategies In Cold Climates," Carleton University, Ottawa, ON, 2015.

[28] E. P. Johnson, "Air-source heat pump carbon footprints: HFC impacts and comparison to other heat sources," Energy Policy, vol. 39, no. 3, pp. 1369-1381, 2011.

[29] Canadian Standards Association, "CAN/CSA-F379.1-88: Solar Domestic Hot Water Systems (Liquid to Liquid Heat Transfer)," Canadian Standards Association, Mississauga, ON, 2004.

[30] R. M. Dickinson, "Analysis and Development of Draw Strategies for a Multi-Tank Thermal Storage System for Solar Heating Applications," Carleton University, Ottawa, ON, 2012.

[31] C. A. Cruickshank, "Evaluation of a Stratified Multi-Tank Thermal Storage for Solar Heating Applications," Queen's University, Kingston, 2009.

[32] C. J. Banister, W. R. Wagar and M. R. Collins, "Validation of a Single Tank, Multimode Solar-assisted Heat Pump TRNSYS Model," Energy Procedia, vol. 48, pp. 299- 
504, 2014.

[33] J. Zhang, A. S. Fung and S. Jhingan, "Analysis and feasibility study of residential integrated heat and energy recover ventilator with built-in economizer using an excel spreadsheet program," Energy and Buildings, vol. 75, pp. 430-438, 2014.

[34] W. Yaïchi, M. Ghorab and E. Entchev, "Numerical analysis of heat and energy recovery ventilators performance based on CFD for detailed design," Applied Thermal Engineering, vol. 51, no. 1-2, pp. 770-780, 2013.

[35] L. Bao, J. Wang and H. Yang, "Investigation on the performance of a heat recovery ventilator in different climate regions in China," Energy, vol. 104, pp. 85-98, 2016.

[36] Thermal Energy System Specialists, LLC, "Getting Started," in TRNSYS 17 Manual, Madison, WI, 2012.

[37] Solar Energy Laboratory, University of Wisconsin-Madison, "Volume 3 - Standard Component Library Overview," in TRNSYS 17, Madison, WI, 2011.

[38] Thermal Energy Systems Specialists, LLC, "TESS Component Libraries: General Descriptions," Madison, WI, 2014, pp. 27, 52-53.

[39] K. Khalaf, "Experimental Characterization and Modelling of a Heat Pump Water Heater," Carleton University, Ottawa, 2017.

[40] C. Baldwin and C. A. Cruickshank, "Assessing the Potential for Reduction in Peak Residential Electrical Loads Using a Heat Pump and Thermal Storage Systems," in International High Performance Buildings Conference, West Lafeyette, IN, 2016.

[41] GE Appliances, "Technical Service Guide - GE Hybrid Water Heater," General 
Electric Company, Louisville, 2012.

[42] General Electric, "GeoSpring Hybrid Electric Residential Water Heaters," 2015.

[43] American Society of Heating, Refrigerating and Air-Conditioning Engineers, "Normative Appendix B - Building Envelope Criteria," in ANSI/ASHRAE/IESNA Standard 90.1-2007, Atlanta, American Society of Heating, Refrigerating and AirConditioning Engineers, 2007.

[44] EnergyPlus, "Weather Data by Region," [Online]. Available: https://energyplus.net/weatherregion/north_and_central_america_wmo_region_4/CAN\%20\%20. [Accessed 2 September 2016].

[45] C. Baldwin, "Design and Construction of an Experimental Apparatus to Assess the Performance of a Solar Absorption Chiller with Integrated Thermal Storage," Carleton University, Ottawa, 2011.

[46] R. S. Figliola and D. E. Beasley, Theory and Design for Mechanical Measurements, Danvers, MA: John Wiley \& Sons, 2011.

[47] Omega, "Revised Thermocouple Reference Tables," [Online]. Available: https://www.omega.ca/temperature/Z/pdf/z207.pdf. [Accessed 29 March 2017].

[48] National Instruments, "NI 9214 High-Accuracy Thermocouple Module," 24 September 2014. [Online]. Available: http://www.ni.com/datasheet/pdf/en/ds314. [Accessed 30 March 2017].

[49] Omega, HX94A Series RH/Temperature Transmitter User's Guide, Stamford, CT. 
[50] Badger Meter, Turbine Flow Meter: 1100 Series Turbine Meter, 2014.

[51] S. Tavoularis, Measurement in Fluid Mechanics, Cambridge University Press, 2005.

[52] F. C. McQuiston, J. D. Parker and J. D. Spitler, Heating, Ventilating, and Air Conditioning, Hoboken: John Wiley \& Sons, Inc., 2005.

[53] Vaisala, "Humidity conversion formulas," Vaisala Oyj, Helsinki, 2013.

[54] Home Ventilating Institute, "HRV/ERV Directory Listing," [Online]. Available: https://hvi-1491.quickbase.com/db/bh6688vwb?a=dr\&ifv=1\&rid=8247\&dfid=12. [Accessed 20 December 2016].

[55] Hydro Ottawa, "Time-of-Use," 2016. [Online]. Available: https://hydroottawa.com/accounts-and-billing/residential/time-of-use. [Accessed 9 January 2017].

[56] Nova Scotia Power, "Domestic Service Time-of-Day Tariff (Optional)," [Online]. Available: http://www.nspower.ca/en/home/about-us/electricity-rates-andregulations/rates/domestic-service-TOD.aspx. [Accessed 9 January 2017].

[57] BC Hydro, "Residential Rates," [Online]. Available: https://www.bchydro.com/accounts-billing/rates-energy-use/electricityrates/residential-rates.html. [Accessed 9 January 2017].

[58] Newfoundland Power Inc., "Schedule of Rates, Rules and Regulations," 2016.

[59] City of Saskatoon, "Electrical Rates," [Online]. Available: https://www.saskatoon.ca/services-residents/power-water/saskatoon-lightpower/electrical-rates. [Accessed 9 January 2017]. 
[60] Northland Utilities, "Yelloknife Bill Calculator Tool," [Online]. Available:

http://www.northlandutilities.com/Your-Electricity-Use/Bill-

Calculators/YECLBillCalculator. [Accessed 9 January 2017].

[61] Hydro Québec, "Domestic Rate for residential and farm customers," [Online].

Available: http://www.hydroquebec.com/residential/customer-space/accountand-billing/understanding-bill/residential-rates/rate-d.html. [Accessed 9 January 2017].

[62] Alberta Utilities Commission, "Electric rates and terms and conditions of service," [Online]. Available: http://www.auc.ab.ca/utility-sector/rates-andtariffs/Pages/MonthlyRegulatedRateOptionRates.aspx.

[63] Enbridge, "Residential Gas Rates - Purchasing Gas from Enbridge," [Online]. Available: https://www.enbridgegas.com/homes/accounts-billing/residential-gasrates/purchasing-gas-from-enbridge.aspx. [Accessed 9 January 2017].

[64] Ontario Energy Board, "Natural Gas Rates," [Online]. Available: http://www.ontarioenergyboard.ca/OEB/Consumers/Natural+Gas/Natural+Gas+R ates. [Accessed 9 January 2017].

[65] Fortis BC, "Mainland rates," [Online]. Available: https://www.fortisbc.com/NaturalGas/Homes/Rates/Mainland/Pages/default.asp x. [Accessed 9 January 2017].

[66] Ultramar, "Heating Oil," [Online]. Available: http://www.ultramarcst.ca/en/atlantic/heating/. [Accessed 9 January 2017]. 
[67] SaskEnergy, "Residential Rates Effective November 1, 2016," [Online]. Available: http://www.saskenergy.com/residential/resrates_curr.asp. [Accessed 9 January 2017].

[68] Statistics Canada, "Gasoline and fuel oil, average retail prices by urban centre (monthly) (Yellowknife)," [Online]. Available: http://www.statcan.gc.ca/tablestableaux/sum-som/I01/cst01/econ152r-eng.htm. [Accessed 9 January 2017].

[69] Alberta Utilities Commission, "Natural gas rates and terms and conditions of service," [Online]. Available: http://www.auc.ab.ca/utility-sector/rates-andtariffs/Pages/NaturalGas-RatesandTermsandConditionofService.aspx. [Accessed 9 January 2017].

[70] Natural Resources Canada, "Energy Sources - Average Retail Prices for Furnace Oil," [Online]. Available: http://www2.nrcan.gc.ca/eneene/sources/pripri/prices_bycity_e.cfm?PriceYear= 0\&ProductID=7\&LocationID=66,8,39,17\#PriceGraph. [Accessed 9 January 2017].

[71] O. O. Parish and T. W. Putnam, "Equations for the determination of humidity from dewpoint and psychrometric data," National Aeronautics and Space Administration, Washington D.C., 1977. 


\section{Appendices}

\section{Appendix A Utility Rates}

The time-of-use electricity rates for Ontario, effective as of November 1, 2016, are shown in Table A-1 [55]. The time-of-use electricity rates for Halifax, Nova Scotia, are shown in Table A-2 [56]. Note that weekends and statutory holidays are billed as offpeak hours. The flat rate electricity costs for all of the other Canadian cities that are discussed in this thesis are shown in Table A-3. The cost of electricity is compared to the cost of the primary heating source of each city in Table A-4.

Table A-1: Time-of-use electricity rates for Ontario [55]

\begin{tabular}{l|c|c}
\hline & \multicolumn{2}{|c}{ Electricity Cost (\$/kWh) } \\
\hline Time of Day & Nov 1 - Apr 30 & May 1 - Oct 31 \\
\hline 12am - 6am & 0.087 & 0.087 \\
7am - 10am & 0.18 & 0.132 \\
11am - 4pm & 0.132 & 0.18 \\
5pm - 6pm & 0.18 & 0.132 \\
$7 p m-11 p m$ & 0.087 & 0.087 \\
\hline
\end{tabular}


Table A-2: Time-of-use electricity rates for Halifax [56]

\begin{tabular}{c|c|c}
\hline & \multicolumn{2}{|c}{ Electricity Cost (\$/kWh) } \\
\hline Time of Day & Dec 1 - Feb 28 & Mar 1 - Nov 30 \\
\hline 12am - 6am & 0.08136 & 0.08136 \\
7am - 11am & 0.19421 & 0.15063 \\
12pm - 3pm & 0.15063 & 0.15063 \\
4pm - 10pm & 0.19421 & 0.15063 \\
11pm & 0.08136 & 0.08136 \\
\hline
\end{tabular}

Table A-3: Flat rate electricity costs for other Canadian cities

\begin{tabular}{c|c}
\hline City & Electricity Cost (\$/kWh) \\
\hline Vancouver [57] & 0.0829 \\
St John's [58] & 0.09719 \\
Regina [59] & 0.1511 \\
Yellowknife [60] & 0.2372 \\
Montreal [61] & 0.0571 \\
Calgary [62] & 0.043943 \\
Edmonton [62] & 0.04111 \\
\hline
\end{tabular}

Table A-4: Costs of electricity and primary heating sources of various Canadian cities

\begin{tabular}{c|c|c|c}
\hline City & $\begin{array}{c}\text { Cost of Electricity } \\
\text { (\$/GJ) }\end{array}$ & $\begin{array}{c}\text { Cost of Primary Heating } \\
\text { (\$/GJ) }\end{array}$ & Primary Heat Source \\
\hline Ottawa [63] & $24.17,36.67,50.00$ & 2.8076 & Natural Gas \\
Toronto [64] & $24.17,36.67,50.00$ & 2.8076 & Natural Gas \\
Vancouver [65] & 23.03 & 7.16 & Heating Oil \\
St John's [66] & 27.00 & 21.4947 & Neating Oil \\
Regina [67] & 41.97 & 3.65 & Heating Oil \\
Yellowknife [68] & 65.89 & 26.649 & Electricity \\
Montreal [61] & 15.86 & 15.86 & Natural Gas \\
Calgary [69] & 12.21 & 3.745 & Natural Gas \\
Edmonton [69] & 11.42 & 3.745 & Heating Oil \\
Halifax [70] & $22.60,41.84,53.95$ & 25.92 & \\
\hline
\end{tabular}




\section{Appendix B Calculating the Dew Point Temperature}

Equation B.1 is used to find the relative humidity of air if the dry bulb and dew point temperatures are known,

$$
R H\left(T, T_{\mathrm{d}}\right)=100\left(\left[\frac{T_{\mathrm{d}}+d}{T+d}\right]^{a} 10^{b\left[\left(T_{\mathrm{d}}+d\right)^{-1}-(T+d)^{-1}\right]}\right), \text { when } T_{\mathrm{d}}>0^{\circ} \mathrm{C}[\%]
$$

where $R H\left(T, T_{\mathrm{d}}\right)$ is the relative humidity, $T$ is the ambient dry bulb temperature of air, $T_{\mathrm{d}}$ is the dew point temperature, and $a, b$, and $d$ are constants [71]. The relative humidity and dry bulb temperature of air are the known quantities, and the dew point temperature of air is unknown. For metric units, when the dew point is above $0^{\circ} \mathrm{C}$, the constants are shown in Equation B.2 [71],

$$
\begin{gathered}
a=-4.9283 \\
b=-2937.4 \\
d=273
\end{gathered}
$$

Equation B.3 can then be rewritten to solve for $T_{d}$, if the dry bulb temperature and relative humidity of air are already known,

$$
\left(\frac{b}{a}\right) T_{\mathrm{d}}^{-1}+\log _{10} T_{\mathrm{d}}=\log _{10}\left(R H\left(T, T_{\mathrm{d}}\right)^{\frac{1}{a}} T\right)+\left(\frac{b}{a}\right) T^{-1}
$$

This equation was repeated iteratively in LabVIEW until the dew point temperature converged within $0.001^{\circ} \mathrm{C}$, which was the smallest interval allowed by the program. If the resulting dew point temperature was below $10^{\circ} \mathrm{C}$, then the dew point was unachievable with the experimental apparatus, due to the cooling coils being unable to cool the air below $10^{\circ} \mathrm{C}$. 


\section{Appendix C Performance Map Data}

Khalaf developed the performance map based on the HPWH used in this thesis [39]. Table C-1 shows the performance map data showing the effect of air temperature, air humidity, and water temperature on the total cooling capacity of the HPWH. Table C-2 shows the effect on the sensible cooling capacity, Table C-3 shows the effect on the compressor power consumption, and Table C-4 shows the effect on the heat delivery of the HPWH.

It can be seen that increasing the supply air temperature increased the total cooling capacity, sensible cooling capacity, and heat delivery. The compressor power increased with higher supply air temperatures, but above $30^{\circ} \mathrm{C}$, the power decreased. As the water temperature increased, the total cooling capacity, sensible cooling capacity, and heat delivery typically decreased, while the compressor power typically increased. As the supply air humidity increased, it negligibly affected the total cooling capacity and sensible cooling capacity, while increasing the compressor power between a supply air temperature of $20^{\circ} \mathrm{C}$ and $30^{\circ} \mathrm{C}$, and increasing the heat delivery at a supply air temperature of $40^{\circ} \mathrm{C}$. 
Table C-1: Total cooling capacity (W) as a function of air temperature, air humidity, and water temperature [39]

\begin{tabular}{|c|c|c|c|c|c|c|c|c|c|c|}
\hline & & & & \multicolumn{7}{|c|}{ Water Temperature $\left({ }^{\circ} \mathrm{C}\right)$} \\
\hline & & & & 10 & 20 & 30 & 40 & 50 & 60 & 70 \\
\hline \multirow{8}{*}{ 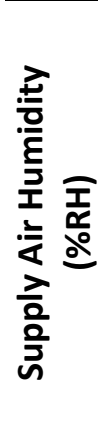 } & \multirow{4}{*}{ 오 } & \multirow{8}{*}{ 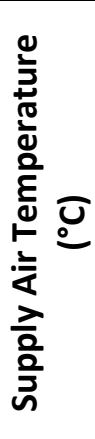 } & 10 & 786.99 & 744.87 & 702.75 & 660.64 & 618.52 & 576.40 & 534.29 \\
\hline & & & 20 & 1380.76 & 1296.51 & 1212.26 & 1128.01 & 1043.76 & 959.51 & 875.26 \\
\hline & & & 30 & 1820.33 & 1671.76 & 1523.19 & 1374.63 & 1226.06 & 1077.50 & 928.93 \\
\hline & & & 40 & 3002.50 & 2901.02 & 2799.53 & 2698.07 & 2596.59 & 2495.12 & 2393.64 \\
\hline & & & 10 & 759.37 & 724.39 & 689.41 & 654.44 & 619.46 & 584.48 & 549.50 \\
\hline & 0 & & 20 & 1335.88 & 1269.10 & 1202.32 & 1135.54 & 1068.76 & 1001.98 & 935.19 \\
\hline & $m$ & & 30 & 1710.94 & 1627.23 & 1543.52 & 1459.82 & 1376.11 & 1292.41 & 1208.70 \\
\hline & & & 40 & 3016.13 & 2925.36 & 2834.58 & 2743.81 & 2653.03 & 2562.26 & 2471.48 \\
\hline
\end{tabular}

Table C-2: Sensible cooling capacity (W) as a function of air temperature, air humidity, and water temperature [39]

\begin{tabular}{|c|c|c|c|c|c|c|c|c|c|c|}
\hline & & & & \multicolumn{7}{|c|}{ Water Temperature $\left({ }^{\circ} \mathrm{C}\right)$} \\
\hline & & & & 10 & 20 & 30 & 40 & 50 & 60 & 70 \\
\hline \multirow{8}{*}{ 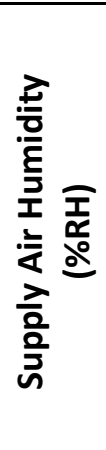 } & \multirow{4}{*}{ 유 } & \multirow{8}{*}{ 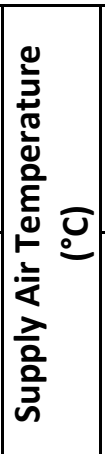 } & 10 & 759.10 & 716.99 & 674.87 & 632.76 & 590.64 & 548.52 & 506.41 \\
\hline & & & 20 & 1253.94 & 1169.69 & 1085.44 & 1001.19 & 916.94 & 832.69 & 748.44 \\
\hline & & & 30 & 1707.24 & 1558.67 & 1410.11 & 1261.54 & 1112.97 & 964.41 & 815.84 \\
\hline & & & 40 & 1957.47 & 1855.99 & 1754.52 & 1653.04 & 1551.57 & 1450.09 & 1348.62 \\
\hline & & & 10 & 727.74 & 692.77 & 657.79 & 622.81 & 587.83 & 552.86 & 517.88 \\
\hline & 0 & & 20 & 1318.00 & 1251.22 & 1184.44 & 1117.66 & 1050.88 & 984.09 & 917.31 \\
\hline & $\bar{m}$ & & 30 & 1543.74 & 1460.03 & 1376.33 & 1292.62 & 1208.92 & 1125.21 & 1041.51 \\
\hline & & & 40 & 1999.25 & 1908.48 & 1817.70 & 1726.93 & 1636.15 & 1545.38 & 1454.60 \\
\hline
\end{tabular}


Table C-3: Compressor power (W) as a function of air temperature, air humidity, and water

temperature [39]

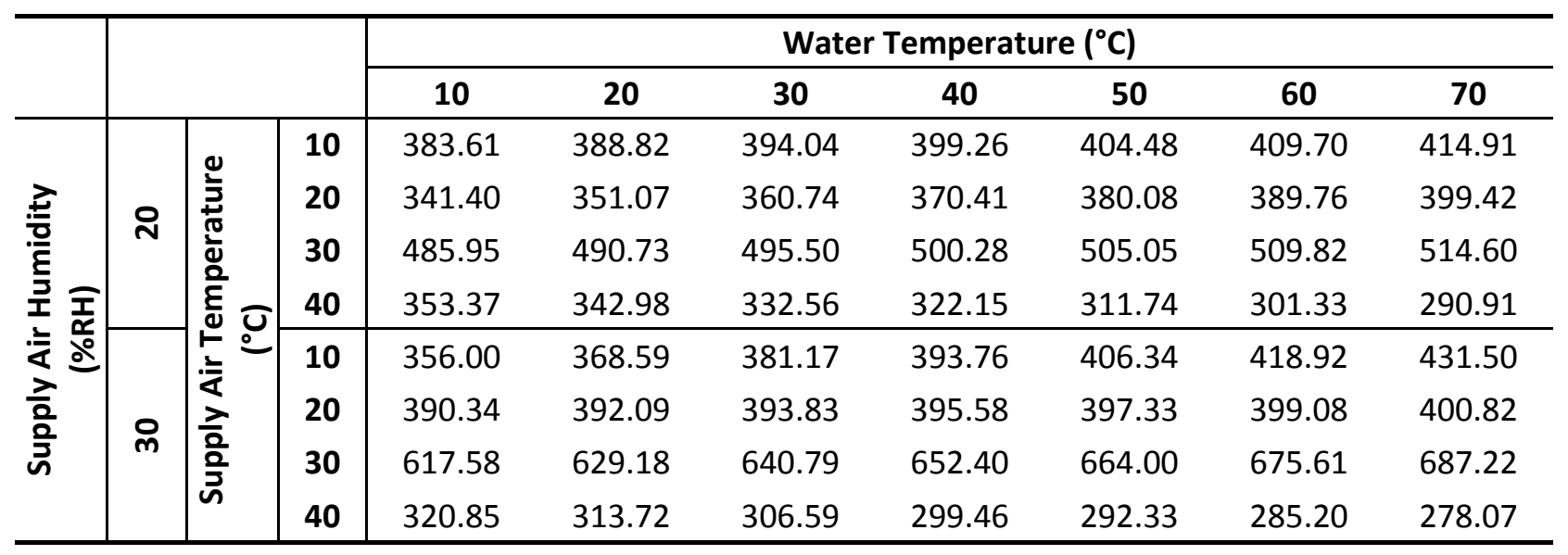

Table C-4: Heat delivery (W) as a function of air temperature, air humidity, and water temperature [39]

\begin{tabular}{|c|c|c|c|c|c|c|c|c|c|c|}
\hline & & & & \multicolumn{7}{|c|}{ Water Temperature $\left({ }^{\circ} \mathrm{C}\right)$} \\
\hline \multirow{9}{*}{ 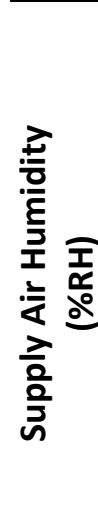 } & & & & 10 & 20 & 30 & 40 & 50 & 60 & 70 \\
\hline & \multirow{4}{*}{ 오 } & \multirow{8}{*}{ 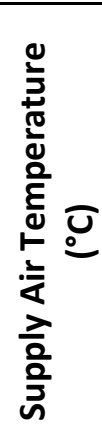 } & 10 & 1514.88 & 1429.52 & 1344.15 & 1258.78 & 1173.42 & 1088.05 & 1002.68 \\
\hline & & & 20 & 2229.65 & 2136.06 & 2042.46 & 1948.86 & 1855.26 & 1761.67 & 1668.07 \\
\hline & & & 30 & 2424.80 & 2275.13 & 2125.46 & 1975.78 & 1826.11 & 1676.44 & 1526.77 \\
\hline & & & 40 & 2306.62 & 2206.41 & 2106.2 & 2005.99 & 1905.78 & 1805.57 & 1705.36 \\
\hline & & & 10 & 1540.39 & 1443.69 & 1346.99 & 1250.29 & 1153.61 & 1056.90 & 960.20 \\
\hline & 0 & & 20 & 1983.86 & 1894.47 & 1805.08 & 1715.68 & 1626.29 & 1536.90 & 1447.51 \\
\hline & m & & 30 & 2265.45 & 2143.12 & 2020.79 & 1898.46 & 1776.12 & 1653.79 & 1531.46 \\
\hline & & & 40 & 2782.06 & 2666.06 & 2550.06 & 2434.07 & 2318.07 & 2202.07 & 2086.08 \\
\hline
\end{tabular}




\section{Appendix D Climate Test and Modelling Data}

Figure D-1 through Figure D-22 show the climate test results. Each test used climate data representative of Canadian cities. Figure D-23 through Figure D-28 show the model validation results for Ottawa, Regina, and Vancouver, comparing the experimental results to those of the TRNSYS model. These were used to determine the performance and electric costs in each climate, as discussed in Section 5.3.

\section{D.1 Additional Climate Test Data}

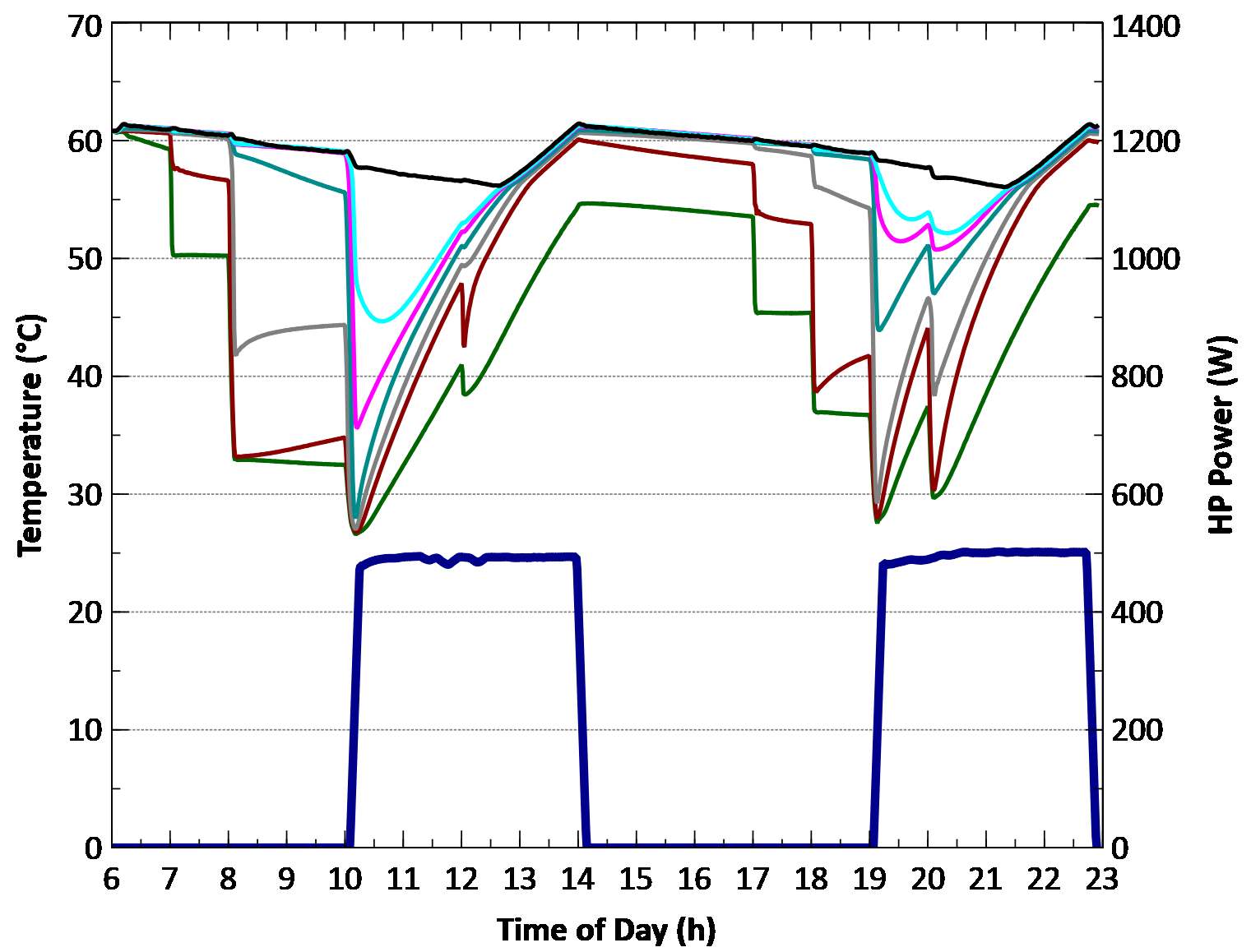

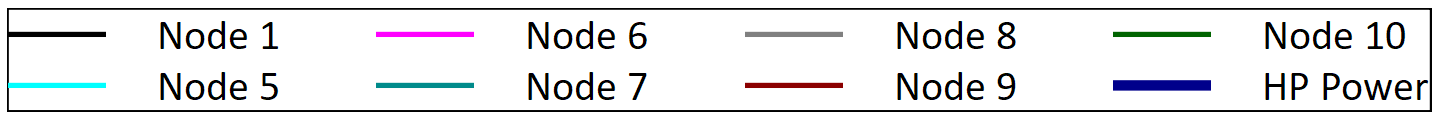

Figure D-1: Temperature and power consumption at $10^{\circ} \mathrm{C}$ without humidification 


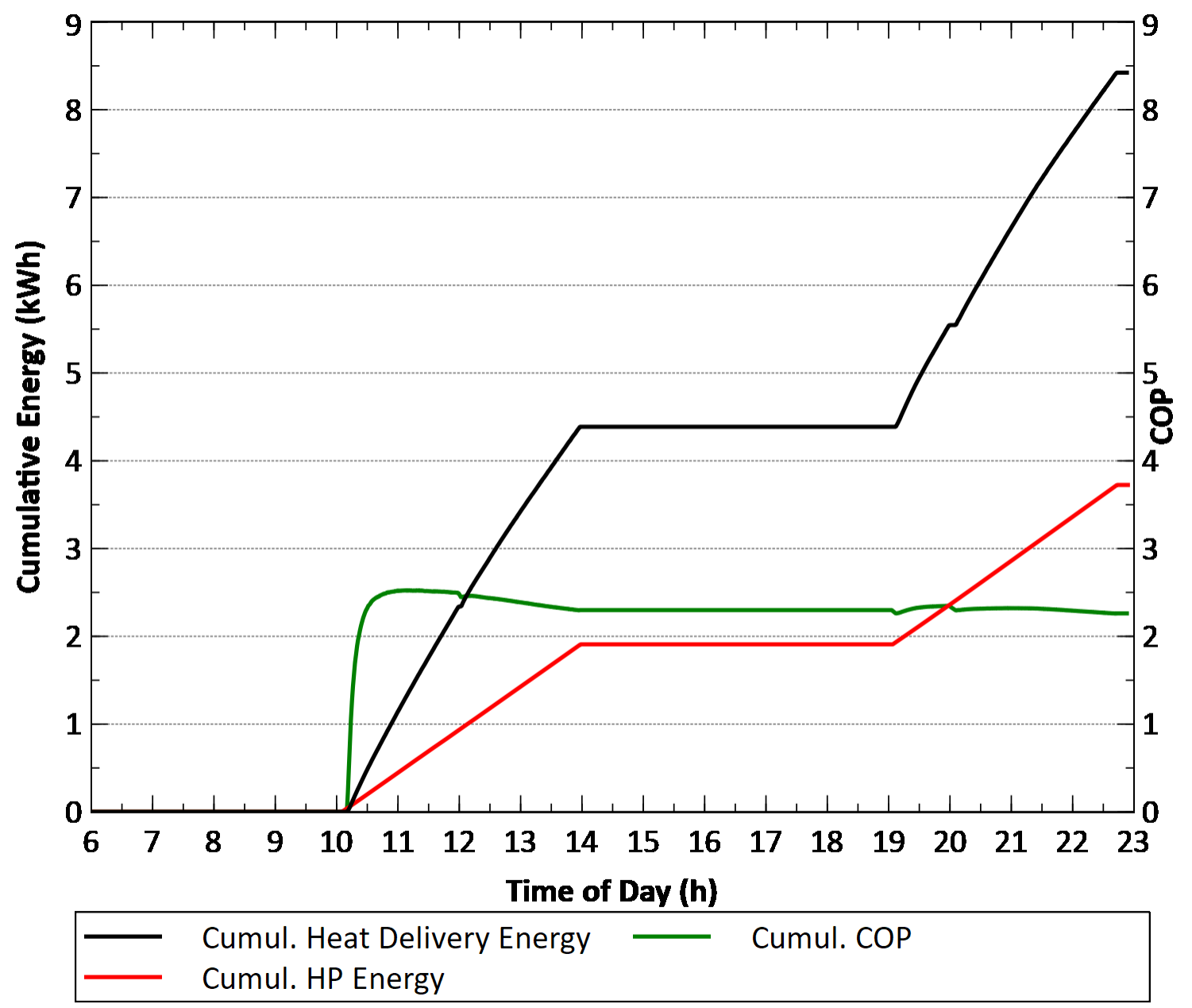

Figure D-2: Cumulative energy and COP at $10^{\circ} \mathrm{C}$ without humidification 


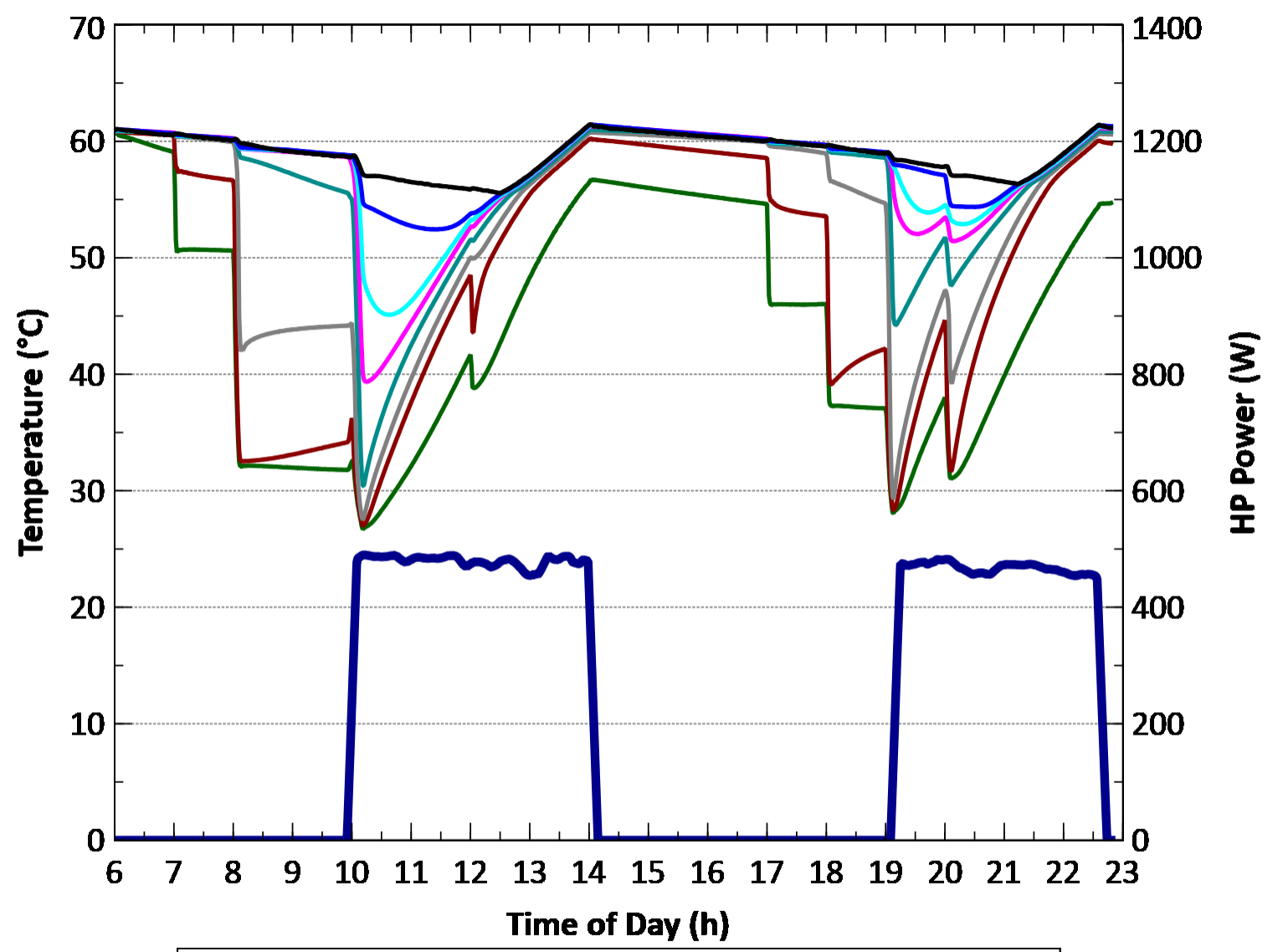

\begin{tabular}{|lllll|}
\hline & Node 1 \\
Node 4 \\
Node 5
\end{tabular}$-\begin{gathered}\text { Node } 6 \\
\text { Node } 7 \\
\text { Node } 8\end{gathered} \quad \begin{aligned} & \text { Node } 9 \\
& \text { Node 10 } \\
& \text { HP Power }\end{aligned}$

Figure D-3: Temperature and power consumption at $10^{\circ} \mathrm{C}$ with humidification 


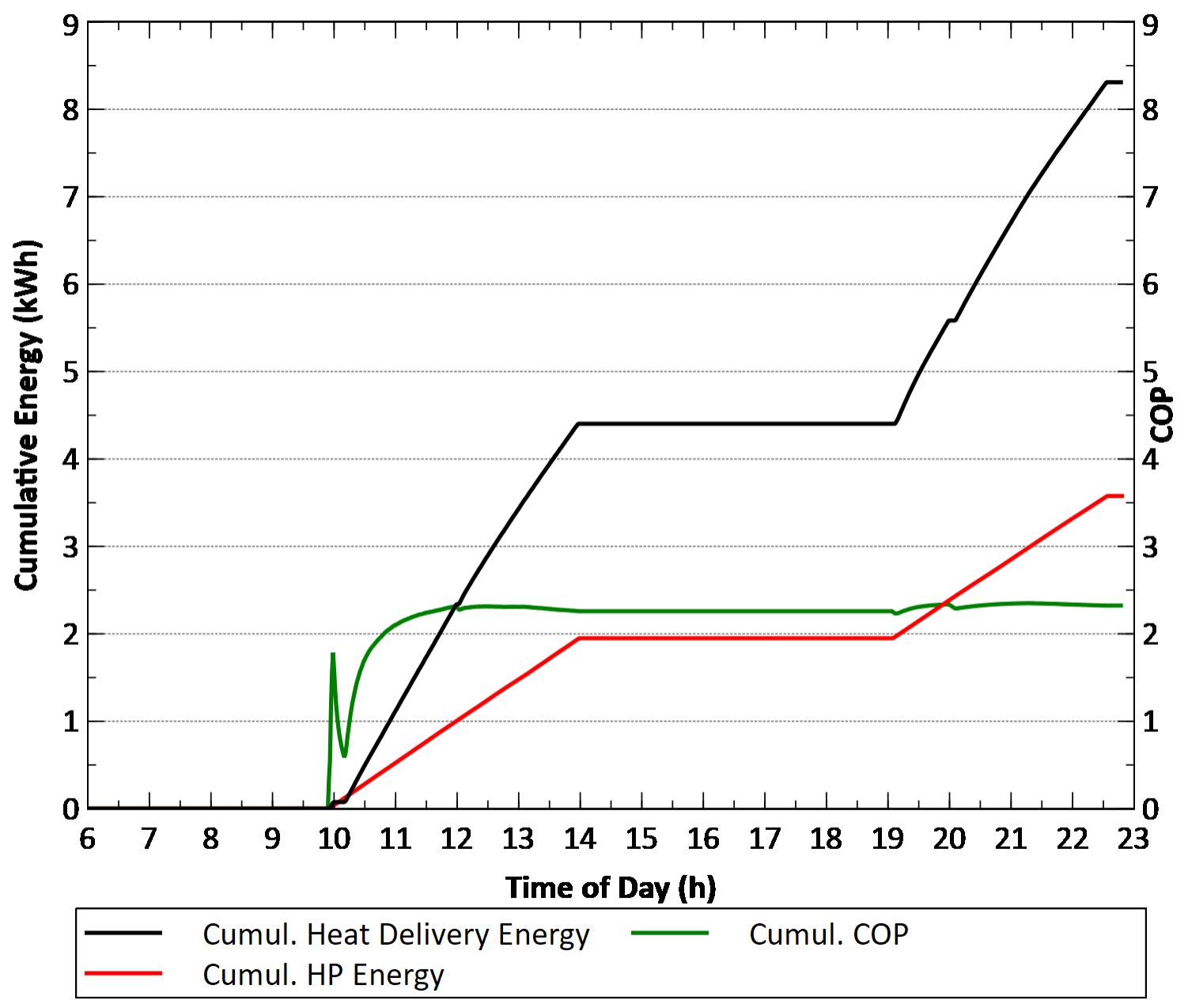

Figure D-4: Cumulative energy and COP at $10^{\circ} \mathrm{C}$ with humidification 


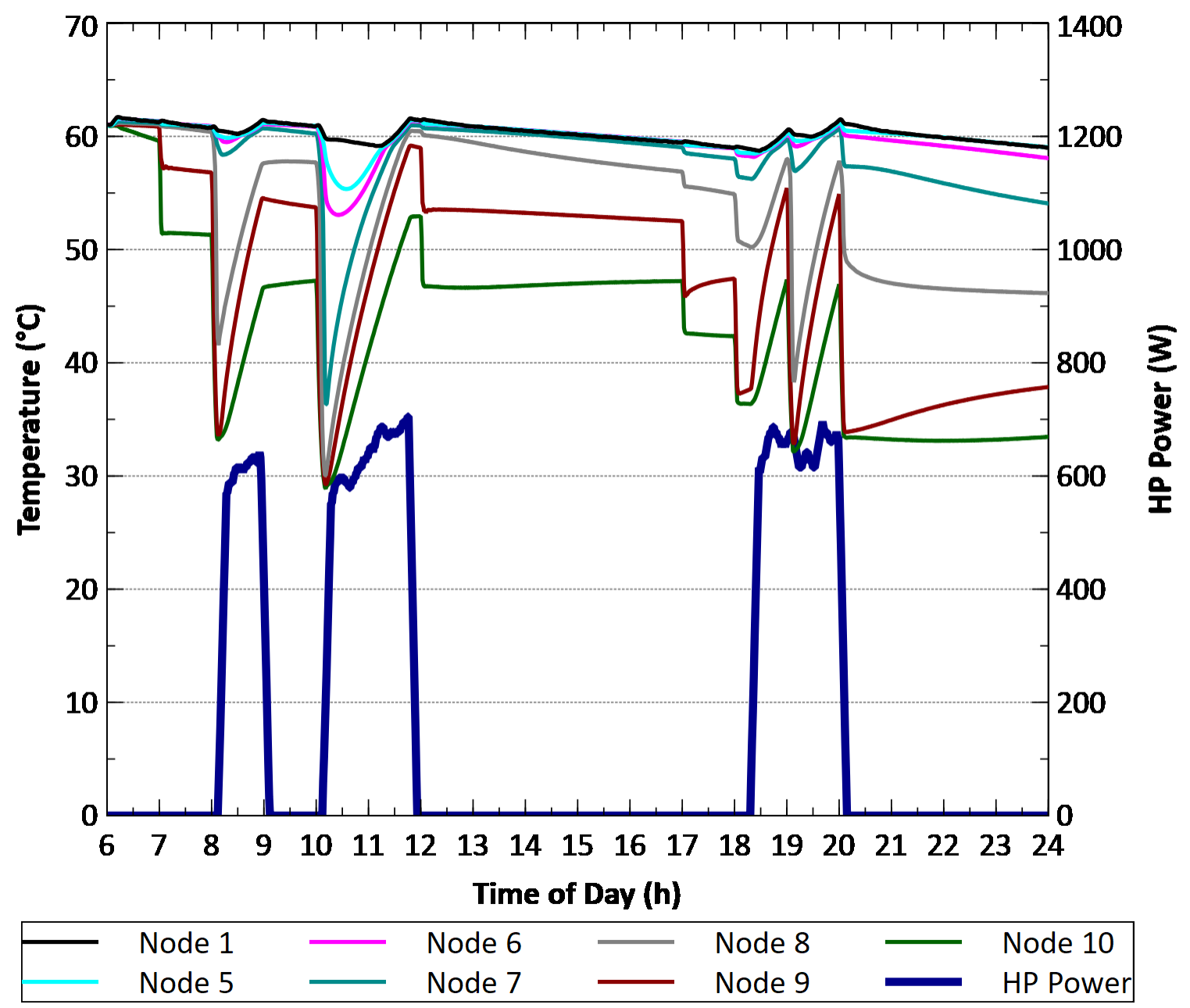

Figure D-5: Temperature and power consumption for a Calgary summer day 


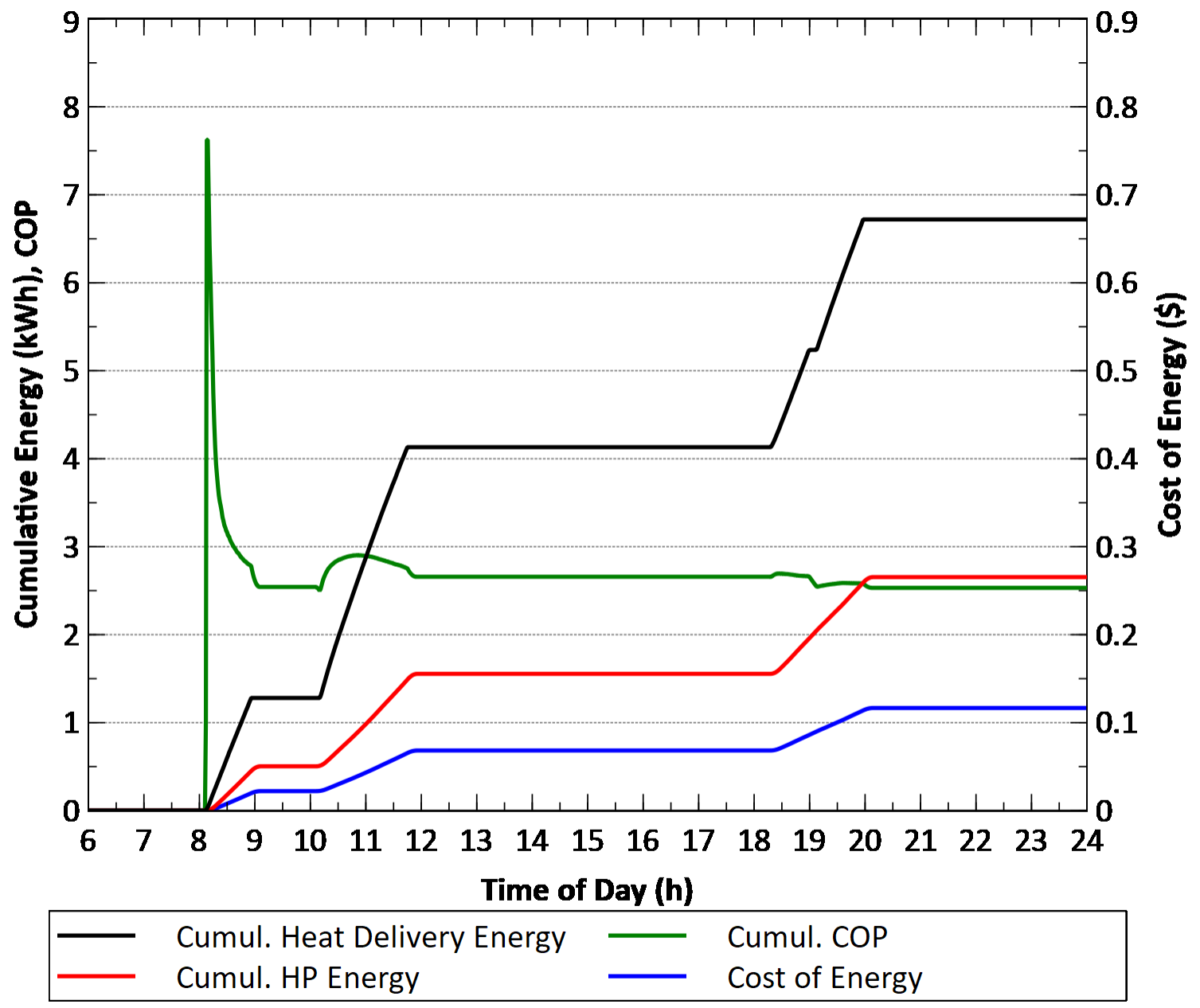

Figure D-6: Cumulative energy, COP, and cost of energy for a Calgary summer day 


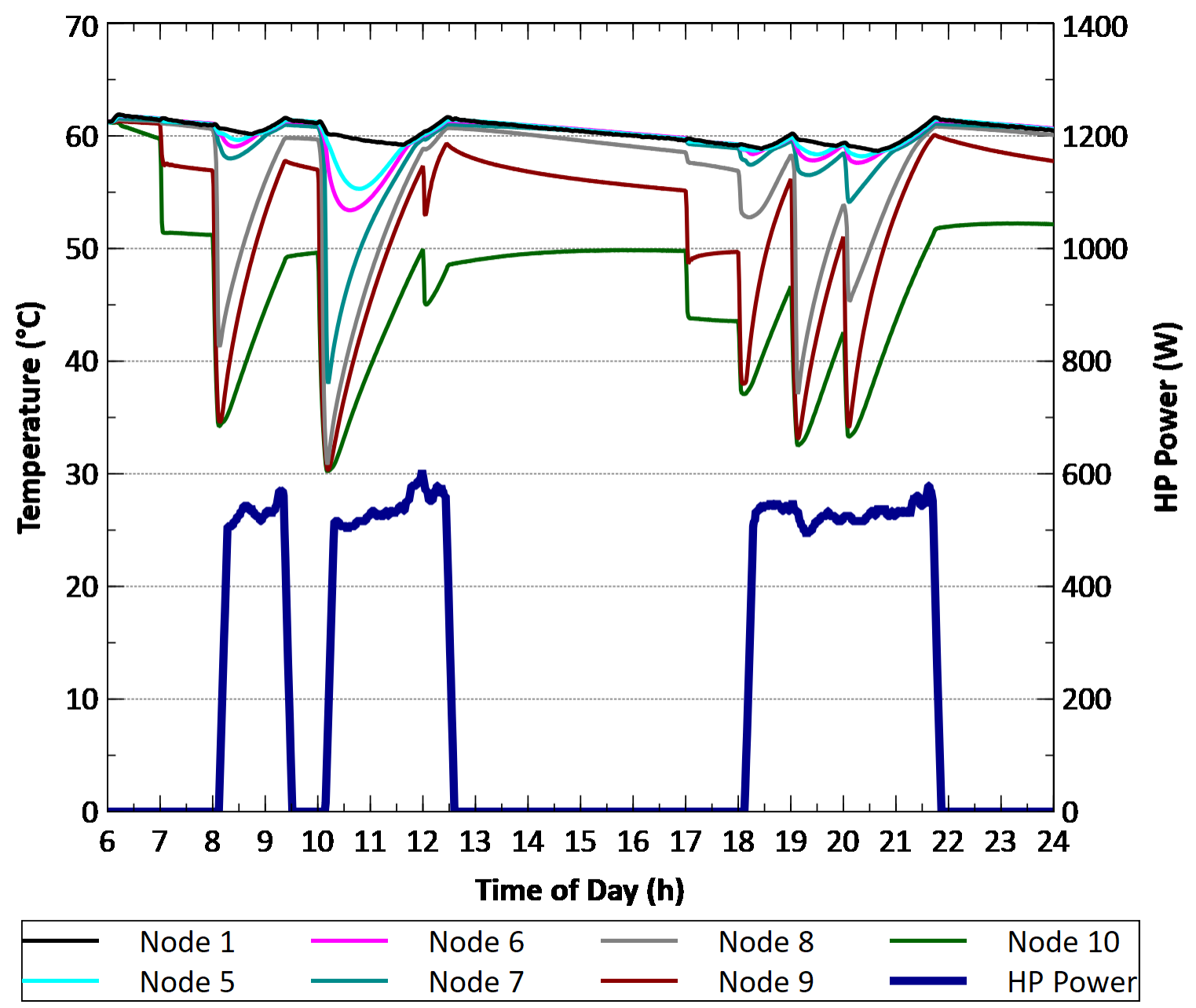

Figure D-7: Water temperature and power consumption for a Calgary fall day 


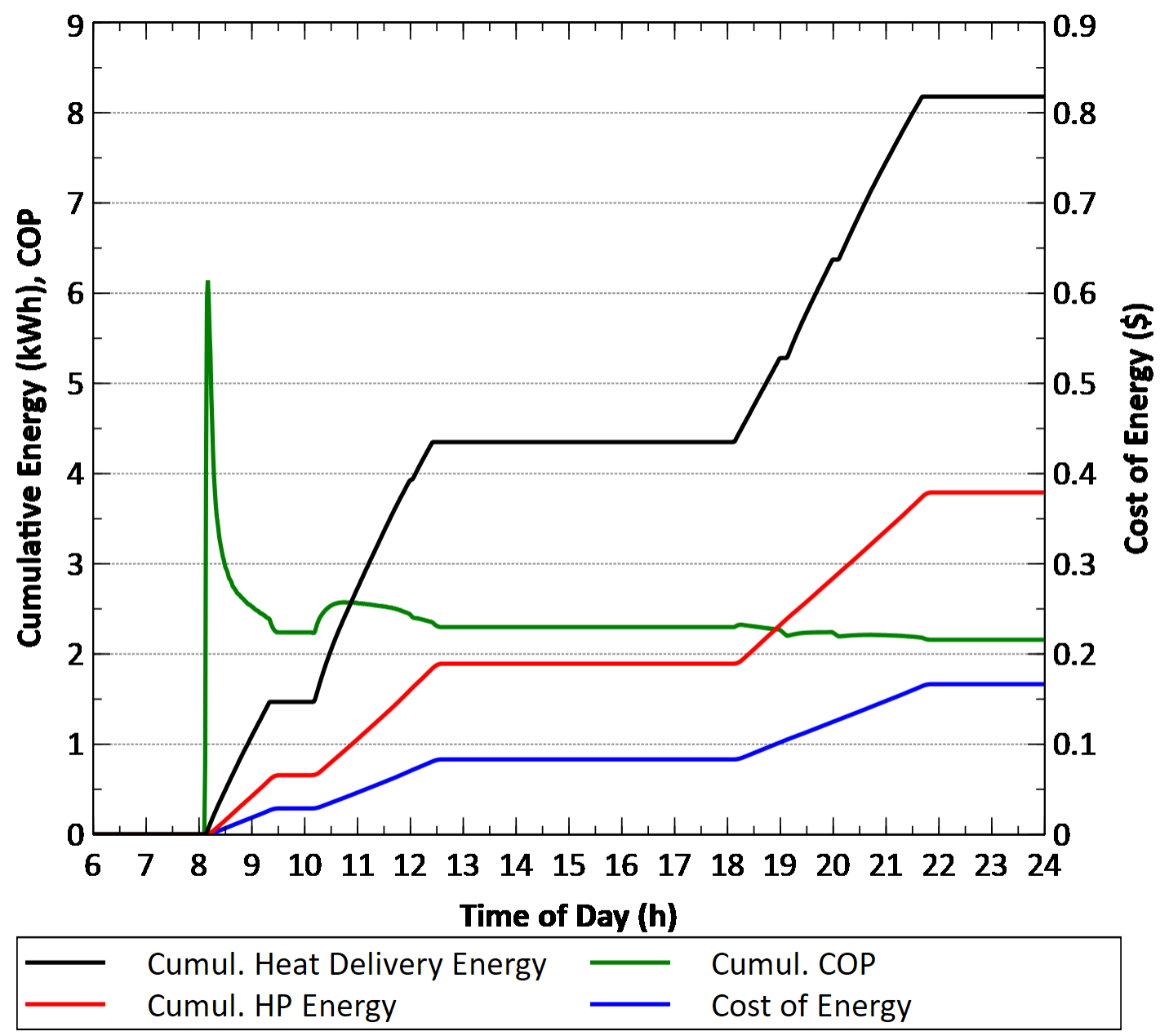

Figure D-8: Cumulative energy, COP, and cost of energy for a Calgary fall day 


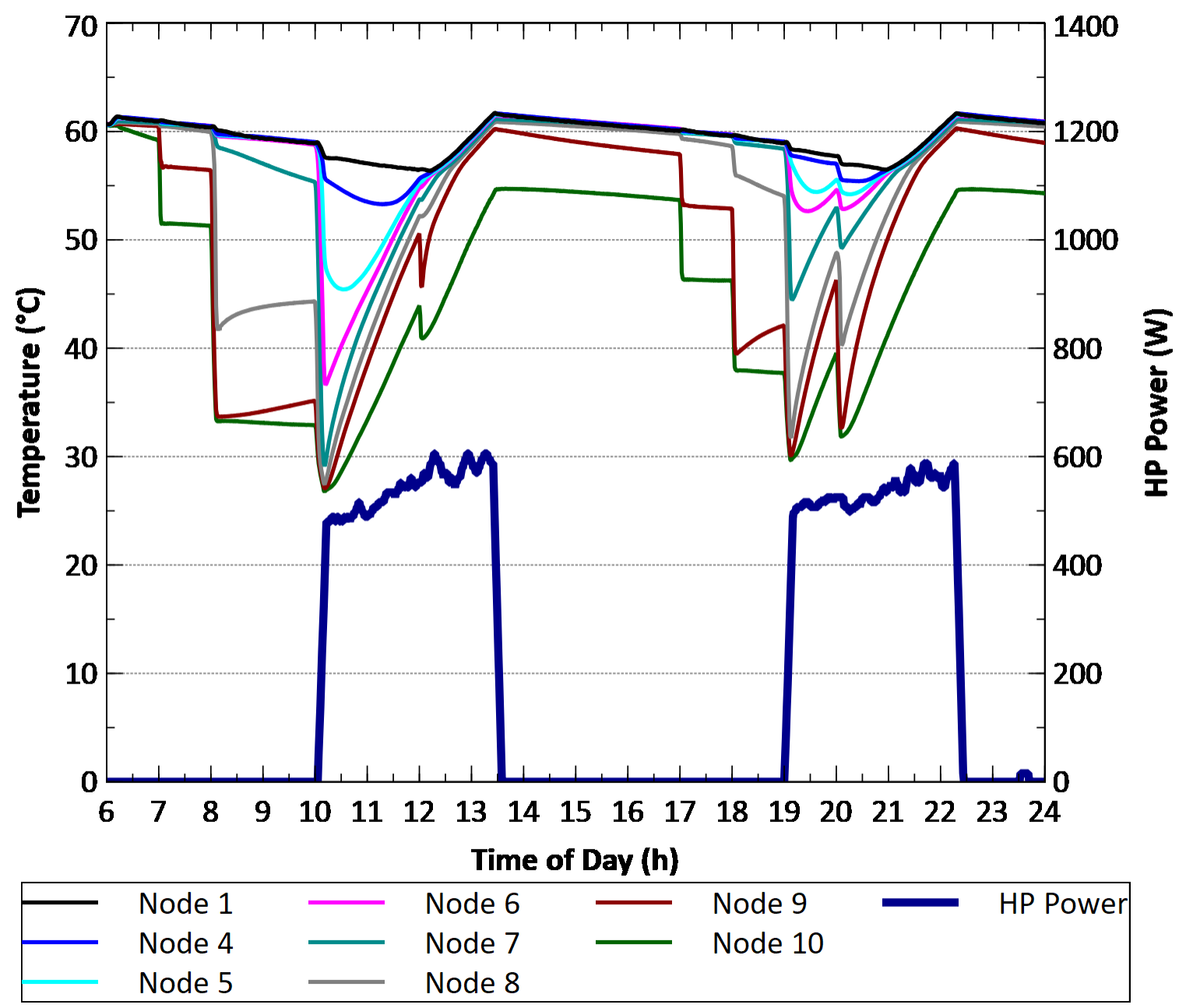

Figure D-9: Water temperature and power consumption for an Edmonton spring day 


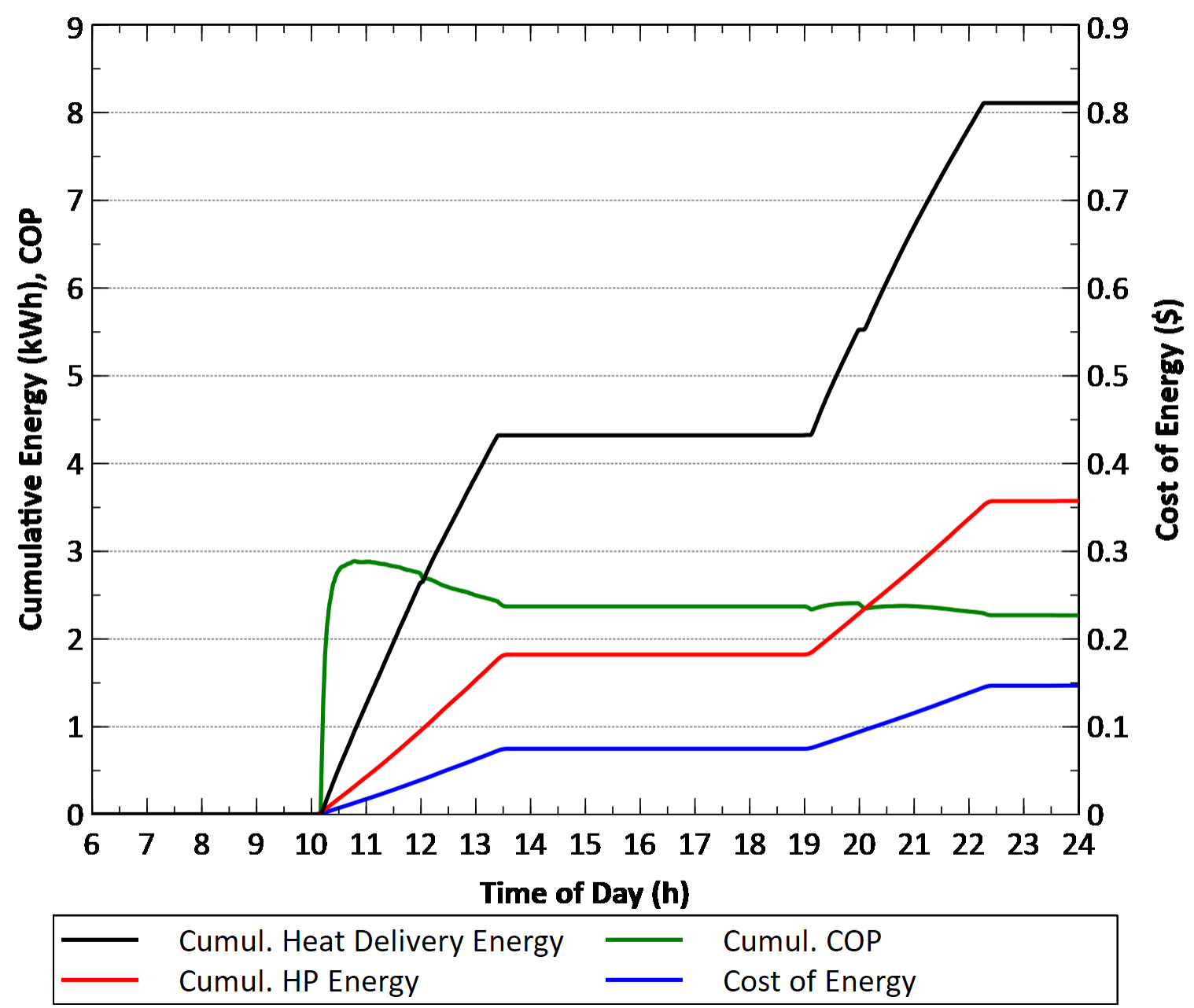

Figure D-10: Cumulative energy, COP, and cost of energy for an Edmonton spring day 


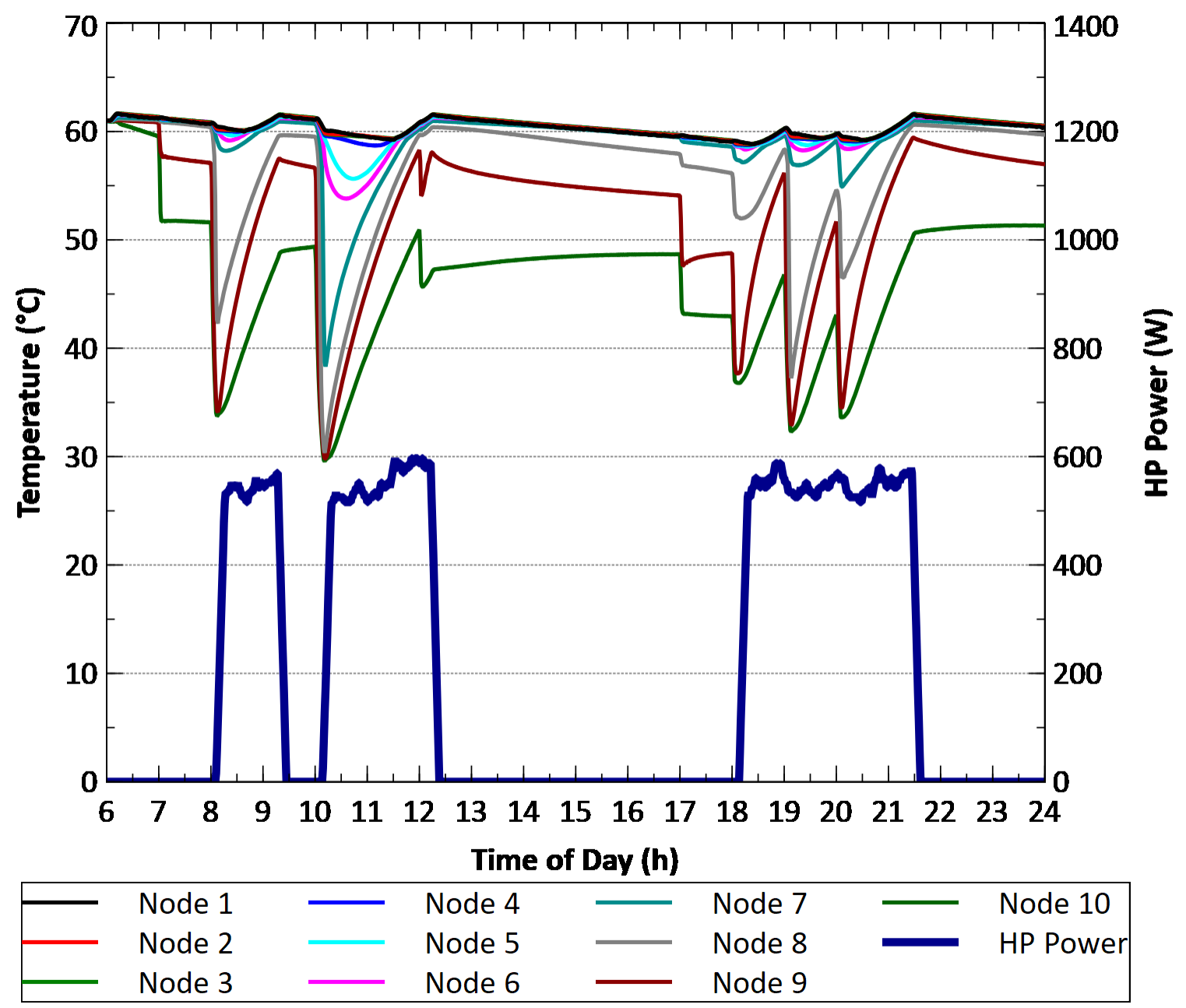

Figure D-11: Temperature and power consumption for an Edmonton summer day 


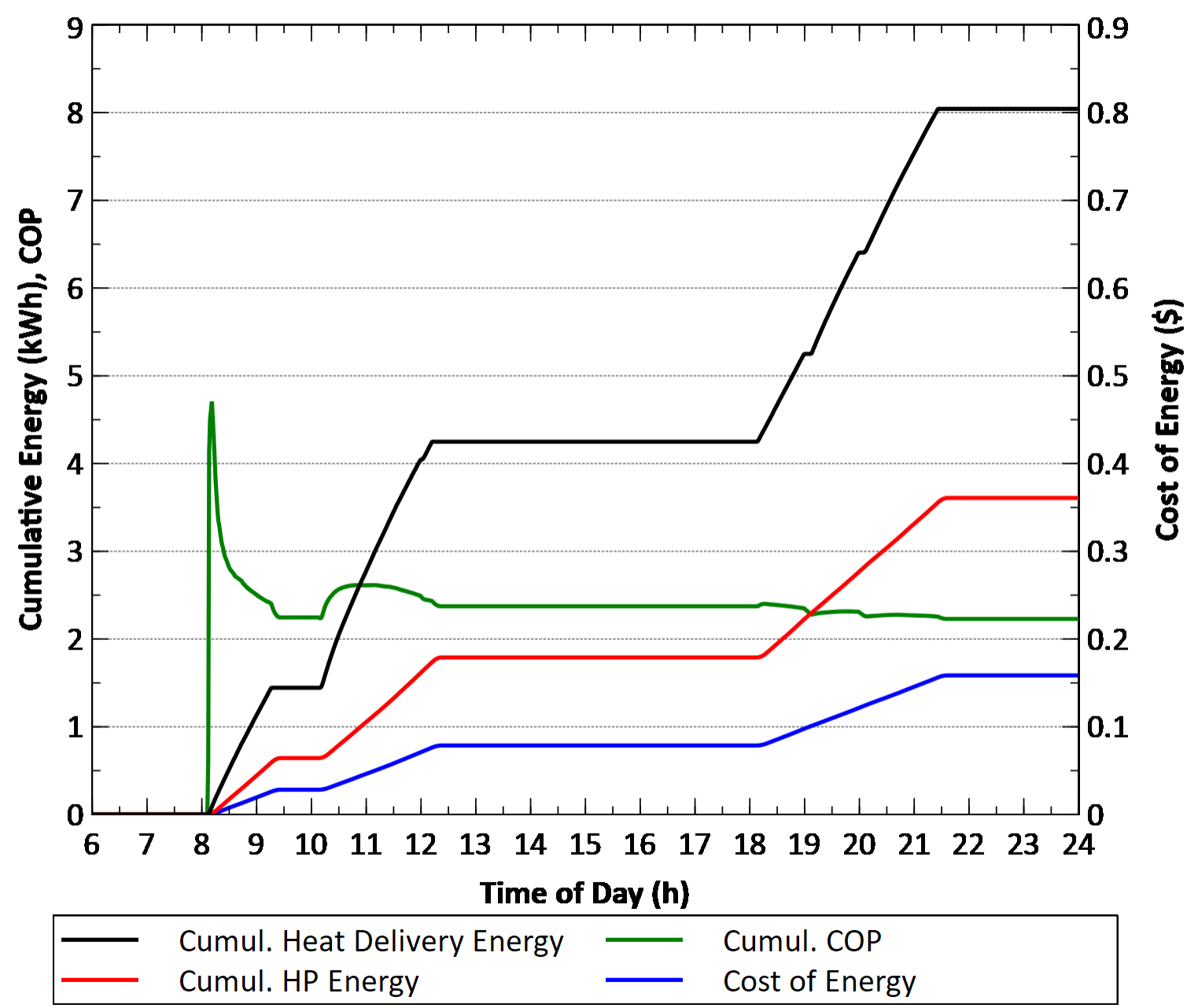

Figure D-12: Cumulative energy, COP, and cost of energy for an Edmonton summer day 


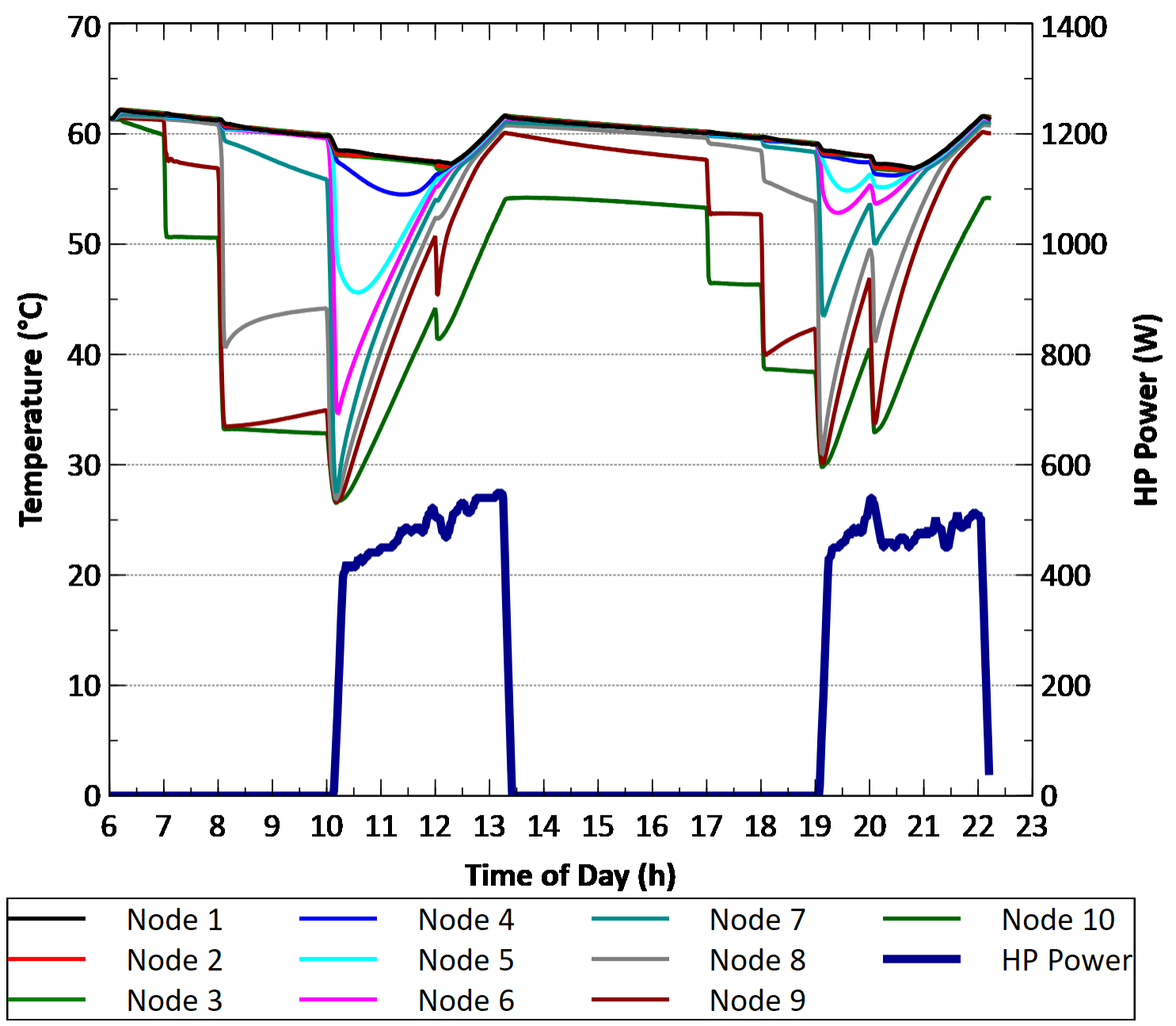

Figure D-13: Temperature and power consumption for a Halifax summer day 


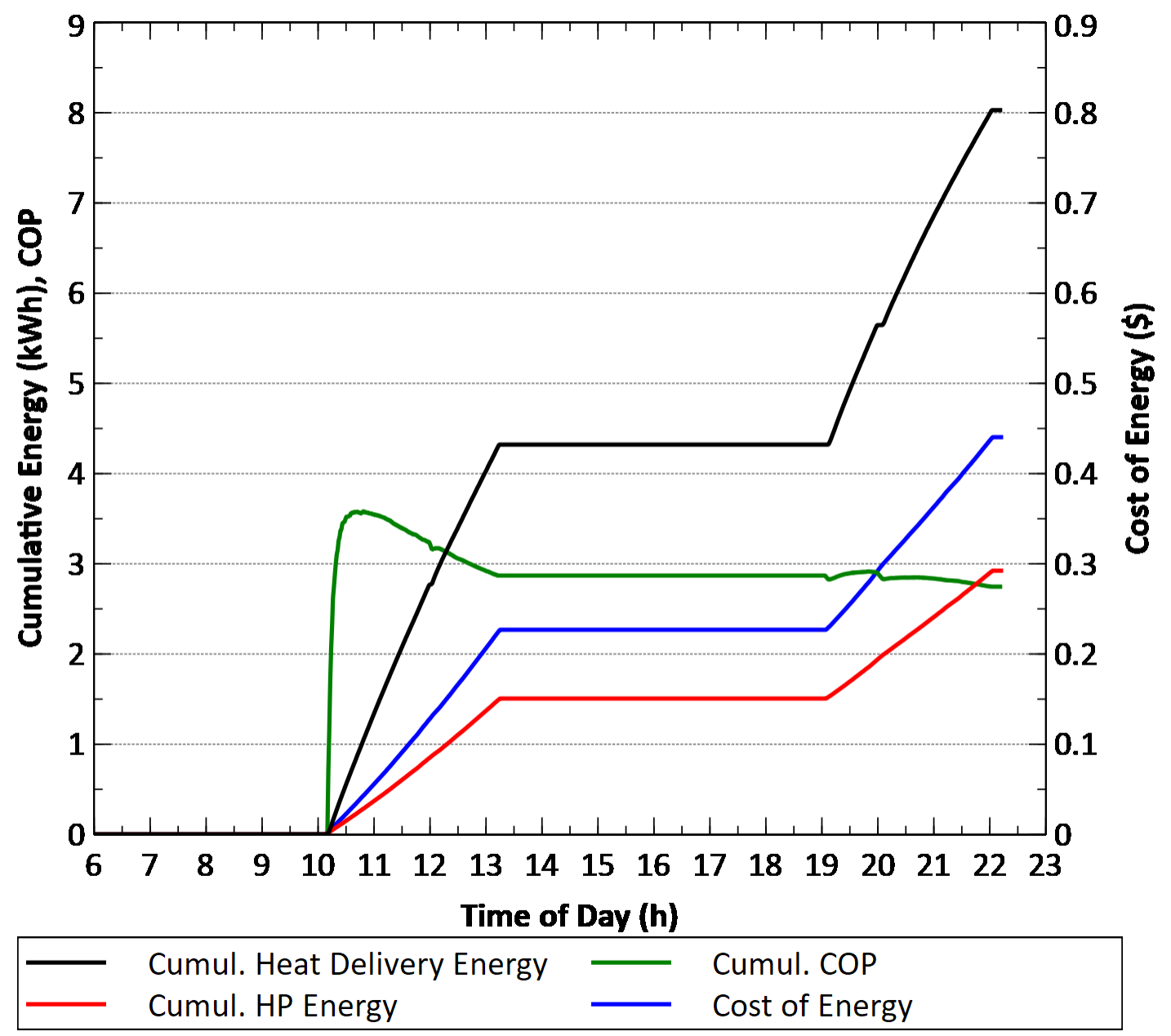

Figure D-14: Energy consumption, CCOP, and cost of energy for a Halifax summer day 


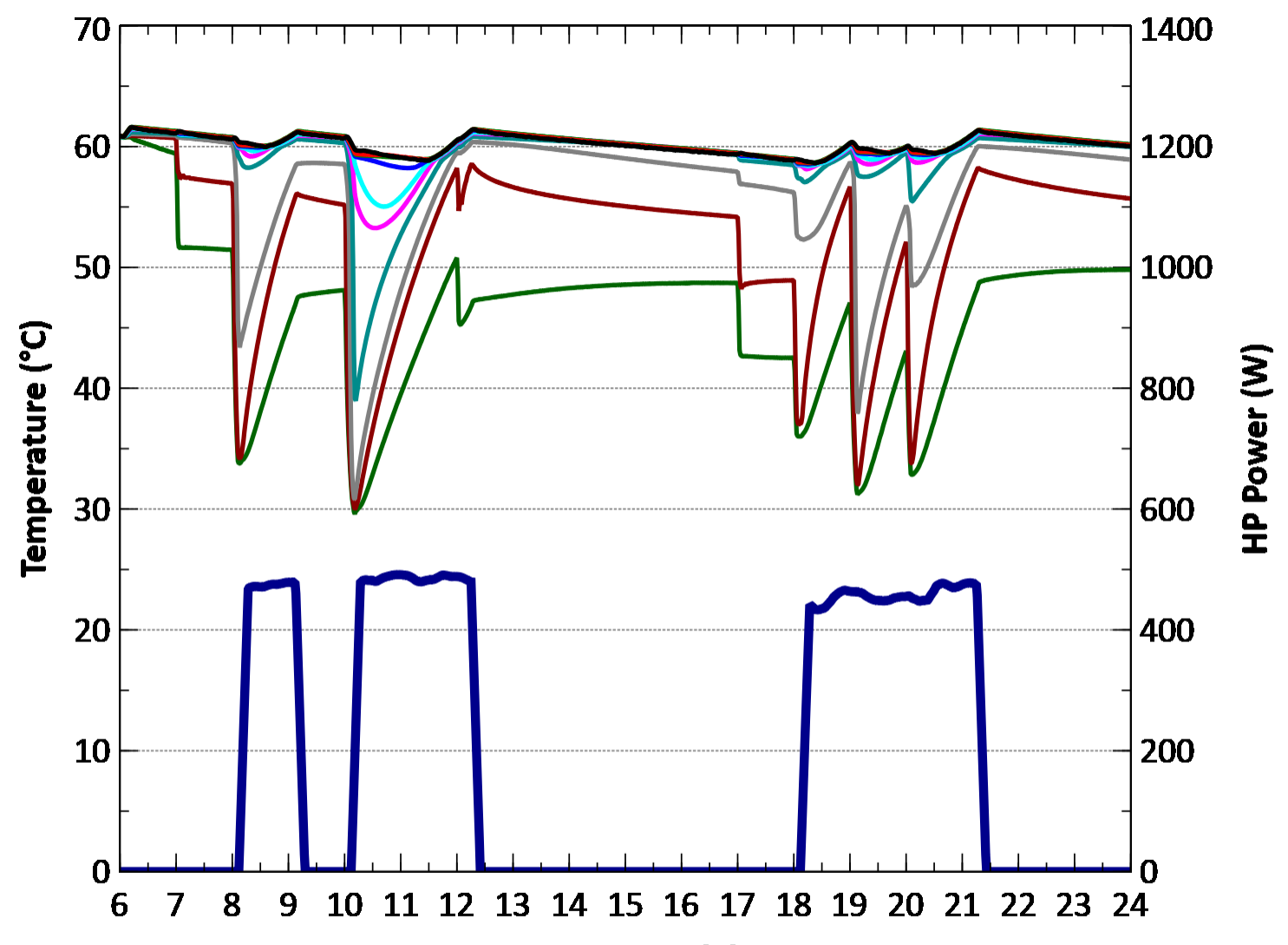

Time of Day (h)

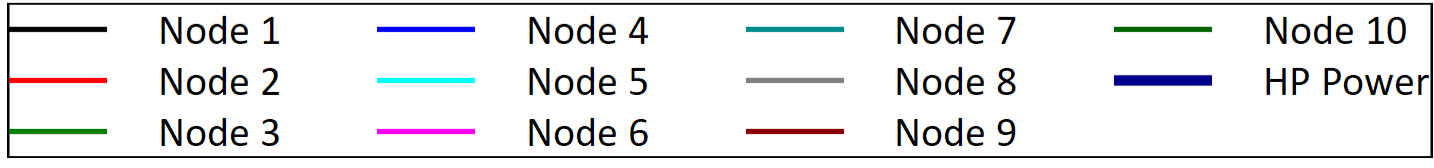

Figure D-15: Temperature and power consumption for a St. John's summer day 


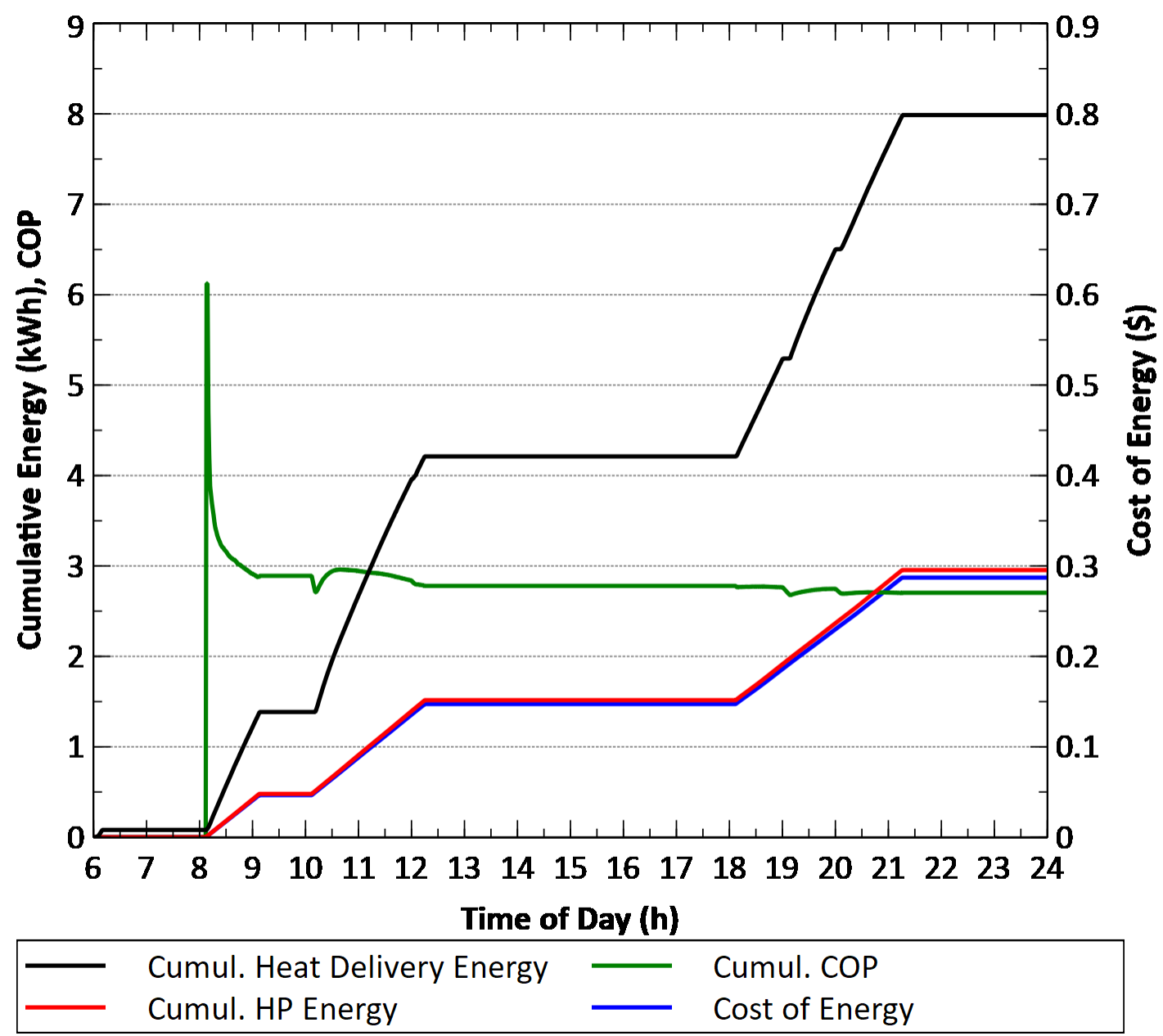

Figure D-16: Energy consumption, CCOP, and cost of energy for a St. John's summer day 


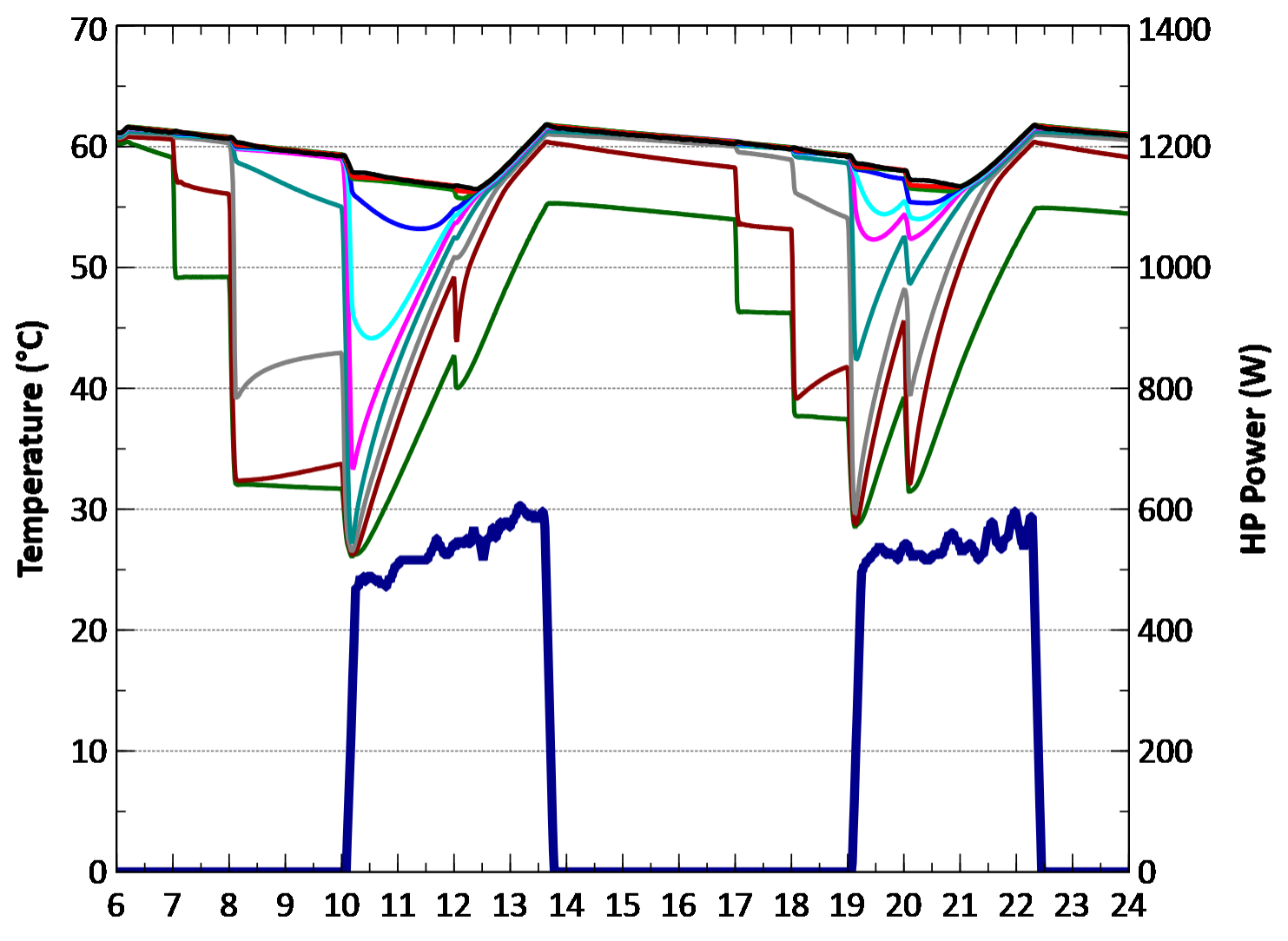

Time of Day (h)

\begin{tabular}{|c|c|c|c|}
\hline Node 1 & Node 4 & Node 7 & Node 10 \\
\hline Node 2 & Node 5 & Node 8 & HP Power \\
\hline Node 3 & Node 6 & & \\
\hline
\end{tabular}

Figure D-17: Temperature and power consumption for a Toronto fall day 


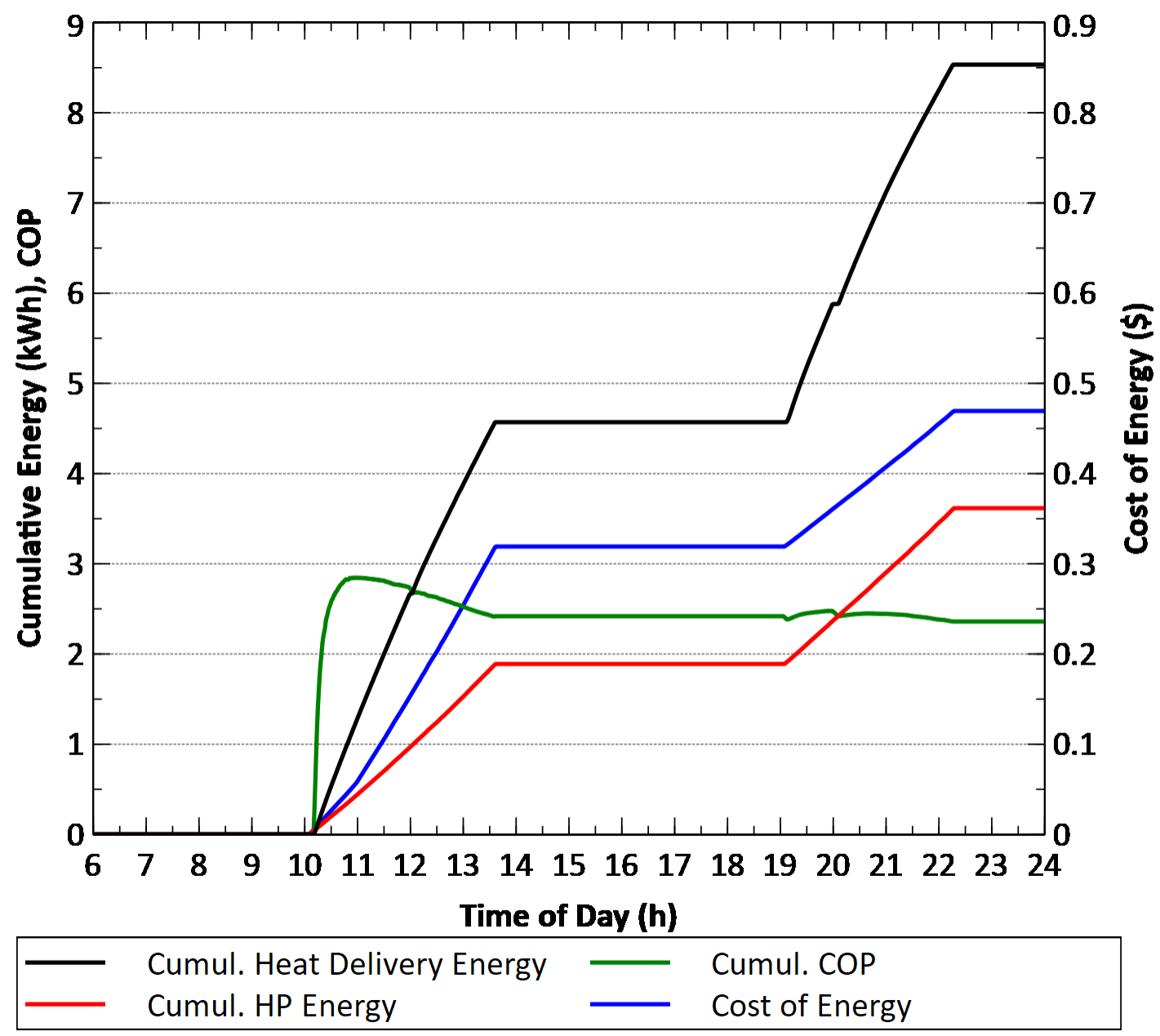

Figure D-18: Energy consumption, CCOP, and cost of energy for a Toronto fall day 


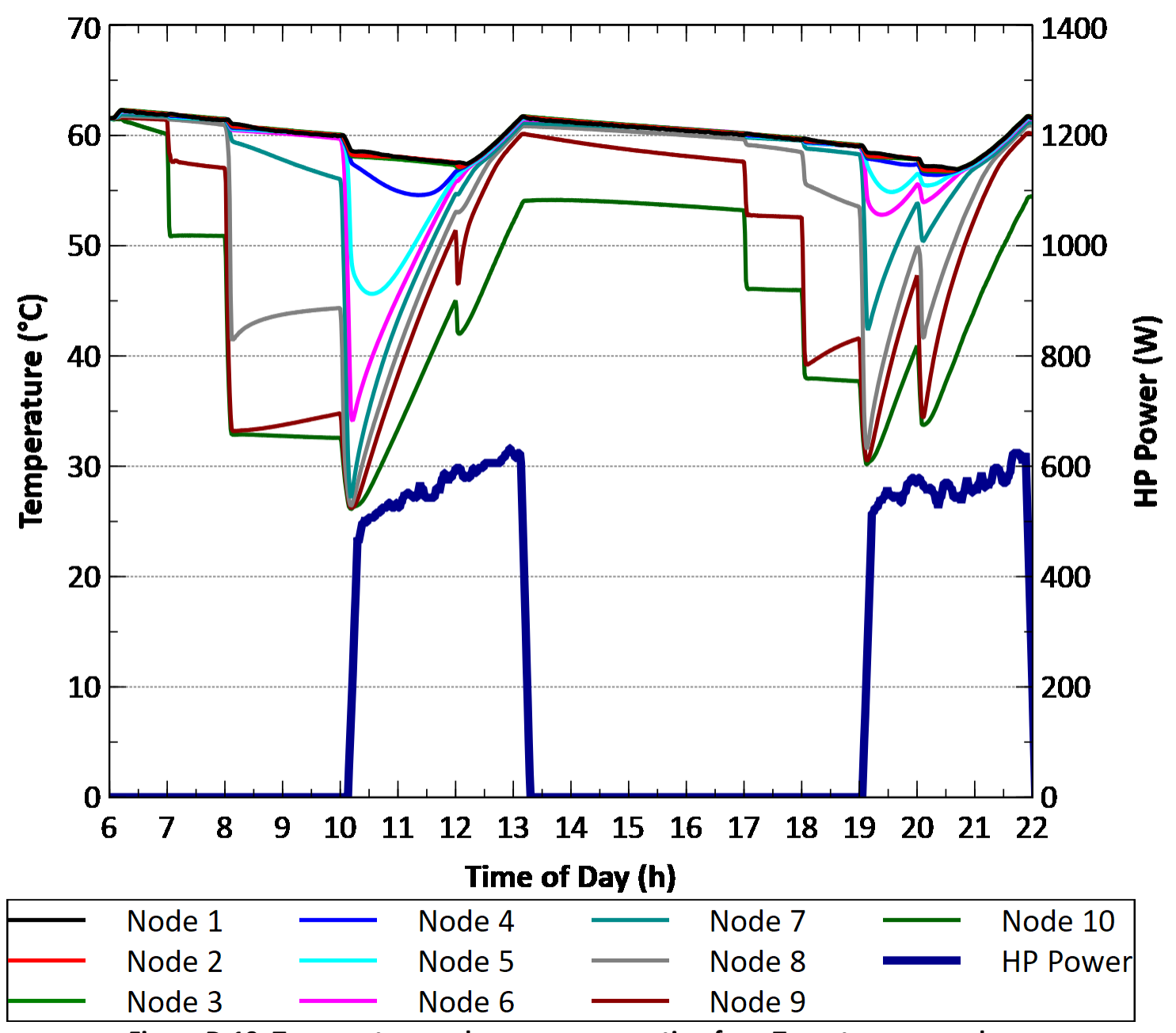

Figure D-19: Temperature and power consumption for a Toronto summer day 


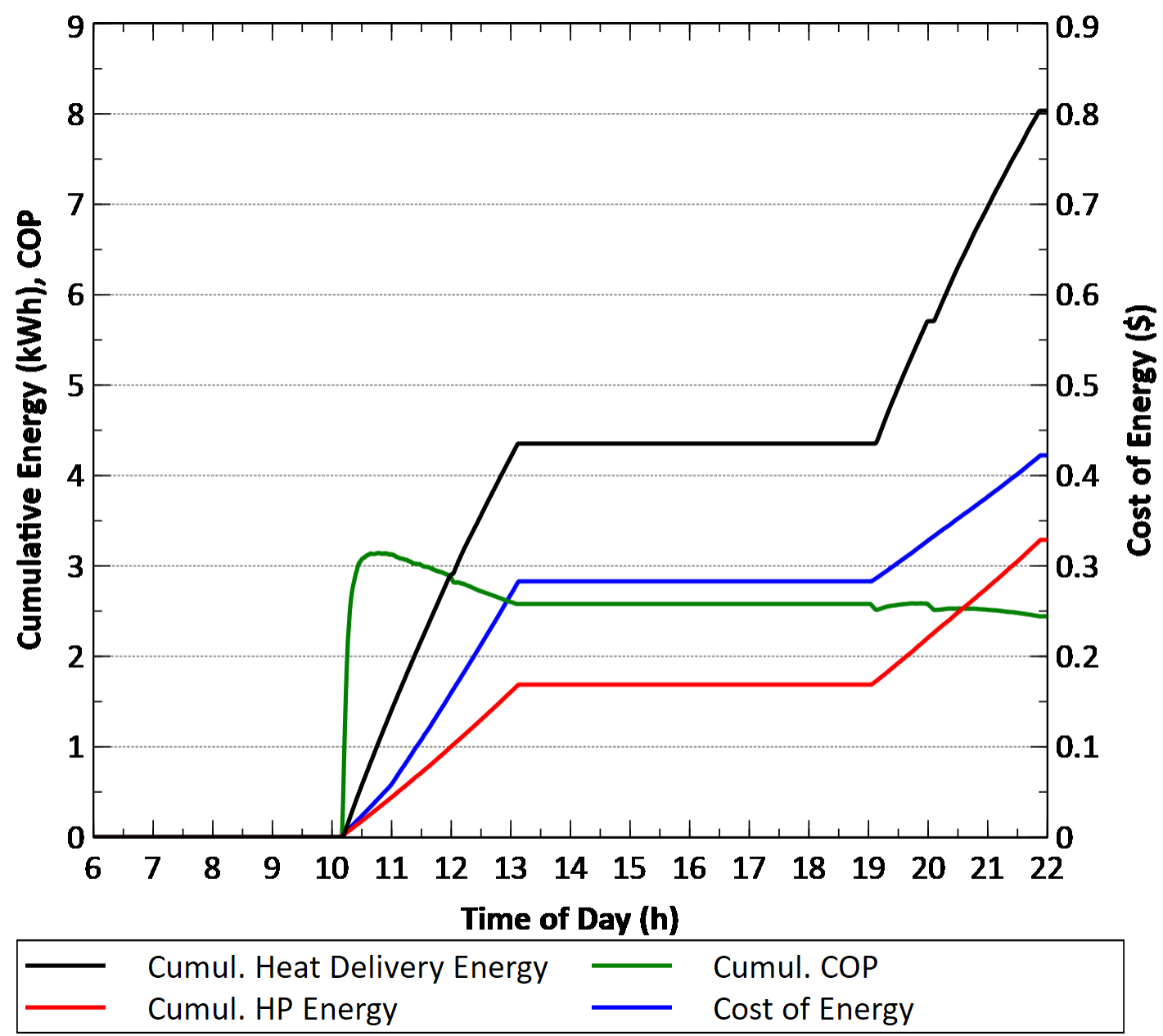

Figure D-20: Energy consumption, CCOP, and cost of energy for a Toronto summer day 


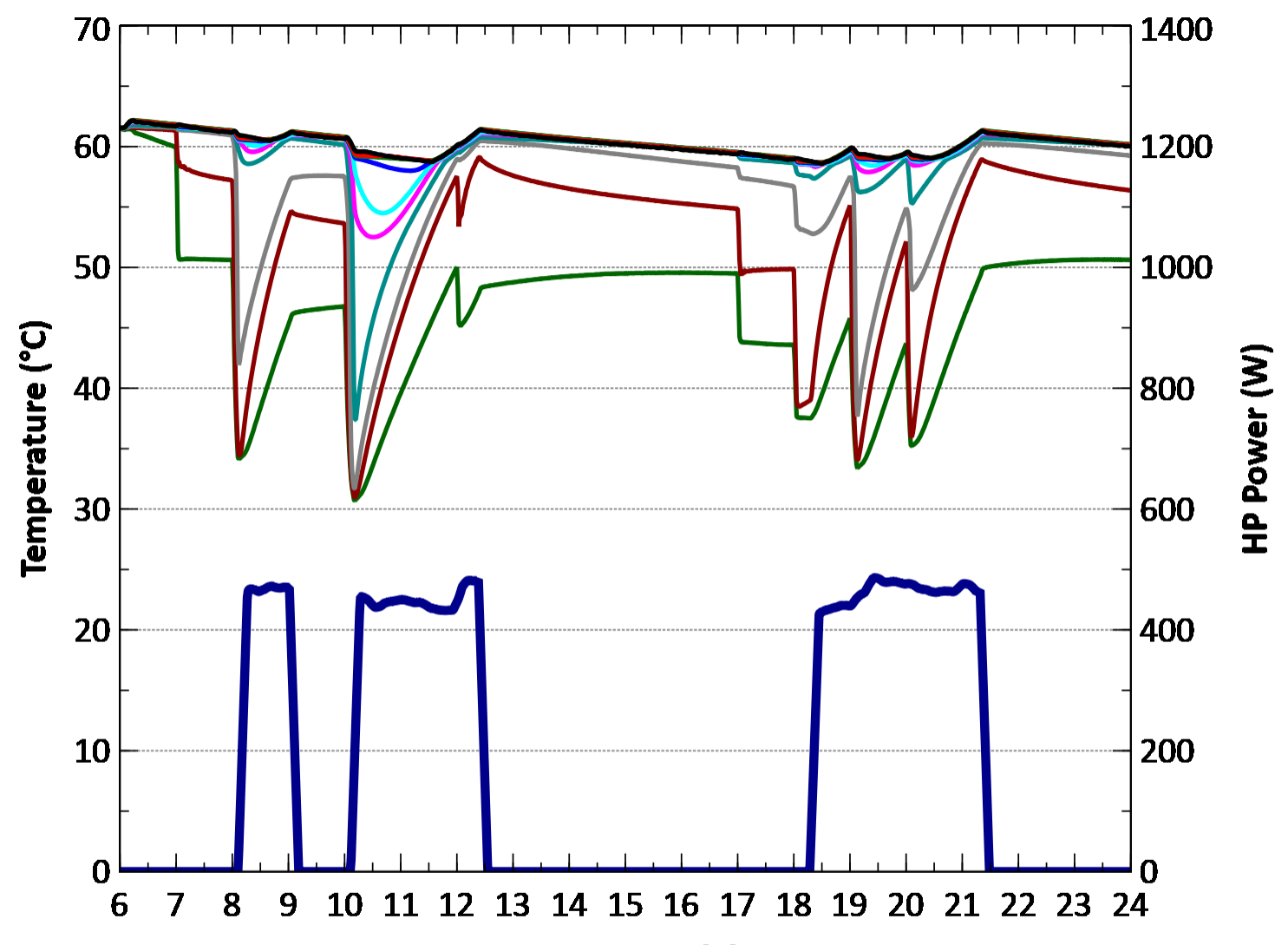

Time of Day (h)

\begin{tabular}{|c|c|c|c|}
\hline Node 1 & Node 4 & Node 7 & Node 10 \\
\hline Node 2 & Node 5 & Node 8 & HP Power \\
\hline Node 3 & & & \\
\hline
\end{tabular}

Figure D-21: Temperature and power consumption for a Yellowknife summer day 


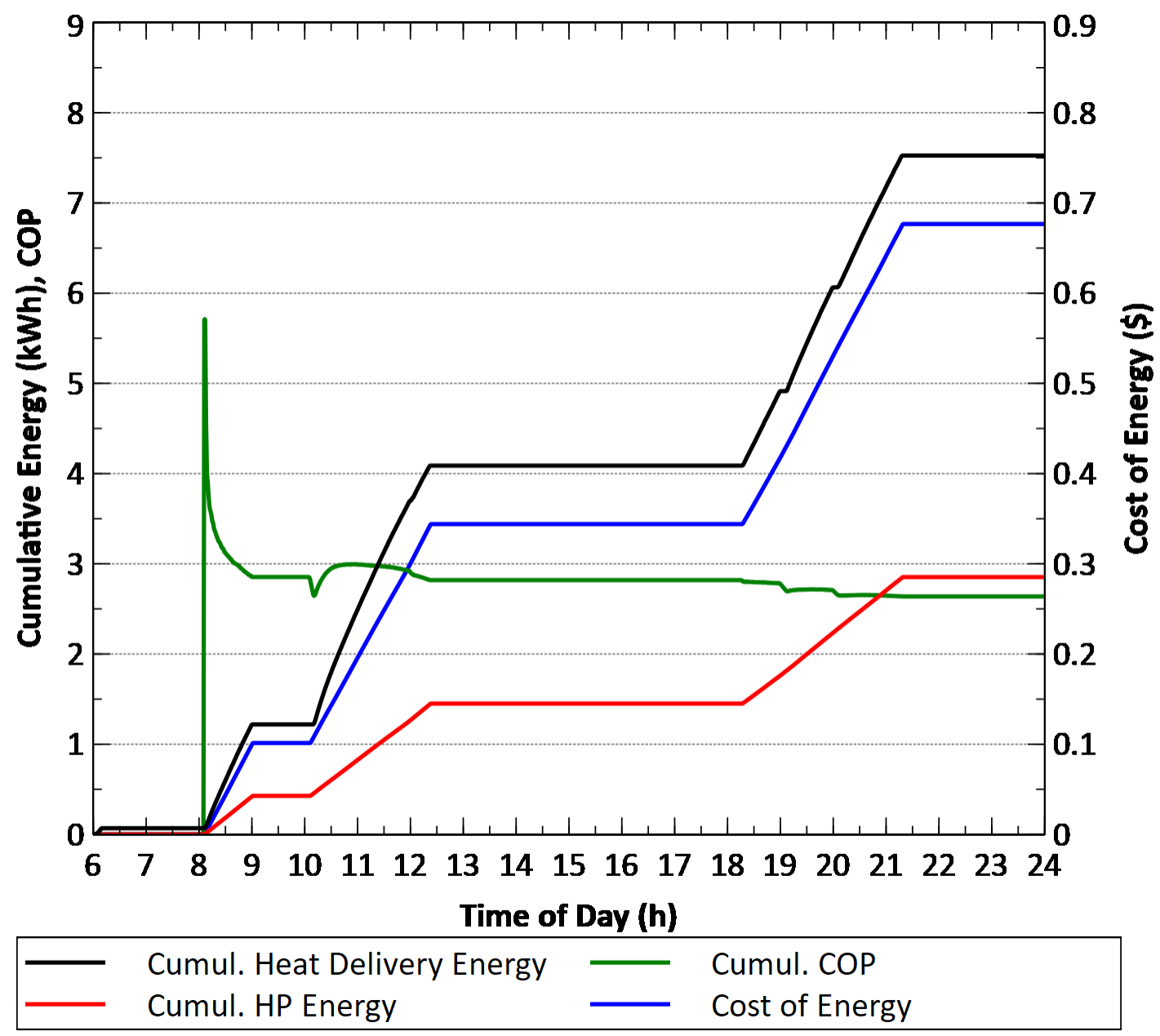

Figure D-22: Energy consumption, CCOP, and cost of energy for a Yellowknife summer day 


\section{D.2 Additional Model Validation Data}

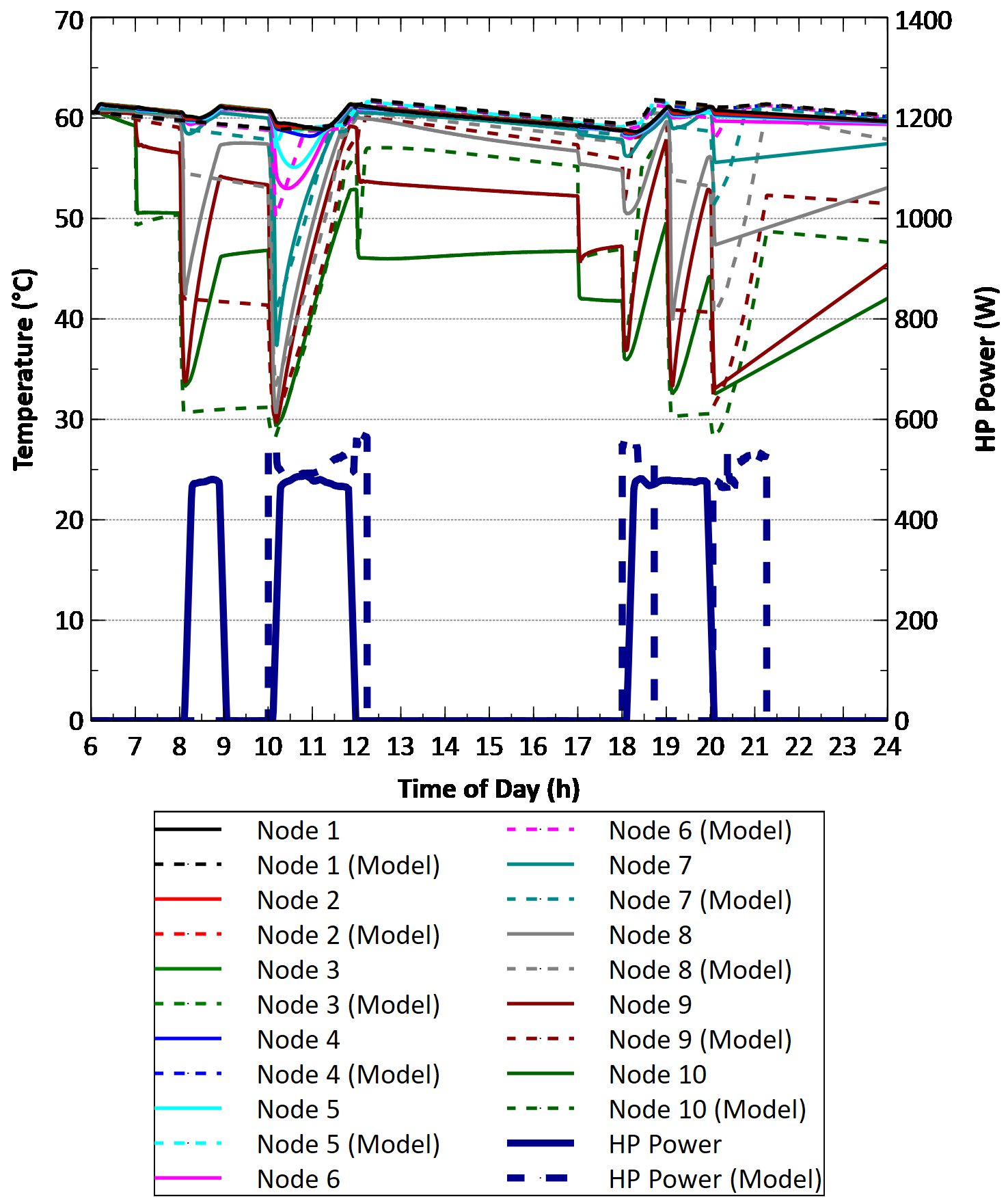

Figure D-23: Experimental and model results for temperature and power consumption for an Ottawa summer day 


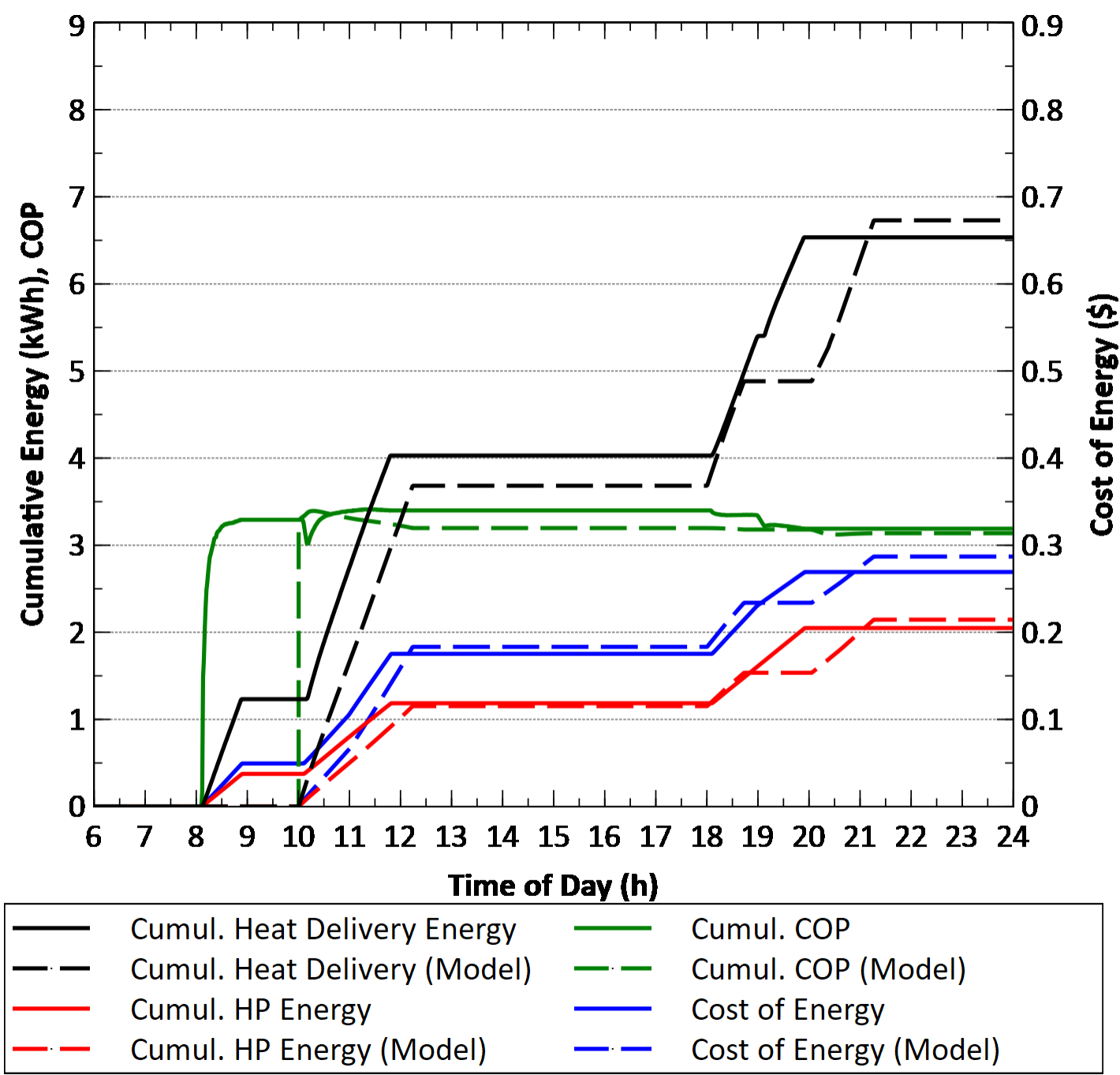

Figure D-24: Experimental and model results for energy consumption, CCOP, and cost of energy for an Ottawa summer day 


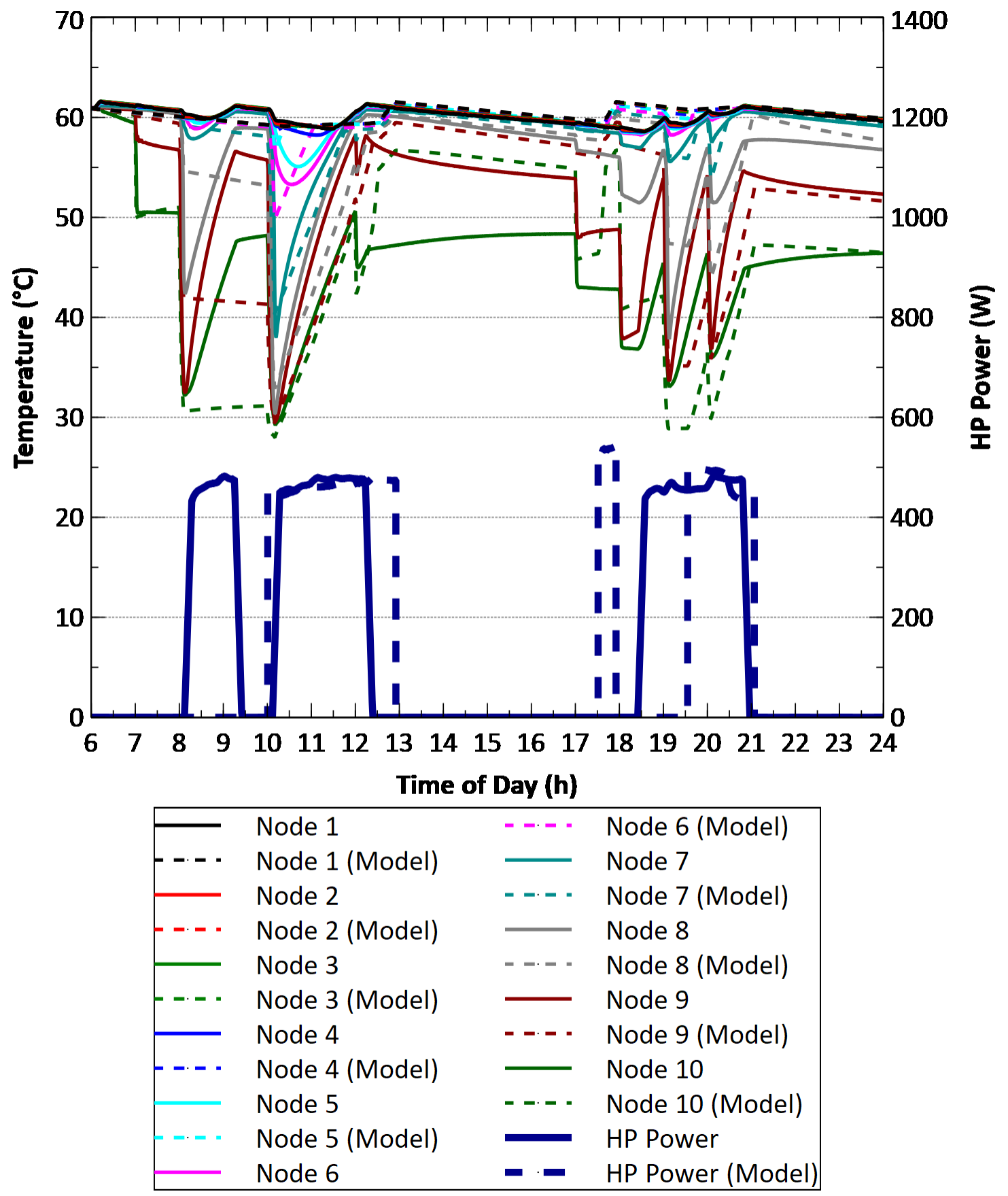

Figure D-25: Experimental and model results for temperature and power consumption for a Regina

summer day 


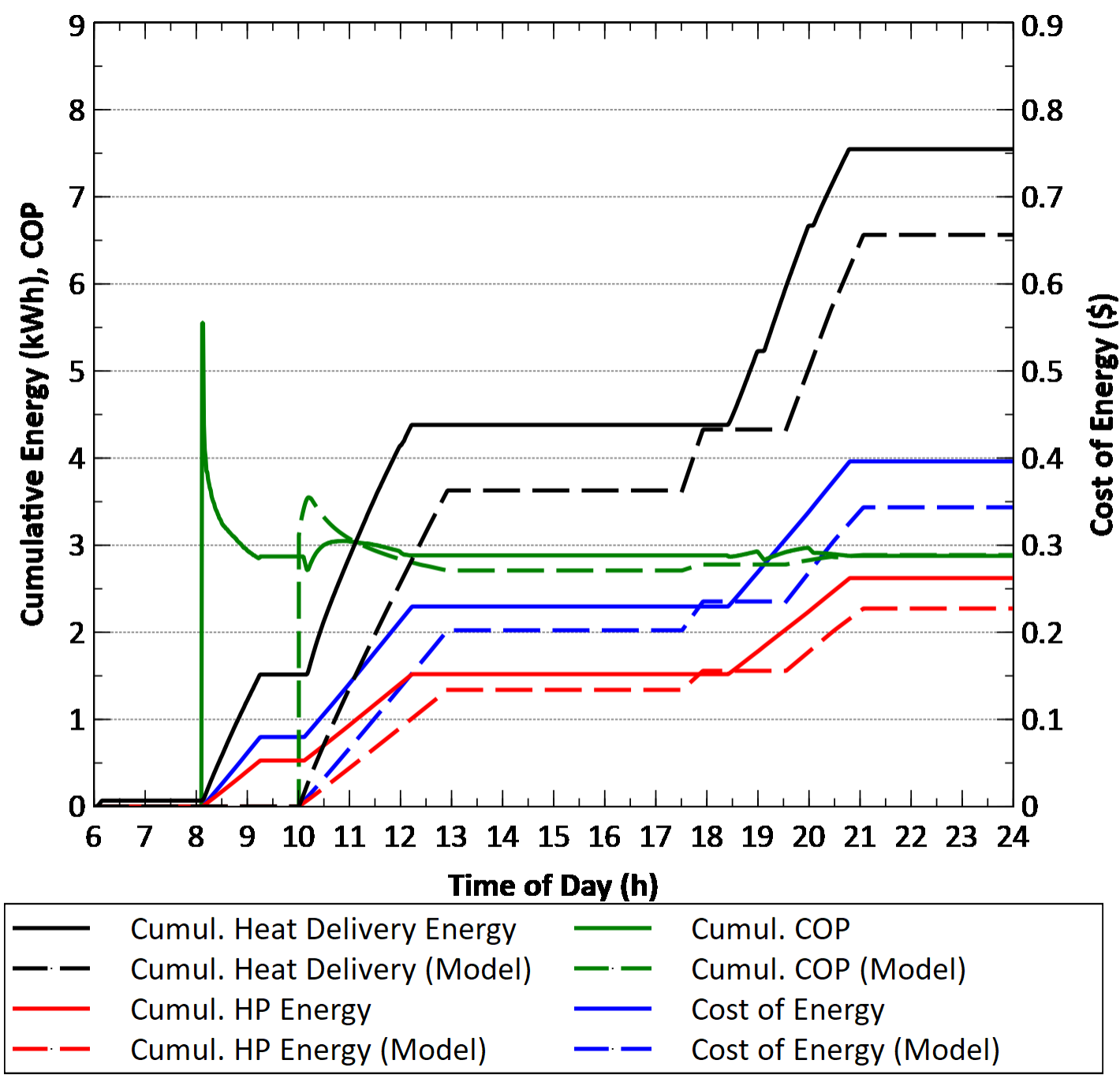

Figure D-26: Experimental and model results for energy consumption, CCOP, and cost of energy for a Regina summer day 


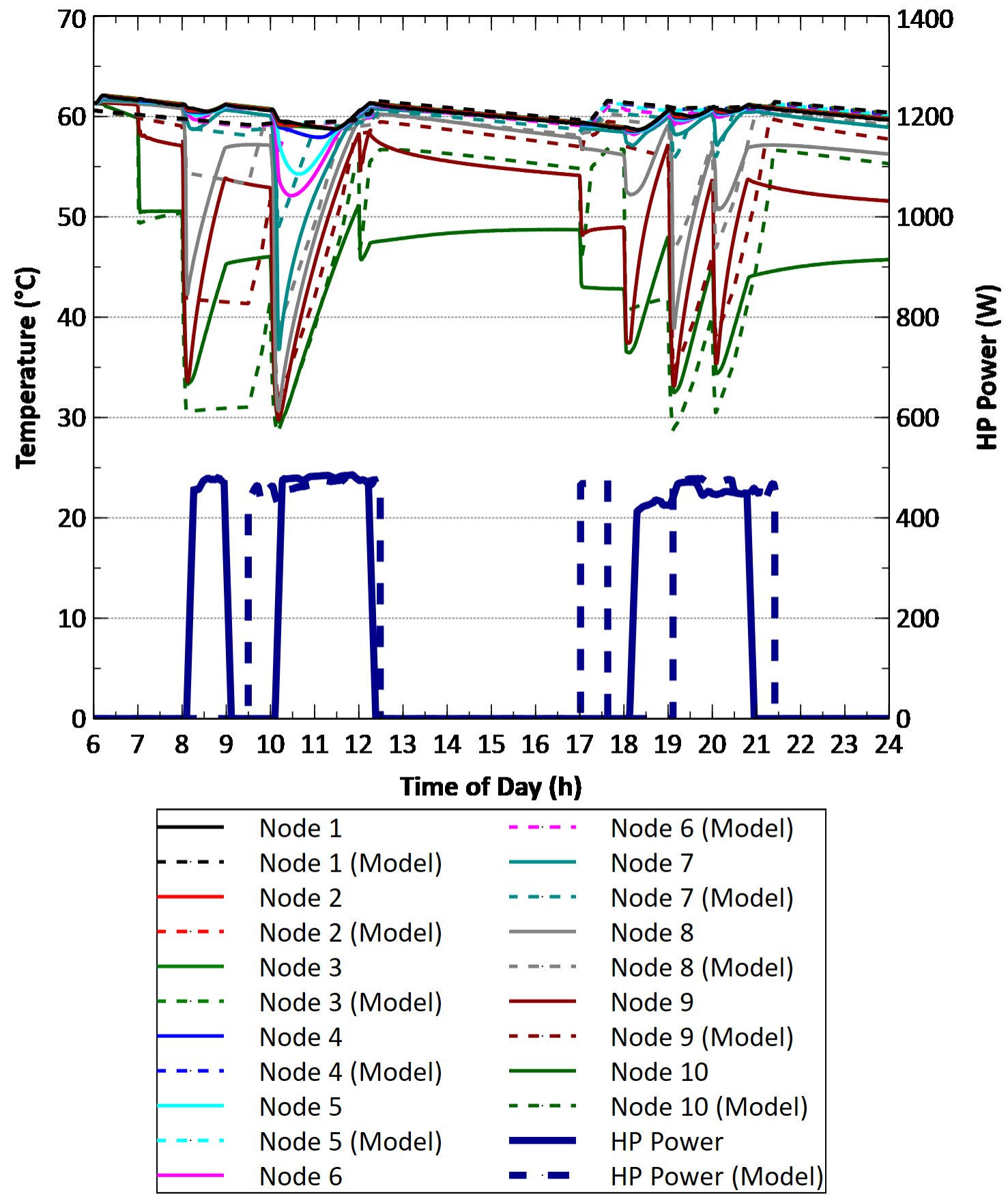

Figure D-27: Experimental and model results for temperature and power consumption for a Vancouver summer day 


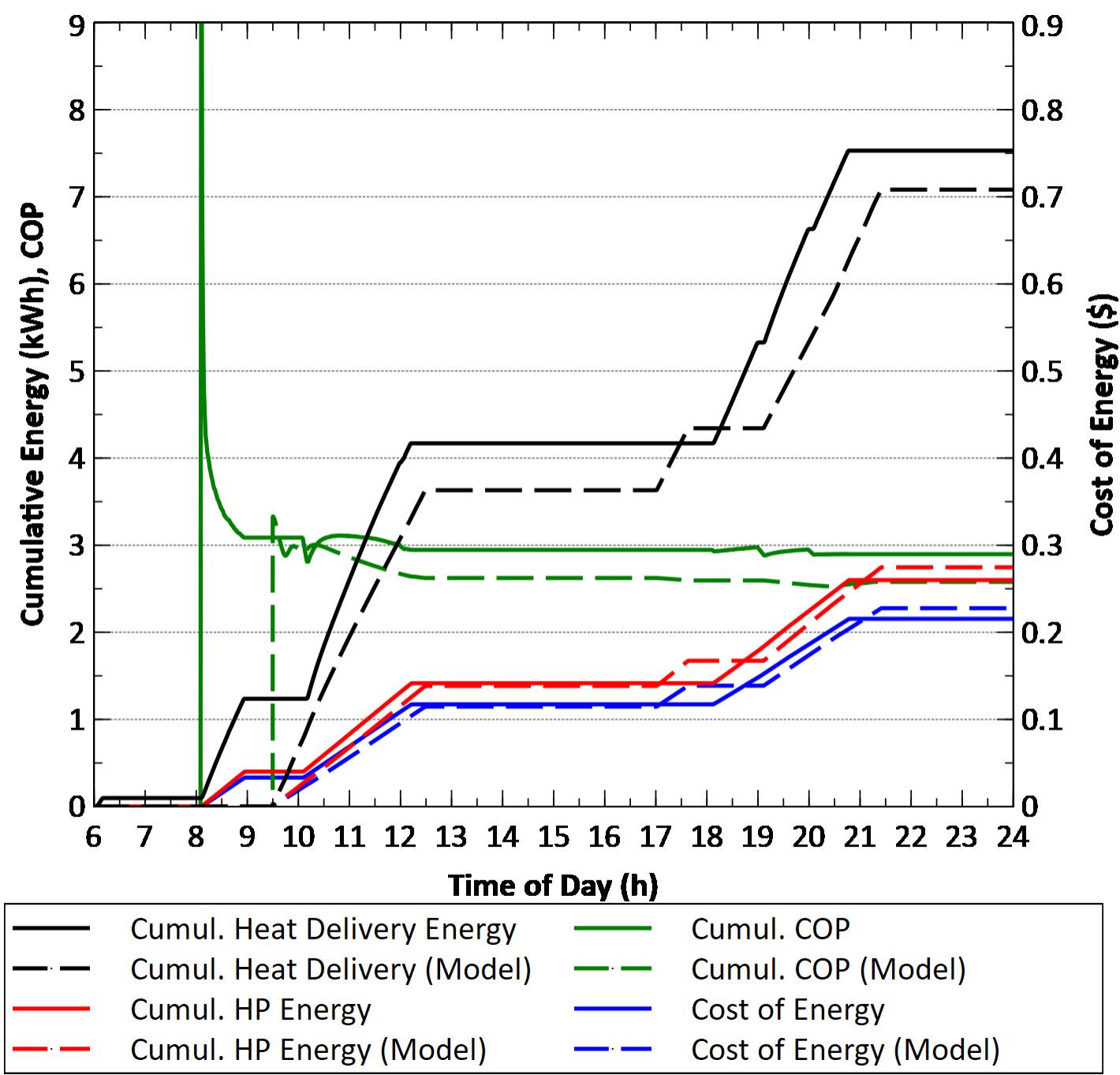

Figure D-28: Experimental and model results for energy consumption, CCOP, and cost of energy for a Vancouver summer day 


\section{Appendix E Cost of Energy of a Water Heater}

Using the electricity rates for each city, the total daily cost of energy for an electric water heater was determined, as shown in Figure E-1. It can be seen that Yellowknife, Halifax, and Regina had the highest daily energy costs, while Edmonton, Calgary, and Montreal had the lowest daily energy costs.

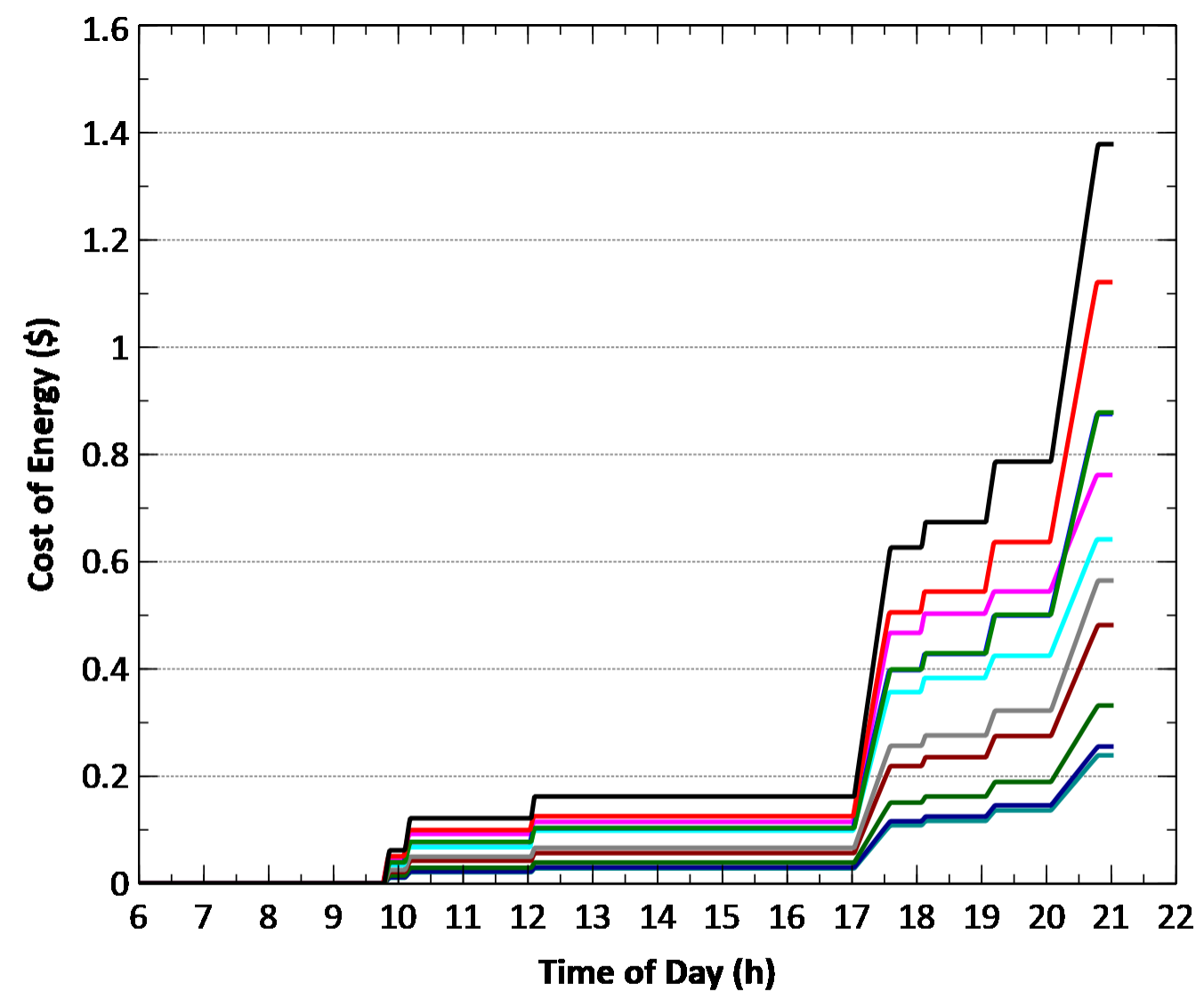

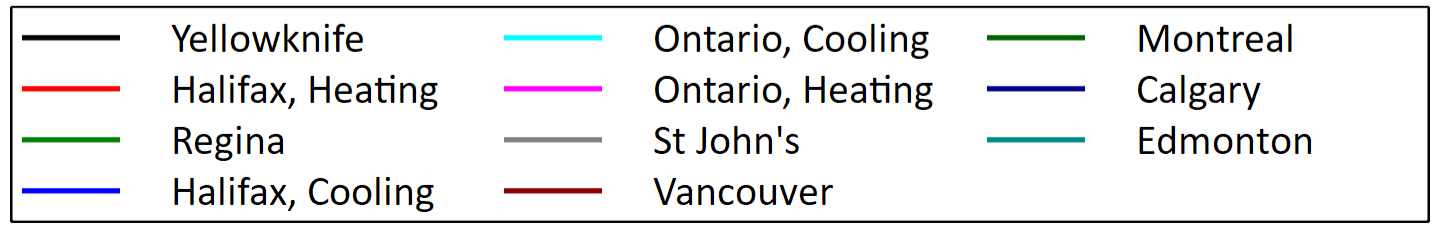

Figure E-1: Cost of energy for various Canadian cities using an electric water heater 
The total cost of energy of the HPWH when using basement air was determined for each city, using the utility rates provided in Appendix A. These results can be seen in Figure E-2. It can be seen that the HPWH had approximately half the cost of energy as the electric water heater for most cases.

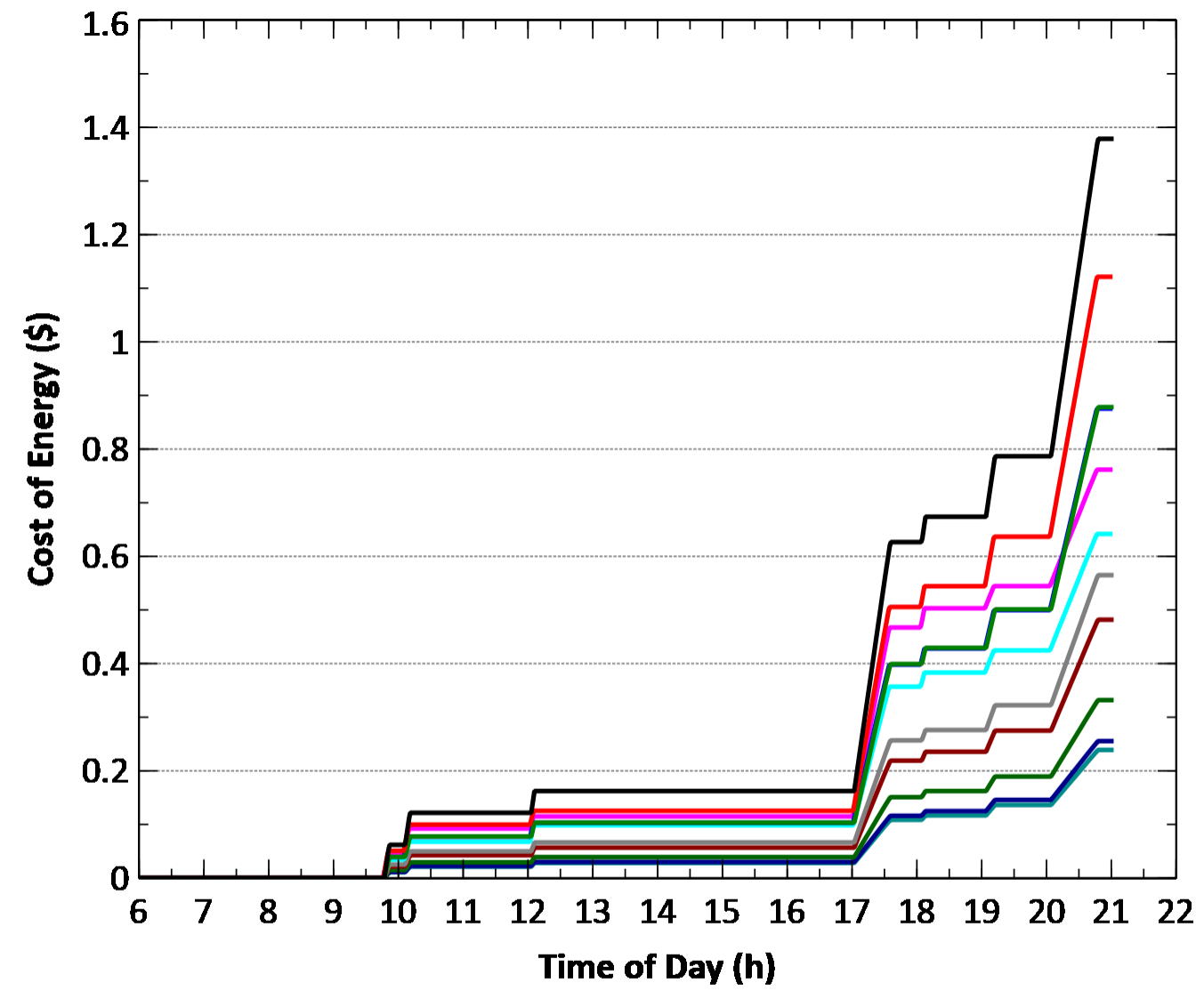

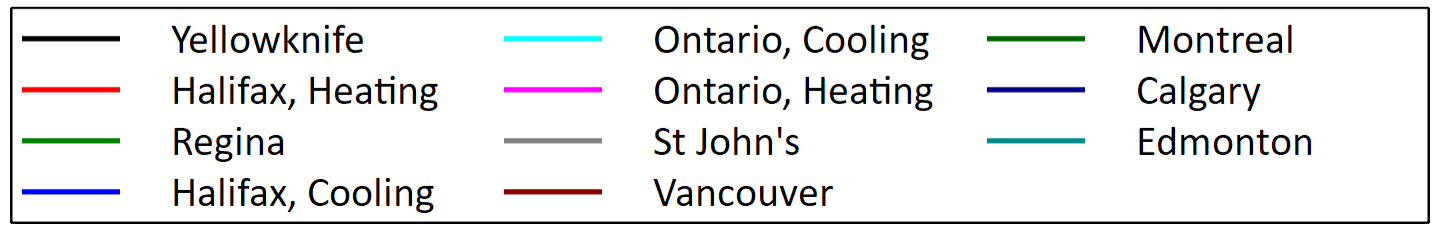

Figure E-2: Cost of energy for various Canadian cities using basement air 